\title{
Über die Wirkung modalitätsspezifischer Hinweisreize im ikonischen Gedächtnis
}

\author{
Dissertation \\ zur Erlangung des Doktorgrades \\ der Mathematisch-Naturwissenschaftlichen Fakultäten \\ der Georg-August-Universität zu Göttingen
}

vorgelegt von

Song YAN

aus Shanghai

Göttingen 2001 
D7

Referent: $\quad$ Prof. Dr. Gerd Lüer

Korreferentin: Prof. Dr. Uta Lass

Tag der mündlichen Prüfung: 29. Januar 2002 
Meiner lieben Familie,

besonders meinem kleinen Neffen

小龙龙 


\section{Danksagung}

An dieser Stelle möchte ich allen jenen Menschen danken, die mir auf die eine oder andere Weise beim Zustandekommen dieser Arbeit geholfen haben.

In erster Linie gilt mein Dank Herrn Prof. Dr. Gerd Lüer, der mir die Promotion im Rahmen eines DFG-Projektes ermöglicht hat und von dem ich wertvolle Anregungen und Kritik zu dieser Arbeit erhielt. Für die fachliche Beratung und Unterstützung möchte ich Frau Prof. Dr. Uta Lass besonders herzlich danken. Herrn Dr. Dietrich Becker danke ich für die Hilfe bei einigen statistischen Auswertungen.

Frau Dr. Jutta Stahl und Frau Dr. Susanne Brandler samt Ehemann Ulrich Seidler-Brandler danke ich herzlich für die kollegiale und moralische Unterstützung sowie das Gegenlesen des Manuskripts. Frau Dr. Jutta Stahl gilt mein besonderer Dank für die vielen fachlichen Diskussionen, was mir den besten Beweis dafür liefert, dass Wissenschaft auch ein dialogisches Unternehmen ist.

Ebenso geht mein Dank an Herrn Dipl.-Psych. Nils Schütte, Frau Christina Petras, Frau Katrin Pietz, Frau Sophie Hinrichs, Frau Iris Bünemann und noch viele andere, die entweder die Datenerhebung der im Rahmen dieser Arbeit durchgeführten Experimente unterstützt oder Korrektur gelesen haben.

Herrn Prof. Dr. Thomas Schulz, Ruhr-Universität Bochum, danke ich für das Interesse am Thema, sachdienliche Diskussionen und Literaturhinweise.

Natürlich danke ich auch meinem Eh e m a n n, Herrn Reiner Stoppok, für seine „,multiple“ Geduld während aller Phasen der Arbeit. Das Motto: „Beobachten können wenig[e], lesen alle“ (G. Chr. Lichtenberg) war ihm dabei ein ständiger Trost.

Ganz zum Schluss, aber nicht zuletzt, danke ich meiner Familie, die inzwischen über die ganze Welt verstreut ist. Sie ist es gewesen, die mir immer wieder die nötige Kraft gab, die Arbeit zu Ende zu führen. Ihr ist diese Arbeit gewidmet. 


\section{Inhaltsverzeichnis}

$\begin{array}{lr}\text { Abkürzungsverzeichnis } & 5 \\ \text { Abbildungsverzeichnis } & 6 \\ \text { Tabellenverzeichnis } & 8\end{array}$

$\begin{array}{lr}\text { Einführung } & 9\end{array}$

\section{$\underline{\text { Kapitel } 1}$ Theoretischer und empirischer Hintergrund}

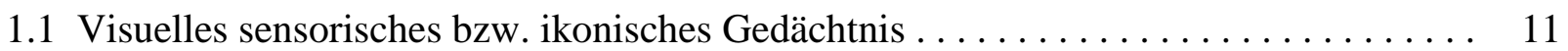

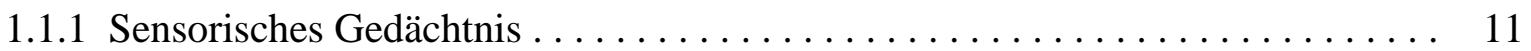

1.1.2 Ikonisches Gedächtnis und seine Funktionen . . . . . . . . . . . . . 12

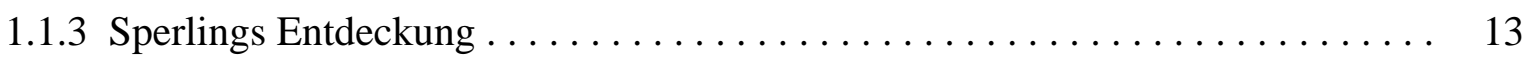

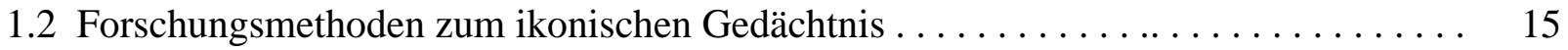

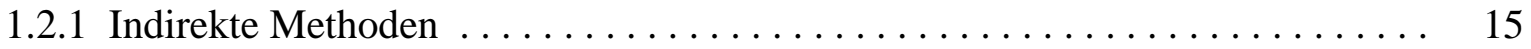

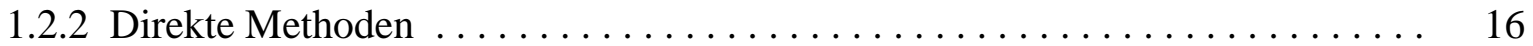

1.3 Konzeptuelle Entwicklung des ikonischen Gedächtnisses $\ldots \ldots \ldots \ldots \ldots \ldots \ldots$

1.3.1 Klassische Phase . . . . . . . . . . . . . . . . . . . . . . . . . . 17

1.3.2 Aufspaltung des Ikons: Colthearts Beitrag $\ldots \ldots \ldots \ldots \ldots \ldots \ldots \ldots \ldots$

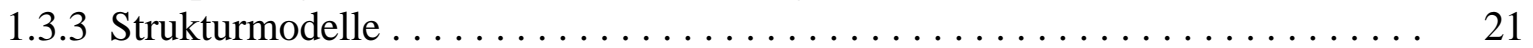

1.3.3.1 Modell von Mewhort et al. ...................... 22

1.3.3.2 Modell von Irwin und Yeomans. . . . . . . . . . . . . . . . . . . . . . 24

1.3.4 Mathematische Modelle . . . . . . . . . . . . . . . . . . . . 26

1.3.4.1 Modelle von Dixon und Di Lollo . . . . . . . . . . . . . . . 26

1.3.4.2 Modell von Massaro und Loftus . . . . . . . . . . . . . . . . . 30

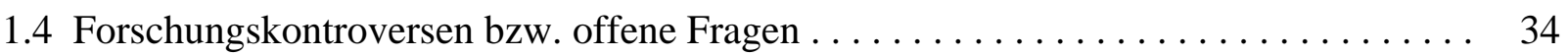

\section{Kapitel 2 Experimentelle Untersuchung zum Modalitätseffekt des} Hinweisreizes im Partial Report (Sperling-Paradigma)

2.1 Modalitätseffekt: Einleitung und Hintergrund $\ldots \ldots \ldots \ldots \ldots \ldots \ldots \ldots \ldots$

2.2 Experiment 1 zum Nachweis eines Modalitätseffekts des Hinweisreizes . . . . . . . . 45

2.2.1 Methode ................................. 46

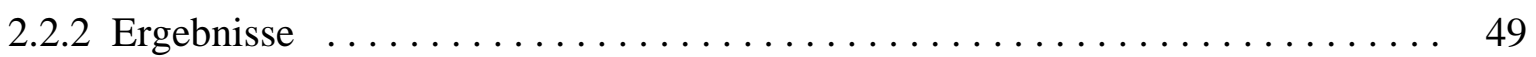

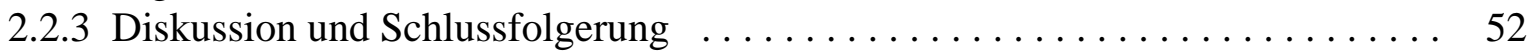

2.3 Maskierung als Erklärung des Modalitätseffekts . . . . . . . . . . . . . 53

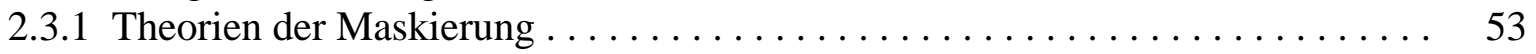

2.3.2 Widerlegung des Arguments anhand der Daten aus Experiment $1 \ldots \ldots \ldots . . \ldots 5$

2.4 Unterschiedliche Verarbeitungszeit bei verschiedenen Modalitäten als Erklärung des

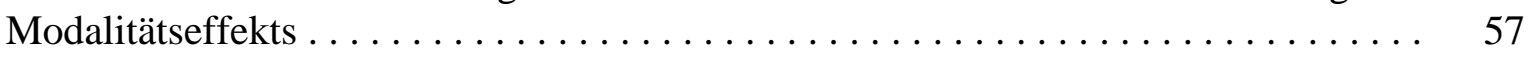

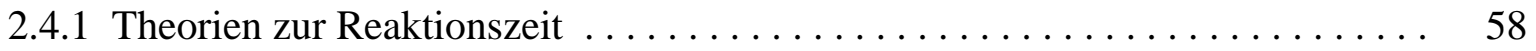

2.4.2 Experiment 2 zur Prüfung der Wahlreaktionszeiten auf die beiden in

Experiment 1 verwendeten Hinweisreizarten . . . . . . . . . . . . . . . . 58

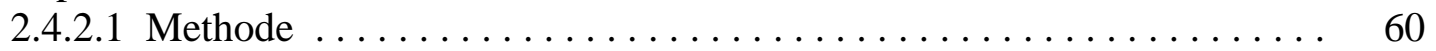

2.4.2.2 Ergebnisse ............................... 62

2.4.2.3 Diskussion .................................. 65 
2.5 Aufmerksamkeitsverschiebung als Erklärung des Modalitätseffekts . . . . . . . . 66

2.5.1 Theorien der visuellen Aufmerksamkeitsverschiebung .............. 66

2.5.2 Experiment 3 zur Prüfung von Hypothesen zur Aufmerksamkeitsverschiebung 68

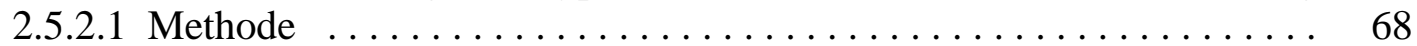

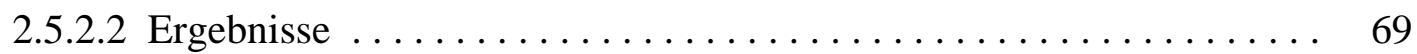

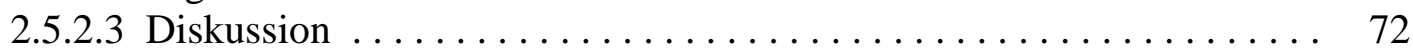

2.6 Intramodale Interferenz als Erklärung des Modalitätseffekts . . . . . . . . . . . . 73

2.6.1 Theoretischer Hintergrund: Multiple-Ressourcen-Theorie (MRT) . . . . . . . 73

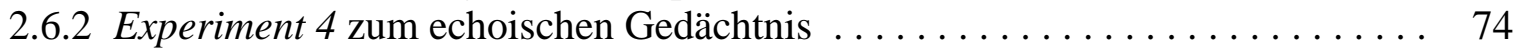

2.6.2.1 Methode ............................. 76

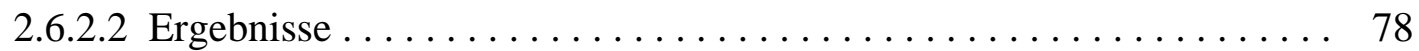

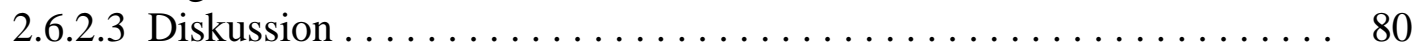

2.7 Zwischenfazit zum Modalitätseffekt des Hinweisreizes in der Partial-report-Methode 81

\section{$\underline{\text { Kapitel } 3}$ Entwicklung und Prüfung eines Modells zur visuellen Informationsverarbeitung}

3.1 Modell zur visuellen Informationsverarbeitung $\ldots \ldots \ldots \ldots \ldots \ldots \ldots \ldots \ldots$

3.1.1 Psychologische Betrachtung von visueller Wahrnehmung ........... 83

3.1.2 Neuropsychologiche Betrachtung von visueller Wahrnehmung . . . . . . . 86

3.1.3 Kognitive neuropsychologische Betrachtung von visueller Aufmerksamkeit . 91

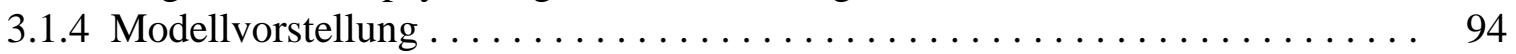

3.1.5 Ikonisches Gedächtnis im vorgestellten Modell . . . . . . . . . . . . . . . . 103

3.1.6 Partial-report-Aufgabe (Sperling-Paradigma) im Rahmen des Modells . . . . . 105

3.2 Experimente zur Prüfung des Modells . . . . . . . . . . . . . . . . . . 110

3.2.1 Experiment 5 zur Lokalisierung des Modalitätseffekts: Modellprüfung . . . . . 110

3.2.1.1 Methode ... . . . . . . . . . . . . . . . . . . . . . . . . . . . . . 114

3.2.1.2 Ergebnisse . . . . . . . . . . . . . . . . . . . . . 116

3.2.1.3 Diskussion . . . . . . . . . . . . . . . . . . . . . . 120

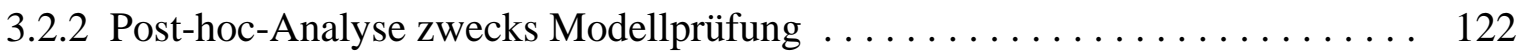

3.2.2.1 Methode bei der Fehleranalyse von Eperiment $1 \ldots \ldots \ldots \ldots . \ldots 124$

3.2.2.2 Ergebnisse der Datenanalyse und statistischen Tests . . . . . . . . . 125

3.2.2.3 Diskussion . . . . . . . . . . . . . . . . . . . . . . . 127

3.2.3 Experiment 6 zum Darbietungsdauereffekt des Hinweisreizes zwecks

Modellprüfung ................................ 128

3.2.3.1 Methode ................................ 132

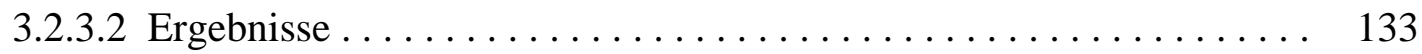

3.2.3.3 Diskussion . . . . . . . . . . . . . . . . . . . . . 136

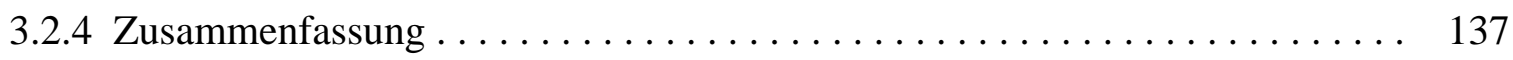

Kapitel 4 Allgemeine Diskussion: Ikonisches Gedächtnis und PR-Methode neu betrachtet

4.1 Ikonisches Gedächtnis und seine Problematik neu betrachtet . . . . . . . . . . . 138

4.2 Partial-report-Methode (Sperling-Paradigma) bzw. deren Phänomene neu betrachtet 143

4.3 Schlussdiskussion und Ausblick . . . . . . . . . . . . . . . . . . . . . 148

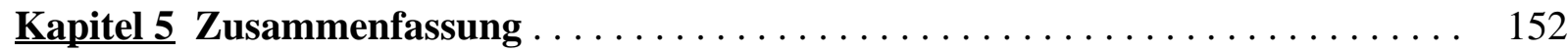

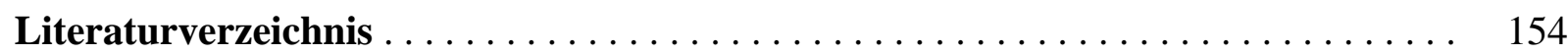


Abkürzungsverzeichnis

Abb.

ALM

bzw.

ca.

cd

$\mathrm{cm}$

d.h.

DLPFC

ebd.

et al.

$\mathrm{Hz}$

inkl.

ISI

KZG

$\mathrm{m}^{2}$

MANOVA

MIT

$\mathrm{mm}$

MRT

ms

p.

$\mathrm{Pb}$

Pbn

PDP

pp.

PR

PRP

$S$

S.

S.

SAS

Sehw.

s.o.

SOA

SPSS

STM

TB

u.a.

usw.

vgl.

VL

VLPFC

vs.

VSTM

z.B.

$\&$

Abbildung

allgemeines lineares Modell

beziehungsweise

circa

Candela (Lichtstärkeeinheit)

Zentimeter

das heißt

dorsolateraler präfrontaler Cortex

ebenda

et alii (und andere)

Hertz

inklusive

Interstimulusintervall

Kurzzeitgedächtnis

Quadratmeter

multivariate analysis of variance (multivariate Varianzanalyse)

Merkmalsintegrationstheorie

Millimeter

Multiple-Ressourcen-Theorie

Millisekunde(n)

page (Seite)

Proband und Probandin

Probanden und Probandinnen

parallel distributed processing

pages (Seiten)

partial report

psychological refractory period

Sekunde(n)

siehe

Seite

supervisory attentional system

Sehwinkel

siehe oben

stimulus onset asynchrony

statistical package for the social sciences

short term memory (Kurzzeitgedächtnis)

Teilbericht

und andere, unter anderem

und so weiter

vergleiche

Versuchsleiter und Versuchsleiterin

ventrolateraler präfrontaler Cortex

versus

visual short-term memory (visuelles Kurzzeitgedächtnis)

zum Beispiel

und

Grad 


\section{Abbildungsverzeichnis}

Seite

Abbildung 1 Das Multispeicher-Modell nach Atkinson und Shiffrin (1968)

Abbildung 2 Ergebnisse in Sperlings Experimenten (1960). Anzahl verfügbarer Buchstaben in Abhängigkeit von ISI im Teilbericht, Anzahl korrekt reproduzierter Buchstaben im Ganzbericht

Abbildung 3 Dual-buffer-Modell zum ikonischen Gedächtnis nach Mewhort et al. (1981)

Abbildung 4 Modell des ikonischen Gedächtnisses von Irwin und Yeomans (1986, S. 358)

Abbildung 5 Klassische Vorstellung von einer ikonischen Verblassenskurve

Abbildung 6 Generierung einer sensorischen Reaktionsfunktion (sensory-response function) in Abhängigkeit von der Zeit (nach Massaro \& Loftus, 1996, S. 85)

Abbildung 7 Ablauf eines Durchgangs in Experiment 1

Abbildung 8 Ergebnisse in Experiment 1; dargestellt in Abhängigkeit von ISI und Hinweisreizart; $\mathrm{N}=48$

Abbildung 9 Zellenweiser Leistungsvergleich zwischen auditiven und visuellen Hinweisreizbedingungen beim Ganzbericht (ISI $=0 \mathrm{~ms}$ ) in Experiment 1

Abbildung 10 Zellenweiser Leistungsvergleich zwischen auditiven und visuellen Hinweisreizbedingungen beim Teilbericht unter verschiedenen ISI in Experiment 1

Abbildung 11 Ablauf eines Durchgangs in Experiment 2

Abbildung 12 Mittelwerte und Standardfehler der Wahlreaktionszeiten für jede Hinweisreizart (über Berichtsarten und ISI-Bedingungen hinweg) in Experiment 2

Abbildung 13 Mittelwerte und Standardfehler der Wahlreaktionszeiten bei jeder Hinweisreizart in Experiment 2

Abbildung 14 Die Maß- und Distanzangaben der visuellen Hinweisreize in Experiment 3

Abbildung 15 Ergebnisse in Experiment 3; dargestellt in Abhängigkeit von ISI und Hinweisreizart; $\mathrm{N}=24$ 
Abbildung 16 Postulierte Ressourcen-Struktur der Informationsverarbeitung in der MRT (Wickens, 1992, S. 375)

Abbildung 17 Ablauf eines Durchgangs in Experiment 4

Abbildung 18 Ergebnisse in Experiment 4; dargestellt in Abhängigkeit von ISI und Hinweisreizart; $\mathrm{N}=40$

Abbildung 19 Treismans Modell zur Wahrnehmung von Merkmal und Objekt (1993, S. 31)

Abbildung 20 Modell zur visuellen Wahrnehmung und visuellen Vorstellung von Kosslyn (Kosslyn, 1994; Kosslyn \& Thompson, 2000)

Abbildung 21 Die Dreiecksbahn-Theorie der Aufmerksamkeit (triangular-circuit of attention) von LaBerge (2000, S. 721)

Abbildung 22 Ein neuropsychologisches Modell zur visuellen Informationsverarbeitung und zum ikonischen Gedächtnis

Abbildung 23 Ablauf eines Durchgangs in der Bedingung A und B in Experiment 5

Abbildung 24 Ergebnisse in Experiment 5A; dargestellt in Abhängigkeit von ISI und (ursprünglicher) Hinweisreizart; $\mathrm{N}=24$

Abbildung 25 Ergebnisse in Experiment 5B; dargestellt in Abhängigkeit von ISI und Hinweisreizart; $\mathrm{N}=24$

Abbildung 26 Mittelwerte und Standardfehler der Identitätsfehler und Lokalisationsfehler unter den beiden Hinweisreizbedingungen beim Ganzbericht in Experiment 1

Abbildung 27 Fehlervergleich zwischen auditiven und visuellen Hinweisreizbedingungen beim Teilbericht in Experiment 1

Abbildung 28 Mittelwerte und Standardfehler für die Anzahl richtig reproduzierter Buchstaben im Ganzbericht mit verschiedener visueller Hinweisreizdauer in Experiment 6 sowie Regressionsgerade

Abbildung 29 Ergebnisse in Experiment 6, dargestellt nach Fehlerarten; $\mathrm{N}=30$ 


\section{Tabellenverzeichnis}

Seite

Tabelle 1 Matrix- und Buchstabengröße sowie Buchstabenabstand in Experiment 1

Tabelle 2 Ergebnisse der Mittelwertsvergleiche zwischen den Leistungen in der auditiven und der visuellen Hinweisreizbedingung in den einzelnen Bedingungskombinationen in Experiment 1

Tabelle 3 Ergebnisse der inter- und intramodalen Mittelwertsvergleiche zwischen den Wahlreaktionszeiten in den auditiven und den visuellen Hinweisreizbedingungen mit verschiedener Darbietungsdauer in Experiment 2

Tabelle 4 Mittelwertsvergleiche der Wahlreaktionszeiten für jede Berichtsart und jede ISI-Bedingung in Experiment 2

Tabelle 5 Ergebnisse der Mittelwertsvergleiche zwischen den Leistungen in der auditiven und der visuellen Hinweisreizbedingung in den einzelnen Bedingungskombinationen in Experiment 3

Tabelle 6 Ergebnisse der Mittelwertsvergleiche zwischen den Reproduktionsleistungen in der auditiven und der visuellen Hinweisreizbedingung in den einzelnen Bedingungskombinationen in Experiment 4

Tabelle 7 Ergebnisse der Mittelwertsvergleiche zwischen den Leistungen in der auditiven und der visuellen (ursprünglichen) Hinweisreizbedingung in den einzelnen Bedingungskombinationen in Experiment 5A

Tabelle 8 Ergebnisse der Mittelwertsvergleiche zwischen den Leistungen in der auditiven und der visuellen Hinweisreizbedingung in den einzelnen Bedingungskombinationen in Experiment 5B

Tabelle 9 Ergebnisse der Mittelwertsvergleiche der Lokalisations- und Identifikationsfehler zwischen der auditiven und visuellen Hinweisreizbedingung beim Teilbericht (Teilbericht 1 und Teilbericht 2 zusammen betrachtet) je ISI in Experiment 1

Tabelle 10 Versuchsergebnisse für die einzelnen Bedingungen der visuellen Hinweisreizdauer im Ganzbericht in Experiment 6 (Anzahl richtig reproduzierter Buchstaben)

Tabelle 11 Versuchsergebnisse bezüglich der Lokalisationsfehler für die einzelnen Bedingungen der visuellen Hinweisreizdauer im Ganzbericht in Experiment 6

Tabelle 12 Ergebnisse bezüglich der Identitätsfehler für die einzelnen Bedingungen der Hinweisreizdauer im Ganzbericht in Experiment 6 


\section{Einführung}

Die Forschung zum visuellen sensorischen Gedächtnis erlebte in den 60er und 70er Jahren ihren Höhepunkt. Bis in die 80er Jahre hinein beschäftigte man sich weiter intensiv mit dem Thema. Dass in den 90er Jahren das Forschungsinteresse langsam abklang, lag unter anderem daran, dass eine theoretische Einbettung des Konzepts in das gesamte kognitive Informationsverarbeitungssystem schwer fiel und eine Abgrenzung gegenüber anderen Forschungskonzepten - wie der visuellen Aufmerksamkeit, der visuellen Wahrnehmung, dem visuellen Gedächtnis und der visuellen Suche, die aktuelle Forschungsthemen sind - nicht immer möglich ist. In der vorliegenden Arbeit wird versucht, das ikonische Gedächtnis als ein theoretisches Konzept mit den jüngsten relevanten theoretischen Entwicklungen in verwandten Gebieten in Verbindung zu bringen und den Gegenstand als Phänomen in dem gesamten visuellen Informationsverarbeitungsprozess zu betrachten. Dazu soll ein neuropsychologisches Modell aufgestellt werden und dies anhand empirischer Fragestellungen überprüft werden.

Die Partial-report-Methode ${ }^{1}$ gilt nach vier Jahrzehnten immer noch als eine der wichtigsten Methoden zur Untersuchung des visuellen sensorischen Gedächtnisses. Die klassischen Untersuchungsmethoden der Partial-report-Methodik sind das Sperling-Paradigma (Sperling, 1960) und das Bar-marker-Verfahren von Averbach und Coriell (1961). Die beiden Verfahren unterscheiden sich in einigen Aspekten, aber der wesentliche Unterschied liegt darin, dass im Sperling-Paradigma auditive Hinweisreize verwendet werden, von Averbach und Coriell hingegen visuelle. In einigen Arbeiten wurden bereits Vermutungen geäußert, dass die Modalität der Hinweisreize einen Effekt haben könnte, aber der folgenden Frage wurde bisher noch nicht explizit experimentell nachgegangen: Hat die Modalität des Hinweisreizes einen Einfluss auf das ikonische Gedächtnis bzw. auf die Leistung des ikonischen Gedächtnisses?

In der vorliegenden Arbeit wird diese Fragestellung untersucht. Dazu wird der mögliche Einfluss der Modalität des Hinweisreizes in Untersuchungen zum ikonischen Gedächtnis zunächst experimentell belegt. Basierend auf verschiedenen theoretischen Überlegungen wird systematisch und themenvertiefend nach einer plausiblen Erklärung für den gefundenen Modalitätseffekt gesucht. Da sich die Arbeit nicht nur mit der Methodik zu beschäftigen beabsichtigt, wird das Thema noch auf dem Hintergrund der Modellprüfung behandelt.

\footnotetext{
${ }^{1}$ Unter „Teilbericht“ (TB) und ,partial report“ $(P R)$ werden in der vorliegenden Arbeit zwei verschiedene Dinge verstanden. Während unter Teilbericht eine Bedingung in Experimenten zu verstehen ist, wird - damit die Termini auseinander gehalten werden können - für die Methode die Bezeichnung ,partial report “ beibehalten.
} 
$\mathrm{Da}$ in dieser Arbeit die theoretische konzeptuelle Annäherung an das ikonische Gedächtnisphänomen im Mittelpunkt steht, werden schwerpunktmäßig viele Theorien und Modelle dargestellt und beschrieben, so dass die vorliegende Arbeit etwas unkonventionell aufgebaut und strukturiert wird.

Die Arbeit beginnt mit einem Überblick über den theoretischen und empirischen Hintergrund der Erforschung des ikonischen Gedächtnisses. Die bisherigen Forschungsmethoden werden kurz dargestellt und die theoretischen Konzepte zum Phänomen des ikonischen Gedächtnisses in ihrer historischen Entwicklung bzw. im theoretischen Zusammenhang beschrieben. Offene Fragen und Kontroversen bezüglich des Forschungsstandes werden abschließend zusammengefasst.

Im empirischen Teil der Arbeit (Kapitel 2) wird zunächst ein möglicher Modalitätseffekt experimentell überprüft. Nachdem in dem durchgeführten Experiment der Modalitätseffekt des Hinweisreizes als nachgewiesen betrachtet werden kann, geht es in der weiteren Arbeit darum, diesen Effekt zu erklären. Dabei wurde eine Reihe von Experimenten durchgeführt, um verschiedenen Hypothesen nachzugehen und eine plausible Erklärung für den Modalitätseffekt zu finden.

Der dritte Teil der Arbeit ist der Entwicklung und Prüfung eines Modells gewidmet. Unter Berücksichtigung relevanter psychologischer und neuropsychologischer Theorien zur visuellen Wahrnehmung und visuellen Aufmerksamkeit wird ein neues Modell der visuellen Informationsverarbeitung und des ikonischen Gedächtnisses aufgestellt. Mit diesem Modell soll der Modalitätseffekt genauer betrachtet und lokalisiert werden. Vor allem aber sollen einige von dem Modell postulierte Annahmen anhand des Beispiels des Modalitätseffektes überprüft werden. Zum Zweck der Modellannahmenprüfung werden die bereits vorhandenen Daten reanalysiert und neue Experimente im Zusammenhang mit dem Modalitätseffekt konstruiert.

Schließlich werden das Phänomen des ikonischen Gedächtnisses und die Partial-reportMethode im Rahmen des vorgestellten Modells neu betrachtet und diskutiert, und zwar eingebettet in eine theoretische Vernetzung. 


\section{$\underline{\text { Kapitel } 1}$ Theoretischer und empirischer Hintergrund}

\subsection{Visuelles sensorisches bzw. ikonisches Gedächtnis}

\subsubsection{Sensorisches Gedächtnis}

Eingebürgert hat sich der Begriff des sensorischen Gedächtnisses in der kognitiven Psychologie vor allem durch den Stufenmodellansatz bezüglich der menschlichen Informationsverarbeitung. In dem weit verbreiteten Multispeicher-Modell von Atkinson und Shiffrin (1968) wird das sensorische Gedächtnis als das früheste Stadium der menschlichen Informationsverarbeitung verstanden, wobei die Autoren diese Anfangsphase des Gedächtnissystems als sensorisches Register bezeichnet haben.

Nach diesem Modell werden aus der Umwelt kommende Informationen zuerst in den sensorischen Systemen aufgenommen, mit Hilfe von Aufmerksamkeitszuwendung werden sie dann in ein zwischengeschaltetes Kurzzeitgedächtnis (KZG) überführt, dort memoriert und anschließend in einem andauernden Langzeitgedächtnis gespeichert (s. Abb. 1). Somit spielt das sensorische Gedächtnissystem in unserem Leben eine wichtige Rolle als Schnittstelle zwischen Umwelt und Individuum.

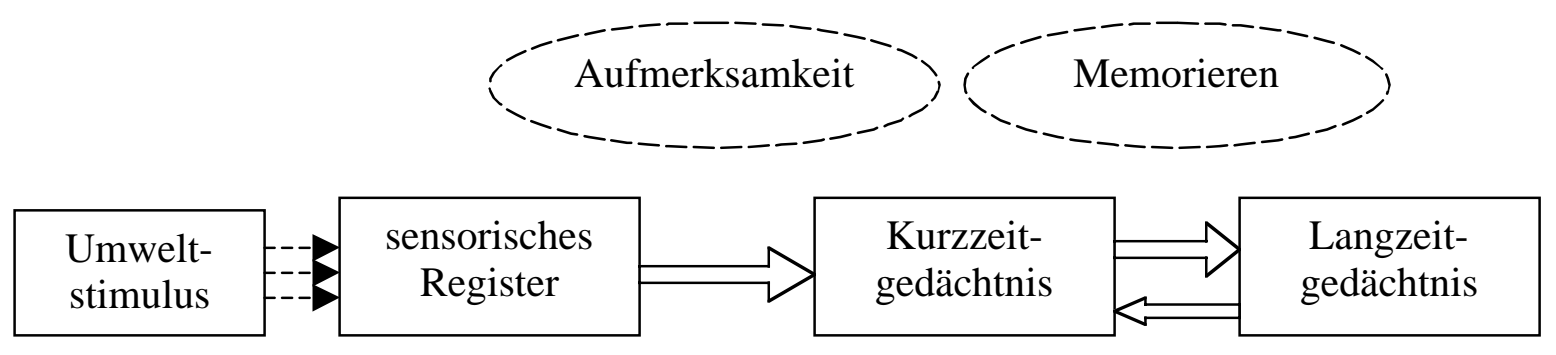

Abbildung 1: Das Multispeicher-Modell nach Atkinson und Shiffrin (1968).

Sensorische Phänomene können ebenfalls in Gedächtnismodelle integriert werden, die nicht von einer Unterteilung des Gedächtnisses in separate Speicher ausgehen. Nach der Aktivationstheorie (z.B. Anderson, 1983; Cowan, 1993) löst der Umweltreiz eine Aktivation aus, welche auf niedriger Ebene der Kodierung kurz andauert, dann aber innerhalb einer sehr kurzen Zeit wieder verloren geht. Das bedeutet, die entsprechenden Repräsentationselemente werden wieder inaktiv.

Ganz gleich von welchem Standpunkt aus es betrachtet wird, scheint das sensorische Phänomen der sehr kurzfristigen Speicherung eine theorieübergreifende Bedeutung für die kognitive Psychologie zu haben, da ein Stadium der initialen Reizaufnahme und -kodierung von jeglicher Art weiterer Verarbeitung vorausgesetzt wird und deshalb in jedem Fall angenommen werden muss. 
Diese Art von Informationsspeicherung wird folgendermaßen charakterisiert: Sie hat eine kurze Lebensdauer und eine große Kapazität, sie ist modalitätsspezifisch und geschieht nicht unter bewusster Kontrolle. Hauptmerkmal des sensorischen Gedächtnisses soll vor allem die Modalitätsspezifizität sein. Es basiert immer auf einer bestimmten sensorischen Modalität, was die Existenz verschiedener sensorischer Register zur Folge hat. Je nachdem, welche Modalität beansprucht wird, gibt es ein visuelles, auditives, taktiles, gustatorisches und olfaktorisches sensorisches Gedächtnis. Neisser (1967) bezeichnete die visuelle, auditive und taktile Form des sensorischen Registers als ikonisches (iconic), echoisches (echoic) und haptisches (haptic) Gedächtnis. Von diesen drei Arten des sensorischen Gedächtnisses hat vor allem das ikonische Gedächtnis in der Vergangenheit sehr viel Forschungsinteresse auf sich gezogen. In der vorliegenden Arbeit wird die Bezeichnung ,ikonisches Gedächtnis“ äquivalent zu der Bezeichnung „,visuelles sensorisches Gedächtnis“ verwendet.

\subsubsection{Ikonisches Gedächtnis und seine Funktionen}

Als eine auf der visuellen Modalität basierende sensorische Kurzspeicherung werden dem ikonischen Gedächtnis oft die folgenden Funktionen zugeschrieben: Bewahrung von Spuren einer sich rasch verändernden Informationswelt, Selektion von Stimuli für die weitere Verarbeitung, Integration von Reizfragmenten in eine einheitliche Wahrnehmung. Die Wichtigkeit des ikonischen Gedächtnisses wird vor allem in der Pufferfunktion für die weitere Informationsverarbeitung gesehen. Damit ist eine Selektion aus einer Überfülle von Reizen erst möglich. Auch eine kontinuierliche und stabile Sicht der Umwelt trotz sakkadischer Augenbewegung ist nur dank des ikonischen Gedächtnisses möglich.

Innerhalb des Stufenmodells wird angenommen, dass ein in der Umwelt vorkommender Reiz immer zunächst sensorisch verarbeitet wird, bevor er in der nächsten Stufe weiterverarbeitet werden kann. In der bisherigen Forschung wurde allerdings das ikonische Gedächtnis oft abweichend von der Definition und dem allgemeinen Verständnis experimentell unter extremen Bedingungen untersucht, dabei geht es speziell um die Informationsaufnahme von sehr kurz dargebotenen Reizen. Die sehr kurze Reizdarbietung wird methodisch für notwendig gehalten, um tatsächlich das sensorische Gedächtnis und nicht bereits das KZG zu untersuchen. Dieses Untersuchungsanliegen hängt auch mit folgender Beobachtung zusammen: Der Mensch besitzt offensichtlich die Fähigkeit, viele Umweltreize, die weit kürzer als eine Sekunde sind, dennoch aufzunehmen und auf sie zu reagieren. Ein sehr kurz erschienener Umweltreiz scheint oft irgendeinen „Eindruck“ zu hinterlassen, der über das Verschwinden des Reizes hinaus noch für eine kurze Dauer anhält. Dieses seit langem beobachtete Phänomen 
wird von kognitiven Psychologen als die Funktion eines sensorischen Gedächtnisses angesehen.

\subsubsection{Sperlings Entdeckung}

Wie in den meisten Gedächtnisforschungsansätzen interessieren sich die Forscher hinsichtlich der sensorischen Gedächtniskomponente vor allem für zwei Aspekte: die inhaltliche und die zeitliche Konstante. Konkret auf das ikonische Gedächtnis bezogen, beschäftigt sich die Forschung seit vielen Jahren mit den Fragen, „wie viel“ und „für wie lang“ das visuelle sensorische Gedächtnis Information ,speichert“.

Der schwedische Forscher von Segner ${ }^{2}$ wollte z.B. schon 1740 wissen, wie lange die Spur eines visuell aufgenommenen Eindrucks im Gedächtnis bleibt. In seinem Experiment befestigte er ein glühendes Stück Kohle an einem rotierenden Rad. Er wählte eine Geschwindigkeit, mit der gerade noch ein vollständig wahrnehmbarer Kreis durch Drehung des Rades zustande kam und maß die Zeit für eine Umdrehung. Daraus schätzte er diese Persistenzdauer auf ungefähr eine Zehntelsekunde (Pagel, 1875).

Die eigentliche Entdeckung des visuellen sensorischen Gedächtnisses ist dem amerikanischen Psychologen George Sperling (1960) zu verdanken. Sein Ausgangspunkt ist das klassische Experiment zur Bestimmung der unmittelbaren Gedächtnisspanne (span of immediate-memory). Er verwendete die Ganzberichtsmethode (whole report procedure), um die Menge der noch verfügbaren Information einer sehr kurzen visuellen Präsentation herauszufinden. Die visuellen Reize, z.B. Buchstaben, wurden in einer 3x4-Matrix mittels eines Tachistoskops für $50 \mathrm{~ms}$ dargeboten, der/die Proband/Probandin ( $\mathrm{Pb}$ ) sollte dann alle Buchstaben, die er/sie gesehen hatte, wiedergeben. Sperling kam zu dem Ergebnis, dass die Probanden/Probandinnen (Pbn) im Durchschnitt 4.3 von 12 Buchstaben reproduzieren konnten.

Jedoch schien diese Idee, die quantitative Limitation der sensorischen Informationsverarbeitung durch diese Ganzberichtsmethode festlegen zu können, nicht mit der empirischen Beobachtung übereinzustimmen, dass die Pbn den Eindruck hatten, dass sie mehr gesehen hatten, als sie berichten konnten. Wie kann man dies überprüfen? Der große Beitrag von Sperling zur sensorischen Gedächtnisforschung ist die Entwicklung der Partial-reportMethode (partial report procedure). Mit diesem partial report $(P R)$ meint man tatsächlich ein methodisches Werkzeug gefunden zu haben, um etwas an sich Unbeobachtbares beobachtbar zu machen. In diesem Verfahren wird der/die $\mathrm{Pb}$ instruiert, einen Teil der Reizvorlage, zum Beispiel eine Reihe der Buchstabenmatrix, zu reproduzieren, wobei er/sie erst nach der

\footnotetext{
${ }^{2}$ Johannes Andreas von Segner (1704-1777) war der Erfinder des Segnerschen Reaktionsrades.
} 
Präsentation der Matrix erfährt, welche Zeile zu reproduzieren ist. Sperling (1960) verwendete in seinen Experimenten Töne mit unterschiedlicher Höhe als Hinweisreize. Der hohe Ton bedeutete die obere Zeile, der mittlere Ton die mittlere und der niedrige Ton die untere Zeile, die jeweils reproduziert werden sollte.

Mit diesem Verfahren kam Sperling zu einer Wiedergabeleistung von durchschnittlich 3.03 Buchstaben pro Zeile. Da der/die Pb vorher nicht wissen konnte, welche Zeile nach der Präsentation abgefragt wird, folgerte Sperling, dass er/sie von allen drei Zeilen eine ähnliche Menge von Information aufgenommen haben muss. Wenn der/die $\mathrm{Pb} 3$ von 4 Buchstaben pro Zeile reproduzieren kann, schien es für ihn plausibel, dass er/sie also von der ganzen dreizeiligen Matrix über 3-mal soviel Information verfügen muss, was insgesamt ungefähr 9 Buchstaben (3x3) entspricht. Dies ist dann wesentlich mehr als die Menge, die man mit der Ganzberichtsmethode erhalten hat, nämlich ca. 4.3 von 12 Buchstaben. Dieser Vorteil der Teilberichtsbedingung wird fortan als „Teilberichtsüberlegenheit“ (partial-report superiority) bezeichnet.

Sperling erklärte das Ergebnis und die indirekt erschlossene Überlegenheit der Teilberichtsbedingung wie folgt: Die Buchstaben müssen von einer rasch verblassenden visuellen Gedächtnisspur ausgelesen (read out) werden. Während des Auslesens von einem Teil der Buchstaben verblassen Sperling zufolge die Spuren der anderen, so dass in der Ganzberichtsbedingung nach vier bis fünf Buchstaben keine Gedächtnisspuren mehr für die restlichen Buchstaben vorhanden seien.

Nach dem ,wie viel“ wollte Sperling noch wissen, wie lange das visuelle Abbild für die Pbn sichtbar bleibt. Um die Existenz eines rasch verblassenden Gedächtnissystems zu beweisen, variierte Sperling systematisch das Zeitintervall zwischen dem Ende der MatrixPräsentation (offset) und dem Beginn des Hinweisreizes (onset), das so genannte Interstimulusintervall (ISI). Sperling konnte zeigen, dass die Leistung tatsächlich mit zunehmendem ISI abnahm (s. Abb. 2). Die Wiedergabeleistung in der Teilberichtsbedingung war bei einer Verzögerung des Hinweisreizes von $500 \mathrm{~ms}$ bereits auf ein niedriges Niveau gesunken und bei einem Intervall von einer Sekunde erreichte sie annähernd nur noch das Leistungsniveau des Ganzberichtverfahrens, d.h., es war keine Überlegenheit der Teilberichtsbedingung mehr zu beobachten. Sperling sah in seinen Experimenten Belege für die Existenz eines persistierenden visuellen Abbilds, welches den Ergebnissen zufolge einen Bruchteil einer Sekunde andauert. 


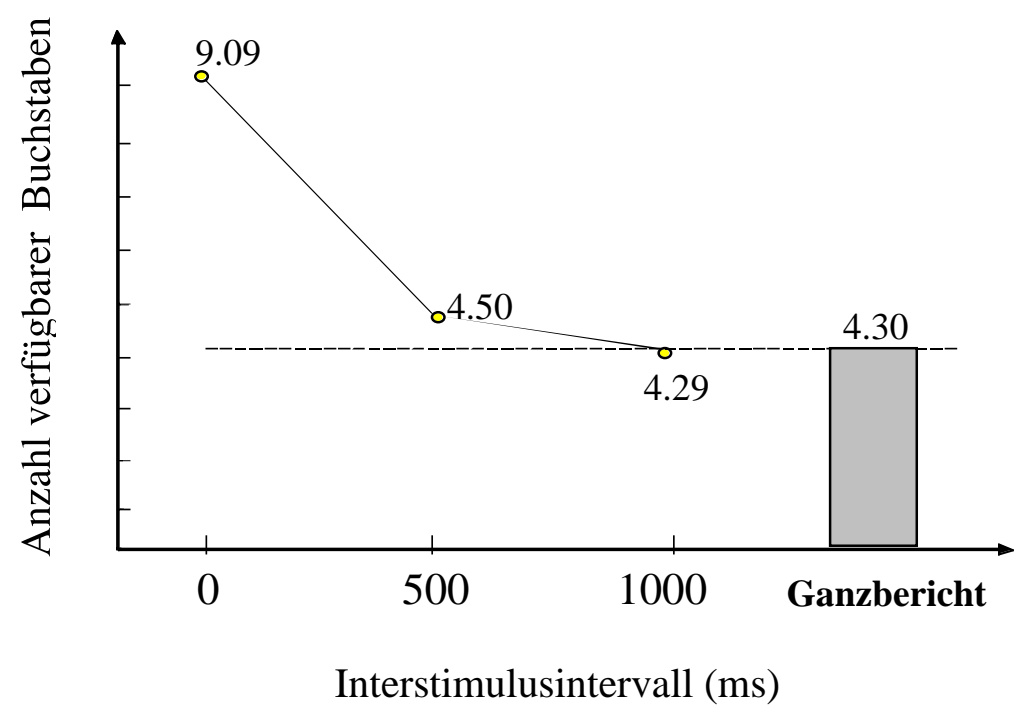

Abbildung 2: Ergebnisse in Sperlings Experimenten (1960). Anzahl verfügbarer Buchstaben in Abhängigkeit von ISI im Teilbericht, Anzahl korrekt reproduzierter Buchstaben im Ganzbericht.

Die „bahnbrechende“ $P R$-Methode, oder besser gesagt, die Interpretation der Ergebnisse, hat ein Jahrzehnte andauerndes Forschungsinteresse ausgelöst. Von da an begann eine langjährige theoretische Auseinandersetzung mit dem Phänomen des kurzlebigen visuellen Speichers, nämlich des visuellen sensorischen Gedächtnisses. Verschiedene Methoden wurden zu seiner Erforschung entwickelt.

\subsection{Forschungsmethoden zum ikonischen Gedächtnis}

Die Methoden der bisherigen Forschung zum visuellen sensorischen Gedächtnis können allgemein in zwei Kategorien eingeteilt werden: in indirekte und direkte Methoden. Über die Methodik zur Untersuchung des ikonisches Gedächtnisses lieferten die Arbeiten von Long (1980) und Coltheart (1980) einen guten Überblick. Während indirekte Methoden auf der Wiedergabe von visuellen Informationen eines Stimulusdisplays durch die Pbn basieren, beruhen direkte Methoden auf Berichten der Pbn über die phänomenologische Sichtbarkeit des Displays (vgl. Coltheart, 1980).

\subsubsection{Indirekte Methoden}

Mit diesen Methoden wird das ikonische Gedächtnis indirekt erschlossen. Zu dieser Kategorie zählen die $P R$-Methode und deren Modifikationen. Bei den PR-Methoden, wie dem Sperling-Paradigma, wird nur nach einem Teil der zuvor dargebotenen Information gefragt. Um die Existenz des sensorischen Gedächtnisses demonstrieren zu können, muss angenommen werden, dass die Leistungskurve (vgl. Abb. 2), die eine Funktion der Verzögerung des 
Hinweisreizes darstellt, der Verfallskurve des Ikons ${ }^{3}$ in Abhängigkeit von der Zeit entspricht. Nur unter dieser Annahme kann die Eigenschaft des ikonischen Gedächtnisses indirekt erschlossen werden, wobei die Annahme an sich nicht überprüft werden kann.

Eine Variation der indirekten Methoden stellt unter anderem noch die Bar-markerProzedur von Averbach und Coriell (1961) dar, bei welcher nur ein einziges Item aus der linear angeordneten visuellen Vorlage benannt werden soll. Die derzeit gängige Methode ist die von Eriksen und Steffy (1964) eingeführte Bar-probe-Methode mit kreisförmiger Anordnung als Reizvorlage. Auch hier wird nur nach einem Item gefragt.

\subsubsection{Direkte Methoden}

Bei den so genannten direkten Methoden wird das ikonische Gedächtnis als phänomenologische Präsenz subjektiv eingeschätzt. Man glaubte, mit diesen Methoden die kurzlebige visuelle Persistenz direkt erfassen und untersuchen zu können. Der oben erwähnte Pionierversuch von Segners verkörpert z.B. diese Vorstellung. Allerdings haben sich in der Zwischenzeit verschiedene Varianten entwickelt. Dazu zählen unter anderem:

(1) Persistence-of-form procedure: Beispiele sind die Methode von Sakitt (1976) und die Phenomenal-continuity-Technik von Coltheart (1980). Bei einem intermittierend dargebotenen visuellen Reiz soll die Präsentationsrate so variiert werden, bis der Reiz dem Beobachter ohne wahrnehmbares Flackern kontinuierlich erscheint.

(2) Judgement of synchrony: Diese Technik ist ursprünglich von Sperling (1967) eingeführt worden. Efron (1970a, 1970b, 1970c) hat diese Technik weiterentwickelt. In einem seiner Experimente soll der/die $\mathrm{Pb}$ den Offset eines Zielreizes mit einem externen kurzen Signal, dem so genannten probe stimulus, z.B. Licht, so synchronisieren, dass der Probereiz und der Offset des Zielreizes subjektiv zeitlich zusammentreffen. Das Intervall zwischen dem physikalischen Offset des Teststimulus und dem physikalischen Onset des Probestimulus wird als die phänomenologische Dauer des Teststimulus angesehen. Mit dieser Methode verwandt ist die Onset/Offset-Reaktionszeit-Technik (Briggs \& Kinsbourne, 1972), worin der Onset und der Offset eines Zielreizes einfach durch eine beliebige Art von Reaktion, wie z.B. durch Knopfdrücken, signalisiert wird. Die Zeitdifferenz zwischen den zwei Urteilen in Bezug auf den phänomenologischen Onset und Offset des Zielreizes wird als die phänomenologische Dauer des Zielreizes betrachtet.

(3) Temporal integration of form parts (vgl. successive-field procedure Long, 1980): Diese Technik wurde zuerst von Eriksen und Collins $(1967,1968)$ angewendet, danach gab es

\footnotetext{
${ }^{3}$ Ikon: visuelles Abbild.
} 
verschiedene Modifikationen. Bei dieser Art von Verfahren ist die Identifikation des geteilten Zielreizes von der Integration aufeinander folgender Displays abhängig. Somit ist der interessante Faktor das Zeitintervall zwischen den Darbietungen, bei dem die Teile des Zielreizes noch subjektiv zu einer Einheit integriert werden können.

$\mathrm{Zu}$ der Kategorie der „direkten Methoden“ sind noch viele andere zu zählen (vgl. Long, 1980; Coltheart, 1980), auf die hier aber nicht mehr eingegangen wird.

Eine Technik, die sowohl bei den indirekten als auch bei den direkten Methoden verwendet wird, ist die Maskierung, vor allem die Rückwärtsmaskierung (s. Sperling, 1964; Haber \& Standing, 1970). Die Maske wird nach dem Offset des Zielreizes mit variiertem ISI dargeboten. Die Technik basiert auf der Vorstellung, dass das Ikon eine maskierbare visuelle Spur ist und die Maske bewirkt, dass der sensorische Verarbeitungsprozess gestoppt wird. Das Ikon bzw. die visuelle Gedächtnisspur endet also dort, wo die Maske keine Auswirkung mehr auf die Leistung hat. Somit soll die effektive Dauer des Ikons direkt von dem ISI zwischen Zielreiz und Maske abgeleitet werden können.

Die Darstellung gängiger Untersuchungsmethoden abschließend bleibt anzumerken, dass der Gegenstand, der mit den direkten und indirekten Methoden untersucht wird, nach Ansicht von Coltheart (1980) unterschiedlich ist, worauf in dem folgenden Abschnitt noch eingegangen wird. Zuvor ist allerdings noch zu betonen, dass Coltheart zufolge (ebd.) der Gegenstand des ikonischen Gedächtnisses nur mit indirekten Methoden, nämlich $P R$-Methoden, untersucht werden kann. Daraus kann man den methodischen Stellenwert der PR-Methode für die bisherige Forschung ableiten. Nach wie vor bleibt die $P R$-Methode die wichtigste Methode zur Erforschung des visuellen sensorischen Gedächtnisses.

\subsection{Konzeptuelle Entwicklung des ikonischen Gedächtnisses}

\subsubsection{Klassische Phase}

Die frühen Arbeiten, angefangen von Sperling (1960), führten zu einer klassischen Konzeption des visuellen sensorischen Gedächtnisses mit folgenden zentralen Gedanken:

(1) Das ikonische Gedächtnis bildet die erste mentale Repräsentation von visuell präsentierten Informationen.

(2) Das ikonische Gedächtnis hat eine sehr große Kapazität, die viel größer als die Kapazität des $\mathrm{KZG}$ ist. 
(3) Die ikonischen Gedächtnisspuren zerfallen sehr schnell. Unmittelbar nach dem Offset der Reizpräsentation beginnen die Gedächtnisspuren zu verblassen. Der Spurenzerfall nimmt exponentiell ab, er findet nach ca. einer Sekunde ein Ende.

(4) Die sich im ikonischen Gedächtnis befindende Reizinformation ist eher präkategorial. Sie beinhaltet nur rohe physikalische Eigenschaften des Reizes, d.h., die Reizinformation wird nicht kognitiv verarbeitet. Das ist es, was der Name „sensorisch“ eigentlich besagt.

(5) Das ikonische Gedächtnis ist an den Offset des visuellen Stimulus gekoppelt. Dies soll erklären, warum die Darbietungszeit des Zielreizes (bis zu einem gewissen Grad) keine Rolle spielt.

(6) Das ikonische Gedächtnis ist eine Art „visuelle Spur“ und kann deswegen ebenso von einem visuellen Reiz (Maske) maskiert werden. Der Maskierungseffekt ist ein Indikator dafür, dass die persistierende Information visueller Art ist.

(7) Die Faktoren, die einen Effekt auf die Effizienz des ikonischen Speichers haben, sind auf das visuelle System begrenzt. Solche Faktoren sind z.B. Reizintensität, Reizdauer oder FigurHintergrund-Kontrast der visuellen Vorlage.

(8) Sowohl die indirekten als auch die direkten Methoden dienen zur Erforschung des ikonischen Gedächtnisses. Der Gegenstand, der mit beiden Arten von Methoden untersucht wird, ist derselbe bzw. von demselben Wesen (Haber \& Standing, 1970), d.h., die noch verfügbare visuelle Information eines Reizes ist gleich dessen phänomenologischer Sichtbarkeit.

Dieses klassische Konzept des ikonischen Gedächtnisses wurde Mitte der 70er Jahre und insbesondere zu Anfang der 80er Jahre erschüttert. Der Anlass dazu waren einige empirische Beobachtungen (Näheres hierzu, s. Abschnitt 1.3.2) :

(1) Die mit den beiden Techniken, nämlich der $P R$-Methode und der direkten Methode, gemessenen Leistungen wurden von Stimulusfaktoren, wie z.B. der Stimulusintensität oder der Stimulusdarbietungsdauer, unterschiedlich beeinflusst.

(2) In der mit der $P R$-Methode gemessenen Stimulus-Persistenz wurden unterschiedliche Informationsanteile (Identitätsinformation und Lokalisationsinformation) festgestellt.

Diese Beobachtungen veranlassten Forscher dazu, das traditionelle Bild des Ikons differenzierter zu betrachten.

\subsubsection{Aufspaltung des Ikons: Colthearts Beitrag}

Die relativ simple und intuitive Frühkonzeption, das ikonische Gedächtnis als einen präkategorialen Speicher mit visuellen Spuren von kurz dargebotenen Stimuli zu betrachten, 
wurde in den frühen 80er Jahren in Frage gestellt. Es wurde erkannt, dass verschiedene Phänomene alle dem so genannten visuellen Speicher zugeordnet worden waren (vgl. Coltheart, 1980; Long, 1980). Coltheart (1980) begann seine Klärungsarbeit mit einer klaren Trennung zwischen drei verschiedenen Phänomenen, die bis dahin alle mit der ,visuellen Persistenz" in Verbindung gebracht worden waren. Eine Persistenz, die einen kurz erscheinenden Stimulus nach dessen physikalischer Beendigung überdauert, kann nach Coltheart (1980) verschiedene Formen annehmen:

(1) Als neurophysiologische Aktivität: Sie wird durch einen Reiz im visuellen System ausgelöst und überdauert das Reizende. Coltheart bezeichnete sie als neuronale Persistenz.

(2) Als visuelle Sichtbarkeit: Ein Stimulus bleibt nach dem Reizende phänomenologisch noch eine Weile für Menschen sichtbar oder gegenwärtig. Von Coltheart wurde dies sichtbare Persistenz genannt.

(3) Als visuelle Information über einen Reiz: Die Information über die charakteristischen Eigenschaften eines Stimulus bleibt kurzzeitig für den Beobachter erhalten. Coltheart bezeichnet dies als informatorische Persistenz.

Eine implizite Auffassung war bis dahin, dass den drei Formen visueller Persistenz ein und derselbe Prozess zugrunde liege, so dass, gleichgültig welche Methode verwendet wird, ein und dasselbe Phänomen untersucht würde. Coltheart (ebd.) behauptete dagegen, dass die an den drei Persistenzformen beteiligten Prozesse in ihrer Natur unterschiedlich seien. Von der neuronalen Persistenz abgesehen, die offensichtlich nur eine rein neuronale Aktivität darstellt und nicht im Mittelpunkt psychologischen Interesses steht, versuchte Coltheart (ebd.) die informatorische Persistenz von dem phänomenologischen Erleben, nämlich der sichtbaren Persistenz abzugrenzen. Für ihn ist die sichtbare Persistenz ein Nebenprodukt der neuronalen Persistenz. Coltheart zufolge untersuchen die direkten und indirekten Methoden unterschiedliche Gegenstände. So prüfe man mit den direkten Methoden, wie z.B. synchrony judgment, temporal integration, in welcher Weise ein visueller Stimulus nach Reizbeendigung noch phänomenologisch gegenwärtig, d.h. sichtbar für den Beobachter ist (sichtbare Persistenz), während mit den indirekten Methoden eher geprüft werde, in welcher Weise die visuelle Information, die in einem Stimulus enthalten ist, nach der Reizbeendigung noch verfügbar ist. Dabei wird die informatorische Persistenz erfasst. Ein solches Ziel verfolgt z.B. die PR-Methode. Nach Colthearts Verständnis ist nur die informatorische Persistenz Gegenstand des ikonischen Gedächtnisses. Die empirische Begründung für die Trennung zwischen sichtbarer Persistenz und informatorischer Persistenz sah er hauptsächlich darin, dass die Untersuchungen mit direkten und indirekten Methoden unterschiedliche Befunde 
ergaben. Die Befunde aus den direkten Methoden (z.B. Allport, 1970; Dixon \& Hammond, 1972) zeigten zwei interessante experimentelle Effekte: den so genannten inversen Reizdauereffekt (inverse-duration effect) und den inversen Reizhelligkeitseffekt (inverseluminance effect). Während der inverse Reizdauereffekt darin besteht, dass die Persistenzdauer eines Reizes nach dessen Beendigung umso kürzer ist, je länger der Reiz dargeboten wird, besagt der inverse Reizhelligkeitseffekt, dass die Persistenz geringer wird, je höher die Reizintensität ist. Im Gegensatz zu den direkten Methoden konnten die beiden inversen Effekte in vielen Untersuchungen (z.B. Sperling, 1960; Di Lollo, 1978) mit indirekten Methoden, bei denen nach Coltheart (1980) die informatorische Persistenz Untersuchungsgegenstand ist, nicht nachgewiesen werden. Er zog daraus die Schlussfolgerung, dass die sichtbare Persistenz (nicht aber die informatorische Persistenz) folgende zwei Eigenschaften aufweist: Ihre Dauer verhält sich umgekehrt proportional zur Reizdauer und zur Reizhelligkeit. Durch diesen Vergleich sah Coltheart es als berechtigt an zu behaupten, dass die informatorische und die sichtbare Persistenz unterschiedliche Phänomene seien. Da sich im ikonischen Gedächtnis nur die informatorische, nicht aber die sichtbare Persistenz manifestiere, könne es nicht mit direkten Methoden sondern nur mit indirekten Methoden untersucht werden.

Colthearts Arbeit wurde zum Meilenstein in der Erforschung des ikonischen Gedächtnisses. Durch sie wurde das bis dahin weit verbreitete klassische Konzept erschüttert, und es wurden weitere Konzeptualisierungen des ikonischen Gedächtnisses angeregt.

Allerdings wurde die theoretische Interpretation von Coltheart (1980) auch mit einigen Kritiken konfrontiert. Die von ihm betrachteten Daten stammten aus unterschiedlichen Experimenten, die sich hinsichtlich mehrerer Aspekte voneinander unterschieden, so dass ein aufgefundener Effekt nicht eindeutig auf einen bestimmten Faktor (z.B. die Reizdarbietungsdauer oder die Reizhelligkeit) zurückgeführt werden kann (zu dieser Kritik vgl. Massaro und Loftus, 1996).

Die von Coltheart angeführte Begründung dafür, dass sichtbare Persistenz und informatorische Persistenz unterschiedliche Prozesse sein müssen, wurde in einigen weiteren empirischen Arbeiten (Adelson \& Jonides, 1980; Long \& Beaton, 1982; Long \& McCarthy 1982) angezweifelt, da gezeigt werden konnte, dass unter bestimmten Bedingungen die Reizhelligkeit oder die Reizdauer doch einen Effekt auf die Leistung in PR-Aufgabe haben kann. Außerdem kann die Beziehung zwischen der sichtbaren Persistenzdauer einerseits und der Reizhelligkeit sowie Reizdarbietungsdauer anderseits in einer „direkten Methode“ nicht immer in eine inverse, sondern auch in die gleiche Richtung verlaufen. Di Lollo und Dixon (1988, 1992; Dixon \& Di Lollo, 1994) konnten auch zeigen, dass sich unter bestimmten 
Bedingungen ein robuster Zusammenhang zwischen Reizdarbietungsdauer und $P R$-Leistung beobachten ließ und die Leistung dort ebenfalls mit zunehmender Reizdarbietungsdauer abnahm.

Diese Befunde brachten Coltheart dazu, seine frühere Aussage aus dem Jahr $1980 \mathrm{zu}$ relativieren: „Nevertheless, given that there are some circumstances ..., the claim (Coltheart, 1980a) that visible persistence and iconic memory must be different processes because they respond differently to manipulations of stimulus luminance or duration currently lacks the force it possessed in 1980" (Coltheart, 1984, S. 267-268).

Trotz der teilweise nicht ganz konformen Daten wurde die Trennung zwischen einem Ikon als phänomenologische Persistenz und einem Ikon als informatorische Persistenz dennoch weiterhin als richtig und theoretisch sinnvoll betrachtet. Ausgehend von der Unterscheidung zwischen informatorischer und sichtbarer Persistenz (wobei die informatorische Persistenz als Inhalt des ikonischen Gedächtnisses betracht wird) ging es bei der weiteren Theorieentwicklung darum, Charakteristika der informatorischen Persistenz zu erforschen und die Repräsentationsart des ikonischen Gedächtnisses zu bestimmen. Fortan werden zwei Arten von Repräsentationen im ikonischen Gedächtnis vermutet. Der Gedanke findet Ausdruck im Dual-buffer-Modell von Mewhort, Campbell, Marchetti und Campbell (1981) sowie in Irwins und Yeomans' Modell (Yeomans \& Irwin, 1985; Irwin \& Yeomans, 1986) des ikonischen Gedächtnisses, die beide als Strukturmodelle betrachtet werden können.

\subsubsection{Strukturmodelle}

Die weitere theoretische Entwicklung, die Repräsentationsart des ikonischen Gedächtnisses zu identifizieren und differenzieren, hat nicht zuletzt mit der Unterscheidung von zwei Fehlerarten zu tun. In einigen Untersuchungen zum ikonischen Gedächtnis (Eriksen \& Rohrbaugh, 1970; Townsend, 1973; Dick, 1974) wurde festgestellt, dass die Pbn zwei Arten von Fehlern machten: entweder Lokalisationsfehler (adjacency error / mislocation error / transposition error) oder Identifikationsfehler (intrusion error / identification error). Ein Fehler der zuerst genannten Art entsteht dann, wenn das benachbarte oder anders platzierte Item als das eigentliche, durch einen Hinweisreiz markierte Item berichtet wird. Mit dem Identifikationsfehler ist der Fall gemeint, dass Pbn Items nennen, die zuvor gar nicht dargeboten wurden.

Das bekannte Phänomen der Leistungsabnahme mit zunehmender Verzögerung des Hinweisreizes in $P R$ wird der klassischen Ansicht nach wie folgt erklärt: In der Leistungsabnahme reflektiere sich die Zeit, die für die Verarbeitung der Zielreize noch zur 
Verfügung steht. Wenn der Hinweisreiz früher da ist, stehe mehr Zeit zur Verfügung, die Aufmerksamkeit auf die relevanten Items in dem sensorischen Speicher zu lenken und sie daraus zu selektieren, während bei längerer Verzögerung die Spuren der Items bereits mehr oder weniger zerfallen seien. Dieser Interpretation zufolge wird also die visuelle Spur eines jeden Items in diesem Speicher als ein Ganzes betrachtet, dasjenige, was verblasst, wäre dessen Identität. Townsend (1973) fand in ihrem PR-Experiment aber heraus, dass die zunehmenden Fehler bei größer werdenden ISI auf die zunehmende Tendenz zurückzuführen sei, Items zu berichten, die sich nicht an der ,ge-cue-ten“ Position befanden, während sich die Fehlerquote hinsichtlich der Identifikationsfehler kaum mit der Verzögerung des Hinweisreizes verändert. Daher nahm sie an, dass im Laufe der Zeit nicht die Information für die Identifizierung des Items verloren gegangen sei, sondern die Information darüber, wo die Items sich befunden hätten. Zu einem ähnlichen Befund kamen auch Mewhort und seine Mitarbeiter (Mewhort, Campbell, Marchetti \& Campbell, 1981). Darüber hinaus konnten Mewhort et al. (ebd.) zeigen, dass die beiden Fehlerarten unter bestimmten experimentellen Manipulationen (z.B. Maskierung) differenziell beeinflusst werden.

Bei den oben angeführten Befunden lässt sich vermuten, dass verschiedene Informationsanteile in der visuellen sensorischen Gedächtnisleistung enthalten sind, die auch unterschiedliche Eigenschaften aufweisen und unterschiedlichen Einflüssen unterliegen. Um diesen Befunden Rechnung zu tragen, haben Mewhort und seine Kollegen ein Dual-bufferModell (Mewhort et al., 1981; Mewhort, Marchetti, Gurnsey \& Campbell, 1984) aufgestellt.

\subsubsection{Modell von Mewhort et al.}

Zwei Speicherkomponenten werden in dem Dual-buffer-Modell (Abb. 3) postuliert. Die erste Komponente speichert Merkmale (features), die zweite speichert die identifizierten Items als Symbole (characters).

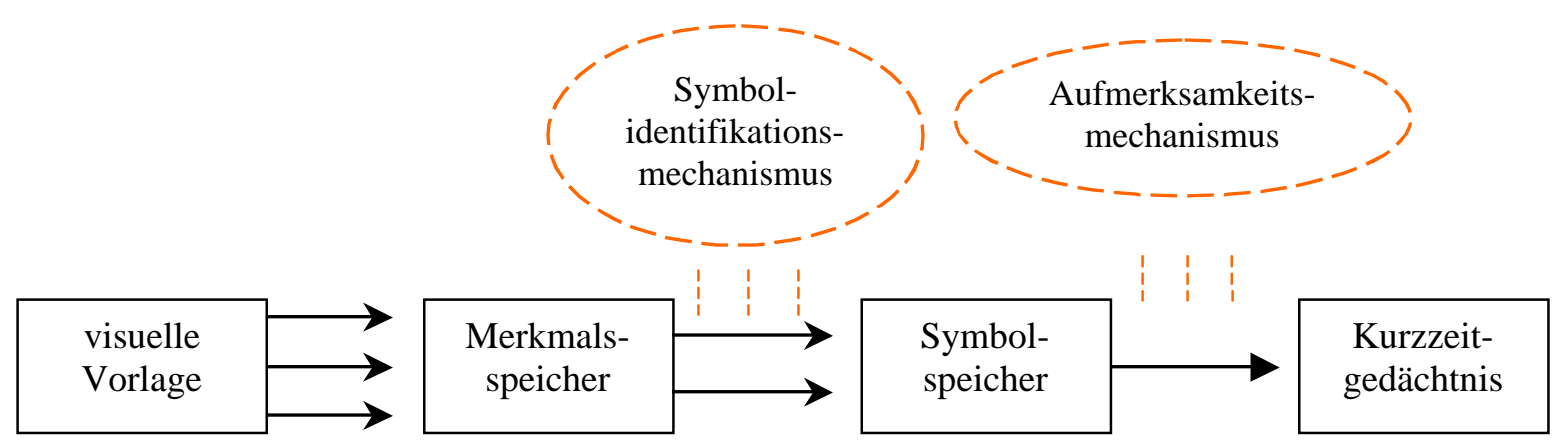

Abbildung 3: Dual-buffer-Modell zum ikonischen Gedächtnis nach Mewhort et al. (1981). 
Dem Modell nach wird die Reizvorlage zunächst in einem Merkmalsspeicher (feature buffer), einem präkategorialen Speicher mit unbeschränkter Kapazität, repräsentiert. Ein Identifikationsmechanismus dient dazu, die Merkmale zu geeigneten Bündeln zusammenzufassen und daraus ein Symbol zu identifizieren. Die identifizierten Symbole werden in einen Symbolspeicher (character buffer) eingetragen. Diese postkategoriale Speicherkomponente speichert nur abstrakte Repräsentationen der Reizvorlage, wobei die räumliche Information der Items noch in reduzierter Form vorhanden ist. Diese räumliche Information ist es schließlich, welche verblasst oder maskiert wird. Ein Aufmerksamkeitsmechanismus, der durch den Hinweisreiz gesteuert wird, selektiert die relevanten abstrakten Kodes in dem Symbolspeicher, übersetzt sie in phonologische oder graphemische Kodes und überträgt sie in einen Reaktionsspeicher (response buffer), womit hier das KZG gemeint ist. Bei mehreren zu übertragenden Symbolen im Symbolspeicher entsteht ein Engpass für die Übertragung in den Reaktionsspeicher. Mewhort et al. (1981) sprachen in diesem Zusammenhang von einer begrenzten Kanalkapazität (channel capacity), d.h. einer Kapazität des Kanals nach Garner (1962, S. 68-69, zitiert nach Mewhort et al., 1981, S. 51) mit linearer Auflösung von ca. 3 bit.

Identifikationsfehler in der $P R$-Aufgabe spiegeln nach Mewhort et al. (1981) die Datenverluste im ersten Speicher, Lokalisationsfehler dagegen die räumliche Konfusion des zweiten Speichers wider. Wenn es dem Identifikationsmechanismus nicht gelingt, die Merkmale zu geeigneter Bündelung zusammenzufassen, entstehen Identifikationsfehler. Wie genau der Aufmerksamkeitsmechanismus arbeiten kann, hängt von der Anzahl der Items in der Stimulusvorlage bzw. von der Menge der Eintragungen im Symbolspeicher ab. Je mehr Items auseinander gehalten werden müssen, desto größer ist die Wahrscheinlichkeit, dass Lokalisationsfehler auftreten. Da nach dem Dual-buffer-Modell der Hinweisreiz in der PRAufgabe genutzt wird, um die Aufmerksamkeit auf den Inhalt der zweiten Speicherkomponente $\mathrm{zu}$ fokussieren, hat die Verzögerung eines Hinweisreizes nur einen Einfluss auf den Symbolspeicher, nicht aber auf den Identifikationsprozess. Je mehr Zeit verstreicht, desto ungenauer wird die noch vorhandene räumliche Information im zweiten Speicher. Es kommt deshalb bei Verzögerung des Hinweisreizes, und damit des Abrufs, zu einer Konfusion der räumlichen Information, wodurch Lokalisationsfehler entstehen. Maskierung wirkt nach dem Modell bei kurzer Stimulus onset asynchrony (SOA) ${ }^{4}$ sowohl auf den Merkmalsspeicher als auch auf den Symbolspeicher. Im Merkmalsspeicher zerstört die Maske die nötigen Merkmalsinformationen für die Symbolidentifikation, wodurch Identitätsfehler entstehen; in

\footnotetext{
${ }^{4}$ Stimulus onset asynchrony: das Zeitintervall zwischen dem Beginn zweier aufeinander folgenden Reize.
} 
dem Symbolspeicher erhöht die Maskierung die räumliche Unsicherheit. Dadurch kommen Lokalisationsfehler zustande. Bei längerer SOA (mehr als $150 \mathrm{~ms}$ ) wirkt Maskierung allerdings nur auf den Symbolspeicher. So viel vorerst zum Dual-buffer-Modell.

\subsubsection{Modell von Irwin und Yeomans}

Ausgehend von Colthearts Begründung und Unterscheidung zwischen informatorischer und sichtbarer Persistenz versuchten Yeomans und Irwin (1985) sowie Irwin und Yeomans (1986), die Charakteristika der informatorischen Persistenz näher zu untersuchen. In den $P R$ Experimenten mit Maskierung von Irwin und Yeomans (1986) wurde herausgefunden, dass bei einer Verzögerung des Hinweisreizes von 0 bis $150 \mathrm{~ms}$ die maskierten Buchstaben schlechter reproduziert wurden als die nicht maskierten, während sich nach $150 \mathrm{~ms}$ Verzögerung die Leistung bei maskierten Buchstaben nicht mehr von der Leistung bei nicht maskierten unterschied. Ein vergleichbarer Befund ergab sich bei variierter Reiz-Darbietungsdauer von 50500 ms. Irwin und Yeomans (ebd.) interpretierten dies als einen Beleg dafür, dass die PRLeistung mindestens auf zwei Gedächtniskomponenten basiert: auf einer relativ kurzlebigen, visuellen (maskierbaren) Komponente, deren Dauer unabhängig von der Reizdarbietungsdauer ist und auf einer zweiten, lang andauernden, nicht maskierbaren postkategorialen Komponente. Zwei Repräsenationsarten wurden somit in dem Modell von Irwin und Yeomans (1986) unterschieden (s. Abb. 4): eine visuell analoge Repräsentation (visual analog) und ein Identitätskode (identity code). Irwin und Yeomans (ebd.) betrachteten beide Repräsentationen als informatorische Persistenz im Sinne von Coltheart (1980).

\section{Translation}

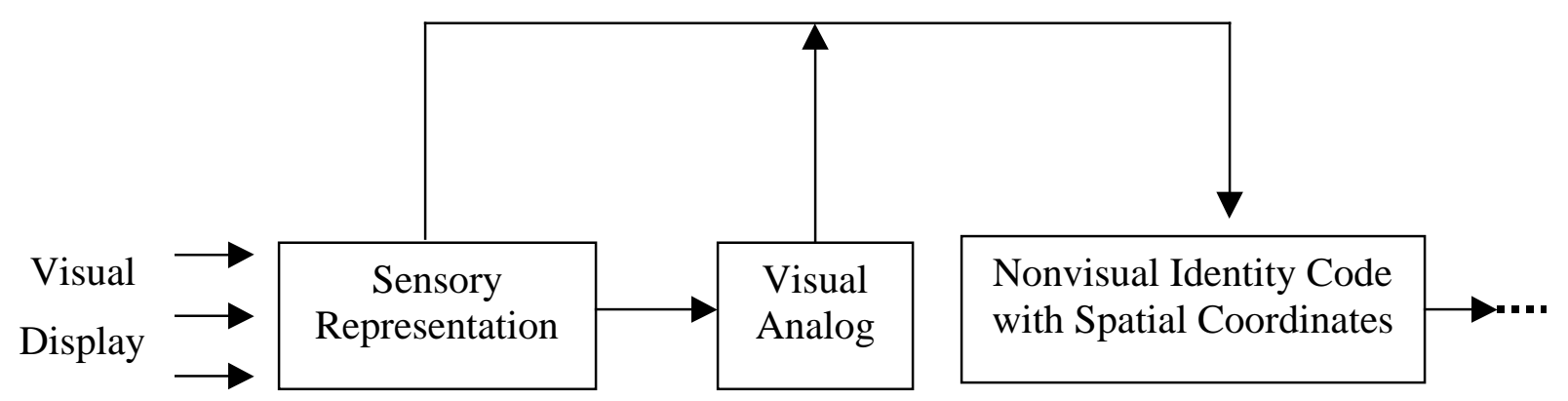

Abbildung 4: Modell des ikonischen Gedächtnisses von Irwin und Yeomans (1986, S. 358).

Das Modell hat eine ähnliche Struktur wie das Dual-buffer-Modell und postuliert ebenfalls eine Übertragung (translation) von einem präkategorialen in einen postkategorialen Speicher. Der Inhalt des Merkmalsspeichers im Dual-buffer-Modell wird allerdings in diesem Modell einmal in die sensorische Repräsentation und zum anderen in die visuell analoge 
Repräsentation unterteilt. Die visuell analoge Repräsentation beginnt nach Irwin und Yeomans (1986) mit dem Stimulus-Offset. Dies ist eine wichtige Annahme für die Unabhängigkeit der visuell analogen Repräsentation von der Reizdarbietungsdauer (im Gegensatz z.B. zu dem späteren Ansatz von Di Lollo und Dixon, 1988). Maskierung wirke nach dem Modell nur auf die visuell analoge Repräsentation, habe aber keinen Effekt auf das „nichtvisuelle Niveau“ (vgl. Dual-buffer-Modell oben).

In einer weiteren Arbeit von Irwin und Brown (1987) zeigten die Autoren, dass die erste Komponente, die „,visuell analoge Repräsentation“, präkategorial ist und die zweite Gedächtnis-Komponente eine beschränkte Kapazität hat, die ca. 4-5 Items betragen soll. Die visuell analoge Repräsentation unterscheidet sich von der sichtbaren Persistenz, weil ihre Dauer unabhängig von der Reizdarbietungsdauer sein soll; sie unterscheidet sich nach Irwin und Brown (ebd.) auch von dem klassischen Konzept des KZG, da die Gedächtniskomponente hier eine kürzere Dauer hat und maskierbar ist. Allerdings ist Irwin und Brown (ebd.) zufolge die zweite Gedächtniskomponente, die an der $P R$-Leistung beteiligt ist, nicht von dem KZG zu unterscheiden. Aus diesem Grund modifizierten Irwin und Brown (ebd.) das Modell von Irwin und Yeomans (1986), indem die zweite Speicherkomponente, die abstrakte Identitätsrepräsentation, mit dem visuellen KZG gleichgesetzt wird. Dies erinnert wiederum an die klassische Konzeption, die den Datenfluss von dem ikonischen Gedächtnis ins KZG postuliert (s. Abb. 1). Diese scheinbar „neue“ Sichtweise kommentierten die Autoren selbstironisch so: „Nonetheless, it would be ironic if a slightly-modified version of the traditional theory turned out to be correct after all these years“ (Irwin \& Brown, 1987, S. 337).

Ein Problem der dargestellten Konzeptualisierung, das noch heute relevant ist, liegt in dem Zusammenhang bzw. der Trennung zwischen der postkategorialen Speicherkomponente (durable storage) des ikonischen Gedächtnisses und dem KZG, worauf in der vorliegenden Arbeit später wiederholt eingegangen wird.

Nach der bisherigen Theoriedarstellung ist festzuhalten, dass die informatorische Persistenz im Sinne von Coltheart (1980) bisher als der einzig wahre Gegenstand des ikonischen Gedächtnisses betrachtet wurde, die nur mittels der $P R$-Methode untersucht werden könne. Es wurde bis dahin vieles versucht, diese informatorische Persistenz noch weiter zu differenzieren und deren Repräsentationsart zu definieren.

Die Gleichsetzung des ikonischen Gedächtnisses mit der informatorischen Persistenz geschieht bei Coltheart ausschließlich per definitionem. Ob mit indirekten Methoden tatsächlich nur informatorische Persistenz untersucht wird, wurde später in Frage gestellt. Eine 
andere Weiterentwicklung bestand in der Annahme, dass das ikonische Gedächtnis sowohl die visuelle Persistenz einschließlich räumlicher Information, als auch die informatorische Persistenz (Identitätsinformation) enthalte und dass sowohl die informatorische als auch die sichtbare Persistenz in Aufgaben wie dem partial report involviert seien.

\subsubsection{Mathematische Modelle}

Nach Mozer und Sitton (1998) können Modelle oft in zwei Kategorien eingeteilt werden: „,deskriptive Modelle“ und „Prozessmodelle“. Deskriptive Modelle beschreiben primär die aus Experimenten erhobenen Daten anhand mathematischer Gleichungen. Im Gegensatz dazu erklären Prozessmodelle die der Leistung in einer Aufgabe zugrunde liegenden kognitiven Mechanismen. Prozessmodelle variieren in ihrem Abstraktionsgrad von qualitativer verbaler Beschreibung bis zu quantitativen Computer-Simulationen. Die im Folgenden dargestellten Modelle können als quantitative Prozessmodelle ikonischer Gedächtnisprozesse betrachtet werden.

\subsubsection{Modelle von Dixon und Di Lollo}

(1) Independent-decay-Modell (Di Lollo \& Dixon, 1988; Dixon \& Di Lollo, 1991)

In der klassischen Auffassung über das ikonische Gedächtnis wurde implizit und als selbstverständlich angenommen, dass die perzeptuelle Spur des kurz dargebotenen Reizes mit dem Stimulus-Onset beginnt, während der Reizpräsentation konstant bleibt und nach dem Stimulus-Offset sofort zu verblassen beginnt (Abb. 5).

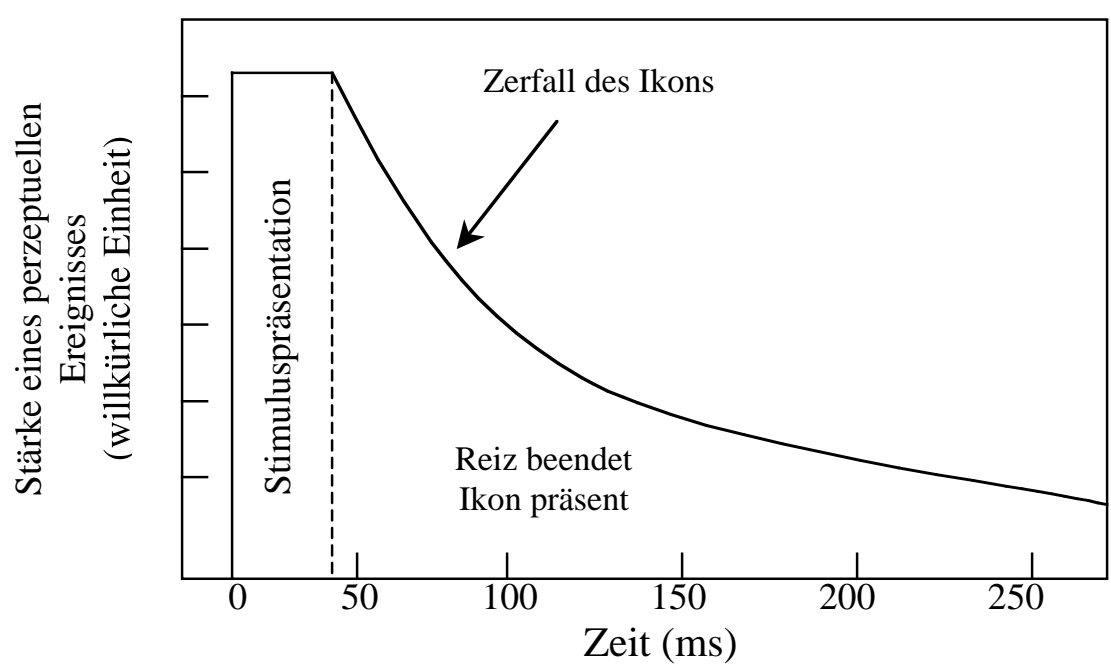

Abbildung 5: Klassische Vorstellung von einer ikonischen Verblassenskurve.

Weitere konzeptuelle Entwicklungen, vor allem die Ausdifferenzierung des Ikons in sichtbare und informatorische Persistenz, machten es notwendig, die oben genannte Annahme neu zu überprüfen. Abgeleitet von dem inversen Reizdauereffekt in Untersuchungen zur 
sichtbaren Persistenz (nicht aber bei der informatorischen Persistenz) nahmen Di Lollo und Dixon (1988) an, dass die Dauer der sichtbaren Persistenz zeitlich auf den Darbietungsbeginn des auslösenden Reizes (Stimulus-Onset) bezogen ist und dass die Dauer der informatorischen Persistenz als zeitgebunden an das Ende der Reizdarbietung (Stimulus-Offset) angesehen werden muss. Dabei betrachteten Di Lollo und Dixon (1988), der Konzeptualisierung von Irwin et al. (Yeomans \& Irwin, 1985; Irwin \& Yeomans, 1986; Irwin \& Brown, 1987) folgend, die „visuell analoge Repräsentation“ als eine Art von informatorischer Persistenz, bzw. schematischer Persistenz in ihrer eigenen Terminologie.

Nach Di Lollo und Dixon (1988) ist sowohl die sichtbare als auch die informatorische (schematische) Persistenz bei der PR-Aufgabe beteiligt. Sichtbare und schematische Persistenz tragen also unabhängig voneinander zur Bewältigung der Aufgabe bei. Aufgrund der unterschiedlichen Eigenschaften der beiden Persistenzarten wird die Leistung in der PRAufgabe in unterschiedlicher Weise beeinflusst, und zwar:

- Je größer die SOA ist, desto geringer ist die sichtbare Persistenz und desto schlechter ist die Leistung.

- Je größer das ISI ist, desto geringer ist die schematische Persistenz und desto schlechter ist die Leistung.

Di Lollo und Dixon (1988) beschrieben anhand ihrer Daten den zeitlichen Verlauf der sichtbaren Persistenz mit einer kumulativen Normalverteilung, den zeitlichen Verlauf der informatorischen Persistenz dagegen mit einer Exponentialfunktion. Der unabhängige Anteil der beiden Persistenzarten an der Leistung kann nach Di Lollo und Dixon (ebd.) in einem probabilistischen Modell kombiniert werden. In einer weiteren Arbeit entwickelten Dixon und Di Lollo (1991) aus den obigen Überlegungen das Independent-decay-Modell:

$$
\mathrm{Pvs}_{\mathrm{v}}=\mathrm{Pv}_{\mathrm{v}}+\mathrm{Ps}_{\mathrm{s}}-\mathrm{P}_{\mathrm{v}} \mathrm{Ps}_{\mathrm{s}}
$$

In dieser Formel ist Pvs die Wahrscheinlichkeit einer korrekten Antwort, die auf beiden Persistenzformen basiert; Pv und Ps sind die Wahrscheinlichkeiten einer korrekten Antwort, die allein auf der sichtbaren Persistenz $\left(\mathrm{Pv}_{\mathrm{v}}\right)$ oder der schematischen Persistenz $\left(\mathrm{Ps}_{\mathrm{s}}\right)$ basiert. Anders formuliert bedeutet die Gleichung, dass eine korrekte Antwort erfolgt, wenn ein Item entweder durch sichtbare Persistenz oder durch schematische Persistenz noch verfügbar ist.

Wie in der Arbeit (1988) zuvor angenommen wurde, nimmt die sichtbare Persistenz mit zunehmender SOA ab (Dixon \& Di Lollo, 1991, S. 58):

$$
P_{v}=a v\left[1-\int_{0}^{S O A} f(x) d x\right]
$$


Die Konstante av ist die maximale durch sichtbare Persistenz verfügbare Informationsmenge. $f(\mathrm{x})$ ist die Wahrscheinlichkeitsdichte der Informationsverarbeitungsdauer.

Im Gegensatz dazu wird angenommen (ebd.), dass die schematische Persistenz mit zunehmendem ISI abnimmt. Sie wird nicht von der Darbietungsdauer beeinflusst und folgt einer Exponentialfunktion:

$$
P_{s}=a_{s} e^{d(I S I)}
$$

Dabei ist $a_{s}$ die anfänglich noch verfügbare Menge schematischer Persistenz und $d$ die Verfallsrate.

Den letzten Beitrag zur Leistung in der PR-Aufgabe leisten in dem Modell (Dixon \& Di Lollo, 1991, S. 59) noch das KZG und das Raten, so dass die overall-Wahrscheinlichkeit P(C) einer korrekten Antwort beträgt:

$$
\mathrm{P}(\mathrm{C})=P v s+(1-P v s) P o
$$

Wobei Po die Wahrscheinlichkeit dafür ist, dass das gefragte Item in dieser dritten Informationsquelle noch verfügbar ist. Von $P o$ wird angenommen, dass es unbeeinflussbar von temporalen Parametern des Displays ist.

Ihrer theoretischen Ableitung folgend haben Dixon und Di Lollo (1991) durch experimentelle Manipulation der Darbietungsdauer des (ersten) Displays und durch Manipulation des ISI versucht, die sichtbare und die schematische Persistenz getrennt zu analysieren und ihre Annahme bezüglich der Natur der beiden Persistenzformen zu überprüfen. Sie untersuchten, wie die beiden Persistenzformen durch verschiedene Faktoren beeinflusst werden. In ihrem $P R$-Experiment mit kreisförmiger Anordnung der Stimuli wurden ein Haupteffekt der Helligkeit des Displays (je heller das Display war, desto schlechter war die Reproduktionsleistung), ein Haupteffekt der Bedeutungshaltigkeit des Stimulusmaterials (die Leistung bei Buchstaben war besser als bei Pseudobuchstaben) und ein Haupteffekt der Darbietungsdauer des Hinweisreizes (je länger der Hinweisreiz dargeboten wurde, desto schlechter war die Leistung) festgestellt.

Während der Effekt der „Helligkeit“ (auf sichtbare Persistenz abzielend) und der Effekt der „Bedeutungshaltigkeit des Stimulusmaterials“ (auf schematische Persistenz abzielend) noch mit dem Independent-decay-Modell zu vereinbaren sind, konnte mit dem Modell (Dixon \& Di Lollo, 1991) der Darbietungsdauereffekt des Hinweisreizes (probe-duration effect) ${ }^{5}$ nicht erklärt werden. Dieser Darbietungsdauereffekt interagierte anscheinend sowohl mit der SOA

\footnotetext{
${ }^{5}$ Dieses Phänomen wird später noch ausführlicher behandelt werden (s. Abschnitt 3.2.3).
} 
als auch mit dem ISI. Das bedeutet, dass sowohl die sichtbare als auch die schematische Persistenz von der Darbietungsdauer des Hinweisreizes beeinflusst wurden. Nach dem Independent-decay-Modell (ebd.) bleibt ein kurz dargebotener Stimulus nach seinem Offset phänomenologisch noch eine Weile sichtbar, und die Dauer der sichtbaren Persistenz entscheidet, ob zwei aufeinander folgende Stimuli als integriert oder getrennt gesehen werden sollen. Wenn die Dauer des zweiten Reizes (in diesem Fall die des Hinweisreizes) verlängert wird, sollte die Leistung (die Integration beider Stimuli) eher begünstigt als verschlechtert werden. Ein weiterer Mechanismus muss zu dem Modell herangezogen werden, um dieses Phänomen erklären zu können. Nicht zuletzt deswegen haben Dixon und Di Lollo (1994) in diesem Zusammenhang den folgenden neuen Ansatz vorgestellt.

(2) Temporale Kodierungshypothese (Dixon \& Di Lollo, 1994)

Dixon und Di Lollo (1994) stellten die „temporale Kodierungshypothese“ (temporal coding hypothesis) auf, um vor allem die Verarbeitung von visuellen, sequenziell dargebotenen Reizen zu erklären. Das neue Modell besagt, dass die Integration bzw. Trennung von aufeinander folgenden visuellen Stimuli auf einem Prozess beruht, der die zeitliche Beziehung zwischen ihnen kodiert. Dixon und Di Lollo (ebd.) gingen davon aus, dass sowohl temporale Integration als auch die $P R$-Aufgabe einem temporalen Kodierungsprozess unterliegen. Die $P R$-Aufgabe ist teilweise von einem temporalen Integrationsprozess abhängig, da in der Aufgabe die visuelle Vorlage und der Hinweisreiz integriert werden müssen, damit sie als Teile eines einzigen (gemeinsamen) Musters gesehen werden können. Somit ist die Wahrscheinlichkeit einer korrekten Antwort (Dixon \& Di Lollo, 1994, S. 44):

$$
\mathrm{Pc}=\mathrm{T}+(1-\mathrm{T}) \mathrm{N}
$$

T entspricht der Wahrscheinlichkeit einer korrekten Antwort. Diese Wahrscheinlichkeit basiert auf temporaler Integration (Anteil der sichtbaren Persistenz). $\mathrm{N}$ ist die Wahrscheinlichkeit einer korrekten Antwort, die auf der nicht sichtbaren Informationsquelle beruht. Die nicht sichtbare Informationsquelle ist nach Dixon und Di Lollo (ebd.) nicht beeinflussbar von der Dauer des ersten und des zweiten Reizes. Diese temporale Kodierungshypothese ist von der Struktur her dem Independency-decay-Modell ähnlich, die nicht sichtbare Informationsquelle entspricht hier dem Anteil der schematischen Persistenz und des KZG innerhalb des Independency-decay-Modells. Nur ein temporaler Kodierungsprozess, der zwei aufeinander folgende Reize in Abhängigkeit des zeitlichen Zusammenhangs zwischen diesen beiden Reizen entweder integriert oder trennt, wurde in der ,temporalen Kodierungshypothese“ zusätzlich postuliert. 
Dixon und Di Lollo versuchten in ihrer Arbeit (1994) zu zeigen, dass mit diesem neuen Modell erklärt bzw. vorausgesagt werden kann, warum sowohl bei der Integrationsaufgabe als auch bei der PR-Aufgabe die Leistung abnimmt, wenn entweder die Darbietungsdauer des ersten Displays oder die des zweiten Displays größer wird. Dies ist das Phänomen, das sie mit ihrem Independency-decay-Modell (Dixon \& Di Lollo, 1991) nicht erklären konnten (s.o.). Und so sahen sie das Modell als gut geeignet an, das ikonische Persistenz-Phänomen zu beschreiben. Ein interessanter Befund in ihrem Experiment war auch, dass, während die Leistung bei der Integrationsaufgabe mit zunehmender Darbietungsdauer des ersten und des folgenden Displays auf Zufallsniveau gefallen war, sie beim $P R$ noch deutlich höher blieb. Das soll wiederum bestätigen, dass die Integrationsaufgabe hauptsächlich von dem temporalen Kodierungsprozess determiniert wird, während in der $P R$-Aufgabe noch weitere Faktoren eine Rolle spielen können, welche die nicht sichtbare Informationsquelle beeinflussen.

\subsubsection{Modell von Massaro und Loftus}

Die „temporale Kodierungshypothese“ von Dixon und Di Lollo (1994) kann zwar die Leistungen in der temporalen Integrationsaufgabe und der $P R$-Aufgabe einigermaßen gut voraussagen, aber es ist nicht klar, wie das Modell andere visuelle Phänomene wie den „,inversen Reizdauereffekt“ in der Synchrony-judgement-Aufgabe erklären kann.

Eine neue konzeptuelle Entwicklung in der Forschung zum ikonischen Gedächtnis (zur informatorischen und sichtbaren Persistenz) entstand aus dem Anspruch, ein noch sparsameres Konzept zu finden. Nach jahrzehntelangem Versuch, das Ikon aufzuspalten, versucht man es nun wiederzuvereinigen. Die Frage ist: Muss man ,icon-as-information repository“ und ,iconas-phenomenological appearance“ als völlig unterschiedliche und unabhängige Phänomene betrachten (vgl. Massaro \& Loftus, 1996)?

Ausgehend von diesem Sparsamkeitsprinzip und zugleich mit dem Anspruch, ein Konzept zu entwickeln, das alle visuellen sensorischen Phänomene beschreiben, erklären und voraussagen kann, wird von Loftus, Massaro und Kollegen ein „lineares temporales Filtermodell“ (linear temporal filter model) vorgeschlagen (Loftus \& Ruthruff, 1994; Massaro \& Loftus, 1996). Sie beschrieben die Reaktion des visuellen Systems auf einen physikalischen Stimulus als einen linearen temporalen Filter, der die Stimulus-Wellenform (stimulus wave form, vgl. Abb. 6b) in eine sensorische Reaktion überführt. Betrachtet man eine sensorische Reaktion auf einen visuellen Reiz als einen Impuls, dann kann man die Stärke der vom Reiz hervorgerufenen neuralen Ereignisse seit dem Auftreten des Impulses als eine ImpulsReaktionsfunktion in Abhängigkeit von der Zeit darstellen (Abb. 6a). Ein Umweltreiz kann nach Massaro und Loftus (ebd.) eine Reihe von Impulsen (Abb. 6b) auslösen. Jeder Impuls 
erzeugt eine eigene unabhängige Impuls-Reaktionsfunktion (Abb. 6c), die in linearer Beziehung zueinander stehen. Die Summe der einzelnen Impuls-Reaktionsfunktionen ergibt eine sensorische Reaktionsfunktion (Abb. 6c, 6d) des auslösenden Stimulus.
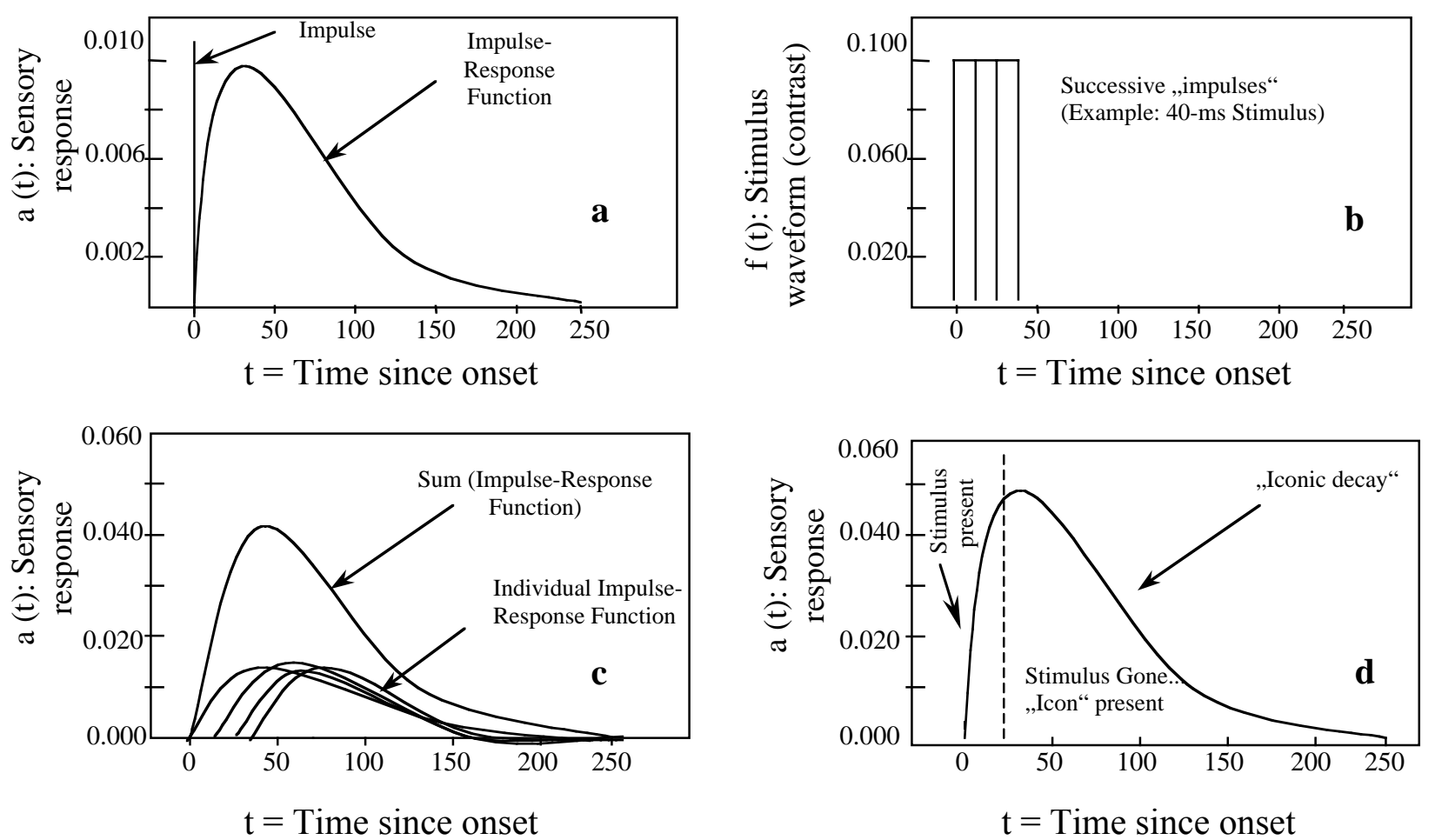

\footnotetext{
Abbildung 6: Generierung einer sensorischen Reaktionsfunktion (sensory-response function) in Abhängigkeit von der Zeit (nach Massaro \& Loftus, 1996, S. 85).

a: Reaktion auf einen Impuls.

b: Eine Stimulus-Wellenform kann als ein Reihe von Impulsen konzeptualisiert werden.

c: Individuelle Impuls-Reaktionsfunktionen werden summiert zur Generierung einer gesamten sensorischen Reaktionsfunktion.

d: Anwendung der durch einen linearen temporalen Filter erzeugten sensorischen Reaktionsfunktion zu der Stimulus-Wellenform.
}

Wenn man die Kurven in Abbildung 6 mit der Kurve in Abbildung 5 vergleicht, die das herkömmliche Verständnis zum zeitlichen Verlauf des Ikons darstellt, stellt man einen prinzipiellen Unterschied fest: Der Zerfall des Ikons in diesem linearen temporalen Filtermodell ist nicht mehr an den Offset des Stimulus gekoppelt. Der Stimulus-Offset ist kein besonders wichtiges Ereignis mehr. Nur die sensorische Reaktionsfunktion ist von Bedeutung.

Dieses lineare temporale Filtermodell beinhaltet folgende Annahmen (Massaro \& Loftus, 1996):

(1) Nach dem Stimulus-Onset springt die Größe der sensorischen Reaktion nicht sofort von Null auf den maximalen Wert, sondern sie steigt graduell.

(2) Bei einer bestimmten Reizintensität nimmt der Maximum-Wert der Funktionskurve mit zunehmender Reizdauer zu. 
(3) Das Verfallen der sensorischen Reaktion beginnt nicht unmittelbar mit dem StimulusOffset, sondern einige Zeit danach. Dies ist vor allem bei kurzen Stimuli der Fall. Erst ab einer bestimmten Darbietungsdauer des Reizes fängt die sensorische Reaktion mehr oder weniger unmittelbar an, nach der Reizbeendigung zu verfallen.

(4) Es gibt keinen qualitativen Unterschied der „Reaktionen“ vor und nach dem StimulusOffset. Entscheidend ist allein die Höhe der sensorischen Reaktionsfunktion. Das Maximum kann vor oder nach dem Stimulus-Offset erreicht werden.

Um ihr Modell zu testen, wendeten Massaro und Loftus (1996) es auf die folgenden drei Arten von Aufgaben an: synchrony judgment, temporal integration und PR-Aufgabe. Ein zentraler Begriff in dem Linear-filter-Modell ist die Informationsextraktionsrate (informationextraction rate; s. Massaro \& Loftus, 1996). Die Leistung in allen drei Aufgaben ist davon abhängig, wie schnell Informationen aus dem Reiz extrahiert werden können. Es wurde angenommen, dass die Information immer mit einer momentanen Rate extrahiert wird und die Stärke der Informationsextraktionsrate eines bestimmten Zeitpunktes von dem Produkt der Größe der sensorischen Reaktion und der noch zu extrahierenden Informationsmenge an diesem Zeitpunkt determiniert ist.

Bei der Synchrony-judgement-Aufgabe wird angenommen, dass der/die $\mathrm{Pb}$, wenn die Informationsextraktionsrate unter eine gewisse Marke gefallen ist, zu der Entscheidung kommt, dass der Stimulus subjektiv phänomenologisch verschwindet. Die Funktion der Informationsextraktionsrate fällt bei länger andauernden Reizen schneller ab als bei kürzer dargebotenen Stimuli, da bei lang andauernden Reizen im Moment des Stimulus-Offsets nur noch wenig Information zu extrahieren ist. Anders ausgedrückt: Je mehr Informationen bereits aus dem Stimulus extrahiert worden sind, desto weniger neue Informationen verbleiben noch im Stimulus. Die Konsequenz des schnelleren Abfallens bei länger andauernden Reizen ist eine frühere Überschreitung der kritischen Marke. Das erklärt dann den inversen Reizdauereffekt in der Synchrony-judgement-Aufgabe.

Für die Temporal-integration-Aufgabe haben Massaro und Loftus (1996) die Annahme der temporalen Ähnlichkeit von Dixon und Di Lollo (1994) übernommen, wobei sie nicht die sensorische Reaktionsfunktion, sondern die Informationsextraktionsrate als die zentrale Variable betrachteten. Das Linear-filter-Modell ist den Autoren zufolge auch in der Lage, den inversen Reizdauereffekt im Zusammenhang mit a) der Dauer des ersten Stimulus, b) der Verzögerung des ISI oder c) der Dauer des zweiten Stimulus zu erklären, denn die Korrelation zwischen den beiden Funktionen der Informationsextraktionsrate sinkt mit zunehmender Darbietungsdauer beider Reize sowie zunehmendem ISI (vgl. oben). 
Was allerdings nicht überzeugend erscheint, ist die auf dem Linear-filter-Modell basierende Erklärung zur PR-Leistung von Massaro und Loftus (1996). Es liegt von ihnen keine Modell-Anpassung an eine herkömmliche $P R$-Aufgabe wie dem Sperling-Paradigma vor, wohl aber an eine Wiedererkennungsaufgabe zum Bildgedächtnis (picture memory). Massaro und Loftus (1996) behaupten, dass in dieser Aufgabe ebenfalls die informatorische Persistenz untersucht werde. Für diese Art von Aufgabe sei nach wie vor die Informationsextraktion entscheidend. Wie viel Information noch verfügbar ist, sei abhängig von der Summe (Fläche) der gesamten Informationsextraktionsrate (vgl. Abb. 6).

Massaro und Loftus (1996) versuchten mit dem Linear-filter-Modell die sichtbare Persistenz und die informatorische Persistenz zu vereinigen. „The two phenomena are both direct consequences of the same information-extraction rate function. Phenomenological experience corresponds to the shape of the function, while information extraction corresponds to the area under the function" (Massaro \& Loftus, 1996, S. 91). Sie stimmten Colthearts (1980) Unterscheidung zwischen den beiden Persistenzarten insofern zu, dass die beiden Phänomene sich in unterschiedlicher Weise verhalten. Auf das beschriebene Modell bezogen bedeutet das lediglich, dass die Form der Funktion und die Fläche unter der Funktion sich etwas unterschiedlich verhalten können. Trotzdem sind die informatorische Persistenz und die phänomenologische Erscheinung beide nur Aspekte ein und derselben einheitlichen sensorischen Reaktionsfunktion. Die sichtbare Persistenz und die informatorische Persistenz sind nun wieder konzeptuell vereint.

Über die kurze Darstellung der bisherigen konzeptuellen Entwicklung zum ikonischen Gedächtnis lässt sich abschließend sagen: Nach fast vier Jahrzehnten intensiver Forschung an dem Phänomen des „kurzlebigen visuellen Speichers“ ist das theoretische Verständnis immer weiter vorangekommen. Colthearts Arbeit (1980) klärte den diffusen Forschungszustand zur damaligen Zeit und wies der weiteren Forschung mit ihrer differenzierten Betrachtung den Weg; das Strukturmodell von Mewhort et al. (1981, 1984) sowie von Irwin und Yeomans (Yeomans \& Irwin, 1985; Irwin \& Yeomans, 1986) lieferten einen qualitativen theoretischen Rahmen dafür, den Gegenstand genauer und differenzierter experimentell zu untersuchen, denn „,... it offers an explicit account, in considerable detail, of how a variety of variables have their effect on tachistoscopic performance ...“ (Coltheart, 1984, S. 278). Die oben beschriebenen mathematischen Modelle verkörpern die Tendenz der Betonung prozeduraler Verarbeitungsmechanismen und einer quantitativen Herangehensweise in der psychologischen Forschung. Allerdings bleiben trotz der theoretischen Fortschritte nach wie vor viele Fragen in Bezug auf das Phänomen des ikonischen Gedächtnisses ungeklärt, bzw. es gibt darüber 
kontroverse Meinungen, die nicht ohne weiteres miteinander zu vereinbaren sind. Diese Uneinigkeit äußert sich auch in der Diskussion über die $P R$-Methode und über die Phänomene, die in der $P R$-Aufgabe auftreten.

\subsection{Forschungskontroversen bzw. offene Fragen}

Die noch offenen und unklar gebliebenen Fragen im Zusammenhang mit dem ikonischen Gedächtnis können aus verschiedener Sicht betrachtet und in einige Kategorien eingeteilt werden. Sie betreffen vor allem die Platzierung des ikonischen Gedächtnisses im menschlichen Informationsverarbeitungssystem, den Inhalt oder die Repräsentationsart, die Kapazitätsfrage des ikonischen Gedächtnisses, sowie die Informationsverarbeitung in dem Gedächtnisprozess und bei der Informationsübertragung.

\section{Platzierung des ikonischen Gedächtnisses im menschlichen Informationsverarbeitungssystem}

Das Problem kann aus zweierlei Sicht betrachtet werden. Zum einen stellt sich die Frage, ob das ikonische Gedächtnis ein rein sensorisches peripheres Phänomen oder ob es bereits kognitiv ist. Zum anderen betrifft es den Zusammenhang und die Abgrenzung zwischen dem ikonischen (bzw. sensorischen) Gedächtnis und dem KZG.

Bei der berühmten Diskussion zentral vs. peripher (s. Long, 1980) geht es darum, ob in dem ikonischen Gedächtnis die Information nur sensorisch aufgenommen oder auch bereits kognitiv verarbeitet wird. In dem klassischen Ansatz wird das sensorische Gedächtnis als ein peripheres Phänomen betrachtet, das nur passiv rohe d.h. unverarbeitete Information vom Reiz behält. Diese Position wurde noch gestärkt durch die Forschungen von Sakitt und Long (1978, 1979). In ihren Experimenten versuchten Sakitt und Long zu zeigen, dass das ikonische Gedächtnis separate Quellen in den Rezeptoren (Stäbchen bzw. Zapfen) der Netzhaut hat. Die Aktivierung von Stäbchen bzw. Zapfen wurde in ihrem Experiment durch Helligkeitsmanipulation isoliert, so dass in den jeweiligen Bedingungen entweder nur Zapfen oder nur Stäbchen angesprochen wurden. Die Ergebnisse wiesen unterschiedliche Beiträge der Stäbchen und Zapfen für das untersuchte ikonische Phänomen nach. Wenn die Stäbchen ausgeschaltet wurden, veränderte sich der ikonische Gedächtnisverlauf substantiell. Die Zapfen sollen Sakitt und Long (ebd.) zufolge nur weniger als $200 \mathrm{~ms}$ zu dem ikonischen Gedächtnis beitragen, während die Stäbchen für das noch längere Andauern des ikonischen Gedächtnisses sorgen. Dies wurde als ein Beleg dafür angesehen, dass sich das ikonische Gedächtnis nur auf der Rezeptor-Ebene ereignet (Long, 1980). 
Es wurde aber auch behauptet, dass das ikonische Gedächtnis ebenfalls einen höheren zentralen bzw. kognitiven Informationsverarbeitungsprozess einschließt. Merikle (1980) zeigte beispielsweise in seinem Experiment, dass die Pbn ikonische Abbilder, die entweder Zahlen oder Buchstaben repräsentieren, selektiv erinnern konnten. Dieser Befund wird oft als ein klares Argument für die ,zentrale“ Betrachtung des ikonischen Gedächtnisses zitiert, weil in diesem Fall die kategoriale Verarbeitung der Stimuli vorausgegangen sein sollte.

Mit der Diskussion peripher vs. zentral eng verbunden ist der Zusammenhang zwischen sensorischem Gedächtnis und KZG. Insbesondere wenn das ikonische Gedächtnis als zentrales Phänomen betrachtet werden soll, stellt sich die Frage, wie es sich vom KZG unterscheidet. In gewissem Sinne könnte man die theoretische Entwicklung bezüglich des ikonischen Gedächtnisses als eine Geschichte der Grenzverschiebung zwischen den beiden Gedächtnisformen betrachten.

Unumstritten ist, dass die Reizinformation, beispielsweise in $P R$-Aufgaben, in einen dauerhaften Speicher (durable storage, Sperling, 1960) übertragen werden muss, damit sie überhaupt berichtet werden kann. Aber das Verhältnis dieses dauerhaften Speichers zum KZG wurde immer komplexer. Tatsächlich wurde dieser dauerhafte Speicher eine zeitlang explizit oder implizit mit dem KZG gleichgesetzt. Das lässt sich ebenfalls mit der klassischen Ansicht vereinbaren, dass das sensorische Gedächtnis nur ein rein sensorisches Phänomen sein soll, und dass die Verarbeitung bzw. der kognitive Teil der Informationsverarbeitung erst später im KZG stattfindet.

Durch Colthearts Differenzierung wurden neue Konzepte entwickelt, mit denen der Übergang zum KZG quasi nach hinten geschoben wurde. Coltheart (1980) hat das Image des ikonischen Gedächtnisses, ein passiver verblassender Speicher zu sein, überzeugend widerlegt und ihm stattdessen die Funktion des informatorischen Behaltens zugeschrieben.

Im Dual-buffer-Modell (s. Abschnitt 1.3.3.1) wird die Information erst in einem postkategorialen Symbolspeicher gelagert und dann durch einen Aufmerksamkeitsmechanismus ins KZG übertragen. Das KZG hat hier die Funktion eines Reaktionsspeichers. Die Übertragung der Information vom Merkmalsspeicher zum Symbolspeicher und dann weiter zum Reaktionsspeicher geschieht durch intelligente Mechanismen, z.B. die Identifikationsmechanismen oder die Mechanismen zwischen dem Symbolspeicher und dem Reaktionsspeicher, die die Information in die phonologischen oder graphemischen Outputs übersetzen. „The intelligence is built into the account by postulating that the processing operators possess knowledge“ (Mewhort, Marchetti, Gurnsey \& Campbell, 1984, S. 297). 
Diese intelligente Operation impliziert eine kognitive Verarbeitung der Stimulusinformation, auch wenn sie nur auf einem niedrigen Niveau geschieht.

Ebenso haben Irwin und Yeomans (1986) am Anfang in ihrem Modell auch postuliert, dass die Information zunächst in nicht sichtbare Identitätskodes übertragen und dann erst ins KZG weitergeleitet wird. Allerdings gerieten sie im Laufe ihrer Modellentwicklung wieder in Zweifel, ob die postulierte Speicherkomponente für Identitätskodes mit ihrer Kapazitätsbeschränkung vielleicht doch schon mit dem KZG gleichzusetzen ist, da beide einer strikten Kapazitätsbeschränkung unterliegen (Irwin \& Brown, 1987).

Di Lollo und Dixon (Di Lollo \& Dixon, 1988; Dixon \& Di Lollo, 1991) folgten zunächst dem theoretischen Konzept von Irwin und Yeomans. Sie blieben in ihrem mathematischen Independent-decay-Modell noch bei einer klaren Trennung zwischen sichtbarer und schematischer Persistenz. In ihrer späteren „temporalen Kodierungshypothese“ (Dixon \& Di Lollo, 1994) wurden jedoch die schematische Persistenz und das KZG zusammengeworfen. Dixon und Di Lollo sprachen nur noch von einer nicht sichtbaren Informationsquelle. In der $P R$-Aufgabe ist die nicht sichtbare Informationsquelle eine ergänzende Informationsquelle zum Informationsanteil der temporalen Integration, wobei dieser Anteil durch zeitliche Kodierung determiniert sei und den eigentlichen Beitrag der sichtbaren Persistenz zur Leistung darstelle.

Der Modellvorschlag von Massaro und Loftus (1996) versucht, die ikonischen Gedächtnisphänomene, d.h. sowohl phänomenologische sichtbare Persistenz als auch informatorische Persistenz, unter „,sensorischen Reaktionen“ zu erfassen und zu vereinigen. Während sie diese Persistenz(en) mit einem Prozesscharakter versehen, sie als ,sensorischen Speicher" bezeichnen, nennen Massaro und Loftus (ebd.) das Ergebnis dieser Persistenz(en) „perzeptuelles Gedächtnis“. Ihnen zufolge ist der sensorische Speicher für die anfängliche Aufrechterhaltung eines Reizereignisses als Ausgangspunkt für unmittelbare Informationsverarbeitung verantwortlich. Die Dauer des sensorischen Speichers setzt das zur Verfügung stehende Zeitlimit für die Informationsverarbeitung. Im Gegensatz dazu sei das perzeptuelle Gedächtnis ein Produkt (outcome) der Informationsverarbeitung des sensorischen Speichers, dessen Lebensdauer nach Massaro und Loftus (1996) wesentlich länger sei als die des sensorischen Speichers. Das visuelle perzeptuelle Gedächtnis könne nach ihrem Verständnis quasi als modalitätsspezifische Dimension des KZG betrachtet werden. Zusammen mit der abstrakten Dimension, dem KZG im herkömmlichen Sinne, mache sie dann das KZG aus (ebd.). Die perzeptuelle Dimension des KZG sei somit von dem sensorischen Speicher zu trennen. „The initial sensory store of roughly 250-ms duration differs from the modality- 
specific perceptual dimensions of $\mathrm{STM}^{60 ،}$ (ebd., S. 93). Eine ähnliche theoretische Vorstellung lieferte auch Cowan $(1984 ;$ 1988). Nach seiner Sichtweise sei das ikonische Gedächtnis im funktionalen Sinne nur noch rein sensorisch, weil sogar selbst dessen Produkt in perzeptueller Form schon dem KZG zugeschrieben werden solle und eine kognitive Beteiligung in der Phase des anfänglichen sensorischen Speichers wohl nicht mehr zu erwarten sei.

Infolge der Schwierigkeit der Trennung von sensorischem Gedächtnis und KZG ergibt sich wieder die Diskussion über das Wesen des ikonischen Gedächtnisses, gefolgt von der Diskussion über dessen inhaltliche Repräsentation.

\section{Der Inhalt bzw. die Repräsentationsart des ikonischen Gedächtnisses}

Das Problem kann mindestens aus zwei Perspektiven diskutiert werden. Zum einen äußert es sich in der Beziehung zwischen sichtbarer und informatorischer Persistenz, zum anderen drückt es sich in der Frage aus, ob der sensorische Gedächtnisinhalt präkategorial oder (post)kategorial ist.

Nach der klassischen Ansicht ist das ikonische Gedächtnis nur eine Art von sichtbarer Persistenz, eine so genannte visuelle Spur (s. Sperling, 1960). Nachdem Coltheart (1980) das Ikon aufgespalten hat, sieht er den wahren Gegenstand bzw. den Inhalt des ikonischen Gedächtnisses lediglich in der informatorischen Persistenz. Yeomans und Irwin bzw. Irwin und Brown (s.o.) folgten anfänglich noch dem Gedanken Colthearts, aber die Beteiligung der informatorischen Persistenz wurde durch die unklare Beziehung zum KZG immer fraglicher. In den Modellen von Dixon und Di Lollo (s.o.) ist der Gedanke schon zu erkennen, dass beide Persistenzarten an ikonischer Gedächtnisleistung zumindest in der PR-Aufgabe beteiligt sein sollen. Massaro und Loftus (1996) haben klar zum Ausdruck gebracht, dass die phänomenologische und die informatorische Persistenz verschiedene Aspekte desselben sensorischen Reaktionsprozesses seien. Allerdings überzeugt ihre Begründung und Belegung der Annahme bei der PR-Aufgabe noch nicht. Ebenso wie die Beziehung zwischen dem ikonischen Gedächtnis und dem KZG ist die Stellung der sichtbaren Persistenz und der informatorischen Persistenz beim ikonischen Gedächtnis immer noch nicht klargestellt.

Einen Hinweis auf die Repräsentationsart des kurzlebigen sensorischen Speichers bieten bereits Sperlings Experimente (1960). Sperling hat in einem seiner Experimente (ebd.) gezeigt, dass die kategoriale Information des Reizes nicht als Selektionskriterium genutzt werden konnte. Teilberichtsüberlegenheit trat nämlich nicht mehr auf, wenn das Hinweisreizkriterium (cueing criteria) eine kategoriale Information war (wie z.B. Zahlen oder Buchstaben). Dieses

\footnotetext{
${ }^{6}$ STM: short-term-memory (Kurzzeitgedächtnis).
} 
Ergebnis wurde so interpretiert, dass der sensorische Speicher ausschließlich präkategoriale Informationen enthält. Viele nachfolgende Untersuchungen haben dann gezeigt, dass die gültigen Hinweisreizkriterien, womit die Teilberichtsüberlegenheit produziert werden kann, vor allem physikalische Eigenschaften, wie z.B. Farbe (von Wright, 1968; Dick, 1969), Helligkeit (von Wright, 1968) und Form (Turvey \& Kravetz, 1970) sind.

Es gibt aber auch Untersuchungen mit Gegenbefunden (Dixon, 1985; Duncan, 1983; Merikle, 1980). Wie oben bereits erwähnt, konnte Merikle (1980) z.B. in seinem Experiment mit ähnlicher Anordnung wie bei Sperling zeigen: Wenn die Pbn nur eine bestimmte Kategorie (entweder Zahlen oder Buchstaben) von Reizmaterial wiedergeben sollten, erbrachten sie bessere Leistung als wenn sie alles berichten sollten (Ganzberichtsbedingung). Diese Teilberichtsüberlegenheit durch Selektion anhand von Kategorie-Informationen wird als Kategorieeffekt bezeichnet. Dieser Effekt könnte bedeuten, dass unter bestimmten Bedingungen kategoriale Informationen im ikonischen Gedächtnis doch eine Rolle spielen könnten, oder anders ausgedrückt, vielleicht auch darin enthalten sind.

\section{$\underline{\text { Kapazitätsfrage }}$}

Die Frage nach der Kapazität des ikonischen Gedächtnisses birgt zweierlei Probleme. Zum einen ist unklar, ob es bei dem ikonischen Gedächtnis eine Kapazitätseinschränkung gibt und zum anderen, wenn ja, wo genau diese Einschränkung liegt, bzw. was diese Einschränkung ausmacht.

Dem klassischen Konzept zufolge sollen die modalitätsspezifischen sensorischen Gedächtnisse eine sehr große Kapazität aufweisen, aber schnell verfallen. Das heißt, bei dem ikonischen Gedächtnis an sich dürften Kapazitätsprobleme keine Rolle spielen. Auf der anderen Seite ist die Leistung in der ikonischen Gedächtnis-Aufgabe $(P R)$ offensichtlich bestimmten Einschränkungen unterworfen. Diese Einschränkung liegt aber der klassischen Ansicht nach in der Übergangsphase zwischen präkategorialem und kategorialem Informationsspeicher, d.h. zwischen dem ikonischen Gedächtnis und dem KZG. Da nicht alle Reizrepräsentationen rechtzeitig in das KZG weitergeleitet werden können, verblassen die Restlichen.

Nach Coltheart $(1980,1984)$ liegt das Kapazitätsproblem des ikonischen Gedächtnisses in dem Übertragungsprozess. Bevor die Items in der $P R$-Aufgabe berichtet werden können, müssen sie in einen dauerhafteren Speicher übertragen werden. Dieser Übertragungsprozess ist ihm zufolge einer bestimmten Kapazitätseinschränkung unterworfen. „The $\mathrm{FR}^{7}$ limitation -

\footnotetext{
${ }^{7}$ FR: full report (Ganzbericht).
} 
only 4.5 items can be given, on the average, in FR - reflects some limitation of this transfer process“" (Coltheart, 1980, S. 186).

In dem Modell von Irwin und Yeomans (s. 1.3.3.2) wurde von einer

Kapazitätseinschränkung des ikonischen Gedächtnisses ausgegangen. Eine Limitation trete bereits vor der Übertragung ins KZG auf, da jeweils nur 4-5 Items im Identitätskode repräsentiert werden können. Die kapazitätsbeschränkte Speicherkomponente wurde allerdings von Irwin und Brown (1987) später mit dem KZG gleichgesetzt. Diese Gleichsetzung scheint in diesem Zusammenhang aber problematisch. Cavanagh (1972) berichtete beispielsweise über eine Gedächtnisspanne des KZG für Ziffern in der Höhe von durchschnittlich 7.7 Items, die Gedächtnisspanne für Buchstaben beträgt nach Cavanagh ca. 6.4 Items. Da in den meisten Experimenten zum ikonischen Gedächtnis entweder Ziffern oder Buchstaben als Material verwendet werden, ist die erwähnte Kapazität von 4-5 Items hier (Irwin \& Brown, 1987) weit kleiner als die übrige in der Literatur berichtete Kapazität des KZG. Es muss sich hier also um unterschiedliche Limitationen handeln.

Im Dual-buffer-Modell soll der Merkmalsspeicher unbeschränkte Kapazität besitzen, die Kapazität des Symbolspeichers ist unklar. Es wurde angenommen, dass die Übertragung vom Merkmalsspeicher zum Symbolspeicher nahezu automatisch und unproblematisch abläuft und in dieser Phase keine Aufmerksamkeit benötigt wird. Diese Annahme hat logischerweise die unbeschränkte Kapazität des Symbolspeichers zur Folge, was aber nicht durch empirische Daten gestützt werden kann (vgl. Coltheart, 1984), denn wenn die Lokalisationsinformation nicht relevant war und die Pbn nur ein Item wieder erkennen mussten, wurde trotzdem keine sonderlich gute Leistung erbracht. Nach dem Dual-buffer-Modell soll die Leistung aber nur durch eine Limitation des Übertragungsprozesses vom Symbolspeicher zum Reaktionsspeicher (hier KZG gemeint) beeinträchtigt werden. Mewhort et al. (1981) gehen von einer eingeschränkten Kanal-Kapazität (channel capacity) aus.

Damit kommen wir zu der nächsten offenen Frage über die Art der Informationsverarbeitung.

\section{Informationsverarbeitung während des Gedächtnisprozesses und bei der}

\section{Informationsübertragung}

Die Uneinigkeit beginnt bereits bei der Frage, wo die Informationsverarbeitung des ikonischen Gedächtnisprozesses anfangen soll. In der traditionellen Auffassung über das ikonische Gedächtnis wurde es als selbstverständlich angenommen, dass die perzeptuelle Spur eines kurz dargebotenen Reizes mit dem Stimulus-Onset beginnt. Diese Gedächtnisspur halte sich so lange, bis die Reizpräsentation beendet sei, dann beginne die Spur sofort zu verblassen 
(s. Abb. 5). Der zeitliche Verlauf des Verblassens stand hierbei im Zentrum des Interesses, daher die Variation des ISI. Die Darbietungsdauer des Reizes soll bis zu einem gewissen Grade keine Rolle spielen. Bei Irwin und Yeomans (1986) ist die visuell analoge Repräsentation auch unabhängig von dem Stimulus-Onset und sie soll mit dem Stimulus-Offset beginnen (s.o.). Di Lollo und Dixon (1988) nahmen aber an, dass die Dauer der sichtbaren Persistenz zeitlich an den Stimulus-Onset und die Dauer der informatorischen Persistenz an den Stimulus-Offset gebunden sei. Massaro und Loftus (1996) behandelten den Stimulus-Offset gar nicht mehr als ein wichtiges Ereignis. Die sensorische Reaktion auf einen Stimulus folgt nach Ansicht dieser Autoren dem Stimulus-Onset, steigt graduell an und sinkt auch nicht immer sofort nach dem Stimulus-Offset ab, sondern ist davon abhängig, ob die sensorische Reaktion das Maximum erreicht hat oder nicht (s. Abb. 6). Diese Kontroverse könnte man als Stimulus-OnsetKopplung versus Stimulus-Offset-Koppelung des ikonischen Gedächtnisses bezeichnen.

Darauf, wie die Information in einzelnen Stufen verarbeitet wird, wurde bisher in kaum einem Modell explizit eingegangen. Die intelligenten Mechanismen in dem Dual-buffer-Modell postulierten zwar gewisse Verarbeitungsweisen der Information, die aber zu sehr auf die Buchstabenverarbeitung zugeschnitten sind, zumal das Modell als Buchstaben-Identifikation auf dem Hintergrund von Wort-Identifikation gedacht war (s. Mewhort \& Beal, 1977; Mewhort \& Campbell, 1980). Somit sind sie nicht ohne weiteres auf allgemeine ikonische Gedächtnisphänomene übertragbar.

Da eine Kapazitätseinschränkung auch in dem Übertragungsprozess zum Ausdruck kommen kann, ist die Übertragungsweise zwischen den verschiedenen Phasen der Informationsverarbeitung von besonderer Bedeutung, worauf später noch ausführlicher eingegangen wird. Wie Sperling in seinem Vortrag festgestellt hat: „The transfer of information from iconic memory to a more durable visual information store (VSTM) is an essential ingredient of all theories of iconic memory“ (1996). Sperling ging von einer parallelen Übertragung von ikonischen Informationen ins Visual Short-Term Memory (VSTM) aus, ,in which several locations simultaneously pass information from iconic memory to VSTM“ (ebd.).

Diese parallele Übertragung konnte mit der Kanalkapazitäts-Vorstellung von Mewhort et al. (1981) in Zusammenhang gebracht werden. Es könnte nämlich sein, dass nur einige parallele Übertragungskanäle verfügbar sind, um die Items vom Symbolspeicher ins KZG zu transferieren. Diese beschränkte Anzahl von Übertragungskanälen erlaubt z.B., dass eben nur maximal 4-5 Items gleichzeitig (innerhalb eines bestimmten Zeitraums) übertragen werden können. Die Kanalkapazität kann aber auch als eine serielle Schnittstelle verstanden werden. 


\section{Die Rolle des Hinweisreizes in der PR-Aufgabe}

Im Zusammenhang mit der PR-Aufgabe soll ein Punkt besonders hervorgehoben werden, der für die Diskussion des ikonischen Gedächtnisses von spezieller Bedeutung ist. Er betrifft die Rolle des Hinweisreizes in der PR-Aufgabe. Der Hinweisreiz (cue) in der PR-Aufgabe soll die Aufmerksamkeit lenken und eine Selektion des Items steuern. Die Frage ist: Wann oder in welcher Phase findet die Selektion statt?

Ein Unterschied zwischen der klassischen Sichtweise und dem Dual-buffer-Modell besteht z.B. in der Platzierung der Selektion. Die Selektion findet nach der klassischen Ansicht zwischen Präkategorial- und Kategorialphase, nach dem Dual-buffer-Modell zwischen Postkategorial- und KZG-Phase statt.

Der traditionellen Auffassung nach wird der präkategoriale Speicherinhalt selektiert. In dem Dual-buffer-Modell dagegen werden Items aus dem postkategorialen Symbolspeicher durch einen Aufmerksamkeitsmechanismus selektiert und in den Reaktionsspeicher weitergeleitet. In dem Modell des ikonischen Gedächtnisses von Irwin und Yeomans (1986) wird die Information des Hinweisreizes sowohl für die Übersetzung der visuell analogen Repräsentation in den nicht visuellen Identitätskode als auch für die weitere Übertragung ins KZG genutzt. Ebenso wie bei den anderen Fragen herrscht hier über die Rolle des Hinweisreizes bzw. der Selektion in der $P R$-Aufgabe Uneinigkeit.

Die oben geschilderten Fragen und die Kontroversen bezüglich des Phänomens des ikonischen Gedächtnisses wurden von den zuvor dargestellten Modellen zwar in größerem oder kleinerem Umfang behandelt, aber nicht genügend oder nicht klar und plausibel beantwortet. Die kurze Schilderung der Problematik und der Kontroverse machte deutlich, dass für die vorhandenen Modelle noch Ergänzungs- bzw. Weiterentwicklungsbedarf besteht. Die Strukturmodelle von Mewhort et al. (s.o.) sowie Irwin und Kollegen (s.o.) sind eigentlich geeignete theoretische Ansätze für eine qualitative und differenzierte experimentelle Untersuchung, allerdings sind einige ihrer Annahmen fraglich. Die mathematischen Modelle verkörpern die Tendenz der Betonung der perzeptuellen Verarbeitungsmechanismen und der quantitativen Herangehensweise in der psychologischen Forschung. Was diesen Modellen fehlt, sind vor allem Vorstellungen über die kognitiven Informationsverarbeitungsmechanismen und Verarbeitungsprozesse in dem visuellen sensorischen Gedächtnisphänomen. Die bisherige Forschung war meist zu sehr mit spezifischen Phänomenen und Effekten in spezifischen Untersuchungen beschäftigt, so dass ein allgemeineres übergreifendes Konzept auch im Zusammenhang mit anderen visuellen Phänomenen nicht entstanden ist. 
Eine oft im Zusammenhang mit ikonischer Gedächtnisforschung vorgebrachte Kritik richtet sich darauf, dass das ikonische Gedächtnis fast ausschließlich anhand tachistoskopisch dargebotener Reize untersucht wird, die selten in der natürlichen Umgebung vorkommen. Sperling (1996) erklärte dies damit, dass bei langer Präsentation von Reizen das Gedächtnis nicht im Beobachter, sondern im Reiz selbst enthalten ist: „Visual short-term memory is studied in brief visual presentations because, when the presentation is not brief, the memory is in the stimulus itself, not in the observer" (Vortrag, Leipzig). Dieses Untersuchungsvorgehen veranlasste einige Forscher zu der Frage, ob dieses so genannte Gedächtnissystem überhaupt in der normalen Wahrnehmung eine Rolle spielt. Haber (1983) z.B. hat die theoretische Relevanz solcher Forschung unter dem Gesichtspunkt der ökologischen Validität bezweifelt. So behauptet er: „Brief discrete flashes have a visual persistence. But normal perception is not made up of brief discrete flashes, singly or in combination. Persistence, there icons, are irrelevant“ (Haber 1983, S. 3). Diese Kritik ist angesichts der verwendeten Methodik in der bisherigen Forschung über das ikonische Gedächtnis angebracht, da sie sich offensichtlich mit speziellen Phänomenen bzw. mit Laborsituationen beschäftigt hat, wofür ein generalisierbares, theoretisch übergreifendes Konzept fehlt.

Angesichts der Kritik an den bisherigen Konzepten und der theoretischen Entwicklung in verwandten Forschungsgebieten, und nicht zuletzt auch, um das Phänomen des ikonischen Gedächtnisses besser beschreiben, erklären und vorhersagen zu können, soll nun in der vorliegenden Arbeit versucht werden, nach einem Modell zu suchen, das den Gegenstand in einen breit angelegten Informationsverarbeitungsfluss eingebettet betrachtet und die beteiligten Informationsverarbeitungsprozesse genauer beschreibt.

Vor dem Hintergrund dieses Zieles wird sich zunächst mit einem konkreten Phänomen in der Untersuchung zum ikonischen Gedächtnis, genauer gesagt, mit einem Phänomen in der $P R$ Aufgabe bzw. dem Sperling-Paradigma auseinandergesetzt. Hierbei handelt es sich um den Modalitätseffekt des Hinweisreizes. Als erstes wird das Phänomen des Modalitätseffektes experimentell überprüft. Anschließend wird den konventionellen psychologischen Theorien folgend nach einer Erklärung für den Effekt gesucht, und zwar mit einer Reihe von Experimenten. Im Anschluss wird ein Modell aufgestellt, in dem die relevanten psychologischen und neuropsychologischen Kenntnisse und Theorien in verwandten Forschungsgebieten berücksichtigt werden. Schließlich werden einige Annahmen des Modells anhand eines konkreten empirischen Beispiels, nämlich des Modalitätseffektes, überprüft. Mit dem aufgestellten Modell soll der Modalitätseffekt besser erklärt werden. 


\section{Kapitel 2 Experimentelle Untersuchung zum Modalitätseffekt des Hinweisreizes im Partial Report (Sperling-Paradigma)}

\subsection{Modalitätseffekt: Einleitung und Hintergrund}

Das Konzept des visuellen sensorischen Gedächtnisses bzw. des ikonischen Gedächtnisses ist seit Anfang der 60er Jahre weit verbreitet. Trotz der unterschiedlichen Bezeichnungen in verschiedenen Gedächtnismodellen ist es in fast allen Lehrbüchern der allgemeinen Psychologie oder Kognitionspsychologie zu finden. Dies ist nicht zuletzt dem bereits erwähnten, inzwischen klassisch gewordenen Experiment von Sperling (1960) zu verdanken.

In dem Sperling-Paradigma (s. Abschnitt 1.1.3) werden mehrere Items auf einmal abgefragt, d.h., es soll eine Zeile mit 3 bis 4 Items (Teilbericht) oder es sollen alle Items der Matrix (Ganzbericht) reproduziert werden. Eine oft vorgebrachte Kritik im Zusammenhang mit dem Sperling-Paradigma, vor allem mit der Teilberichtsüberlegenheit gegenüber dem Ganzbericht, ist die so genannte Output-Interferenz (Dick, 1971; Holding, 1975; Appelman, 1980). Das heißt, die berichteten Items könnten retroaktiv mit den noch nicht berichteten Items interferieren; je mehr Items zu berichten sind, desto größer ist die Interferenz (s. auch Long, 1980; Coltheart, 1980). Man kann zwar diese beliebte Output-Interferenz-Erklärung für die Teilberichtsüberlegenheit in Verbindung mit dem cue-delay-effect zu widerlegen versuchen (s. Coltheart, 1975), es besteht jedoch eine Möglichkeit, dieses Problem von vornherein zu umgehen, indem man die von den Pbn zu berichtende Menge auf ein Item reduziert.

Eine alternative Prozedur zum Sperling-Paradigma, ein ebenso häufig im Zusammenhang mit dem ikonischen Gedächtnis zitiertes Verfahren, ist das Bar-marker-Paradigma von Averbach und Coriell (1961). Das Verfahren ist von der Idee her dem Sperling-Paradigma ähnlich und ebenfalls eine Art des PR. In ihrem Design (1961) wurde jedoch eine 2x8-ItemMatrix tachistoskopisch präsentiert und der/die $\mathrm{Pb}$ sollte danach nur ein Item benennen, und zwar das, welches zuvor von einem visuellen bar marker indiziert wurde. Hier sahen Averbach und Coriell einen wesentlichen Unterschied zur Sperling-Methode: „The experiment ... although conceived independently of Sperling, is of essentially the same form as his. The essential difference lies in the use of a visual signal to designate the part of the array to be reported by the subject“" (Averbach \& Coriell, 1961, S. 311).

Sperling (1960) leitete von der Beobachtung, dass sich die Teilberichtsleistung in seinem $P R$-Experiment bei einer Verzögerung von einer Sekunde nicht mehr vom Ganzbericht unterschied, ab, dass die Information in dieser Persistenzform für weniger als eine Sekunde verfügbar sei. 
Die Lebensdauer des ikonischen Gedächtnisses wird von Averbach und Coriell (Averbach \& Coriell, 1961) folgenderweise geschätzt: Sie gingen davon aus, dass die Information in dem Bar-marker-Experiment zwei Quellen entstammen, nämlich dem nonselective readout, welches unabhängig von dem bar marker ist, und dem selective readout, welches erst nach der Erscheinung des marker in Gang gesetzt wird. Die Wahrscheinlichkeit der richtigen Antwort setzt sich aus den Wahrscheinlichkeiten in den beiden Prozessen zusammen (ebd., S. 324):

$$
\mathrm{PT}_{\mathrm{T}}=\mathrm{PB}_{\mathrm{B}}+\left(1-\mathrm{PB}_{\mathrm{B}} \mathrm{PA}_{\mathrm{A}}\right.
$$

$\mathrm{P}_{\mathrm{T}}$ entspricht der Wahrscheinlichkeit einer richtigen Antwort in ihrem normalen Barmarker-Experiment. Die Wahrscheinlichkeit des nonselective readout $\left(\mathrm{P}_{\mathrm{B}}\right)$ kann anhand der Maskierungsmethode, bei der ein maskierender Kreis anstelle des bar marker verwendet wurde, ermittelt werden. Die Prozentzahl der richtigen Antworten in ihrem Bar-markerExperiment mit Maskierung ist ein Maß für den Anteil des nonselective readout, den der/die $\mathrm{Pb}$ vor dem Auftreten des maskierenden Kreises aus der verfügbaren Itemmenge nonselektiv auslesen konnte. Somit ergibt sich der Anteil des selective readout ( $\mathrm{PA}_{\mathrm{A}}$ (ebd., S. 324-325):

$$
\mathrm{P}_{\mathrm{A}}=\mathrm{P}_{\mathrm{T}}-\mathrm{PB}_{\mathrm{B}} /\left(1-\mathrm{PB}_{\mathrm{B}}\right)
$$

Averbach und Coriell (1961) nahmen weiter an, dass die Leistung hier unter dem Vorgang leidet, den marker zu identifizieren, um den entsprechenden Buchstaben auszulesen, so dass für die eigentliche Lebensdauer der ikonischen Persistenz noch die dadurch verloren gegangene Zeit addiert werden muss. Diese Zeit haben Averbach und Coriell (1961) ebenfalls aus ihren Daten ermittelt. Somit kamen sie auf eine Schätzung von 250-300 ms für die Lebensdauer des ikonischen Gedächtnisses. „The storage time is of the order of one-quarter second“ (Averbach \& Coriell, 1961, S. 326). Ihre Schätzung bezüglich der Lebensdauer des ikonischen Gedächtnisses ist damit ein wenig niedriger als die Schätzung Sperlings.

Abgesehen von anderen Unterscheidungen in Bezug auf das experimentelle Vorgehen in dem Sperling- und dem Bar-marker-Verfahren, hier z.B., ob so viele Items (einer Zeile) wie möglich auf einmal oder nur ein Item zu reproduzieren war(en), liegt ein wesentlicher Unterschied tatsächlich in der Modalität des Hinweisreizes. Im Sperling-Verfahren wurden ausschließlich auditive Hinweisreize verwendet, während in der Methode von Averbach und Coriell ein visueller marker als Hinweisreiz diente. Diese Beobachtungen führen zu der Frage, ob der genannte Unterschied zwischen den Schätzungen der ikonischen Gedächtnisdauer in beiden Verfahren eventuell auf den Modalitätsunterschied der verwendeten Hinweisreize zurückzuführen ist. 
Black und Barbee (1985) haben in ihrem Experiment unter der Verwendung des SperlingParadigmas anstelle des auditiven Hinweisreizes einen visuellen Pfeil verwendet, um den Einfluss des visuellen Hinweisreizes auf die ikonische Gedächtnisleistung in Abhängigkeit von Helligkeit und Stimulustyp zu untersuchen. Neben anderen Ergebnissen haben sie auch berichtet, ,when the visual cue was presented, subjects had less information available for recall then reported in previous studies employing auditory cues“ (ebd., S. 815). Es könnte auch in diesem Zusammenhang vermutet werden, dass die Modalität der verwendeten Hinweisreize ein Einflussfaktor auf die Leistung in der Untersuchung sein kann.

Bisher ist noch keine systematische Untersuchung bezüglich dieses möglichen Einflussfaktors durchgeführt worden. Angesichts des Stellenwertes der $P R$-Methode für die Erforschung des ikonischen Gedächtnisses scheint es sehr nützlich, diesen eventuellen Einfluss der Hinweisreizmodalität näher zu untersuchen und abzuklären. Diese Überlegungen bildeten den Anlass für die nachfolgende gezielte experimentelle Untersuchung. Es wird zunächst ein möglicher Effekt der Modalität des Hinweisreizes auf die Leistung überprüft. Anschließend wird anhand verschiedener psychologischer Theorien nach einer ersten Erklärung für den Effekt gesucht.

\subsection{Experiment 1 zum Nachweis eines Modalitätseffekts des Hinweisreizes}

Die Dauer des ikonischen Gedächtnisses wurde durch die erbrachten Leistungen ,indirekt“ erschlossen. Wenn das ikonische Gedächtnis tatsächlich eine kürzere Lebensdauer unter der Bedingung mit visuellem Hinweisreiz haben sollte, bedeutet dies, dass weniger Zeit für die Reizverarbeitung unter dieser Bedingung zur Verfügung stünde. Dies müsste auch darin zum Ausdruck kommen, dass die Leistung unter sonst konstant gehaltenen Bedingungen mit visuellem Hinweisreiz schlechter ausfällt als mit auditivem Hinweisreiz (was vielleicht bei dem Experiment von Black und Barbee der Fall war). Diesem Gedanken folgend wurde in Experiment 1 die Modalitätsspezifizität des Hinweisreizes in Hinblick auf die Reproduktionsleistung untersucht. Somit kann die Ausgangsfrage wie folgt formuliert werden: Gibt es einen Leistungsunterschied in Abhängigkeit von Modalität der Hinweisreize in den experimentellen Untersuchungen zum ikonischen Gedächtnis?

Ausgehend von dem Indiz in der Literatur (s.o) wurde erwartet, dass unter den Bedingungen mit auditiven Hinweisreizen bessere Reproduktionsleistungen als unter denen mit visuellen Hinweisreizen erbracht werden. Als Untersuchungsmethode diente das SperlingParadigma, allerdings wurden nicht nur auditive sondern auch visuelle Hinweisreize verwendet. 
Um den möglichen Einfluss der Hinweisreizmodalität noch unter zeitlichem Aspekt betrachten zu können, wurde das ISI zwischen dem Offset der visuellen Vorlage und dem Onset des Hinweisreizes variiert.

\subsubsection{Methode}

Probanden. An der Hauptuntersuchung nahmen 48 Psychologiestudierende der Universität Göttingen teil. Das durchschnittliche Alter der Stichprobe betrug 20.7 Jahre (SD = 1.5, Range 18-24). Für die Teilnahme an der Untersuchung wurden die Pbn jeweils entweder mit 30 DM bezahlt, oder es wurden ihnen drei Versuchspersonenstunden für ihr Studium bescheinigt. Alle Teilnehmer gaben an, eine normale oder bis auf normal korrigierte Sehschärfe zu haben.

Apparate und Versuchsraum. Zur Durchführung des Experiments wurde ein Macintosh Powerbook G3 der Marke Apple verwendet, das sowohl die millisekundengenaue Präsentation der Buchstabenmatrix als auch die Aufzeichnung der Daten gewährleistete. Ein externer AppleFarbmonitor (14-Zoll-RGB-Monitor mit einer 67-Hz-Trinitron-Röhre) für Pbn wurde an das Powerbook angeschlossen und im $90^{\circ}$ Winkel zum Laptop-Bildschirm aufgestellt. Für die Pbn wurde eine spezielle Tastatur angefertigt. Auf der Tastatur waren nur die 20 Konsonanten (ohne ,Y“) sowie die vier Pfeiltasten zur Steuerung des Cursors zu sehen. Die Tastatur wurde an das Powerbook angeschlossen. Ein Stereo-Kopfhörer (HD 414 der Marke SENNHEISER) wurde eingesetzt. Der Raum wurde durch zugezogene Vorhänge halb verdunkelt, die Beleuchtungsstärke lag im Raum zwischen 400-500 Lux.

Versuchsmaterial. In dem Versuch wurde ein Itemset aus 20 Konsonanten des Alphabets ohne „Y“" verwendet, und zwar als Großbuchstaben. Das Stimulusmaterial war eine 2x4-Matrix, die aus einer zufälligen Auswahl aus Itemsets bestand, wobei jeder Buchstabe in einer Matrix nur einmal vorkommen durfte (Ziehung ohne Zurücklegen). Die Matrix- und Buchstabengröße sowie die Distanzen zwischen den Buchstaben (Buchstabenabstand) in der Matrix werden unten in Tabelle 1 jeweils in Millimetern und mit dem Grad des Sehwinkels angegeben.

Tabelle 1. Matrix- und Buchstabengröße sowie Buchstabenabstand in Experiment 1

\begin{tabular}{cccccccccc}
\hline & \multicolumn{3}{c}{ Matrixgröße } & \multicolumn{3}{c}{ Buchstabengröße } & & \multicolumn{2}{c}{ Buchstabenabstand } \\
\multicolumn{2}{c}{ vertikal } & \multicolumn{2}{c}{ horizontal } & \multicolumn{2}{c}{ vertikal } & \multicolumn{2}{c}{ horizontal } & \multicolumn{2}{c}{ vertikal und horizontal } \\
\hline Maß & Sehw. & Maß & Sehw. & Maß & Sehw. & Maß & Sehw. & Maß & Sehw. \\
$20 \mathrm{~mm}$ & $1.91^{\circ}$ & $42 \mathrm{~mm}$ & $4.01^{\circ}$ & $6 \mathrm{~mm}$ & $0.57^{\circ}$ & $6 \mathrm{~mm}$ & $0.57^{\circ}$ & $10 \mathrm{~mm}$ & $1.04^{\circ}$ \\
\hline
\end{tabular}

Anmerkung. Die Sehwinkel (Sehw.) wurden ausgehend von einem Abstand von $60 \mathrm{~cm}$ zwischen $\mathrm{Pb}$ und Bildschirm berechnet. 
Zwei Arten von Hinweisreizen wurden eingesetzt: Als auditiver Hinweisreiz dienten ein niedriger Ton $(1047$ Hz), ein hoher Ton $(2093$ Hz) und ein Doppelton (2093 Hz). Der auditive Hinweisreiz wurde mittels eines Stereo-Kopfhörers dargeboten. Bei dem visuellen Hinweisreiz handelte es sich um einen Pfeil links oben von der Matrix, der nach rechts unten $(\checkmark)$ zeigte, einen Pfeil links unten von der Matrix, der nach rechts oben $(\pi$ ) zeigte, und doppelte Pfeile waagrecht links von der Matrix mit Pfeilrichtung zur Matrix $(\rightarrow)$. Die Pfeile hatten eine Größe von $6.5 \mathrm{~mm}$, d.h. einen Sehwinkel von ca. 0.62 ${ }^{\circ}$. Die Distanz zur Mitte des Fixationskreuzes betrug $22.5 \mathrm{~mm}$, was einem Sehwinkel von $2.15^{\circ}$ entspricht.

Die Konsonanten und die Pfeile wurden auf dem Bildschirm schwarz vor grauem Hintergrund dargeboten. Die Bildschirmhelligkeit betrug $46 \mathrm{~cd} / \mathrm{m}^{2}$.

Aufgabenanforderung und Versuchsablauf. Das Experiment orientierte sich am klassischen Sperling-Paradigma. Die Aufgabe der Pbn bestand darin, so viele Buchstaben wie möglich von einer 2x4-Buchstabenmatrix, die zuvor auf dem Computerbildschirm kurz dargeboten wurde, an der richtigen Position wiederzugeben. Dabei sollten die Pbn entweder eine der beide Zeilen (Teilbericht) oder beide Zeilen (Ganzbericht) reproduzieren. Die jeweiligen Aufgabenanforderungen wurden durch unterschiedliche auditive Töne oder visuelle Pfeile nach der Darbietung der Matrix signalisiert.

Jedem/Jeder $\mathrm{Pb}$ wurden zunächst alle in dem Experiment verwendeten Buchstaben in der richtigen Schriftart und -größe einzeln hintereinander für jeweils 400 ms vorgeführt. Danach wurden die jeweiligen Hinweisreize mit den entsprechenden Aufgabenanforderungen demonstriert. Nachdem der/die $\mathrm{Pb}$ die Hinweisreize kennen gelernt hatte, folgte eine Übungsphase von 20 Durchgängen ohne Wiederholungsmöglichkeit. Die Abbildung 7 veranschaulicht den Ablauf eines Durchgangs.

\section{Antwort}

auditiver (200 ms)

Hinweisreiz

$50 \mathrm{~ms}$

D $\quad F \quad G \quad H$

B $S$ W $\mathrm{X}$

\section{ISI}

$\checkmark$ visueller (50 ms)

\section{Start}

Abbildung 7: Ablauf eines Durchgangs in Experiment 1. 
$\mathrm{Zu}$ Beginn eines jeden Durchgangs erschien in der Mitte des Bildschirms ein schwach angedeutetes Plus-Zeichen (+) als Fixationskreuz. Der/Die Pb sollte nun seine/ihre Aufmerksamkeit auf die Mitte des Kreuzes richten. Durch Drücken auf die Eingabetaste wurde der Durchgang gestartet, eine 2x4-Buchstabenmatrix erschien in der Mitte des Bildschirmes für $50 \mathrm{~ms}$. Nach einem ISI von entweder $0 \mathrm{~ms}$ bei dem Ganzbericht bzw. 0, 100, 300 oder $1000 \mathrm{~ms}$ bei dem Teilbericht erschien der visuelle Hinweisreiz für 50 ms oder der auditive Hinweisreiz für 200 ms, um die Berichtsart bzw. die zu berichtende Zeile zu signalisieren. Anschließend erschien ein Antwortgitter, in das der/die $\mathrm{Pb}$ seine/ihre Antwort per Tastatur eingeben konnte. Das Zeitintervall zwischen dem Offset des Hinweisreizes und dem Onset des Antwortgitters betrug bei einem vorausgehenden visuellen Hinweisreiz 950 ms, bei einem Durchgang mit auditivem Hinweisreiz war ein Intervall von 800 ms vorgesehen. Da sich der auditive und der visuelle Hinweisreiz in ihrer Darbietungszeit unterschieden, wurde somit eine Gesamtdauer von 1000 ms vom Onset des Hinweisreizes bis zum Auftauchen des Antwortgitters für beide Hinweisreizbedingungen konstant gehalten. Im Falle eines Ganzberichts hatte das Gitter die Form einer 2x4-Matrix, bei der Teilberichtsaufgabe die Form einer Zeile mit 4 Zellen. Ein Cursor blinkte in der linken (oberen) Zelle. Der/Die Pb konnte ihn jedoch mit den Pfeiltasten zu einer beliebigen Zelle bewegen. Die Eintragungen konnten durch Überschreiben korrigiert werden. Erst nachdem alle Zellen des Gitters ausgefüllt waren, konnte der/die Pb seine/ihre Antwort durch das Drücken der Eingabetaste abgeben. Ein Feedback erschien direkt nach Abgabe der Antwort. Es bestand aus drei Zahlen, wodurch a) die Anzahl der richtig wiedergegebenen Buchstaben, b) die Anzahl der Buchstaben, die zwar in der dargebotenen Buchstabenmenge enthalten waren, aber im Antwortgitter an die falsche Stelle gesetzt wurden, und c) die Anzahl der möglichen richtigen Antwort insgesamt, angezeigt wurden. Anschließend erschien wieder das Fixationskreuz für den nächsten Durchgang.

Versuchsdurchführung. Die Pbn saßen auf einem höhenverstellbaren Stuhl. Ihre Augen und die Oberkante des Bildschirmes sollten sich auf einer waagerechten Linie befinden. Zwischen den Augen der Pbn und dem Bildschirm wurde eine Distanz von $60 \mathrm{~cm}$ eingehalten.

Der Versuch wurde nach der Art des Hinweisreizes (auditiv bzw. visuell) in zwei Sitzungen eingeteilt. Jede Sitzung mit acht Blöcken dauerte ca. anderthalb Stunden. Die Reihenfolge der auditiven und visuellen Sitzung wurde permutiert. Zwischen den zwei Sitzungen waren einige Tage Pause vorgesehen. Jede Sitzung wurde in zwei Teilversuche untergliedert, jeder Teilversuch bestand aus vier Blöcken à 30 Durchgänge. Insgesamt wurden bei jedem/jeder $\mathrm{Pb}$ für jede Hinweisreizbedingung 240 Durchgänge bzw. insgesamt 480 Durchgänge durchgeführt. Innerhalb eines jeden Blockes wurden die Aufgaben per Zufall auf 
die fünf möglichen Bedingungen, nämlich Ganzbericht (ISI $=0 \mathrm{~ms}$ ) und Teilbericht mit verschiedenen ISI $(0,100,300,1000 \mathrm{~ms}$ Bedingung) aufgeteilt, so dass jede Bedingungskombination mit 6 Durchgängen in einem Block getestet wurde, wobei die 6 Durchgänge wiederum auf drei Teilbericht-1-Aufgaben (T1, Reproduktion der ersten Zeile) und drei Teilbericht-2-Aufgaben (T2, Reproduktion der zweiten Zeile) verteilt waren.

\subsubsection{Ergebnisse}

Für den Ganzbericht wurde die Anzahl der korrekt reproduzierten Buchstaben als Gedächtnisleistung definiert, als Teilberichtsleistung diente die Anzahl verfügbarer Buchstaben, die auf der Grundlage der Anzahl korrekt reproduzierter Buchstaben im Teilbericht hochgerechnet (mit 2 multipliziert) wurde. Die Abbildungen 8a und 8b veranschaulichen die Ergebnisse des Experiments.
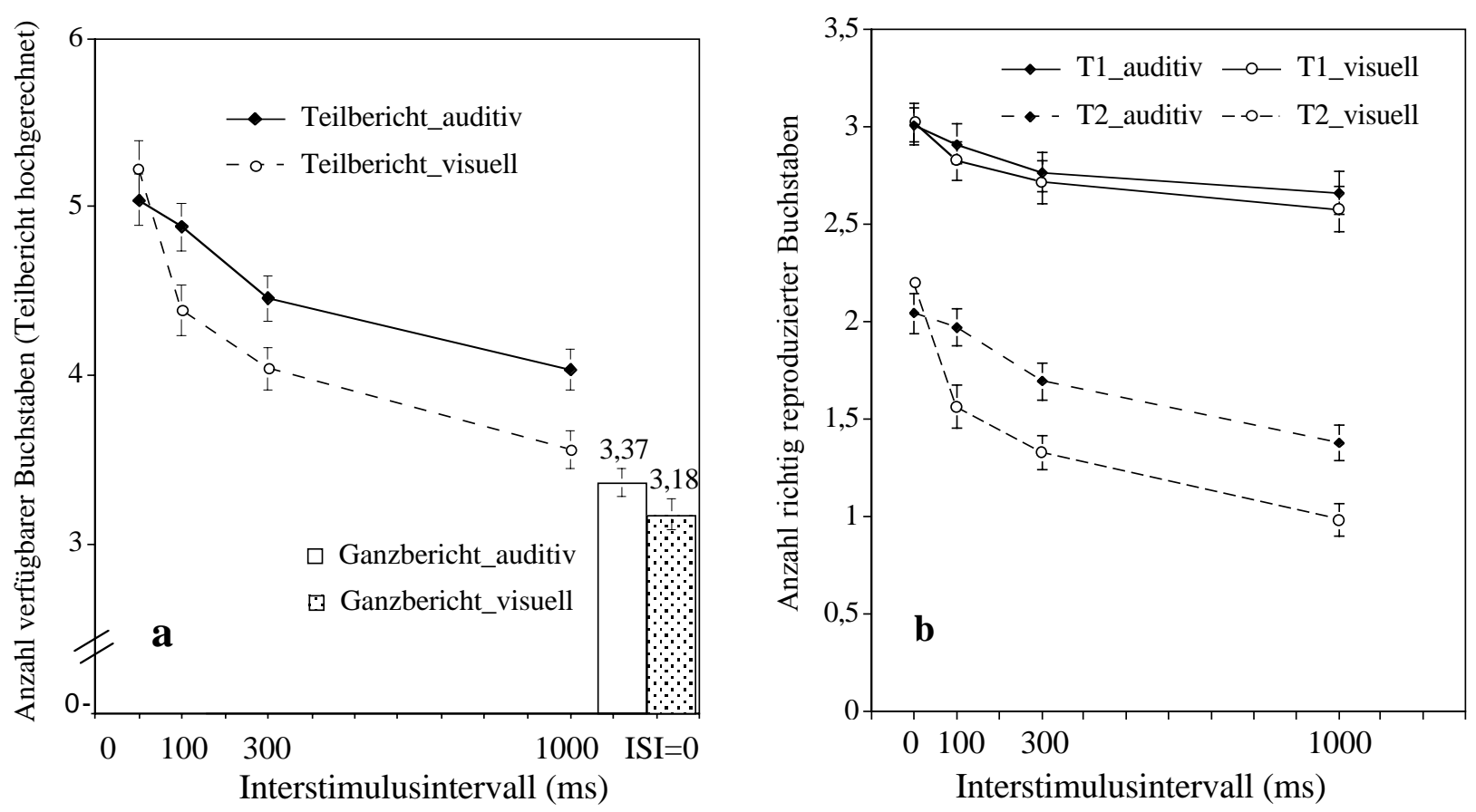

Abbildung 8: Ergebnisse in Experiment 1; dargestellt in Abhängigkeit von ISI und Hinweisreizart; $\mathrm{N}=48$.

a: Mittelwerte und Standardfehler für die Anzahl richtig reproduzierter Buchstaben im Ganzbericht und die Anzahl verfügbarer Buchstaben im Teilbericht (hochgerechnet auf der Grundlage der Anzahl korrekt reproduzierter Buchstaben). Das ISI zwischen dem Offset der Buchstabenmatrix und dem Onset des Hinweisreizes variierte in der Teilberichtsbedingung zwischen 0 und 1000 ms. Beim Ganzbericht betrug das ISI 0 ms.

b: Mittelwerte und Standardfehler für die Anzahl richtig reproduzierter Buchstaben im Teilbericht je Berichtsart (T1: Reproduktion der oberen Zeile; T2: Reproduktion der unteren Zeile) und je ISI.

In beiden Hinweisreizbedingungen zeichnete sich eine klare Teilberichtsüberlegenheit ab, wenn man die Ganzberichtsleistung mit der hochgerechneten Teilberichtsleistung vergleicht. Die Ergebnisse replizierten den Haupteffekt des klassischen Sperling-Experiments, dass die 
Teilberichtsleistung mit zunehmender Verzögerung des Hinweisreizes abnimmt und sich an die Ganzberichtsleistung annähert. Aber vor allem zeigten die Daten in fast allen Bedingungen eine schlechtere Leistung unter visuellen Hinweisreizbedingungen im Vergleich zu auditiven Hinweisreizbedingungen.

Eine dreifaktorielle MANOVA ${ }^{8}$ mit den Innersubjekt-Faktoren „Hinweisreizmodalität“, „Berichtsart“ und „ISI“ wurde mit den Daten aus der Teilberichtsbedingung durchgeführt. Der erste Faktor „Hinweisreizmodalität“ war zweifach gestuft (auditiv und visuell). Der zweite Faktor „Berichtsart“ bezog sich auf die Unterscheidung, welche der beiden Zeilen der Matrix zu reproduzieren war (Teilbericht 1: Reproduktion der oberen Zeile; Teilbericht 2: Reproduktion der unteren Zeile). Der Faktor „ISI“ hat 4 Stufen, nämlich Bedingung ISI von 0, 100, 300 und 1000 ms. Für alle drei Faktoren ergab sich ein hoch signifikanter Haupteffekt. Neben dem erwarteten Haupteffekt des ,ISI“ $\left[F(3,45)=70.24, \Lambda(3,45)=.18, p<.001, \eta^{2}=\right.$ 0.82], dass nämlich die Reproduktionsleistung systematisch mit zunehmendem ISI abnahm, erwies sich die „Hinweisreizmodalität“ tatsächlich als ein bedeutsamer Faktor $[F(1,47)=16.69$, $\left.\Lambda(1,47)=.74, p<.001, \eta^{2}=0.26\right]$, wobei bei visuellen Hinweisreizen eine schlechtere Wiedergabeleistung als bei auditiven Hinweisreizen erfolgte (s. Abb. 8b). Der Faktor „Berichtsart“" trat mit unerwartetem Effekt $\left[F(1,47)=77.23, \Lambda(1,47)=.38, p<.001, \eta^{2}=0.62\right]$ auf. Wie Abbildung $8 \mathrm{~b}$ zu entnehmen ist, zeigte sich im Vergleich zwischen den beiden Teilberichten eine eindeutig bessere Reproduktionsleistung bei Teilbericht 1. Das heißt, wenn die obere Zeile verlangt wurde, wurde besser reproduziert, als wenn die untere Zeile wiedergegeben werden sollte ${ }^{9}$. Dieser Zeilenunterschied in Bezug auf die Reproduktionsleistung trat bei beiden Hinweisreizbedingungen auf, wobei der Effekt bei visuellem Hinweisreiz stärker ausgeprägt war als bei auditivem. Es zeigte sich auch eine signifikante Interaktion der „Hinweisreizmodalität“ und der „Berichtsart“ $[F(1,47)=5.52, \Lambda(1$, $\left.47)=.90, p<.05, \eta^{2}=0.11\right]$. Der Leistungsunterschied zwischen beiden Hinweisreizbedingungen trat vor allem deutlich beim Teilbericht 2 auf, mit Ausnahme der Bedingung mit ISI $=0$ ms. Dagegen war der Leistungsunterschied zwischen den beiden Hinweisreizarten bei Teilbericht 1 nicht bedeutsam (s. Abb. 8 b und Tabelle 2). Die Wechselwirkung zwischen der „Hinweisreizmodalität“ und dem „ISI“ war hoch signifikant $\left[F(3,45)=26.8, \Lambda(3,45)=.36, p<.001, \eta^{2}=0.64\right]$. Dies wurde vor allem durch das andersartige Leistungsverhältnis zwischen den beiden Hinweisreizbedingungen bei einem ISI

\footnotetext{
${ }^{8}$ Das allgemeine lineare Modell (ALM) mit Messwiederholung wird bei SPSS auch als MANOVA behandelt, bei allen in der vorliegenden Arbeit berichteten varianzanalytischen Auswertungen werden immer die Ergebnisse des multivariaten Tests (neben dem F-Wert noch Wilks-Lambda) wiedergegeben.

${ }^{9}$ Dieses Phänomen wird fortan als ,Zeileneffekt“ bezeichnet (mehr dazu s. Lass et al., 2001).
} 
von $0 \mathrm{~ms}$ hervorgerufen. Bei einem ISI von $0 \mathrm{~ms}$ ergab sich sowohl bei Teilbericht 1 als auch bei Teilbericht 2 keine Überlegenheit des auditiven Hinweisreizes (s. Abb. 8b). Die Wechselwirkung zwischen der „Berichtsart“ und dem „ISI“ war ebenfalls hoch signifikant [F(3, $\left.45)=15.69, \Lambda(3,45)=.62, p<.001, \eta^{2}=0.51\right]$. Wie man aus der Abbildung $8 \mathrm{~b}$ entnehmen kann, nahm die Leistung im Teilbericht 2 mit zunehmendem ISI steiler ab als die Leistung im Teilbericht 1 .

Wenn man die statistischen Testergebnisse (t-Test) der Einzelvergleiche betrachtet, unterschieden sich die Wiedergabeleistungen der beiden Hinweisreizbedingungen in fast allen Bedingungskombinationen signifikant, wie man der Tabelle 2 entnehmen kann.

Tabelle 2. Ergebnisse der Mittelwertsvergleiche zwischen den Leistungen in der auditiven und der visuellen Hinweisreizbedingung in den einzelnen Bedingungskombinationen in Experiment 1

\begin{tabular}{|c|c|c|c|c|c|c|c|c|}
\hline \multirow{3}{*}{ Berichtsart } & \multirow{3}{*}{$\mathrm{ISI}^{\mathrm{a}}$} & \multicolumn{4}{|c|}{ Hinweisreiz } & \multirow{3}{*}{$t$} & \multirow{3}{*}{$p$} & \multirow{3}{*}{$\varepsilon$} \\
\hline & & \multicolumn{2}{|c|}{$\underline{\text { auditiv }}$} & \multicolumn{2}{|c|}{ visuell } & & & \\
\hline & & $M$ & $S D$ & $M$ & $S D$ & & & \\
\hline Ganzbericht & 0 & 3.37 & 0.57 & 3.18 & 0.62 & 3.10 & .003 & 0.86 \\
\hline \multirow[t]{4}{*}{ Teilbericht $^{\mathrm{b}}$} & 0 & 5.04 & 1.02 & 5.22 & 1.20 & -1.76 & .086 & -0.58 \\
\hline & 100 & 4.88 & 1.00 & 4.39 & 1.03 & 5.47 & $<.001$ & 1.81 \\
\hline & 300 & 4.46 & 0.91 & 4.04 & 0.86 & 4.21 & $<.001$ & 1.12 \\
\hline & 1000 & 4.03 & 0.83 & 3.56 & 0.78 & 4.65 & $<.001$ & 1.09 \\
\hline \multirow[t]{4}{*}{ Teilbericht 1} & 0 & 3.00 & 0.67 & 3.02 & 0.68 & -0.28 & .783 & -0.08 \\
\hline & 100 & 2.91 & 0.69 & 2.83 & 0.68 & 1.12 & .269 & 0.30 \\
\hline & 300 & 2.76 & 0.72 & 2.72 & 0.77 & 0.60 & .552 & 0.16 \\
\hline & 1000 & 2.66 & 0.76 & 2.57 & 0.82 & 0.92 & .364 & 0.23 \\
\hline \multirow[t]{4}{*}{ Teilbericht 2} & 0 & 2.04 & 0.70 & 2.20 & 0.81 & -2.21 & .032 & -0.70 \\
\hline & 100 & 1.97 & 0.66 & 1.56 & 0.77 & 7.20 & $<.001$ & 2.78 \\
\hline & 300 & 1.69 & 0.67 & 1.33 & 0.61 & 5.91 & $<.001$ & 1.81 \\
\hline & 1000 & 1.38 & 0.62 & 0.98 & 0.59 & 5.40 & $<.001$ & 0.50 \\
\hline
\end{tabular}

Anmerkungen. M: Mittelwert, SD: Standardabweichung der Mittelwerte, $\varepsilon$ : Effektgröße.

${ }^{a}$ Interstimulusintervall in ms.

${ }^{\mathrm{b}}$ Hochgerechnete Teilberichtsleistung.

Teilbericht 1: Reproduktion der oberen Zeile.

Teilbericht 2: Reproduktion der unteren Zeile.

Der Vergleich zwischen den beiden Hinweisreizbedingungen bei dem Ganzbericht ergab eine signifikant bessere Leistung für die auditive Hinweisreizbedingung $[t(47)=3.10, p=.003$, $\varepsilon=0.86]$. Betrachtet man Teilbericht 1 und Teilbericht 2 zusammen (hochgerechnet), so zeigte sich ein Nachteil des visuellen Hinweisreizes bei den meisten Bedingungen, mit Ausnahme der Bedingung ISI $=0 \mathrm{~ms}$. Differenziert betrachtet trat der Leistungsunterschied bei den 
Teilberichtsbedingungen nur signifikant beim Teilbericht 2 auf, ebenso mit der Ausnahme bei der Bedingung mit ISI = 0 ms. Der Leistungsunterschied zwischen den beiden Hinweisreizarten war beim Teilbericht 1 nicht statistisch bedeutsam. Bei einem ISI von $0 \mathrm{~ms}$ ergab sich sowohl beim Teilbericht 1 als auch beim Teilbericht 2 keine Überlegenheit des auditiven Hinweisreizes. Es zeigte sich sogar ein geringfügiger numerischer Vorteil des visuellen Hinweisreizes. Bei Teilbericht 2 war er sogar signifikant $[t(47)=-2.21, p<0,05, \varepsilon=-0.70]$.

\subsubsection{Diskussion und Schlussfolgerung}

Das Hauptinteresse in dem Experiment galt vor allem der Modalität des Hinweisreizes als möglichem Einflussfaktor. Das Experiment 1 konnte die Ergebnisse des klassischen SperlingParadigmas replizieren. Der hier gezeigte Effekt der Teilberichtsüberlegenheit, der mit zunehmendem ISI abnahm, ist nach dem herkömmlichen Konzept ein wichtiges Charakteristikum des ikonischen Gedächtnisses. Der Effekt berechtigt daher, die gemessene Leistung im Sinne der ikonischen Gedächtnisleistung nach dem klassischen Konzept zu interpretieren. Diese Voraussetzung ist sowohl bei der auditiven als auch bei der visuellen Hinweisreizbedingung erfüllt. Wie erwartet zeigten sich in dem Experiment unter visuellen Hinweisreizen im Vergleich zu auditiven Hinweisreizen fast überall deutlich schlechtere Leistungen - bis auf eine Teilberichtsbedingung mit einem Zeitintervall von 0 Millisekunden zwischen dem Offset der Reizvorlage und dem Onset des Hinweisreizes, d.h. bei der unmittelbaren Darbietung des Hinweisreizes. Dies deutet darauf hin, dass die Information unter dieser visuellen Hinweisreizbedingung im Vergleich zu einer auditiven Hinweisreizbedingung schlechter oder weniger verarbeitet wird. Darüber hinaus wird die Information anders verarbeitet, wenn der (visuelle) Hinweisreiz unmittelbar nach dem Offset der Matrix präsentiert wird, als wenn der Hinweisreiz verzögert dargeboten wird.

Insgesamt weist dieser Befund auf einen Effekt in der PR-Methode zur Untersuchung des ikonischen Gedächtnisses hin, der möglicherweise durch die Modalität des Hinweisreizes verursacht ist. Der Effekt besteht darin, dass der visuelle Hinweisreiz im Vergleich zu einem auditiven Hinweisreiz zu schlechterer Reproduktionsleistung führt.

Allerdings muss zunächst noch sichergestellt werden, dass der Leistungsunterschied unter visuellem und auditivem Hinweisreiz tatsächlich auf einen modalitätsbedingten Effekt zurückzuführen ist. Im Folgenden wird zunächst auf die bereits geäußerten bzw. nahe liegenden Erklärungsansätze eingegangen. Danach werden schrittweise Hypothesen aufgestellt und eine Reihe von Experimenten durchgeführt, um letztendlich eine plausible Erklärung für das Phänomen zu finden. 


\subsection{Maskierung als Erklärung des Modalitätseffekts}

Wie bereits erwähnt, haben Black und Barbee (1985) in ihrem $P R$-Experiment, in dem anstelle des auditiven Hinweisreizes ein visueller Pfeil verwendet wurde, festgestellt, dass die Reproduktionsleistung geringer war als die in der Arbeit von Sperling (1960). Sie hielten u.a. Maskierung durch den visuellen Hinweisreiz für eine mögliche Erklärung des Leistungsunterschiedes.

Diese Vermutung ist in unserem Fall auch nahe liegend, da die verwendeten visuellen Hinweisreize in Experiment 1 links von der Matrix platzierte Pfeile waren. Sie wurden zeitlich unmittelbar nach der Reizpräsentation oder nach einem ISI dargeboten. Eine Art von lateraler Rückwärtsmaskierung ist also denkbar. Der Matrixinhalt, nämlich die Buchstaben, könnte (teilweise) von dem Pfeil oder den Pfeilen maskiert werden, so dass in diesem Fall weniger Buchstaben für die Antwort verfügbar wären als in der Bedingung mit auditiven Hinweisreizen. Somit kann die erste Annahme in Bezug auf die Erklärung für den Leistungsunterschied zwischen den beiden Hinweisreizbedingungen in Experiment 1 lauten: Ein möglicher Maskierungseffekt durch die Präsentation des visuellen Hinweisreizes war für die schlechtere Leistung in den visuellen Hinweisreizbedingungen im Vergleich zu den auditiven Hinweisreizbedingungen verantwortlich.

\subsubsection{Theorien der Maskierung}

Visuelle Maskierung entsteht, wenn die Sichtbarkeit oder Identifikation eines kurz dargebotenen Zielreizes durch einen räumlich überlappenden oder angrenzenden, zeitlich vorausgehenden oder folgenden und ebenso kurz erscheinenden Reiz (Maske) beeinträchtigt wird (Breitmeyer, 1984). Wenn der erste Reiz von dem nachfolgenden zweiten Reiz maskiert wird, spricht man von Rückwärtsmaskierung. Umgekehrt wird der zweite vom ersten Reiz vorwärtsmaskiert. Breitmeyer (ebd.) sprach von Metakontrast, wenn der Zielreiz von einem räumlich angrenzenden, zeitlich folgenden zweiten Reiz maskiert wird. Wenn die zeitliche Reihenfolge umgekehrt ist, der zweite Reiz also von dem benachbarten ersten Reiz maskiert wird, dann ist dies nach Breitmeyer ein Parakontrast, also eine Art der Vorwärtsmaskierung (ebd.). In solchen Fällen spricht man manchmal auch von lateraler Maskierung, weil die Maske dem Zielreiz gegenüber seitlich platziert ist.

Es gibt unterschiedliche Erklärungsansätze für Phänomene der Maskierung bzw. der lateralen Maskierung. Eine neurophysiologische Betrachtung erklärt das Phänomen des Metakontrastes als eine Interaktion von Neuronen (z.B. Löffler, 1982). Danach soll der Zielreiz im Zentrum eines rezeptiven Feldes eine Neuronengruppe aktivieren. Wenn nachfolgend an der 
Peripherie der Retina ein weiterer Reiz eine Neuronengruppe eines anderen rezeptiven Feldes aktiviert, so führt dieses über Hemmungsprozesse zur Verringerung des Aktivitätsniveaus der zentralen Neuronengruppe. Diese Erklärung impliziert, dass laterale Maskierung in einer frühen Verarbeitungsphase stattfindet.

Nach Lachman, Lachman und Butterfield (1979) kann eine Maske auf unterschiedliche Phasen der Reizerkennung wirken. Breitmeyer (1984) unterschied zwischen zwei Wirkungsweisen von Maskierung:

(1) Licht-Maskierung (masking by light). Sie entsteht, wenn die Sichtbarkeit des Zielreizes durch die Helligkeit des Maskierungsreizes beeinträchtigt wird.

(2) Muster-Maskierung (masking by pattern). Sie entsteht, wenn die Identitätsinformation des Zielreizes durch Muster des Maskierungsreizes beeinträchtigt wird.

In diesem Sinne beeinträchtigt die Maske nach Lachman, Lachman und Butterfield (1979) bei der Licht-Maskierung die „Formation“, bei der Muster-Maskierung aber die „Identifikation“ des Zielreizes. Daraufhin wird angenommen, dass Licht-Maskierung in der peripheren, Muster-Maskierung hingegen in der zentralen Phase der Informationsverarbeitung wirke. Als Folge der letzteren Art von Maskierung entstehen Identifikationsfehler.

Allerdings wird auch behauptet, dass selbst ein Identifikationsverlust durch Interaktion zwischen Merkmalskomponenten des Zielreizes und der Maske in der frühen Verarbeitungsphase zustande kommen kann (Huckauf, Heller \& Nazir, 1999). Diese Behauptung stimmt auch mit Befunden aus einigen empirischen Arbeiten (z.B. McClelland \& Rumelhart, 1981) überein. Dort wurde beobachtet, dass der flankierende Stimulus (Maske) mit den einzelnen Merkmalskomponenten des Zielreizes interagiert. Demnach findet die Interaktion bei der Integration zum Symbol auf der Merkmalsebene statt, wodurch die Identitätsinformation des Zielreizes verzerrt und als Konsequenz ein völlig anderes Symbol als Zielreiz erkannt wird.

Abgesehen von der Uneinigkeit über die Wirkungsweise des Maskierungsphänomens soll Maskierung zunächst als eine mögliche Erklärung für den beobachteten Leistungsunterschied zwischen den beiden Hinweisreizbedingungen in Experiment 1 betrachtet werden. Man könnte nämlich behaupten, dass in Experiment 1 die Matrix der Zielreiz sei, dass der visuelle Pfeil oder die visuellen Pfeile als Maske fungiere/fungierten, so dass die Leistungen unter visuellen Hinweisreizen entweder durch die Beeinträchtigung der Sichtbarkeit oder durch die Beeinträchtigung der Identifikation schlechter ausfallen müssten. 
2.3.2 Widerlegung des Arguments anhand der Daten aus Experiment 1

Um das Argument der Maskierung als Erklärung überprüfen zu können, muss man die allgemeinen Eigenschaften der zwei Arten von Maskierung genau analysieren. Nach Spencer (1969) hat die Licht-Maskierung ihre größte Wirkung, wenn die Maske zeitgleich mit Zielreizen dargeboten wird. 100 ms oder etwas länger nach Beendigung der ZielreizDarbietung (offset) verliert sie ihre Wirkung. Während die Maske der Muster-Maskierung bei simultaner Darbietung mit dem Zielreiz keinen Effekt haben soll, erreicht sie dagegen ihren maximalen Maskierungseffekt bei ca. 100 ms oder auch etwas länger nach StimulusBeendigung. Nach 300 ms soll sie dann aber ebenfalls keine Wirkung mehr haben.

Betrachtet man die Ergebnisse in Experiment 1 global, ergibt sich aber ein anderes Bild (s. Abb. 8a und 8b, sowie Tabelle 2) :

- Bei der Bedingung ISI = 0 ms war der Leistungsunterschied zwischen beiden Hinweisreizbedingungen nicht signifikant. Tendenziell wurden unter visuellem Hinweisreiz sogar bessere Leistungen erbracht. Somit kann es sich hier nicht um Lichtmaskierung handeln.

- Laut der Annahme der Mustermaskierung muss der Maskierungseffekt nach 300 ms aufhören. Der Leistungsunterschied in Experiment 1 bestand jedoch selbst nach einer Verzögerung von 1000 ms nach wie vor. Somit kann auch die Mustermaskierung nicht für den beobachteten Effekt verantwortlich sein.

Da die schlechtere Leistung in der visuellen Hinweisreizbedingung in Experiment 1 durch eine laterale Maskierung, die positionsbedingt maskiert, zustande kommen könnte, scheint hier ein zellenweises Vergleichen der Leistung notwendig. Denn wenn der Matrixinhalt lateral von den links platzierten visuellen Hinweisreizen maskiert werden sollte, müssten die linken Spalten der Matrix mehr betroffen sein als die rechten.

Die Daten in Experiment 1 wurden aufgrund dieser oben genannten Vermutung zellenweise neu ausgewertet. In der Abbildung 9 wird die Ganzberichtsleistung in Experiment 1 für beide Hinweisreizbedingungen zellenweise dargestellt. Da dieser mögliche Maskierungseffekt auch vom ISI abhängig sein könnte, wurde der zellenweise Leistungsvergleich zwischen den beiden Hinweisreizbedingungen beim Teilbericht für jede ISI-Bedingung getrennt durchgeführt (Abb. 10a, 10b, 10c, 10d). 


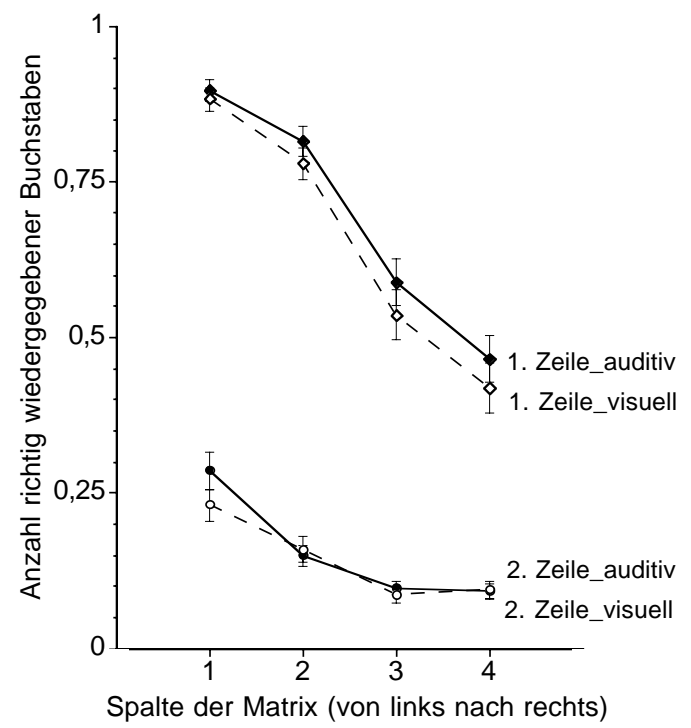

Abbildung 9: Zellenweiser Leistungsvergleich zwischen auditiven und visuellen Hinweisreizbedingungen beim Ganzbericht (ISI $=0 \mathrm{~ms}$ ) in Experiment 1 .

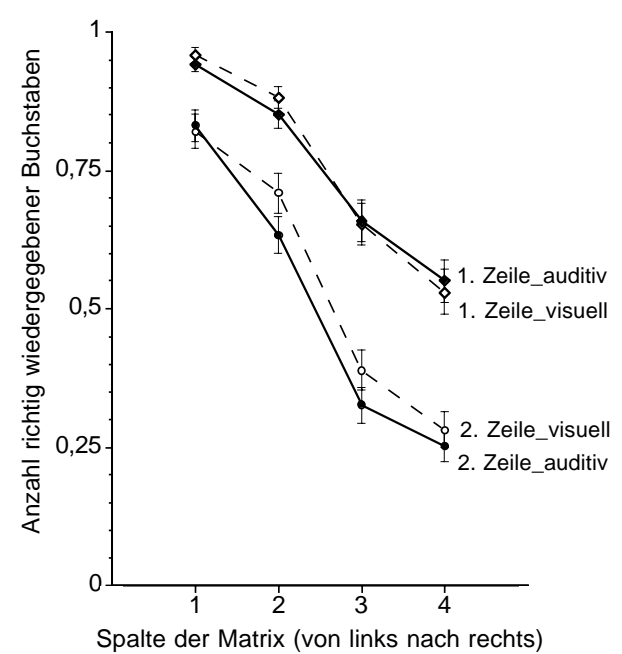

a: $\mathrm{ISI}=0 \mathrm{~ms}$

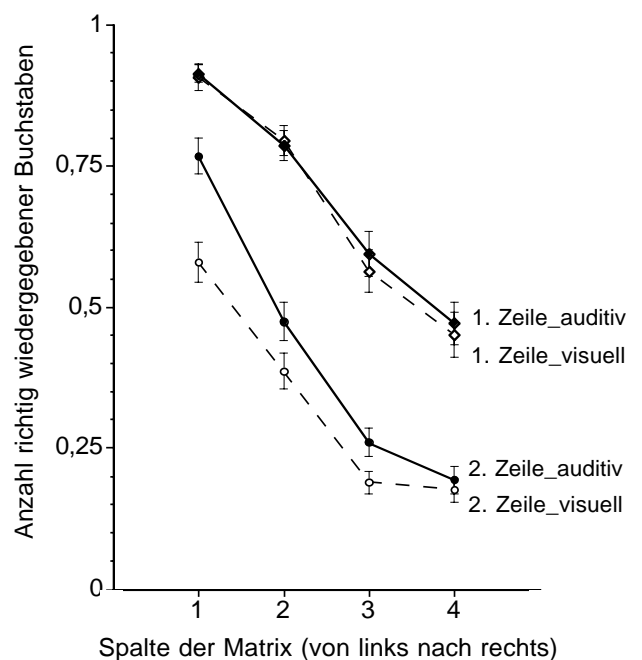

c: $\mathrm{ISI}=300 \mathrm{~ms}$

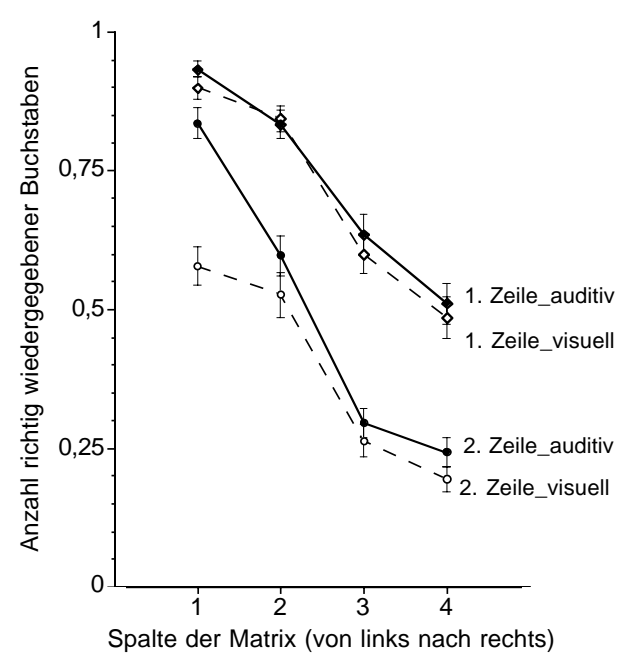

b: ISI $=100 \mathrm{~ms}$

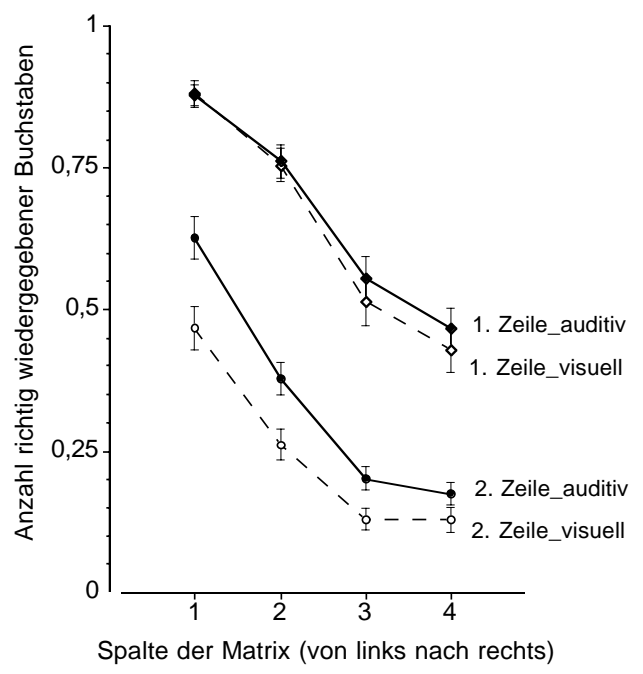

d: $\mathrm{ISI}=1000 \mathrm{~ms}$

Abbildung 10: Zellenweiser Leistungsvergleich zwischen auditiven und visuellen Hinweisreizbedingungen beim Teilbericht unter verschiedenen ISI in Experiment 1. 
Zellenweise betrachtet nahm die Leistung insgesamt sowohl beim Ganzbericht als auch beim Teilbericht von links nach rechts ab. Dies gilt für jede Zeile, jedes ISI, ebenso für beide Hinweisreizbedingungen. Beim Ganzbericht zeigte sich die tendenzielle Unterlegenheit der visuellen Hinweisreizbedingung nur in der ersten Zeile. Diese Unterlegenheit bestand aber über alle Spalten der ersten Zeile hinweg, d.h., nicht nur die linken zwei Spalten waren schlechter. In der Teilberichtsbedingung mit einem 0-ms-ISI (Abb. 10a), bei der eine Licht-Maskierung eigentlich die stärkste Wirkung haben sollte, zeigte sich keine Beeinträchtigung der Leistung unter der visuellen Hinweisreizbedingung. Bei den drei anderen ISI-Bedingungen wurde der Leistungsunterschied nach der zellenweisen Betrachtung eher in der zweiten Zeile ausgemacht. Die Zelle unten links wurde unter der visuellen Hinweisreizbedingung bei einem ISI von 100 ms (Abb. 10b) und einem ISI von $300 \mathrm{~ms}$ (Abb. 10c) viel schlechter reproduziert als unter der auditiven Hinweisreizbedingung. Dennoch ist dies kein Beleg für Maskierung, denn die erste Zelle links in den beiden Bedingungen schien nicht von der Maskierung betroffen zu sein. In der ersten Zeile, nämlich dort in der ersten Zelle, wo sie eigentlich ebenso von einem links platzierten Pfeil gestört werden müsste, zeigte sich keine Beeinträchtigung gegenüber der auditiven Hinweisreizbedingung. Vor allem blieb die Leistungsüberlegenheit der auditiven Hinweisreizbedingung in der zweiten Zeile bei ISI $=1000 \mathrm{~ms}$ (Abb. 10b) nach wie vor bestehen, wo eigentlich jegliche Art von Maskierung keine Wirkung mehr haben sollte.

Da die differenzielle deskriptive Datenanalyse von Experiment 1 insgesamt keinen überzeugenden Hinweis auf Maskierungseffekte ergab, wurde auf eine weitere inferenzstatistische Auswertung verzichtet. Der gefundene Leistungsunterschied zwischen den beiden Hinweisreizbedingungen in Experiment 1 kann somit nicht auf eine Maskierung der visuellen Hinweisreize zurückgeführt werden.

\subsection{Unterschiedliche Verarbeitungszeit bei verschiedenen Modalitäten als Erklärung des Modalitätseffekts}

Als zweiter Erklärungsansatz zu dem gefundenen Leistungsunterschied in Experiment 1 werden durch Modalitätseigenschaften bedingte Unterschiede herangezogen:

Kann der Leistungsunterschied durch die jeweiligen Eigenschaften der Modalitäten bzw. durch den Unterschied zwischen den Modalitäten hinsichtlich relevanter Eigenschaften hervorgerufen worden sein?

Gedacht wird hier vor allem an einen möglichen modalitätsbedingten Unterschied in der Reaktionszeit auf die verwendeten Hinweisreize in Experiment 1. 


\subsubsection{Theorien zur Reaktionszeit}

Mit Reaktionszeit bezeichnet man die Zeit, die zwischen dem Beginn der Präsentation eines Reizes und dem Beginn der offen beobachtbaren Reaktion auf den Reiz verstreicht.

Seit Donders (1868) wird zwischen Einfachreaktion (oder a-Reaktion), Wahlreaktion (oder b-Reaktion) sowie Unterscheidungsreaktion (Go/Nogo-Reaktion oder c-Reaktion) unterschieden. Man spricht von einer Einfachreaktion, wenn man nur auf einen Reiz mit einer Reaktion reagieren muss. In einer Wahlreaktionsaufgabe weiß man nicht im Voraus, welche von mehreren Reizalternativen erscheinen wird, wobei jede Reizalternative eine eigene Reaktionsalternative erfordert. In der Unterscheidungsreaktionsaufgabe wird eine Reaktion mehreren Reizalternativen zugeordnet. Man soll dann nur auf einen Teil oder einen bestimmten Aspekt der Reize reagieren.

Nach Brebner und Welford (1980) variiert die Reaktionszeit zwischen den sensorischen Modalitäten, wobei dieser Unterschied sowohl die Fortleitung (afferent conduction) des Reizes als auch die Geschwindigkeit der Zustandsänderung und die Reizschwelle des sensorischen Systems betreffen kann. So beträgt z.B. die Zeit, die ein auditiver Reiz braucht, um die zentralen Mechanismen zu erreichen, 8-10 ms; ein visueller Reiz braucht dagegen viel länger, d.h. ca. 20-40 ms. Im Allgemeinen geht man von einer Reaktionszeit von $140 \mathrm{~ms}$ auf auditive, und von 180 ms auf visuelle Signale aus (ebd.). Während bei diesem Vergleich zwischen der visuellen und auditiven Modalität von der Einfachreaktion die Rede ist, können Unterscheidungsreaktions- und Wahlreaktionszeit bis zum Vierfachen der Einfachreaktionszeit betragen. In Situationen, in denen eine Wahlreaktion gefordert wird, müssen mindestens vier Prozesse ablaufen: a) das Signal muss wahrgenommen und an das Gehirn durch afferente Nervenbahnen weitergeleitet werden; b) das Signal muss identifiziert werden; c) eine entsprechende Reaktion muss gewählt werden; d) die Reaktion muss initiiert werden. Der erste und letzte Prozess dauern relativ kurz, während Identifikation und Auswählen der entsprechenden Reaktion den größten Teil der Wahlreaktionszeit ausmachen (Welford, 1980).

\subsubsection{Experiment 2 zur Prüfung der Wahlreaktionszeiten auf die beiden in Experiment 1} verwendeten Hinweisreizarten

Bereits Averbach und Coriell (1961) haben einen Einfluss des modalitätsbedingten Reaktionszeitunterschieds auf die Leistung vermutet. Ihr Bar-marker-Verfahren (ebd.) ähnelt prinzipiell dem Sperling-Paradigma und ist ebenfalls eine Variante der PR-Methode. In diesem Verfahren wird eine 2x8-Matrix tachistoskopisch präsentiert und der/die $\mathrm{Pb}$ soll anschließend nur das Item benennen, das vorher durch einen visuellen bar marker indiziert wurde. Als Averbach und Coriell das PR-Paradigma mit dem Sperlings verglichen, glaubten sie, dass es 
ein methodischer Vorteil sei, einen visuellen statt eines auditiven Hinweisreizes zu verwenden. „This has the virtue that it assures that the array and signal are transmitted to wherever they are processed in the brain at approximately the same rate. It is known that the reaction time to a light is significantly longer than the reaction time to a tone“ (Averbach \& Coriell, 1961, S. 311).

Es ist zwar nicht klar, weswegen dies ein Vorteil sein sollte, es wäre aber trotzdem denkbar, dass sich der Unterschied in den modalitätsspezifischen Reaktionszeiten auf die Hinweisreize in den Leistungen niederschlagen kann und dass der Leistungsunterschied zwischen den beiden Hinweisreiz-Bedingungen in Experiment 1 eine Folge von ReaktionszeitUnterschieden ist. In Experiment 1 entstammen die zwei Arten von Hinweisreizen aus zwei verschiedenen Modalitäten (der auditiven und der visuellen). Wenn die Pbn schneller auf den auditiven als auf den visuellen Hinweisreiz reagieren würden, könnten sie quasi in der auditiven Hinweisreizbedingung früher als in der visuellen Hinweisreizbedingung mit der Verarbeitung der Buchstaben beginnen und dadurch mehr Zeit gewinnen. Dies würde dann eine bessere Leistung in der auditiven Hinweisreizbedingung zur Folge haben.

In Experiment 1 muss der Hinweisreiz sensorisch aufgenommen und dann interpretiert werden, d.h., es muss eine entsprechende Aufgabenart (Wiedergabe der oberen, unteren Zeile oder beider Zeilen) dem Hinweisreiz zugeordnet werden, wonach eine unterschiedliche Antwort gegeben werden soll. In diesem Fall werden Wahlreaktionen verlangt, so dass man hier nicht nur von einer möglichen Zeitdifferenz von 20-40 ms zwischen den Reaktionen auf den auditiven und den visuellen Hinweisreiz ausgehen kann.

Um die Erklärungsmöglichkeit überprüfen zu können, dass der Leistungsunterschied zwischen den beiden Hinweisreizbedingungen auf die unterschiedlichen modalitätsbedingten Reaktionszeitunterschiede zurückzuführen sei, muss man zunächst feststellen, ob die beiden Hinweisreize in dem aktuellen experimentellen Design tatsächlich unterschiedliche (Wahl-) Reaktionszeiten hervorrufen, bzw. ob die Pbn wirklich schneller auf den auditiven Hinweisreiz reagieren.

Falls sich in der folgenden Untersuchung tatsächlich ein Reaktionszeit-Unterschied feststellen lässt, könnte man die ermittelte numerische Zeitdifferenz in einem weiteren Experiment zu kompensieren versuchen, und zwar dadurch, dass die visuellen Hinweisreize einen zeitlichen Vorsprung erhalten. Angenommen, es würde ein zeitlicher Vorteil von $40 \mathrm{~ms}$ bei der Reaktionszeit für auditive Hinweisreize festgestellt, kann nun der numerische Unterschied in dem durchgeführten Experiment durch unterschiedliche ISI-Einstellungen kompensiert werden. Das heißt, ein 100-ms-ISI für einen visuellen Hinweisreiz müsste einem 
ISI von 140 ms für einen auditiven Hinweisreiz entsprechen. Wenn die Pbn in diesem Fall vergleichbare Leistungen in der Sperling-Aufgabe unter den beiden Hinweisreizbedingungen erbringen würden, dann könnte man den Leistungsunterschied bzw. den Modalitätseffekt eindeutig auf den modalitätsbedingten Unterschied in der Reaktionszeit auf die Hinweisreize zurückführen.

Ein weiterer Weg, den möglichen Reaktionszeit-Unterschied zwischen den beiden Hinweisreizarten zu vermeiden, ist, die Einflussfaktoren auf die Reaktionszeit soweit wie möglich zu kontrollieren. Die Reaktionszeit hängt außer von der Sinnesmodalität des Reizes noch von vielen anderen Faktoren ab, z.B. von der Intensität des Reizes, dem Ort und der Fläche des gereizten Netzhaut-Areals bei visueller Reizung und dem Reaktionsmodus. Wenn wir wissen, dass die Reaktionszeit von der Reizintensität abhängig ist und diese wiederum von der Darbietungsdauer beeinflussbar ist, kann man in einem weiteren Experiment nach einem „,idealen“ Paar der Hinweisreize suchen, d.h. einem visuellen und einem auditiven Hinweisreiz sowohl mit gleicher Darbietungsdauer als auch mit der gleichen subjektiven Intensität. Dieses „,ideale“ Paar soll dann vergleichbare (Wahl-)Reaktionszeiten in dem Versuchsdesign aufweisen. Wenn der Reaktionszeit-Unterschied tatsächlich für den Leistungsunterschied in Experiment 1 verantwortlich ist, müsste der Leistungsunterschied durch die Verwendung des neuen ,idealen“ Hinweisreiz-Paares mit gleicher Reaktionszeit-Anforderung eliminiert werden.

Dem Gedanken folgend werden in Experiment 2 noch die Wahlreaktionszeiten auf einen neuen visuellen Hinweisreiz und einen neuen auditiven Hinweisreiz, die jeweils für $100 \mathrm{~ms}$ dargeboten werden, gemessen, wobei die subjektive Intensität der beiden neuen Hinweisreize subjektiv angeglichen (,gematched“) wird, und zwar durch Steuerung der Lautstärke des auditiven Hinweisreizes.

\subsubsection{Methode}

Probanden. An dem Experiment nahmen 24 Studierende im Alter von 19 bis 31 Jahren teil. Das Durchschnittsalter betrug 22.5 Jahre $(\mathrm{SD}=3.01)$. Die Pbn wurden für die Teilnahme mit 15 DM entlohnt. Alle Teilnehmer gaben an, eine normale oder bis auf normal korrigierte Sehschärfe zu haben.

Apparate und Versuchsraum. Die Apparaturen und der Versuchsraum waren die gleichen wie in Experiment 1. Darüber hinaus wurden die drei Buchstaben-Reihen auf einer normalen Tastatur jeweils für drei Reaktionen (Aufgaben) definiert. Die obere Reihe wurde für die Reaktion „oben“, die untere Reihe für die Reaktion „unten“ und die mittlere Reihe für die Reaktion ,ganz“ festgesetzt. 
Reizmaterial. Es wurde die visuelle Vorlage in Form einer 2x4-Buchstabenmatrix aus 20 Konsonanten wie in Experiment 1 eingesetzt. Zusätzlich zu den beiden Hinweisreizarten des ersten Experiments wurden noch ein weiterer visueller Hinweisreiz (in Form von Pfeilen) und ein auditiver Hinweisreiz mit jeweils einer Darbietungsdauer von 100 ms verwendet. Die Größe der visuellen Hinweisreize und die Frequenzen der auditiven Hinweisreize entsprachen denen aus Experiment 1. Die Intensitäten der beiden neuen Hinweisreizarten wurden auf der Grundlage von fünf Versuchsleiter-Urteilen so weit wie möglich aneinander angeglichen, und zwar durch Regulierung der Lautstärke der auditiven Töne, so dass die jeweils gepaarten auditiven und visuellen Hinweisreize „subjektiv“ als annähernd gleich intensiv empfunden wurden.

Aufgabenanforderung und Versuchsablauf. Die Abbildung 11 veranschaulicht den Ablauf eines Durchgangs in Experiment 2. Ein Fixationskreuz erschien in der Mitte des Displays. Ein Durchgang wurde mittels Tastendruck gestartet. Die Reizvorlage einer per Zufall ausgewählten 2x4-Konsonanten-Matrix wurde für $50 \mathrm{~ms}$ dargeboten. Anschließend erschien nach unterschiedlichen Zeitintervallen (ISI) von 0, 100, 300 oder $1000 \mathrm{~ms}$ ein visueller Hinweisreiz (für 50 ms oder 100 ms) oder es ertönte ein auditiver Hinweisreiz (für 200 ms oder 100 ms). Die Aufgabe der Pbn bestand darin, nur auf den Hinweisreiz zu reagieren, d.h., wenn der Pfeil links oben erschien oder ein hoher Ton ertönte, sollten sie eine beliebige Taste der oberen Reihe der Tastatur drücken (Reaktion „oben“); wenn der Pfeil rechts unten erschien oder ein tiefer Ton ertönte, eine beliebige Taste der unteren Reihe drücken (Reaktion „unten“); und auf Doppelpfeile oder einen Doppelton dann eine beliebige Taste der mittleren Reihen drücken (Reaktion „ganz“). Gemessen wurde die Reaktionszeit für die richtige Reaktion, d.h. die Zeit zwischen dem Offset des Hinweisreizes und dem Tastendruck. Anschließend erschien wieder das Fixationskreuz und ein neuer Durchgang begann.

Reaktion:

oben (T1)

Mitte (ganz)

unten (T2)

\section{Start}

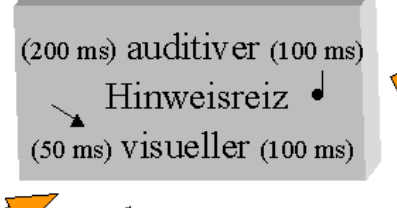
D $\quad \mathrm{F} \quad \mathrm{G} \quad \mathrm{H}$
B S W X
1000 tos
0,

ISI

Abbildung 11: Ablauf eines Durchgangs in Experiment 2. 
Design und Versuchsdurchführung. Der Versuch wurde in zwei Teilversuche eingeteilt. In einem Teilversuch wurden auditive Hinweisreize mit einer Dauer von $200 \mathrm{~ms}$ und visuelle Hinweisreize mit einer Dauer von 50 ms (alte Bedingungen, wie in Experiment 1), getrennt in zwei Unterteile, eingesetzt. Im anderen Teilversuch wurden „neue“ auditive und „neue“ visuelle Hinweisreize mit jeweils einer Darbietungsdauer von 100 ms getrennt in zwei Unterteile verwendet. Die Reihenfolge der beiden Teilversuche sowie der Unterteile innerhalb eines Teilversuchs wurden permutiert. Das ganze Experiment bestand aus 240 Durchgängen. Ein Teilversuch enthielt 120 Durchgänge, so dass auf jede Hinweisreizbedingung 60 Durchgänge entfielen, die in zwei Blöcke à 30 Durchgänge geteilt waren. Diese wurden per Zufall zwischen einer Ganzberichtsbedingung mit einem ISI von $0 \mathrm{~ms}$ und den Teilberichtsbedingungen mit vier verschiedenen ISI variiert.

\subsubsection{Ergebnisse}

Entgegen den Erwartungen ließen sich keine Vorteile der auditiven Hinweisreize bezüglich der (Wahl-)Reaktionszeit in Experiment 2 feststellen, selbst wenn die Darbietungsdauer der beiden Hinweisreizarten gleich und die subjektiven Intensitäten der beiden Hinweisreize einigermaßen angeglichen waren. Im Gegenteil, es wurde in Experiment 2 sogar schneller auf die visuellen Hinweisreize reagiert als auf die auditiven. Die Abbildung 12 stellt die über alle Bedingungskombinationen hinweg ermittelten (overall) Wahlreaktionszeiten für jede Hinweisreizart dar.

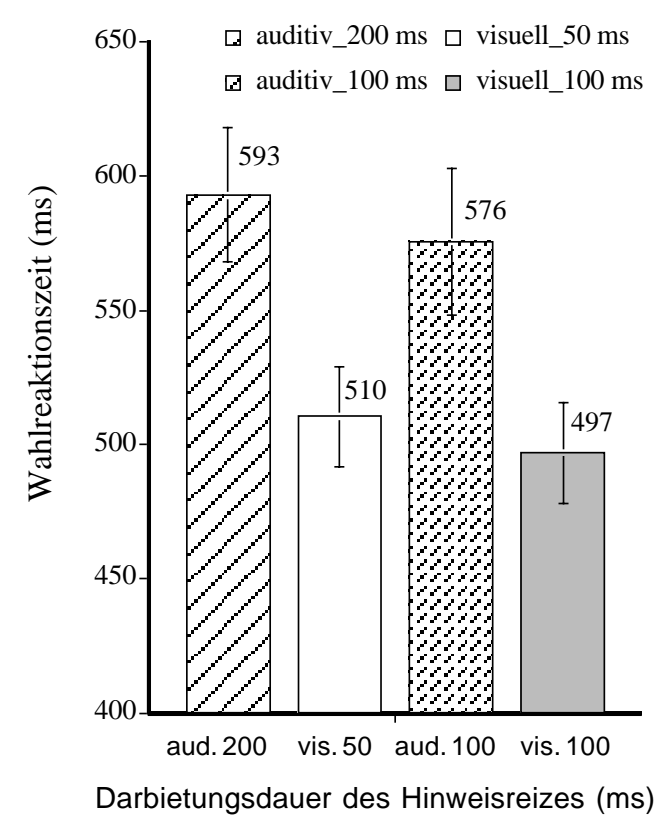

Abbildung 12: Mittelwerte und Standardfehler der Wahlreaktionszeiten für jede Hinweisreizart (über Berichtsarten und ISI-Bedingungen hinweg) in Experiment 2. 
Die Wahlreaktionszeiten auf die visuellen und auditiven Hinweisreize, die auch in Experiment 1 verwendet wurden, wiesen einen signifikanten Unterschied auf $[t(23)=4.37, p<$ $.001, \varepsilon=1.52]$. Das als idealer erwartete neue Hinweisreizpaar unterschied sich hinsichtlich der Wahlreaktionszeit ebenfalls voneinander $[t(23)=5.92, p<.001, \varepsilon=3.71]$. Für visuelle Hinweisreize zeigte sich immer eine signifikant kürzere Wahlreaktionszeit. Insgesamt gesehen ergaben intermodale Vergleiche signifikante Unterschiede, aber intramodal unterschieden sich die Wahlreaktionszeiten nicht (s. Tabelle 3).

Tabelle 3. Ergebnisse der inter- und intramodalen Mittelwertsvergleiche zwischen den Wahlreaktionszeiten in den auditiven und den visuellen Hinweisreizbedingungen mit verschiedener Darbietungsdauer in Experiment 2

\begin{tabular}{|c|c|c|c|c|c|c|c|}
\hline \multirow{2}{*}{ Vergleich } & \multicolumn{4}{|c|}{ Hinweisreiz } & \multirow[b]{2}{*}{$t$} & \multirow[b]{2}{*}{$p$} & \multirow[b]{2}{*}{$\varepsilon$} \\
\hline & $M$ & $S D$ & $M$ & $S D$ & & & \\
\hline \multirow[t]{8}{*}{ intermodal } & \multicolumn{2}{|c|}{ aud. $200 \mathrm{~ms}$} & \multicolumn{2}{|c|}{ vis. $50 \mathrm{~ms}$} & & & \\
\hline & 593.06 & 121.87 & 510.45 & 91.45 & 4.37 & .000 & 1.52 \\
\hline & \multicolumn{2}{|c|}{ aud. $100 \mathrm{~ms}$} & \multicolumn{2}{|c|}{ vis. $100 \mathrm{~ms}$} & & & \\
\hline & 575.51 & 132.72 & 496.93 & 92.00 & 5.92 & .000 & 3.71 \\
\hline & \multicolumn{2}{|c|}{ aud. $200 \mathrm{~ms}$} & \multicolumn{2}{|c|}{ vis. $100 \mathrm{~ms}$} & & & \\
\hline & 593.06 & 121.87 & 496.93 & 92.00 & 5.40 & .000 & 2.01 \\
\hline & \multicolumn{2}{|c|}{ aud. $100 \mathrm{~ms}$} & \multicolumn{2}{|c|}{ vis. $50 \mathrm{~ms}$} & & & \\
\hline & 575.51 & 132.72 & 510.45 & 91.45 & 3.39 & .002 & 1.28 \\
\hline \multicolumn{8}{|l|}{ intramodal } \\
\hline & \multicolumn{2}{|c|}{ aud. $200 \mathrm{~ms}$} & \multicolumn{2}{|c|}{ aud. $100 \mathrm{~ms}$} & & & \\
\hline & 593.06 & 121.87 & 575.51 & 132.72 & 0.86 & .399 & 0.32 \\
\hline & \multicolumn{2}{|c|}{ vis. $100 \mathrm{~ms}$} & \multicolumn{2}{|c|}{ vis. $50 \mathrm{~ms}$} & & & \\
\hline & 496.93 & 92.00 & 510.45 & 91.45 & -1.31 & .204 & -0.68 \\
\hline
\end{tabular}

Anmerkungen. M: Mittelwert, SD: Standardabweichung der Mittelwerte, $\varepsilon$ : Effektgröße.

aud.: auditiv, vis.: visuell.

Da es auch möglich ist, dass die Wahlreaktionszeit in Abhängigkeit vom ISI bzw. der Berichtsart (Ganzbericht vs. Teilbericht) variiert, wurden die Daten noch differenzierter betrachtet. Abbildung 13a und Abbildung 13b veranschaulichen die mittleren Wahlreaktionszeiten für den Ganzbericht und den Teilbericht. Für den Teilbericht wurden die Wahlreaktionszeiten noch als eine Funktion des ISI betrachtet. 


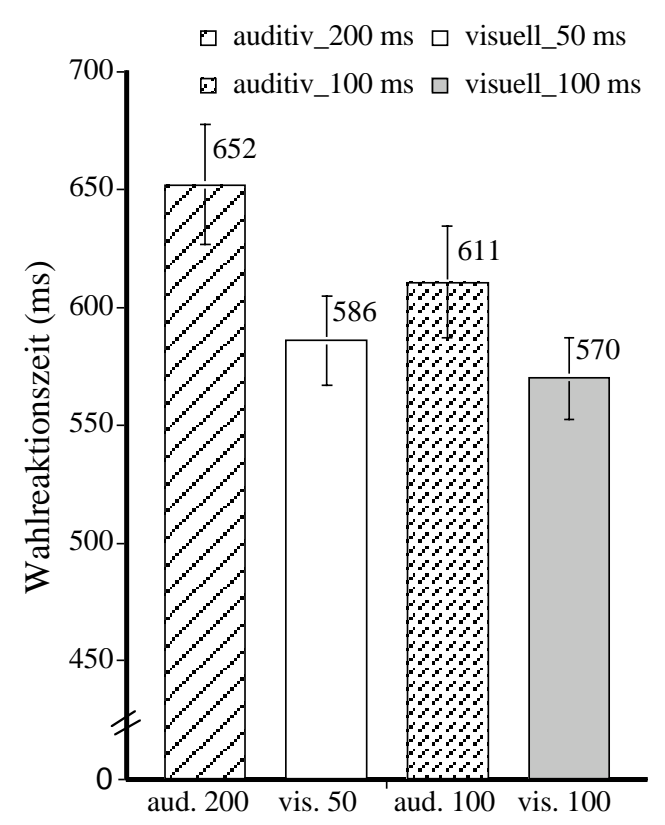

a Darbietungsdauer des Hinweisreizes (ms)

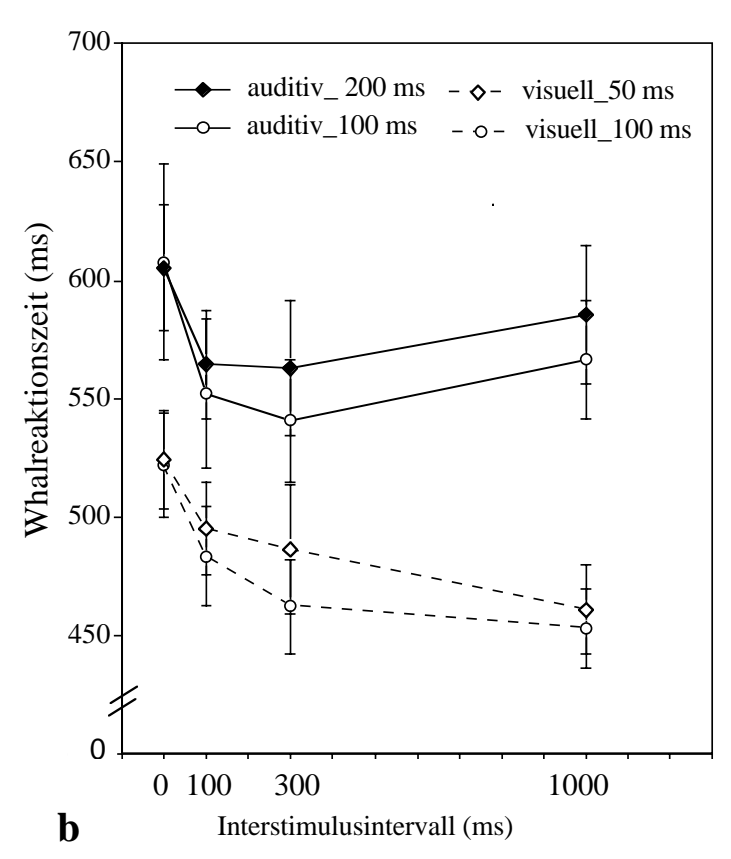

Abbildung 13: Mittelwerte und Standardfehler der Wahlreaktionszeiten bei jeder Hinweisreizart in Experiment 2.

a: Beim Ganzbericht.

b: Beim Teilbericht als Funktion von ISI.

Eine zweifaktorielle MANOVA mit den Innersubjekt-Faktoren „Hinweisreizmodalität“ (zwei Stufen: visuell und auditiv) und „ISI“ (vier Stufen: 0, 100, 300, 1000 ms Bedingung) ergab bei den Daten aus der Teilberichtsbedingung einen hoch signifikanten Haupteffekt der „Hinweisreizmodalität“ $\left[F(3,21)=16.53, \Lambda(3,21)=.30, \mathrm{p}<.001, \eta^{2}=.70\right]$. Der Haupteffekt des Faktors „ISI“ war ebenfalls hoch signifikant $\left[\mathrm{F}(3,21)=16.28, \Lambda(3,21)=.30, \mathrm{p}<.001 \eta^{2}=.70\right]$. Die Wahlreaktionszeit schien in Abhängigkeit vom ISI zu variieren, eine Wechselwirkung zwischen „Hinweisreizmodalität“ und „ISI“ war aber nicht statistisch bedeutsam $[\mathrm{F}(9,15)=$ $\left.2.01, \Lambda(9,15)=.45, \mathrm{p}=0.111, \eta^{2}=.55\right]$.

Auch unter der differenzierteren Betrachtung nach Berichtsart und ISI zeigten sich sowohl beim Ganzbericht als auch beim Teilbericht signifikant kürzere Wahlreaktionszeiten auf den visuellen Hinweisreiz. Diese Differenz war nicht nur bei dem alten Hinweisreiz-Paar, sondern auch beim neuen Paar deutlich. Dieser Unterschied war in fast allen Bedingungen signifikant (s. Tabelle 4). 
Tabelle 4. Mittelwertsvergleiche der Wahlreaktionszeiten für jede Berichtsart und jede ISIBedingung in Experiment 2

\begin{tabular}{|c|c|c|c|c|c|c|c|c|}
\hline \multirow{3}{*}{ Berichtsart } & \multicolumn{6}{|c|}{ Hinweisreiz } & \multirow{3}{*}{$p$} & \multirow{3}{*}{$\varepsilon$} \\
\hline & ISI $^{\mathrm{a}}$ & \multicolumn{2}{|c|}{ auditiv (200 ms) } & \multicolumn{2}{|c|}{ visuell $(50 \mathrm{~ms})$} & \multirow[t]{2}{*}{$t$} & & \\
\hline & & $M$ & $S D$ & $M$ & $S D$ & & & \\
\hline Ganzbericht & 0 & 652.48 & 125.56 & 586.22 & 93.05 & 2.86 & .009 & 0.82 \\
\hline \multirow[t]{6}{*}{ Teilbericht } & 0 & 605.19 & 129.79 & 524.52 & 101.44 & 3.37 & .003 & 0.98 \\
\hline & 100 & 564.44 & 111.40 & 495.34 & 96.31 & 4.07 & $<.001$ & 1.49 \\
\hline & 300 & 562.76 & 138.92 & 486.43 & 133.37 & 2.64 & .015 & 0.73 \\
\hline & 1000 & 585.34 & 142.58 & 461.07 & 91.28 & 5.31 & $<.001$ & 1.71 \\
\hline & & \multicolumn{2}{|c|}{ auditiv $(100 \mathrm{~ms})$} & \multicolumn{2}{|c|}{ visuell $(100 \mathrm{~ms})$} & & & \\
\hline & & $M$ & $S D$ & $M$ & $S D$ & & & \\
\hline Ganzbericht & 0 & 610.80 & 116.03 & 570.21 & 84.64 & 3.51 & .002 & 2.13 \\
\hline \multirow[t]{4}{*}{ Teilbericht } & 0 & 607.72 & 202.24 & 522.07 & 108.07 & 3.36 & .003 & 1.74 \\
\hline & 100 & 552.03 & 154.59 & 483.62 & 102.67 & 3.64 & .001 & 1.74 \\
\hline & 300 & 540.69 & 125.86 & 462.43 & 97.84 & 4.18 & $<.001$ & 1.53 \\
\hline & 1000 & 566.48 & 122.41 & 453.22 & 81.37 & 7.84 & $<.001$ & 3.92 \\
\hline
\end{tabular}

Anmerkungen. M: Mittelwert, SD: Standardabweichung der Mittelwerte, $\varepsilon$ : Effektgröße.

${ }^{\mathrm{a}}$ Interstimulusintervall in $\mathrm{ms}$.

\subsubsection{Diskussion}

Die Hypothese, dass die Pbn in dem experimentellen Design schneller auf die auditiven Hinweisreize reagieren können als auf die visuellen, konnte durch die vorliegenden Ergebnisse aus Experiment 2 nicht bestätigt werden. Nach den Ergebnissen hätten die Pbn in Experiment 1 im Durchschnitt sogar schneller auf den visuellen Hinweisreiz als auf den auditiven Hinweisreiz reagieren müssen. Dies kann an den spezifischen Reizkonstellationen des Experiments liegen. Viele andere Faktoren, die auf die Reaktionszeit einen Einfluss haben können, könnten die Leistung so stark beeinflusst haben, dass der nachgewiesene Vorteil für auditive Signale nicht zum Vorschein kommen konnte. Aber das Anliegen des Experiments 2 war es, herauszufinden, ob der Leistungsunterschied, oder besser gesagt: die Leistungsüberlegenheit der auditiven Hinweisreizbedingung, durch einen Unterschied der Wahlreaktionszeiten auf die beiden Arten von Hinweisreizen erklärt werden kann, d.h., ob die Pbn den auditiven Hinweisreiz schneller als den visuellen verarbeiteten, so dass sie mehr Zeit für die Verarbeitung des erfragten Reizmaterials hatten und somit bessere Leistung erbringen konnten. Ein Zeitvorteil für auditive Hinweisreize konnte aber nicht nachgewiesen werden. Die Annahme in Bezug auf einen Reaktionszeitvorteil des auditiven Hinweisreizes als Erklärung 
für den gefundenen Leistungsunterschied in Experiment 1 muss folglich zurückgewiesen werden. Die Suche nach einem ,idealen“ Hinweisreizpaar, um einen möglichen Zeitunterschied in Bezug auf die Reaktionszeit zu kompensieren und damit den gefundenen Leistungsunterschied eventuell eliminieren zu können, erweist sich aufgrund der dargestellten Ergebnisse nicht mehr als sinnvoll.

\subsection{Aufmerksamkeitsverschiebung als Erklärung des Modalitätseffekts}

Bevor man den Leistungsunterschied der beiden Hinweisreizbedingungen in Experiment 1 als Modalitätseffekt im engeren Sinne bezeichnen kann, muss eine weitere mögliche Erklärung überprüft werden. Modalitätseffekt im engeren Sinne soll bedeuten, dass die Modalität per se die Ursache ist, d.h., ein Effekt allein durch die Beteiligung von unterschiedlichen Modalitäten entsteht, und nicht etwa durch Variation innerhalb einer Modalität. Es stellt sich die Frage, ob der Leistungsunterschied in Experiment 1 möglicherweise durch ein methodisches Artefakt, d.h. durch gewisse Merkmale des visuellen Hinweisreizes, zustande gekommen sein kann, z.B. durch die Größe oder die Position des Hinweisreizes. Eine häufig intuitiv vorgebrachte Kritik zu dem experimentellen Design des Experiments 1 ist die seitliche Platzierung der visuellen Hinweisreize. Es könnte nämlich Folgendes angenommen werden: Die ungünstige Platzierung des visuellen Hinweisreizes in Experiment 1 verursachte eine Aufmerksamkeitsverschiebung, die Aufmerksamkeitsverschiebung benötigte Zeit, und dies ging auf Kosten der Verarbeitungszeit der Reizvorlage, so dass unter der visuellen Hinweisreizbedingung die Reizvorlage schlechter (weniger) verarbeitet wurde.

$\mathrm{Ob}$ das ikonische Gedächtnis als aufmerksamkeitsabhängiger Prozess zu betrachten ist, wird später in der Arbeit noch ausführlicher diskutiert werden. Allein aufgrund der Tatsache, dass die tachistoskopische Aufgabe (in moderner Version in der aktuellen Untersuchung) eine hohe Konzentration erfordert, scheint es für die vorliegende Arbeit unabdingbar, sich auch mit den Theorien der Aufmerksamkeit auseinanderzusetzen. Im weiteren Verlauf der Arbeit wird das Thema der Aufmerksamkeit noch eingehend behandelt. Zunächst werden jedoch die allgemeinen psychologischen Theorien der visuellen Aufmerksamkeit bzw. der Aufmerksamkeitsverschiebung in Betracht gezogen.

\subsubsection{Theorien der visuellen Aufmerksamkeitsverschiebung}

„Aufmerksamkeit“" wird oft als Zuweisung von Ressourcen betrachtet. Die visuelle Aufmerksamkeit richtet sich auf eine Lokalität, diese Lokalität hat eine eingeschränkte Ausdehnung. Nach Erikson und Mitarbeitern (Erikson \& Hofman, 1972, 1973; Erikson \& 
Erikson, 1974) existiert ein Aufmerksamkeitsfokus, dessen räumliche Ausdehnung ca. 0.5-1 Sehwinkelgrad beträgt. Diese visuelle Aufmerksamkeit kann im Sinne der Spotlight-Metapher nicht auf zwei örtlich getrennte Objekte aufgespalten werden (Posner, Snyder \& Davidson, 1980). Zwei räumlich voneinander getrennte Objekte können also innerhalb der visuellen Modalität nicht gleichzeitig fokussiert werden. Um einen zweiten Reiz fokussieren zu können, muss die Aufmerksamkeit verschoben werden.

Über die Verschiebung der Aufmerksamkeit von einem zum anderen Ort gibt es verschiedene Modelle. Tatsächlich ist die Aufmerksamkeitsverschiebung vielleicht das umstrittenste Thema neben den Diskussionen über den Umfang, die Intensität des Aufmerksamkeitsbereichs und die Dauer der Aufmerksamkeit in der Aufmerksamkeitsforschung (vgl. LaBerge, 1995). Worüber man sich in den Modellvorstellungen noch uneinig ist, ist die Frage, ob die Verschiebung der Aufmerksamkeit „kontinuierlich“ oder „,diskret““ (s. Yantis, 1998) erfolgt. Ein „kontinuierliches“ Modell wie die Spotlight-Metapher betrachtet die Aufmerksamkeitsverschiebung als eine kontinuierliche Bewegung von einer Lokalisation zu der nächsten, als ob sie wie ein Scheinwerfer über die Oberflächen schweift. Diese Sichtweise steht im Gegensatz zu einem Gradienten- oder ZoomModell (z.B. Eriksen \& St. James, 1986). Für diese Modelle wird nicht die Lokalisation, sondern die Größe des Aufmerksamkeitsfokus kontinuierlich verändert, während sich die Lokalisation der Aufmerksamkeit diskontinuierlich ändern kann. Trotz der Uneinigkeit zwischen den Modellen scheint eine neue Orientierung der Aufmerksamkeit jedenfalls Zeit zu kosten. Die Zeit, die benötigt wird, um die Richtung des Aufmerksamkeitswechsels zu bestimmen und die Aufmerksamkeitsbewegung zu initiieren, wurde von Tsal (1983) mit $50 \mathrm{~ms}$ geschätzt. Nach Eriksen und St. James (1986) beansprucht die Orientierung der Aufmerksamkeit auf eine visuelle periphere Stelle und die Einstellung der Fokusgröße ca. 100 ms. Im Sinne einer kontinuierlichen Scheinwerfer-Hypothese ist die für die Aufmerksamkeitsverschiebung benötigte Zeit abhängig von der Entfernung zwischen zwei Stellen (Eriksen \& Schultz, 1977). ${ }^{10}$ Tsal (1983) kam zu einer konstanten Geschwindigkeit des Aufmerksamkeitswechsels, die ca. $1^{\circ}$ (Sehwinkelgrad) pro $8 \mathrm{~ms}$ beträgt. Während der Aufmerksamkeitsverschiebung kann nur wenig Information verarbeitet werden (ebd.). Bei fokussierter Aufmerksamkeitsausrichtung sollen wenige oder gar keine Ressourcen für die Verarbeitung anderer Lokalisationen übrig sein (Erikson \& Yeh, 1985).

\footnotetext{
${ }^{10}$ Allerdings kamen Remington und Pierce (1984) in ihrem Experiment zu der entgegengesetzten Schlussfolgerung, dass die für die Aufmerksamkeitsverschiebung benötigte Zeit nicht von der zu überquerenden Distanz abhängig wäre.
} 


\subsubsection{Experiment 3 zur Prüfung von Hypothesen zur Aufmerksamkeitsverschiebung}

Dem kontinuierlichen Scheinwerfer-Modell folgend geht man in Experiment 3 zunächst davon aus, dass die visuelle Aufmerksamkeitsverschiebung Zeit benötigt und die benötigte Zeit von der Entfernung abhängig ist. Auf das Experiment 1 übertragen kann man die Matrix und den Pfeil (oder die Pfeile) als zwei fast zeitgleich oder kurz aufeinander folgende visuelle Reize betrachten. Ein visuell peripher dargebotener Reiz induziert eine reflexartige Aufmerksamkeitsausrichtung im Sinne von exogener Aufmerksamkeit (s. Posner, 1980; Jonides, 1981; Müller \& Rabbitt, 1989), die nicht willentlich kontrollierbar ist. Die Distanz zwischen dem/den Pfeil(en) und der Mitte des Fixationskreuzes hatte einen Sehwinkel von 2,15 , d.h., die Pfeile in Experiment 1 lagen außerhalb des Aufmerksamkeitsfokus um den Fixationspunkt herum. Unter der Bedingung mit visuellen Hinweisreizen müsste nach der Theorie ein Aufmerksamkeitswechsel von dem Fixationspunkt zu dem Pfeil, bzw. den Pfeilen hin stattfinden. Da der Wechsel oder die Verschiebung Zeit benötigte, und da während der Verschiebung keine Verarbeitung für die Matrix möglich war, könnte ein Leistungsnachteil entstanden sein. Somit lautet die Frage hier: Ist der in Experiment 1 beobachtete Leistungsunterschied auf einen Zeitverlust durch die Aufmerksamkeitsverschiebung aufgrund der ungünstigen Platzierung des visuellen Hinweisreizes zurückzuführen?

Um diese Erklärungsmöglichkeit zu überprüfen, wurden in einem neuen Experiment Dreiecke in der Mitte der Matrix (horizontale Ausrichtung, s. Abb. 13) als visuelle Hinweisreize verwendet. Es wurde erwartet, dass unter Verwendung mittig platzierter Dreiecke als visuelle Hinweisreize der Leistungsunterschied gegenüber den Bedingungen mit auditiven Hinweisreizen reduziert wird oder gar verschwindet.

Es ist zwar nicht klar, ob hier ebenfalls eine Aufmerksamkeitsverschiebung auf die neuen visuellen Hinweisreize stattfindet, aber selbst wenn dieser Fall eintrifft, fällt die Distanz zur Mitte des Fixationspunktes kleiner aus als im Fall mit links platzierten Pfeilen. ${ }^{11}$ Das bedeutet dann, dass für die Aufmerksamkeitsverschiebung weniger Zeit benötigt werden soll und dass dann eine Leistungsverbesserung im Vergleich zu der Pfeile-Bedingung zu erwarten ist. Damit müsste auch der Leistungsunterschied reduziert werden.

\subsubsection{Methode}

Probanden. 24 Studierende nahmen an dem Experiment teil. Das Durchschnittsalter der Stichprobe lag bei 23.8 Jahren (Range 20-30, SD = 2.65).

\footnotetext{
${ }^{11}$ Eigentlich wird hier im Vergleich zu Experiment 1 nicht nur die physikalische Distanz zur Matrix, sondern auch die Größe des Hinweisreizes geändert.
} 
Apparate und Versuchsraum. Die Apparaturen und der Versuchsraum waren die gleichen wie in Experiment 1.

Versuchsmaterial. Das Material entsprach Experiment 1, aber als visuelle Hinweisreize wurden ein Dreieck für den Teilbericht (oben oder unten) und zwei Dreiecke für den Ganzbericht verwendet. Mit einer Distanz von $60 \mathrm{~cm}$ von dem/der Pb aus betrachtet hatte das Dreieck ein horizontales Maß von $0.47^{\circ}$ und ein vertikales Maß von $0.24^{\circ}$. Die Distanz von der Eckspitze zu der Matrix-Mitte betrug $1.05^{\circ}$ und die von der Basisseite zur Matrix-Mitte $1.34^{\circ}$. Die Distanz zwischen den beiden Dreiecken betrug $2.20^{\circ}$ bzw. $2.72^{\circ}$ (Abb. 14).
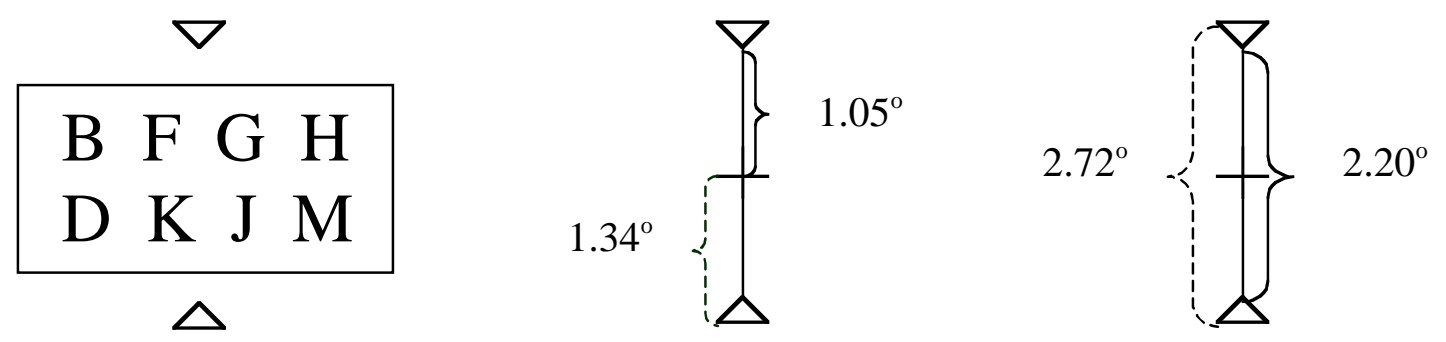

Abbildung 14: Die Maß- und Distanzangaben der visuellen Hinweisreize in Experiment 3.

Aufgabenanforderung und Versuchsablauf. Der Versuch hatte den gleichen Ablauf wie Experiment 1. Jedoch wurden anstelle der Pfeile Dreiecke als visuelle Hinweisreize verwendet. Der visuelle Hinweisreiz wurde für $50 \mathrm{~ms}$ dargeboten. Erschien das Dreieck oberhalb der Matrix, sollte lediglich die obere Zeile der Matrix wiedergegeben werden. Ein unterhalb der Matrix erscheinendes Dreieck war das Signal für die Reproduktion der unteren Zeile. Erschienen die zwei Dreiecke gemeinsam, dann sollten alle Items reproduziert werden (Ganzbericht). In der Teilberichtsbedingung wurde das ISI zwischen 0, 100, 300 oder $1000 \mathrm{~ms}$ variiert. Beim Ganzbericht betrug das ISI immer 0 ms. Alle Bedingungskombinationen wurden beim experimentellen Programm durch den Computer per Zufall generiert.

Design und Versuchsdurchführung. Das Experiment wurde nach den Hinweisreizarten in zwei Teilversuche eingeteilt. Die Reihenfolge der auditiven und visuellen Teilversuche wurde permutiert. Jeder Teilversuch bestand aus 20 Übungsdurchgängen und 120 Testdurchgängen zu je vier Blöcken à 30 Durchgängen, so dass jeder/jede $\mathrm{Pb}$ insgesamt 240 Durchgänge absolvieren musste.

\subsubsection{Ergebnisse}

Die Ergebnisse von Experiment 3 werden in der Abbildung 15a und 15b veranschaulicht. Die Ergebnisse zeigten sowohl bei den Ganz- als auch bei den Teilberichtsbedingungen wieder 
fast überall schlechtere Leistungen unter der Verwendung visueller Hinweisreize, mit Ausnahme der Bedingung mit einem ISI von $0 \mathrm{~ms}$.
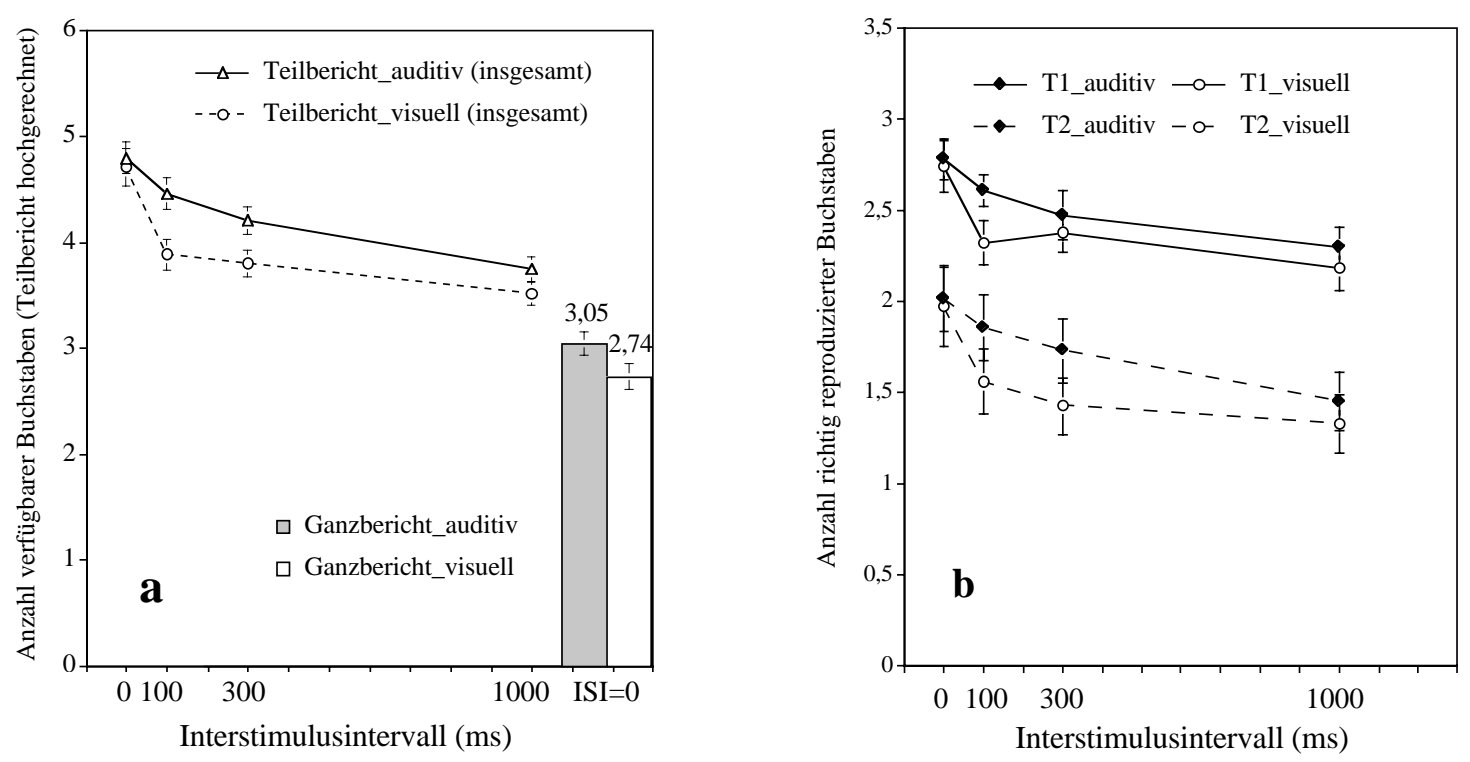

Abbildung 15: Ergebnisse in Experiment 3; dargestellt in Abhängigkeit von ISI und Hinweisreizart; $\mathrm{N}=24$.

a: Mittelwerte und Standardfehler für die Anzahl richtig reproduzierter Buchstaben im Ganzbericht und die Anzahl verfügbarer Buchstaben im Teilbericht (hochgerechnet auf der Grundlage der Anzahl korrekt reproduzierter Buchstaben). Das ISI zwischen dem Offset der Buchstabenmatrix und dem Onset des Hinweisreizes variierte in der Teilberichtsbedingung zwischen 0 und 1000 ms. Beim Ganzbericht betrug das ISI 0 ms.

b: Mittelwerte und Standardfehler für die Anzahl richtig reproduzierter Buchstaben im Teilbericht je Berichtsart und je ISI.

Eine dreifaktorielle MANOVA mit den Innersubjekt-Faktoren „Hinweisreizmodalität“, „Berichtsart“ und „ISI“ wurde mit den Daten aus den Teilberichtsbedingungen berechnet. Der erste Faktor „Hinweisreizmodalität“" war zweifach gestuft (auditiv und visuell). Der zweite Faktor „Berichtsart“ hatte ebenfalls zwei Stufen (Teilbericht 1: Reproduktion der oberen Zeile; Teilbericht 2: Reproduktion der unteren Zeile). Der Faktor „ISI“ hatte 4 Stufen, nämlich Bedingung ISI von 0, 100, 300 und 1000 ms. Für alle drei Faktoren ergab sich ein hoch signifikanter Haupteffekt. Neben dem klassischen Haupteffekt des ,ISI“ $[F(3,21)=21.36, \Lambda(3$, $\left.21)=.25, p<.001, \eta^{2}=0.75\right]$, dass die Reproduktionsleistung systematisch mit zunehmendem ISI abnahm, erwies sich die „Hinweisreizmodalität“ wieder als ein bedeutsamer Faktor $[F(1,23)$ $\left.=8.87, \Lambda(1,23)=.72, p=0.007<.05, \eta^{2}=0.28\right]$, weil eine schlechtere Wiedergabeleistung unter visuellen Hinweisreizen zu finden war. Der in Experiment 1 gefundene Zeileneffekt trat ebenfalls wieder auf, so dass die „Berichtsart“ sich wiederum als ein bedeutsamer Faktor herausstellte $\left[F(1,23)=28.28, \Lambda(1,23)=.45, p<.001, \eta^{2}=0.55\right]$. Wie aus Abbildung $15 \mathrm{~b}$ zu entnehmen ist, wurden im Teilbericht 1 (T1) eindeutig bessere Reproduktionsleistungen als im 
Teilbericht 2 (T2) erbracht. Numerisch ist der Leistungsunterschied zwischen den beiden Hinweisreizbedingungen bei Teilbericht 2 größer, aber die Interaktion von „Hinweisreizmodalität“ und „Berichtsart“ $\left[F(1,23)=0.36, \Lambda(1,23)=.98, p=0.533, \eta^{2}=0.02\right]$ war nicht bedeutsam. Es ergab sich in diesem Experiment auch keine signifikante Wechselwirkung von „Hinweisreizmodalität“ und „ISI“ $[F(3,21)=1.77, \Lambda(3,21)=.80, p=$ 0.184, $\left.\eta^{2}=0.20\right]$. Ebenfalls waren die Wechselwirkung zwischen „Berichtart“ und „ISI“ [F (3, 21) $\left.=0.38, \Lambda(3,21)=.95, p=0.770, \eta^{2}=0.051\right]$ sowie die Interaktion zwischen den drei Faktoren $\left[F(3,21)=0.58, \Lambda(3,21)=.92, \mathrm{p}=0.636, \eta^{2}=0.08\right]$ nicht signifikant.

Wenn man die statistischen Testergebnisse (t-Test) der Einzelvergleiche, welche man der Tabelle 5 entnehmen kann, betrachtet, wiesen die Wiedergabeleistungen zwischen beiden Hinweisreizen wieder in fast allen Bedingungskombinationen einen signifikanten Unterschied auf. Die Leistung unter visueller Hinweisreizbedingung war signifikant schlechter.

Tabelle 5. Ergebnisse der Mittelwertsvergleiche zwischen den Leistungen in der auditiven und der visuellen Hinweisreizbedingung in den einzelnen Bedingungskombinationen in Experiment 3

\begin{tabular}{|c|c|c|c|c|c|c|c|c|}
\hline \multirow{3}{*}{ Berichtsart } & \multirow{3}{*}{$\mathrm{ISI}^{\mathrm{a}}$} & \multicolumn{4}{|c|}{ Hinweisreiz } & \multirow{3}{*}{$t$} & \multirow{3}{*}{$p$} & \multirow{3}{*}{$\varepsilon$} \\
\hline & & \multicolumn{2}{|c|}{ auditiv } & \multicolumn{2}{|c|}{ visuell } & & & \\
\hline & & $M$ & $S D$ & $M$ & $S D$ & & & \\
\hline Ganzbericht & 0 & 3.05 & 0.56 & 2.74 & 0.59 & 3.59 & .002 & 1.43 \\
\hline \multirow[t]{4}{*}{ Teilbericht $^{\mathrm{b}}$} & 0 & 4.79 & 1.27 & 4.71 & 1.61 & 0.38 & .705 & 0.16 \\
\hline & 100 & 4.45 & 1.17 & 3.88 & 1.21 & 3.45 & .002 & 1.45 \\
\hline & 300 & 4.20 & 1.15 & 3.80 & 1.03 & 3.12 & .005 & 1.56 \\
\hline & 1000 & 3.74 & 0.87 & 3.51 & 1.00 & 1.72 & .100 & 0.70 \\
\hline \multirow[t]{4}{*}{ Teilbericht 1} & 0 & 2.78 & 0.55 & 2.74 & 0.68 & 0.37 & .717 & 0.13 \\
\hline & 100 & 2.60 & 0.42 & 2.32 & 0.59 & 2.82 & .010 & 0.88 \\
\hline & 300 & 2.47 & 0.67 & 2.37 & 0.53 & 0.89 & .383 & 0.28 \\
\hline & 1000 & 2.30 & 0.53 & 2.18 & 0.61 & 1.15 & .260 & 0.40 \\
\hline \multirow[t]{4}{*}{ Teilbericht 2} & 0 & 2.01 & 0.89 & 1.97 & 1.05 & 0.33 & .741 & 0.15 \\
\hline & 100 & 1.85 & 0.89 & 1.56 & 0.86 & 2.34 & .028 & 0.97 \\
\hline & 300 & 1.73 & 0.87 & 1.42 & 0.77 & 3.14 & .005 & 1.59 \\
\hline & 1000 & 1.45 & 0.78 & 1.33 & 0.78 & 1.13 & .271 & 0.48 \\
\hline
\end{tabular}

Anmerkungen. $M$ : Mittelwert, $S D$ : Standardabweichung der Mittelwerte, $\varepsilon$ : Effektgröße.

${ }^{\mathrm{a}}$ Interstimulusintervall in ms.

${ }^{\mathrm{b}}$ Hochgerechnete Teilberichtsleistung.

Teilbericht 1: Reproduktion der oberen Zeile.

Teilbericht 2: Reproduktion der unteren Zeile.

Der Vergleich zwischen den beiden Hinweisreizbedingungen beim Ganzbericht ergab eine signifikant bessere Leistung für die auditive Hinweisreizbedingung $[t(23)=3.59, p=.002<.05$, 
$\varepsilon=1.43]$. Betrachtet man alle Teilberichtsbedingungen gemeinsam, d.h. aus Teilbericht 1 und Teilbericht 2 zusammen ermittelt, zeigte sich ein signifikanter Nachteil des visuellen Hinweisreizes bei den ISI-100-ms- und ISI-300-ms-Bedingungen, und bei ISI-1000-msBedingung ist der Unterschied auf einem $10 \%$-Niveau signifikant. Ausgenommen von diesem Trend bleibt die Bedingung mit ISI = 0. Das ist ein Phänomen, das bereits in Experiment 1 beobachtet worden ist. Es scheint sich dabei also um ein relativ stabiles Phänomen zu handeln.

\subsubsection{Diskussion}

Die Veränderung des visuellen Hinweisreizes in Experiment 3 hat den Leistungsunterschied zur auditiven Hinweisreizbedingung nicht kompensieren können. Hier zeigt sich wie in Experiment 1 nach wie vor ein Leistungsnachteil für die visuelle Hinweisreizbedingung. Es sieht so aus, als ob die Platzierung, die Größe sowie die physikalische Distanz des visuellen Hinweisreizes zum Aufmerksamkeitsfokus keinen bedeutsamen Einfluss auf die Leistung in den durchgeführten Experimenten haben, obwohl es ebenfalls Hinweise in der Literatur gibt (z.B. Henderson, 1991), wonach die Größe der peripheren visuellen Hinweisreize einen Aufmerksamkeitseffekt haben könnte. ${ }^{12}$ Demzufolge müssten in diesem Fall auch bessere Leistungen durch einen größeren visuellen Hinweisreiz zu erwarten sein. Dennoch blieb der Leistungsnachteil im Vergleich zu der auditiven Hinweisreizbedingung nach wie vor bestehen. Die aufgestellte Hypothese hat sich somit nicht bestätigt. Der Vergleich der Effektgrößen der „Hinweisreizmodalität“ in Experiment 1 und 3 (s. Tabelle 3 und Tabelle 5) ergab keinen klaren Hinweis auf eine Reduzierung des Effektes, bei der Ganzberichtsbedingung ist beispielsweise der Effekt in Experiment $3(\varepsilon=1.43)$ sogar größer als in Experiment $1(\varepsilon=0.86)$. Die ähnlich stark gebliebenen Effekte, nämlich die Leistungsunterschiede zwischen den „neuen“ visuellen und den ,alten“ auditiven Hinweisreizbedingungen sprechen nicht für eine graduelle Veränderung, daher wurde auf weitere statistische Vergleiche zwischen den „,neuen“ (Dreieck) und den ,,alten“ (Pfeil) visuellen Hinweisreizbedingungen verzichtet. Man könnte in der Tat die visuellen Hinweisreize auch anders, oder sozusagen „besser“ (durch andersartige visuelle Symbolisierung) manipulieren, jedoch scheint sich der Leistungsunterschied nicht durch äußere Merkmale oder Eigenschaften des visuellen Hinweisreizes erklären zu lassen. Die Ergebnisse in Experiment 3 sind ein Hinweis darauf, dass der festgestellte Leistungsunterschied in Experiment 1 kein methodisches Artefakt war, d.h., künstlich durch ein unglückliches experimentelles Design bzw. durch die experimentelle Programm-Konstruktion eingeführt wurde, sondern dass es sich

\footnotetext{
${ }^{12}$ Je größer der Cue (Hinweisreiz) ist, desto größer ist die Erleichterung für die ge-cue-te Position und desto größer ist die Hemmung für die nicht ge-cue-te Position (Henderson, 1991).
} 
hier wahrscheinlich um einen stabilen, auf die Beteiligung unterschiedlicher Modalitäten zurückführbaren Effekt handelt. Darauf wird gleich eingegangen.

\subsection{Intramodale Interferenz als Erklärung des Modalitätseffekts}

Nachdem durch Experiment 2 und 3 weitgehend ausgeschlossen werden konnte, dass der festgestellte Leistungsunterschied der beiden Hinweisreizbedingungen durch modalitätsspezifische und physikalische Eigenschaften erklärt werden kann, bleibt anzunehmen, dass der Leistungsunterschied in Experiment 1 und 3 allein durch die Tatsache bedingt sei, dass die visuellen Hinweisreize ebenfalls aus derselben Modalität wie die visuelle Vorlage stammen. Somit stellte sich die Frage: Geht der Modalitätseffekt in den Experimenten 1 und 3 auf einen intramodalen Konflikt zurück? Oder anders formuliert: Wird die Verarbeitung der visuellen Matrix von der Verarbeitung des visuellen Hinweisreizes gestört?

\subsubsection{Theoretischer Hintergrund: Multiple-Ressourcen-Theorie (MRT)}

Im Vergleich zu anderen Aufmerksamkeitstheorien, wie z.B. „Engpass“-Theorien, StrukturTheorien und Ressourcen-Theorien, lässt sich der Ansatz der MRT von Navon und Gopher (1979) sowie Wickens (1992) als strukturorientierte Ressourcen-Theorie bezeichnen. Diese Theorie ist in der Vergangenheit vielfach kritisiert worden. Es gibt jedoch auch einige die Theorie stützende empirische Befunde, vor allem im Zusammenhang mit den Phänomenen bei der Bewältigung von Doppelaufgaben. Die offensichtliche Aufmerksamkeitslimitation bei Doppeltätigkeit wie auch beim PRP-Effekt ${ }^{13}$ wird unter anderem entweder durch Annahme eines Flaschenhalses, durch Überschneidung aufgrund der Ähnlichkeit oder Verwechselbarkeit der Aufgaben (cross talk), oder durch das Problem der Kapazitätsaufteilung bei der Informationsverarbeitung zu erklären versucht (s. Pashler \& Johnston, 1998). Die MRT zählt zu der letzten Kategorie, nämlich der Kapazitätstheorie. In diesem MRT-Ansatz wird nicht mehr von einer einzigen, sondern gleich von mehreren Ressourcen ausgegangen. Wickens (1992) hat die Ressourcen entlang dreier Dimensionen dichotom aufgeteilt: Je nachdem, in welcher Phase (stage) der Informationsverarbeitung, in welcher Modalität (modality) oder in welcher Kodierungsart (processing code) sich die Information befindet, gibt es spezifische Ressourcen (s. Abb. 16). Durch die Verknüpfungen verschiedener Merkmale zwischen den Dimensionen ergibt sich dann ein Satz unabhängiger, einander nicht überlappender Ressourcen,

\footnotetext{
${ }^{13}$ Psychological Refractory Period (PRP): psychologische Refraktärperiode. Wenn man auf zwei zeitlich dicht hintereinander folgende Reize reagieren soll, entsteht in Abhängigkeit von dem Zeitintervall zwischen den beiden Reizen eine Phase, während der man nach der ersten Reaktion nicht mehr auf den zweiten Reiz reagieren kann. Diese Phase bezeichnet man als psychologische Refraktärperiode.
} 
von denen jede durch eine Kombination von Stufen auf den drei zweistufigen Dimensionen definiert ist. Eine Ressource ist somit eine Verknüpfung von Verarbeitungsmerkmalen.

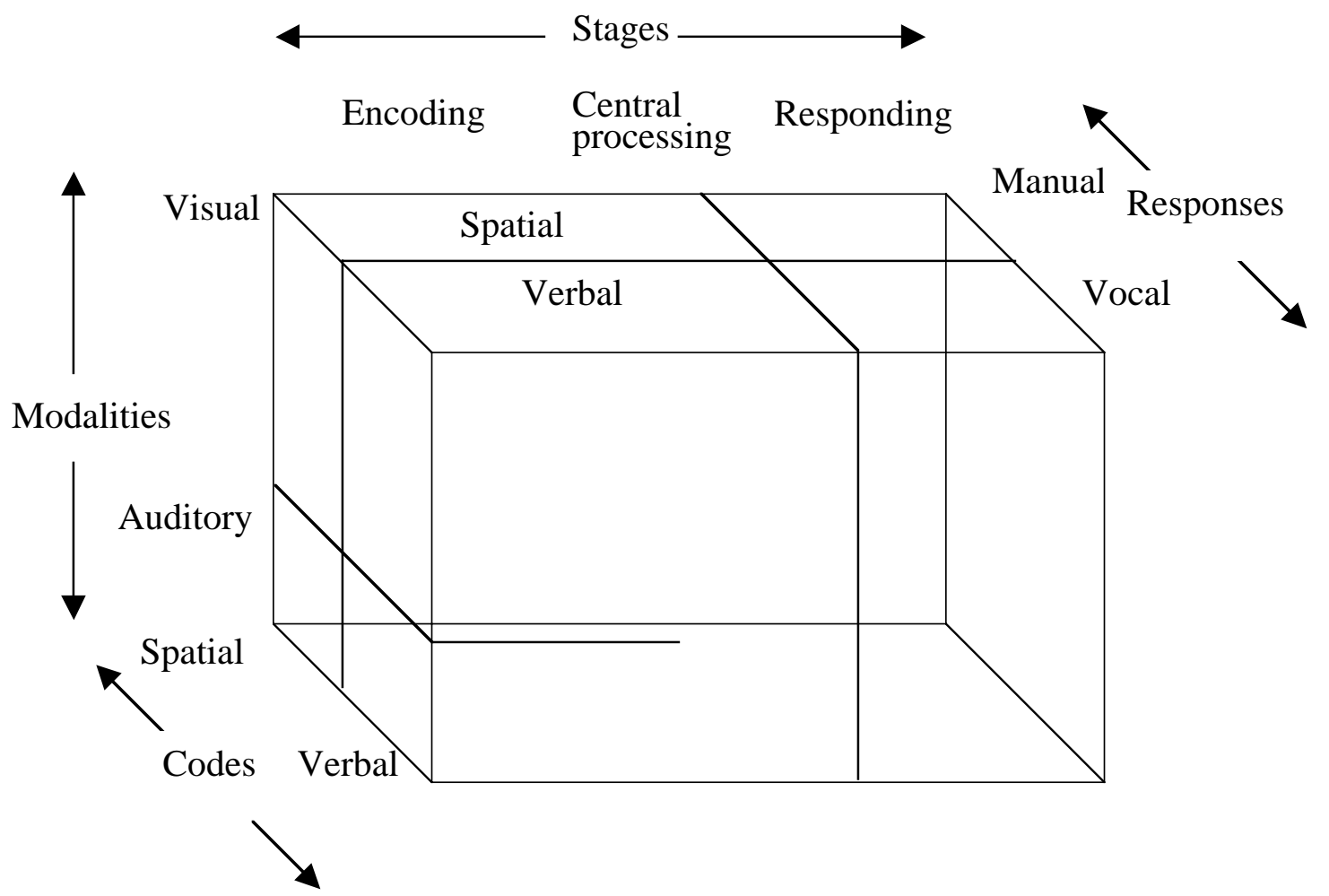

Abbildung 16: Postulierte Ressourcen-Struktur der Informationsverarbeitung in der MRT (Wickens, 1992, S. 375).

Wickens (1992) weist darauf hin, dass es zu Interferenz kommt, wenn Aufgaben nur in einem dieser Verarbeitungsmerkmale übereinstimmen, auch wenn sie sich auf den anderen Dimensionen unterscheiden. Eine Interferenz bei der Bearbeitung von Doppelaufgaben kann dadurch vermieden werden, dass unterschiedliche Modalitäten verwendet werden (ebd.).

Für die vorliegende Untersuchung ist vor allem die Modalitätsdimension von Interesse. Nach der MRT gilt: wenn zwei Aufgaben Ressourcen aus derselben Modalität beziehen, kommt es zu Interferenz.

\subsubsection{Experiment 4 zum echoischen Gedächtnis}

Die Aufgabenanforderungen in Experiment 1 und Experiment 3 stellten eine Art Doppelaufgabe dar, da einerseits der Matrixinhalt zu verarbeiten, und andererseits der Hinweisreiz $\mathrm{zu}$ registrieren und $\mathrm{zu}$ interpretieren war. Ausgehend von der MRT ist anzunehmen, dass bei Verwendung eines visuellen Hinweisreizes dieselbe Ressource wie zur Verarbeitung der visuellen Matrix beansprucht wurde. Dies führte zu einer ineffizienteren Verarbeitung des Matrixinhaltes und somit auch zu einer schlechteren Leistung im Vergleich 
zu der Bedingung mit auditiven Hinweisreizen, bei der unterschiedliche Ressourcen zur Bewältigung der Aufgabe verwendet wurden. Eine Erklärung für den Leistungsunterschied in den berichteten Experimenten könnte somit z.B. dies sein: Ein Ressourcen-Konflikt zwischen der Verarbeitung der visuellen Matrix und der Verarbeitung des visuellen Hinweisreizes führt zur Reduzierung der Ressourcen für die Verarbeitung der Matrix, was wiederum eine schlechtere Leistung zur Folge haben muss.

Zur Belegung dieser Annahme soll eine Situation geschaffen werden, in der eine Interferenz innerhalb der auditiven Modalität, aber nicht zwischen auditiver und visueller Modalität auftritt. Auf unseren Fall übertragen, wäre ein paralleles Design des SperlingParadigmas interessant, wenn eine auditiv dargebotene Buchstabenmatrix reproduziert werden soll, wobei der Hinweisreiz wiederum auditiv oder visuell sein kann. Unter dieser Bedingung müsste dann der MRT zufolge ein Ressourcenkonflikt zwischen den zu behaltenden auditiv dargebotenen Buchstaben und dem auditiven Hinweisreiz auftreten und dadurch eine schlechtere Leistung in der auditive Hinweisreizbedingung verursacht werden.

Vor der Vorstellung eines Experimentes, das diese Idee umsetzt, sollen zunächst einmal wichtige Sachverhalte zum sensorischen Behalten von kurz dargebotenen auditiven Reizen vorgestellt werden.

Exkurs: Echoisches Gedächtnis und einige einschlägige Untersuchungen

Wie visuelle Reize scheinen auch auditive Stimuli die eigentliche Existenz überdauern zu können. Für die Speicherung von sehr kurz dargebotener auditiver Information prägte Neisser (1967) den Begriff echoisches Gedächtnis (echoic memory). Für die Erforschung des echoischen Gedächtnisses gibt es ebenso verschiedene Methoden wie für die Untersuchung des ikonischen Gedächtnisses. Eine oft verwendete Forschungsmethode, vor allem im Zusammenhang mit auditiver Aufmerksamkeit, ist die „shadowing“-Aufgabe, also eine Aufgabe zum dichotischen Hören. Mit der shadowing-Methode ist auch die Anforderung einer Teilwiedergabe möglich, und so konnten auch die Existenz und die Dauer des echoischen Gedächtnisses mit dem PR-Verfahren nachgewiesen werden (Moray, Bates \& Barnett, 1965). Eines der bekanntesten Experimente zum echoischen Gedächtnis stammt von Darwin, Turvey und Crowder (1972). Sie haben das Teilberichtsverfahren von Sperling auf die auditive Modalität übertragen. In ihrem Experiment wurden den Pbn simultan drei Listen (Kolumnen) von Buchstaben und Zahlen über Stereo-Kopfhörer sehr schnell, in etwa einer Sekunde, vorgetragen. Dabei hörten sie gleichzeitig ein Item auf dem linken Ohr, ein zweites auf dem rechten Ohr und ein drittes auf beiden Ohren, was so klang, als ob der Ton von vorne kommen würde. Analog zu der Sperling-Aufgabe wurde als Ganzberichtsaufgabe gefordert, so viele 
Items wie möglich wiederzugeben. Bei der Teilberichtsbedingung sollten die Pbn die Items der drei Listen nennen, wobei die entsprechende Liste durch ein Licht von drei in einer Reihe stehenden Lichtern signalisiert wurde. Auch hier wurde also eine Art von visuellem Hinweisreiz verwendet. Die linken, mittleren und rechten Lichter wiesen die Pbn an, die Liste wiederzugeben, die sie zuvor von rechts, aus der Mitte und von links gehört hatten. Dieser visuelle Hinweisreiz wurde 0, 1, 2, 3 oder $4 \mathrm{~s}$ nach der Präsentation der auditiven Listen dargeboten. Wie bei Sperling zeigte sich eine Überlegenheit der Teilberichtsbedingung - auch wenn sie nur geringfügig war - gegenüber der Ganzberichtsbedingung, wenn das Intervall (ISI) 2 s nicht überstieg. Bei Intervallen mit $4 \mathrm{~s}$ ergab sich keine Überlegenheit mehr. Die Pbn konnten in der Ganzberichtsbedingung im Durchschnitt 4.3 Items korrekt reproduzieren, in der Teilberichtsbedingung 4.9. Diese kleine Überlegenheit war dennoch zuverlässig. Dieses Ergebnis wurde oft als Beleg dafür angesehen, dass ein auditives sensorisches Gedächtnis existiert. Es sieht also so aus, als ob das echoische Gedächtnis etwas länger andauert als das ikonische Gedächtnis.

Das Verfahren von Darwin et al. (1972) in Kombination mit dem Sperling-Paradigma zum ikonischen Gedächtnis bietet eine geeignete Methode zur Überprüfung der MRT. Damit kann auch überprüft werden, ob der Leistungsunterschied in berichteten Experimenten durch einen intramodalen Ressourcen-Konflikt zu erklären ist, und ob der Leistungsunterschied tatsächlich ein Modalitätseffekt ist.

Diesem Gedanken folgend wurde ein neues Experiment mit einem parallelen experimentellen Design zu Experiment 1 konstruiert. Eine imaginäre ,,auditive Matrix“ wurde statt der visuellen Matrix dargeboten und es wurde entweder ein auditiver oder ein visueller Hinweisreiz verwendet. Da der untersuchte Gegenstand das echoische Gedächtnis ist, dessen Dauer normalerweise auf 2-4 s geschätzt wird, wurde in dem Experiment ein maximales ISI von 4 s vorgesehen. Das ISI sollte zwischen 0, 1000 und 4000 ms variieren. Basierend auf der MRT wurde die Hypothese aufgestellt: Die Reproduktionsleistung in der auditiven Hinweisreizbedingung ist schlechter als in der visuellen Hinweisreizbedingung, wenn das in dem PR-Paradigma zu reproduzierende Reizmaterial auditiver Natur ist.

\subsubsection{Methode}

Probanden. 40 Psychologiestudierende nahmen an dem Experiment teil. Der Altersdurchschnitt lag bei 22.4 Jahren (Range 19-31, SD = 2.57).

Apparate. Zur Durchführung des Experiments wurde ein Powerbook (G3) eingesetzt. Ein externer Monitor und eine externe Tastatur für die Eingabe der Antwort wurden an das 
Powerbook angeschlossen. Ein Stereo-Kopfhörer Typ HD 414 der Marke SENNHEISER wurde verwendet.

Reizmaterial. 20 Konsonanten außer ,Y““ wurden von einer weiblichen Stimme klar artikuliert und mit dem SoundEdit ${ }^{\mathrm{TM}}$ 16, Version 2, aufgenommen. Das Soundformat der Einzelbuchstaben wurde so weit verarbeitet, dass die Aussprechzeit bei jedem Buchstaben ca. $150 \mathrm{~ms}$ betrug, wobei zugleich darauf geachtet wurde, dass die auditive Erkennbarkeit einzelner Buchstaben garantiert war. Das experimentelle Steuerungsprogramm wurde mit der Software PsyScope 1.25 geschrieben.

Ein kurzer Piepton als auditiver Hinweisreiz wurde über Kopfhörer ins linke Ohr, rechte Ohr oder in beide Ohren eingespielt. Als visuelle Hinweisreize dienten einmal ein links von dem (nicht mehr sichtbaren) Fixationskreuz platziertes Sternchen (*), einmal ein rechts platziertes Sternchen sowie zwei gemeinsam um dem Fixationskreuz herum erscheinende Sternchen auf dem Bildschirm.

Aufgabenanforderung und Versuchsablauf. Der Ablauf eines Durchgangs wird in Abbildung 17 dargestellt. Ein Durchgang begann mit dem Erscheinen eines Fixationskreuzes in der Bildschirmmitte. Durch Tastendruck wurde der Durchgang gestartet. In das linke und das rechte Ohr wurde dann gleichzeitig ein Konsonantenpaar über Kopfhörer eingespielt. Insgesamt wurden innerhalb einer Sekunde vier Paare hintereinander dargeboten. Nach einem ISI von entweder 0, 1000 oder $4000 \mathrm{~ms}$ folgte dann entweder der auditive oder der visuelle Hinweisreiz, um zu signalisieren, welche Buchstaben zu reproduzieren waren. Wenn der Ton in das linke (bzw. rechte) Ohr eingespielt wurde, sollten die vom linken (bzw. rechten) Ohr gehörten Buchstaben reproduziert werden. Wenn der Ton in beide Ohren eingespielt wurde, sollten von allen gehörten Konsonanten so viele wie möglich wiedergegeben werden (Ganzbericht). Schließlich sollte die Antwort per Tastatur eingegeben werden.

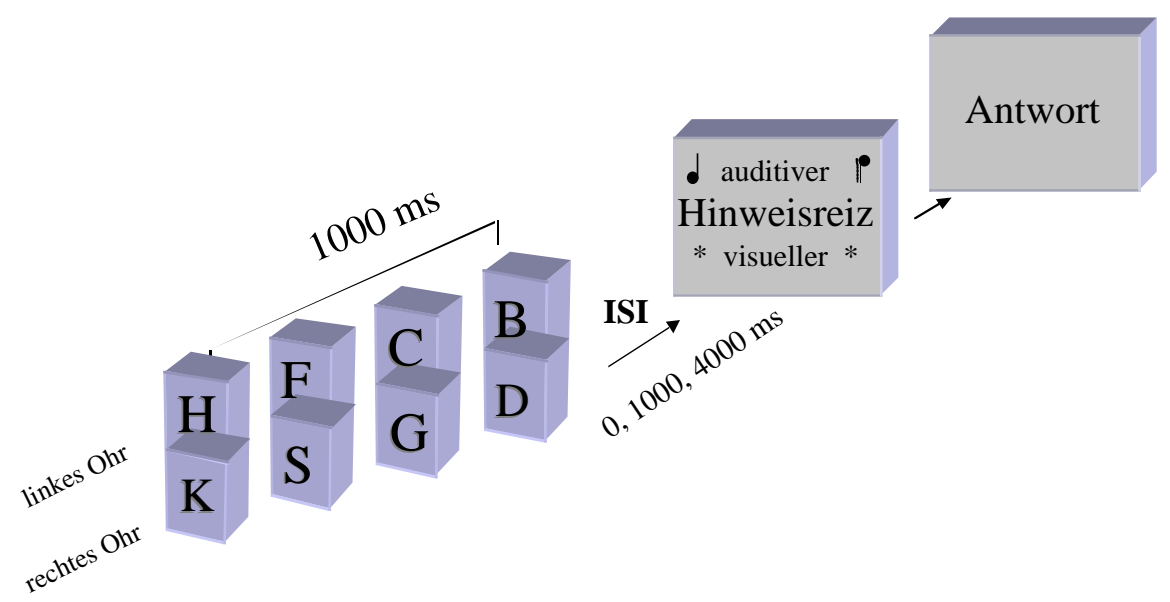

Abbildung 17: Ablauf eines Durchgangs in Experiment 4. 
Versuchsdurchführung. Eine Versuchssitzung dauerte ca. 45 Minuten. Der Versuch wurde in zwei Teilversuche eingeteilt. Analog zu Experiment 1 wurden in einem Teilversuch auditive Hinweisreize und in dem anderen visuelle Hinweisreize eingesetzt. Die Reihenfolge der Teilversuche wurde permutiert. Für jeden Teilversuch waren fünf Übungsdurchgänge vorgesehen. Ein Teilversuch bestand aus 40 Testdurchgängen. Die Abfolge der Durchgänge, in denen Ganzberichte oder Teilberichte mit verschiedenen ISI verlangt wurden, wurde per Zufall vom Programm gesteuert. Da das Programm nicht einwandfrei funktioniert hatte, wurde für beide Hinweisreizbedingungen kein Durchgang von der Bedingungskombination Teilbericht vom linken Ohr mit einem ISI von 0 ms getestet.

\subsubsection{Ergebnisse}

Die Ergebnisse sind in der Abbildung 18a und 18b veranschaulicht.
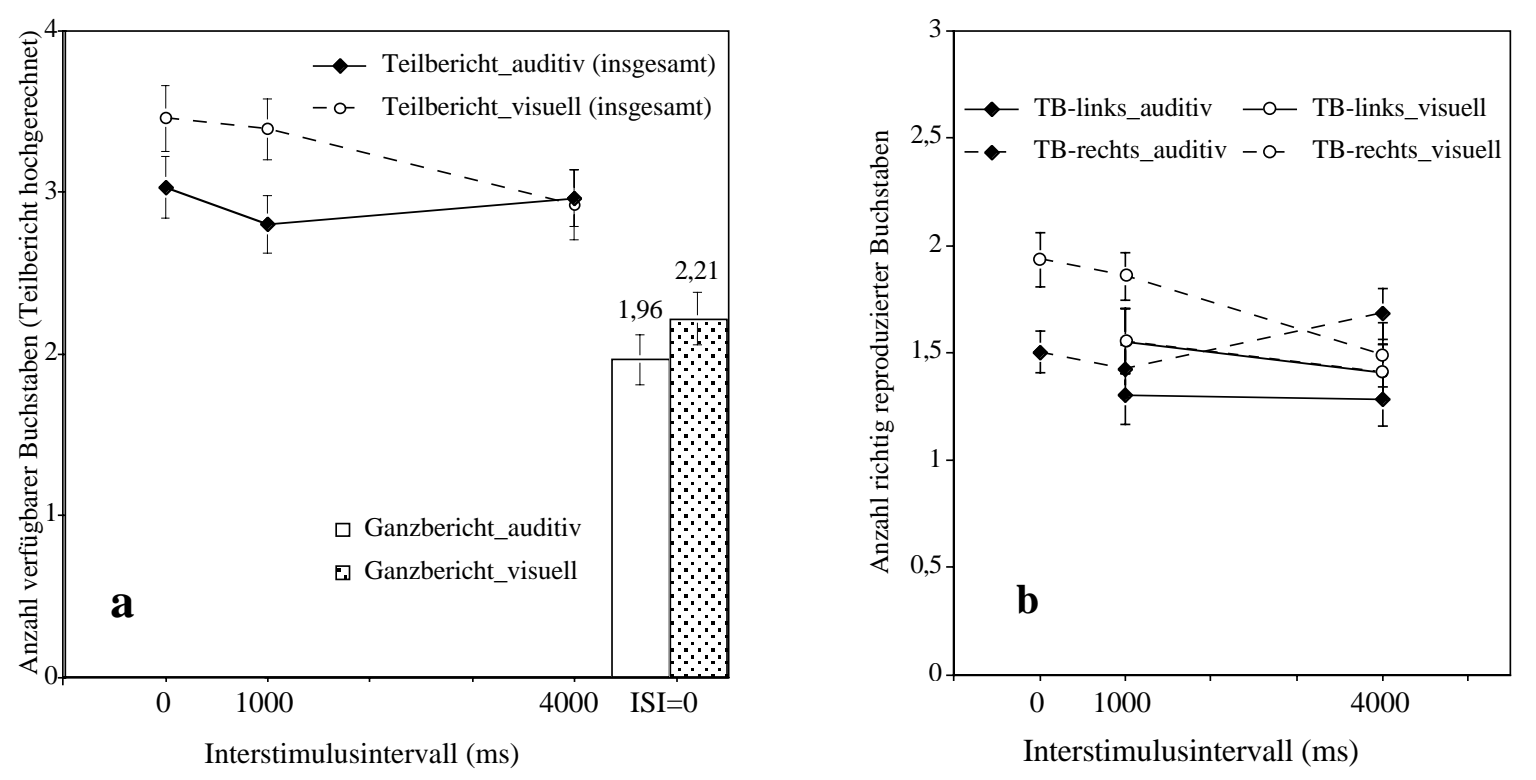

Abbildung 18: Ergebnisse in Experiment 4; dargestellt in Abhängigkeit von ISI und Hinweisreizart; $\mathrm{N}=40$.

a: Mittelwerte und Standardfehler für die Anzahl richtig reproduzierter Buchstaben im Ganzbericht und die Anzahl verfügbarer Buchstaben im Teilbericht (hochgerechnet auf der Grundlage der Anzahl korrekt reproduzierter Buchstaben). Das ISI zwischen dem Offset der auditiv dargebotenen „Buchstabenmatrix“ und dem Onset des Hinweisreizes variierte in der Teilberichtsbedingung zwischen 0, 1000 und 4000 ms. Beim Ganzbericht betrug das ISI 0 ms.

b: Mittelwerte und Standardfehler für die Anzahl richtig reproduzierter Buchstaben im Teilbericht je Berichtsart (TB-links: Reproduktion der vom linken Ohr gehörten Buchstabenreihe, TB-rechts: Reproduktion der vom rechten Ohr gehörten Buchstabenreihe) und je ISI.

Die Leistungen waren insgesamt schlechter als die, die in der Literatur über das echoische Gedächtnis berichtet worden sind (s.o.). Vor allem beim Ganzbericht war die Leistung sehr schwach, und zwar unter beiden Hinweisreizbedingungen. Dennoch zeigten die Ergebnisse einen signifikanten Leistungsunterschied zwischen den beiden Hinweisreizbedingungen, 
diesmal war aber eine signifikant schlechtere Leistung unter auditiven Hinweisreizen in fast allen Bedingungen festzustellen. Dieser signifikante Leistungsunterschied trat sowohl beim Ganzbericht als auch beim Teilbericht (mit Ausnahme der ISI-Bedingung von $4000 \mathrm{~ms}$ ) auf.

Eine zweifaktorielle MANOVA mit den Innersubjekt-Faktoren „Hinweisreizmodalität““ (zwei Stufen: auditiv und visuell) und „ISI“ (drei Stufen: 0, 1000 und 4000 ms Bedingung) wurde mit den aus beiden Teilberichtsarten (Teilbericht-links und Teilbericht-rechts) zusammen ermittelten Gesamt-Teilberichtsleistungen berechnet. Die Analyse ergab einen signifikanten Haupteffekt der „Hinweisreizmodalität“ $[F(1,39)=5.17, \Lambda(1,39)=.88, p=.028$ $\left.<.05, \eta^{2}=0.12\right]$. Der Haupteffekt des ,ISI“" war aber nicht signifikant $[F(2,38)=1.93, \Lambda(2,38)=$ $\left..91, p=.160, \eta^{2}=0.09\right]$. Die Wechselwirkung zwischen den beiden Faktoren wurde ebenfalls nicht signifikant. In Abbildung 18b zeigte sich eine Tendenz, dass die Reproduktionsleistung der vom rechten Ohr gehörten Buchstabenreihe (TB-rechts) besser war als die vom linken (TBlinks). Da allerdings die Bedingung mit ISI $=0 \mathrm{~ms}$ beim Teilbericht-links nicht realisiert wurde, konnte eine Varianzanalyse für den Faktor „Berichtsart“ nur mit zwei ISI-Bedingungen berechnet werden. Unter dieser Gegebenheit war der Haupteffekt der „Berichtsart“ nicht signifikant $\left[F(1,31)=1.48, \Lambda(1,31)=.95, p=0.233, \eta^{2}=0.05\right]$, wobei in diesem Fall die Wechselwirkung zwischen der „Hinweisreizmodalität“ und dem ,ISI“ $[F(1,31)=7.03, \Lambda(1,31)$ $=.82, p=0.013, \eta^{2}=0.19$ ] signifikant wurde, da sich die Leistungen zwischen den beiden Hinweisreizbedingungen signifikant bei der Bedingung ISI $=1000 \mathrm{~ms}$, aber nicht bei der Bedingung ISI = $4000 \mathrm{~ms}$ unterschieden. Keine andere Interaktion war signifikant.

Betrachtet man die statistischen Testergebnisse (t-Test) der Einzelvergleiche, kann man aus Tabelle 6 entnehmen, dass die Wiedergabeleistung zwischen beiden Hinweisreizbedingungen bei vielen Bedingungskombinationen einen signifikanten Unterschied aufwies. Die Leistung unter auditiver Hinweisreizbedingung war signifikant schlechter. Der Vergleich der Ganzberichtsleistungen zwischen den beiden Hinweisreizbedingungen ergab einen signifikanten Unterschied [ $t(39)=-3.07, p=.004<.05, \varepsilon=-1.32]$. Betrachtet man alle Teilberichtsbedingungen gemeinsam (aus Teilbericht-links und Teilbericht-rechts zusammen ermittelt), zeichnete sich ein signifikanter Nachteil des auditiven Hinweisreizes ebenfalls bei einem ISI von $0 \mathrm{~ms}$ und von $1000 \mathrm{~ms}$ ab, ausgenommen bei der Bedingung mit einem ISI von $4000 \mathrm{~ms}$. 
Tabelle 6. Ergebnisse der Mittelwertsvergleiche zwischen den Reproduktionsleistungen in der auditiven und der visuellen Hinweisreizbedingung in den einzelnen Bedingungskombinationen in Experiment 4

\begin{tabular}{|c|c|c|c|c|c|c|c|c|}
\hline \multirow{3}{*}{ Berichtsart } & \multirow{3}{*}{ ISI $^{a}$} & \multicolumn{4}{|c|}{ Hinweisreiz } & \multirow{3}{*}{$t$} & \multirow{3}{*}{$p$} & \multirow{3}{*}{$\varepsilon$} \\
\hline & & \multicolumn{2}{|c|}{$\underline{\text { auditiv }}$} & \multicolumn{2}{|c|}{ visuell } & & & \\
\hline & & $M$ & $S D$ & $M$ & $S D$ & & & \\
\hline Ganzbericht & 0 & 1.96 & 0.98 & 2.21 & 1.02 & -3.07 & .004 & -1.32 \\
\hline \multirow[t]{3}{*}{ Teilbericht $^{\mathrm{b}}$} & 0 & 3.03 & 1.19 & 3.45 & 1.28 & -1.72 & .094 & -0.30 \\
\hline & 1000 & 2.80 & 1.14 & 3.39 & 1.17 & -2.97 & .005 & -0.61 \\
\hline & 4000 & 2.96 & 1.09 & 2.92 & 1.35 & 0.17 & .864 & 0.03 \\
\hline \multirow{3}{*}{$\begin{array}{l}\text { Teilbericht } \\
\text {-links }\end{array}$} & $0^{c}$ & & & & & & & \\
\hline & 1000 & 1.30 & 0.83 & 1.55 & 0.93 & -1.85 & .073 & -0.44 \\
\hline & 4000 & 1.29 & 0.77 & 1.41 & 0.79 & -0.85 & .401 & -0.17 \\
\hline \multirow{3}{*}{$\begin{array}{l}\text { Teilbericht } \\
\text {-rechts }\end{array}$} & 0 & 1.50 & 0.60 & 1.94 & 0.80 & -3.70 & .001 & -0.83 \\
\hline & 1000 & 1.42 & 0.81 & 1.86 & 0.66 & -3.16 & .003 & -0.67 \\
\hline & 4000 & 1.68 & 0.73 & 1.49 & 0.91 & 1.23 & .225 & 0.24 \\
\hline
\end{tabular}

Anmerkungen. M: Mittelwert, $S D$ : Standardabweichung der Mittelwerte, $\varepsilon$ : Effektgröße.

${ }^{\text {a }}$ Interstimulusintervall in ms.

${ }^{\mathrm{b}}$ Hochgerechnete Teilberichtsleistung.

${ }^{\mathrm{c}}$ Bei dieser Bedingungskombination fehlen aufgrund eines Programmfehlers die Werte.

\subsubsection{Diskussion}

Die Ergebnisse von Experiment 4 bestätigen die Hypothese, dass bei der Verwendung auditiver Hinweisreize in der echoischen Gedächtnisaufgabe schlechtere Leistungen erbracht werden, als beim Einsatz visueller Hinweisreize. Dies ist ein Beleg dafür, dass der in Experiment 1 und Experiment 3 festgestellte Leistungsunterschied zwischen beiden Hinweisreizarten tatsächlich ein Modalitätseffekt ist, nämlich ein Effekt, der aufgrund der Beteiligung unterschiedlicher Modalitäten zustande gekommen ist. Es handelt sich somit um einen stabilen Modalitätseffekt des Hinweisreizes in der Untersuchung zum ikonischen Gedächtnis. Die Ergebnisse von Experiment 4 zeigten auch, dass es ebenfalls einen Modalitätseffekt des Hinweisreizes in der Untersuchung zum echoischen Gedächtnis gibt. Fasst man die Ergebnisse der Experimente 1, 3 und 4 zusammen, kann man zunächst grob die Schlussfolgerung ziehen, dass der modalitätsspezifische Leistungsunterschied in Untersuchungen zum sensorischen Gedächtnis durch einen intramodalen Ressourcen-Konflikt bzw. eine intramodale Interferenz im Sinne der MRT erklärt werden kann. Das heißt, die Verarbeitung des Zielreizes wird beeinträchtigt, wenn der verwendete Hinweisreiz aus derselben Modalität wie der Zielreiz stammt, da die Ressourcen nämlich modalitätsspezifisch aufgeteilt sind und für jede Modalität nur eine beschränkte Ressource zu Verfügung steht. 


\subsection{Zwischenfazit zum Modalitätseffekt des Hinweisreizes in der Partial-report-Methode}

Der erste empirische Teil der Arbeit befasste sich mit einem konkreten Phänomen, nämlich dem Modalitätseffekt des Hinweisreizes in der Untersuchung zum ikonischen Gedächtnis. Zunächst wurde das Phänomen experimentell belegt, dann wurde schrittweise nach einer plausiblen Erklärung gesucht. Schließlich konnte das Phänomen eindeutig als Modalitätseffekt identifiziert werden, der durch einen so genannten intramodalen Ressourcen-Konflikt zwischen der Verarbeitung des Zielreizes und des Hinweisreizes in den Untersuchungen hervorgerufen wird.

Die hier gelieferte Erklärung zum Modalitätseffekt des Hinweisreizes in der Untersuchung zum visuellen sensorischen Gedächtnis ist dennoch nicht ganz befriedigend. Denn was hier die „Ressource“ sein mag, ist mehr als unklar. Ebenfalls ist damit nicht geklärt, wie der ikonische Gedächtnisprozess diese Ressource beansprucht und wo genau dieser Ressourcenkonflikt stattfindet. Solche Fragen können ohne eine klarere theoretische Vorstellung und Konkretisierung sowohl des Konzepts der Aufmerksamkeit als auch des Modells des ikonischen Gedächtnisses nicht beantwortet werden, und die „Ressourcen“ werden dann immer eine „theoretische Suppe“ bleiben. Es scheint deswegen auch in diesem Zusammenhang notwendig, nach einem neuen theoretischen Konzept zum ikonischen Gedächtnis zu suchen. 


\section{$\underline{\text { Kapitel } 3}$ Entwicklung und Prüfung eines Modells zur visuellen Informationsverarbeitung}

\subsection{Modell zur visuellen Informationsverarbeitung}

In dem Teil, der den theoretischen und empirischen Hintergrund behandelt, wurde in der vorliegenden Arbeit die konzeptuelle Entwicklung zum ikonischen Gedächtnis in Umrissen dargestellt: Die Strukturmodelle von Mewhort et al. (1981, 1984), sowie von Irwin und Kollegen (Yeomans \& Irwin, 1985; Irwin \& Yeomans, 1986; Irwin \& Brown, 1987) lieferten theoretische Ansätze dafür, den Gegenstand qualitativ und differenziert experimentell zu untersuchen. Allerdings sind einige ihrem Modell zugrunde liegende Annahmen fraglich. Die mathematischen Modelle von Dixon und Di Lollo (Di Lollo \& Dixon, 1988; Dixon \& Di Lollo, 1991; Dixon \& Di Lollo, 1994) sowie von Massaro und Loftus (1996) verkörpern die Tendenz der Betonung von prozeduralen Verarbeitungsmechanismen und der quantitativen Herangehensweise in der psychologischen Forschung. Sie liefern aber wenige Anhaltspunkte über die Mechanismen und genaueren Prozesse in der ikonischen Informationsverarbeitung. Was den Forschungsstand über das Thema des ikonischen Gedächtnisses betrifft, sind viele Fragen noch offen geblieben, die in den Modellen nicht explizit geklärt bzw. widersprüchlich sind (s. Abschnitt 1.4). Es handelt sich dabei beispielsweise um Fragen über die Platzierung des ikonischen Gedächtnisses im Informationsverarbeitungssystem, über die Repräsentationsart und über das Kapazitätsproblem des ikonischen Gedächtnisses sowie die Informationsverarbeitung des Gedächtnisprozesses. Sie betreffen teilweise die ihren Modellen zugrunde liegenden Annahmen.

Die genannten Modelle scheinen auch den empirischen Befunden nicht genügend Rechnung zu tragen. Für die bisherige experimentelle Untersuchung in der vorliegenden Arbeit ist z.B. nicht klar: wenn eine intramodale Verarbeitungsinterferenz als Ursache für den Modalitätseffekt angesehen wird, in welcher Phase dann die Interferenz in diesen Modellen zutage tritt. Ebenso wenig können die Modelle in Bezug auf die aktuelle Untersuchung beantworten, worin sich die Teilberichtsbedingung mit einem ISI von $0 \mathrm{~ms}$ von den anderen ISI-Bedingungen hinsichtlich der Informationsverarbeitung unterscheidet. Damit ist auch nicht geklärt, warum der Modalitätseffekt vor allem bei Teilbericht 2 (Reproduktion der unteren Zeile) auftritt und wie der Zeileneffekt, nämlich die bessere Reproduktion der oberen Zeile im Vergleich zu der unteren Zeile bei einer zweizeiligen Matrix, zu erklären ist.

Das übergeordnete bzw. angestrebte Ziel der vorliegenden Arbeit ist es, nach einem theoretischen Konzept zu suchen, das das Phänomen des ikonischen Gedächtnisses in 
annähernder Weise beschreiben und erklären kann. Ausgehend von diesem Anliegen will sich die Arbeit deshalb nicht nur mit einem methodischen Aspekt, nämlich der Modalität des Hinweisreizes, als Selbstzweck begnügen. In der Hoffnung, die empirischen Befunde besser erklären und womöglich für die offenen Fragen eine klare Antwort geben zu können, wird im Folgenden ein kognitives neuropsychologisches Modell zum ikonischen Gedächtnisprozess bzw. zu der Informationsverarbeitung aufgestellt. Es wird dabei angestrebt, den Gegenstand als in einen großen Informationsverarbeitungsfluss eingebettet vor dem Hintergrund der visuellen Informationsverarbeitung $\mathrm{zu}$ betrachten und diese Informationsverarbeitung mit neurobiologischer Implementierung in Verbindung zu bringen. Zu diesem Zweck werden zunächst einige jüngere theoretische Entwicklungen zur visuellen Wahrnehmung und zur Aufmerksamkeit aus psychologischer und neuropsychologischer Sicht herangezogen.

\subsubsection{Psychologische Betrachtung von visueller Wahrnehmung}

Die Gedächtniskapazität, die mit Methoden zum ikonischen Gedächtnis ermittelt werden soll, wird manchmal auch als Wahrnehmungsspanne im Unterschied zur Gedächtnisspanne (des KZG) bezeichnet. Nicht zuletzt wird das ikonische Gedächtnis auch als wahrnehmungsnaher Gedächtnisprozess betrachtet. Es scheint daher angebracht, zunächst die relevanten Theorien über die visuelle Wahrnehmung in Betracht zu ziehen.

Innerhalb der Psychologie hat sich zur Charakterisierung des Wahrnehmungsprozesses die Idee „erst Teilelemente, dann deren Kombination“ weitgehend durchgesetzt. Einen ähnlichen Gedanken findet man zum Beispiel in dem Modell der Merkmalsanalyse zur visuellen Mustererkennung oder auch bei der recognition-by-components theory von Biederman (1987), worin die Erkennung eines Objekts als eine Konfiguration einfacher Komponenten betrachtet wird.

Die Merkmalsintegrationstheorie (MIT, feature integration theory) von Treisman et al. (Treisman \& Gelade, 1980; Treisman \& Schmidt, 1982; Treisman, 1986, 1988) hat seit den 80er Jahren einen großen Einfluss erlangt. Sie wird heute nach wie vor als eine der wichtigsten Theorien im Zusammenhang mit visueller Aufmerksamkeit, Objektwahrnehmung und visueller Suche angesehen. Der ursprüngliche Gedanke der Theorie war, dass die sensorischen Merkmale (features) eines Objektes, wie Farben und Größe, unabhängig voneinander durch verschiedene darauf spezialisierte Module präattentiv kodiert, und dann zum Objekt integriert werden. Die Kodierung der Merkmale soll automatisch und parallel ablaufen. Um aber die Merkmale korrekt zu einem Objekt zusammenfügen zu können, ist gerichtete Aufmerksamkeit notwendig. Der für die Merkmalsintegration notwendige Aufmerksamkeitsprozess kann aber jeweils nur Merkmale eines Objekts zusammenfügen. Ohne gerichtete Aufmerksamkeit 
(focused attention) oder effektive Top-down-Verarbeitung werden die Merkmale auf einer Zufallsbasis gebündelt und somit können fälschliche Verbindungen (illusory conjunctions) entstehen (Treisman \& Gelade, 1980, S. 98).

Die gerichtete Aufmerksamkeit in der MIT ist räumlich orientiert. Die Aufmerksamkeit richtet sich auf eine Lokalisation und dient dann als Leim (glue) für die Merkmale, die sich in dieser Lokalisation befinden, um diese zu integrieren. Die Rolle der Aufmerksamkeit besteht darin, eine Lokalisation in einer Lokalisationskarte (master map of locations) (Treisman, 1988), auf der alle Merkmalskarten (feature map) verbunden sind, zu selektieren. Sobald eine Position fokussiert wird, werden alle Merkmale in dieser Position mit ihren Repräsentationen in verschiedenen Merkmalskarten aktiviert und zu einer temporären Repräsentation eines Objektes geformt (Treisman, 1988). Angesicht der Sonderrolle der räumlichen Lokalisation wird die MIT auch als Position-special-Theorie im Gegensatz zu Position-not-special-Theorie, wie der von Duncan and Humphreys (1989, 1992), klassifiziert (Van der Heijden, 1993).

Diese infolge von gerichteter Aufmerksamkeit geformte temporäre Repräsentation eines Objektes wird als eine Objektdatei (object file) bezeichnet. Das ist ein wichtiger Terminus in der Weiterentwicklung von MIT, der erstmals von Kahneman und Treisman (1984) eingeführt wurde. Bei der Objektdatei handelt sich um eine episodische temporäre Repräsentation eines Objektes (Kahneman \& Treisman, 1984; Kahneman, Treisman \& Gibbs, 1992), in der ,information about a particular, presently visible object is collected, interrelated and updated, as the object moves or changes its appearance“ (Treisman, 1992, S. 863). Treisman zufolge verkörpert eine Objektdatei ein temporäres perzeptuelles Gedächtnis, ,that links the present state of an object to its immediately preceding history and integrates visual information across time to represent a unitary object moving or changing within an ongoing perceptual experience“ (ebd., S. 865). Die Repräsentation in einer Objektdatei ist als token von gespeicherter Repräsentation als type im Langzeitgedächtnis zu unterscheiden. Types sind nach Treisman die gespeicherten Repräsentationen von vertrauten Objekten, die zur Identifikation und Klassifikation verwendet werden, tokens werden in einer Objektdatei gebündelt und repräsentieren Erlebnisse in einem bestimmten Fall oder zu einer bestimmten Gelegenheit mit spezifischen Eigenschaften (Treisman, 1992, 1996; Kahneman, Treisman \& Gibbs, 1992), alles was eben das Episodische ausmacht. Explizite Wiedererkennung geschieht, wenn die Objektdatei aufgebaut ist und die sensorische Beschreibung mit gespeicherten Repräsentationen von bekannten Objekten verglichen wird (Kahneman, Treisman \& Gibbs, 1992). Der Position-special-Betonung zufolge wird die Objektdatei vor allem durch die Lokalisation in einer bestimmten Zeit und nicht durch irgendein Merkmal oder ein 
identifizierendes Etikett definiert (Kahneman, Treisman \& Gibbs, 1992). Aufmerksamkeit ist nach der MIT sowohl für den Aufbau der Objektdatei und die Merkmalsintegration in der Objektdatei als auch für das Aufrechterhalten der Objektdatei notwendig (Treisman, 1993), so dass auch angenommen wird, dass nur eine bestimmte Anzahl von Objektdateien zu gleicher Zeit aufrechterhalten werden kann und die Auflösung in einer Objektdatei beschränkt ist (Kahneman, Treisman \& Gibbs, 1992, S. 178).

Die MIT hat einige Kritik erhalten (z.B. Duncan \& Humphreys, 1989, 1992), unter diesem Druck wurde sie immer weiter entwickelt. In den 90er Jahren wurde die Theorie von Treisman selbst weitgehend modifiziert (Treisman 1993, 1996). Treisman hat z.B. die Merkmale weiter differenziert (shape-defining vs. surface-defining features) und ein Kontinuum der Aufmerksamkeit eingeführt, in dem ,geteilte Aufmerksamkeit“ (divided attention) als ein Ende und „gerichtete Aufmerksamkeit“ als das andere Ende des Kontinuums dargestellt wird. Der Einsatz dieser beiden Aufmerksamkeitsarten wird von einem Aufmerksamkeitsfenster (attentional window) in Abhängigkeit von dessen Größenvariation gesteuert. In einem großen Aufmerksamkeitsfenster mit geteilter Aufmerksamkeit werden die Struktur des Objektes segregiert, visuell extrahiert und es wird die Ausrichtung und Form des Objektes entdeckt. Die Integration der Merkmale folgt in diesem Fall auf einer globalen Ebene. Für die präzise und genaue Lokalisation und Integration der Merkmale für einzelne Objekte muss das Aufmerksamkeitsfenster verkleinert und fokussiert werden (Treisman, 1993).

Eine andere wichtige Modifikation in der MIT betrifft die Selektionsmechanismen. Die MIT galt bis dahin als ein Modell der Frühselektion. Das 80er-Jahre-Modell kann man als ein auf Lokalisation basierendes (location-based) Selektionsmodell betrachten, weil die Merkmale aufgrund der Lokalisation selektiert werden sollen. Nur die in der selektierten Lokalisation befindlichen Merkmale konnten richtig integriert werden. Diese Theorie mit lokalisationsbasierter Selektion kann aber objektbasierte (object-based) Selektion nicht erklären und so erweitert Treisman die Selektion auf verschiedenen Ebenen (Treisman, 1993). Objektwahrnehmung und Aufmerksamkeit werden danach als abhängig von der Interaktion zwischen Merkmalskarte, Lokalisationskarte und Objektdatei betrachtet, so dass auch Selektion auf der Basis von merkmalsdefinierter (feature-defined) oder objektdefinierter (object-defined) Lokalisation möglich ist (Abb. 19). Um die ewige Kontroverse zwischen „früher“ und „später“ Selektion miteinander zu vereinbaren, macht Treisman die Selektionsphase von der „,perzeptuellen Belastung“ (load on perception) abhängig (vgl. auch Lavie, 1994, 1995). Wenn das System perzeptuell hoch belastet ist, wird früh selektiert; wenn das perzeptuelle System nicht so sehr beansprucht ist, findet die Selektion erst bei der Reaktion statt und es handelt sich 
somit um eine späte Selektion. Angepasst hat Treisman (1993) noch die Idee der Merkmalsund der Lokalisationskarte an die inzwischen weiterverbreitete Annahme der getrennten visuellen Informationsverarbeitung von Identitäts- und Lokalisationsinformation (s. Abb. 19). Auf diese Annahme, die neuropsychologisch gestützt ist und als „Was“- und „Wo“-Bahnen im Gehirn lokalisiert sind, wird im Folgenden eingegangen.

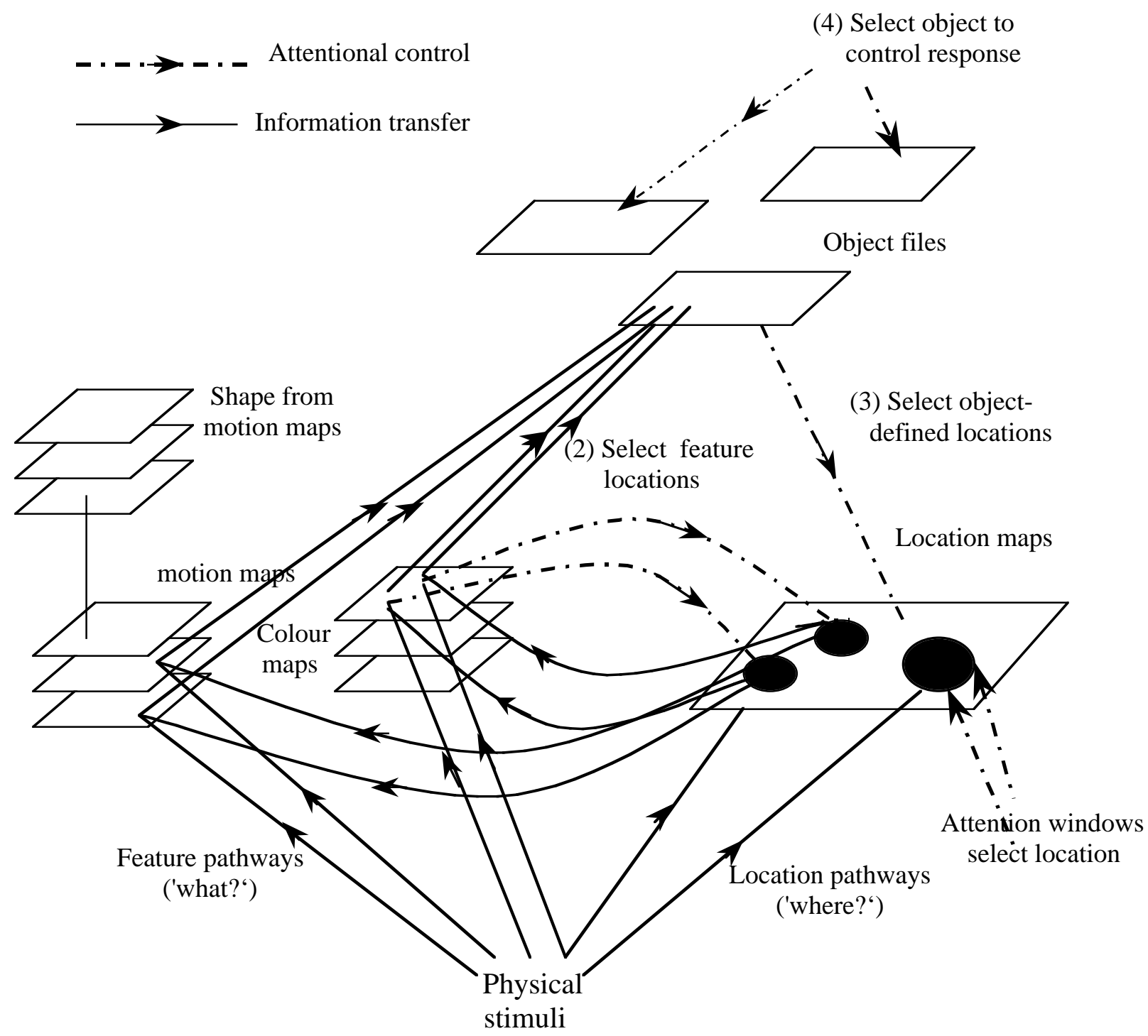

Abbildung 19: Treismans Modell zur Wahrnehmung von Merkmal und Objekt (1993, S. 31).

\subsubsection{Neuropsychologische Betrachtung von visueller Wahrnehmung}

Durch die Fortschritte in der Neurophysiologie können immer mehr klare Spezifikationen in Zellen, in Bahnen und Areale des Gehirns aufgezeigt werden. Es gibt gute Belege, dass (mindestens) zwei parallele Strömungen im Cortex mit visueller Informationsverarbeitung assoziiert sind. Eine verläuft vom visuellen Cortex aus zum inferioren Temporallappen und die andere zum posterioren parietalen Cortex (Ungerleider \& Mishkin, 1982; Posner \& Peterson, 
1990; Zeki, 1980; Zeki et al., 1991). Die vor allem von Ungerleider und Mishkin (1982) vorgeschlagene Trennung zwischen einer dorsalen und einer ventralen Verarbeitungsbahn für visuelle Informationsverarbeitung erlangt inzwischen breite Akzeptanz. Dabei war eine ähnliche Annahme spätestens schon bei Schneider (1969) einflussreich. Nach Ungerleider und Mishkin (1982) ist die dorsale Bahn, die vom primären visuellen Cortex (V1) zu den parietalen visuellen Regionen verläuft, hauptsächlich damit befasst, wo die visuelle Information im Raum lokalisiert ist, während die von V1 zu den temporalen visuellen Regionen verlaufende ventrale Bahn hauptsächlich damit beschäftigt ist, um was es sich bei der visuellen Information handelt.

$\mathrm{Zu}$ dem „Was-Wo”-Modell gibt es inzwischen auch Ergänzungen und Modifikationen (Goodale, 2000; Goodale, Milner, Jakobson \& Carey, 1991; Goodale, 1993; Milner \& Goodale, 1995). Milner und Goodale (1995) z.B. betrachten das dorsale System nicht als ein reines „Wo"-System, sondern vielmehr als eine Gruppe von mehreren Systemen für die simultane visuelle Kontrolle von Bewegung. Deshalb sollten ihrer Meinung nach die beiden Bahnen besser als „Erkennungs- und Bewegungsbahn” betrachtet werden (ebd., S. 24). Beide Bahnen sollen Information über die Struktur der Objekte sowie ihre räumliche Lokalisation verarbeiten, aber sie verwenden die Information zu verschiedenen Zwecken und in verschiedener Weise (Goodale, 2000). Auch Ungerleider, Mishkin und ihre Kollegen haben inzwischen die wichtige Rolle des dorsalen Systemes bei der visuomotorischen Kontrolle anerkannt, darüber hinaus stellen sie sich neben den beiden Bahnen noch eine dritte Bahn im Sulcus temporalis superior vor (Boussaoud, Ungerleider \& Desimone, 1990). Diese dritte Bahn hat ihren Ursprung in Strukturen, die sowohl mit den parietalen als auch mit den temporalen Bahnen assoziiert sind. Sie zieht in eine Region des Temporallappens, die im Sulcus temporalis superior verborgen liegt. Allerdings ist die Funktion der dritten Bahn noch unklar. Betrachtet man die aktuelle Diskussion insgesamt, scheint vieles dafür zu sprechen, dass der dorsale Verarbeitungsweg, bzw. der posteriore parietale Cortex für Bewegung und Bewegungskontrolle eine wichtige Rolle spielt. Für die Bewegungssteuerung müssen aber dort in jedem Fall die Positionsinformationen vorhanden sein, d.h. sehr wahrscheinlich auch dort verarbeitet werden.

Eine gut gelungene Verbindung zwischen einem psychologischen Konzept und neurophysiologischen Erkenntnissen stellte Kosslyns Modell zur Objektwahrnehmung (Kosslyn, 1994; Kosslyn \& Thompson, 2000) dar. In diesem Modell, worin Kosslyn auch gemeinsame neuronale Mechanismen für visuelle mentale Vorstellung (visual imagery) annimmt, wird ebenfalls von zwei cortikalen visuellen Verarbeitungssystemen ausgegangen. Das System der visuellen Objektwahrnehmung wird in diesem Modell in sieben (Kosslyn, 1994) bzw. sechs Subsysteme (Kosslyn \& Thompson, 2000) eingeteilt (s. Abb. 20). 


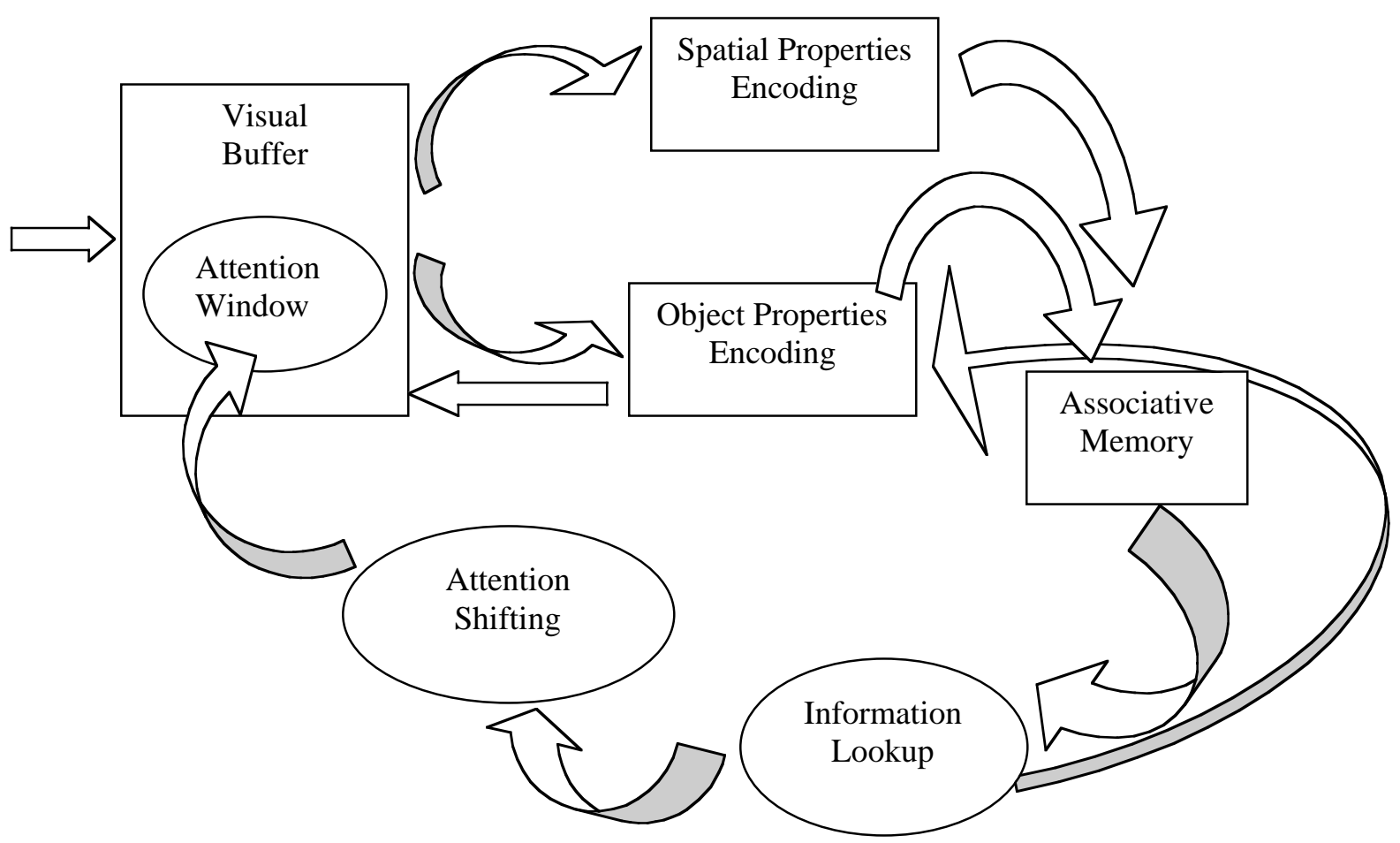

Abbildung 20: Modell zur visuellen Wahrnehmung und visuellen Vorstellung von Kosslyn (nach Kosslyn, 1994; Kosslyn \& Thompson, 2000).

(1) Der visual buffer bekommt als erstes die eingehende visuelle Information. Er arbeitet nach dem Prinzip der Figur-Grund-Unterscheidung und liefert das Input für die restlichen high-levelvisuellen Systeme. Dieses Subsystem mit topographisch organisierten Repräsentationen ist in Arealen des Occipitallappens, und dort vielleicht in den Arealen 17 und 18, implementiert, wo es die höchste räumliche Auflösung aufweist.

(2) Das attention window ist derjenige Teil des visual buffer, welcher an höhere Areale der Objektwahrnehmung, also zu zwei cortikalen visuellen Systemen weitergeleitet wird. Das Subsystem muss sich auch in dem Occipitallappen befinden, wo der visual buffer implementiert ist. Die Auswahl der zu verarbeitenden Information kann durch den Pulvinar gesteuert werden. Die top-down gesteuerte Selektion aus dem visual buffer könnte über reziproke Verbindungen des Pulvinars mit IT und V4 vor sich gehen (Kosslyn, 1994). In der jüngeren Arbeit (Kosslyn \& Thompson, 2000) wird das attention window allerdings nicht mehr als ein separates Subsystem, sondern zusammen mit dem visual buffer als ein Subsystem betrachtet (s. Abb. 20).

(3) Die Information entlang der ventralen Bahn gelangt in den inferioren Temporallappen (Kosslyn, 1994) oder auch in den mittleren Temporallappen (Kosslyn \& Thompson, 2000), dort ist der Sitz des Object-properties-encoding-Subsystems. Dieses Subsystem ist für Kosslyn (1994) mit dem visuellen Gedächtnis vergleichbar. Die Objekteigenschaften, z.B. Form, Farbe und Struktur, werden hier enkodiert und mit vorhandenen Objektrepräsentationen verglichen. 
Wenn eine Übereinstimmung vorliegt, wird ein Objekt wieder erkannt (recognition). Die Wiedererkennungsfunktion des ventralen Systems ist Kosslyn (ebd.) zufolge relativ unabhängig von der Distanz vom Betrachter und der Lokalisation des fokussierten Teils im Gesichtsfeld.

(4) Der dorsale Weg führt parallel zu der ventralen Bahn und mündet in den posterioren Parietallappen. Dort befindet sich das Kosslynsche Spatial-properties-encoding-Subsystem (Kosslyn, 1994, Kosslyn \& Thompson, 2000). Räumliche Eigenschaften wie Lokalisation, Distanz, Größe und Orientierung werden dort enkodiert.

(5) Die Informationen über Objekteigenschaften und räumliche Eigenschaften kommen in dem Kosslynschen Modell (ebd.) in einem associative memory zusammen. Das Associativememory-Subsystem kombiniert die beiden Arten von Informationen und vergleicht sie mit gespeicherten multimodalen und amodalen Repräsentationen. Wenn der Input mit einer gespeicherten Information übereinstimmt, wird der Stimulus identifiziert (Identifikation). Sobald ein Objekt identifiziert ist, wird die zu ihm gehörende Information, z.B. der Name und die Kategorie des Objektes, zugänglich (ebd.). Für die Bindung von verschiedenen Informationen spielt nach Kosslyn (1994) der Hippocampus eine wichtige Rolle. Von der anatomischen Lokalisation des associative memory nahm Kosslyn (ebd.) zunächst an, dass die Implementierung im posterioren, superioren temporalen Cortex und im Übergangsbereich zwischen temporalem, parietalem und occipitalem Cortex sein könnte. In der jüngeren Veröffentlichung (Kosslyn \& Thompson, 2000) spezifizierte er diesen Sitz ins Areal 19 und den Gyrus angularis.

(6) Wenn eine Wiedererkennung, also „Recognition“ im Object-properites-encodingSubsystem, misslingt, müssen nach dem Kosslynschen Modell (Kosslyn, 1994; Kosslyn \& Thompson, 2000) zusätzliche Informationen über das Objekt gesammelt werden, d.h., eine Suche nach der Repräsentation, die am meisten mit dem Reiz übereinstimmt, wird in Gang gesetzt. Das Information-lookup-Subsystem im dorsolateralen präfrontalen Cortex macht Information über einen distinktiven Teil oder über Charakteristiken des am meisten aktivierten Objektes im associative memory zugänglich, eine Top-down-Suche wird dann gestartet (ebd.).

(7) Schließlich verwendet das Attention-shifting-Subsystem im Kosslynschen Modell (ebd.) die Lokalisationsrepräsentation dieses Teiles oder dieser Charakteristik, um die Aufmerksamkeit zu der entsprechenden Position zu steuern. Gleichzeitig wird das ventrale System für den gesuchten Teil oder die Charakteristik gebahnt. Zu dem Subsystem gehören Areale im posterioren parietalen Cortex, insbesondere Areal 7b und LIP (lateral intraparietal), sowie die frontalen Augenfelder (Kosslyn, 1994). 
Sowohl in der MIT von Treisman (s.o.) als auch in dem Modell der High-level-Version von Kosslyn (s.o.) muss notwendigerweise eine Zentralannahme darüber gemacht werden, wie die getrennt verarbeiteten Merkmale oder Informationskodierungen des Objektes zusammengefügt und integriert werden. Dies betrifft eine der wichtigsten Fragen in der Erforschung visueller Wahrnehmungsprozesse und ist ein aktuelles Thema, das als Bindungsproblem (Hummel, 1997; Singer, 1994; Von der Malsburg, 1996) bezeichnet wurde.

\section{Exkurs: Bindungsproblem (binding problem)}

Das Bindungsproblem kann aus verschiedenen Perspektiven betrachtet werden. Es gibt verschiedene Bindungsarten von getrennten Repräsentationen. Außer Eigenschaftsbindung (property binding, Bindung von Eigenschaften eines Objektes) und Teilbindung (part binding, Teile zu einem Ganzen zu binden) unterscheidet z.B. Treisman (1996) noch range binding, wo ein bestimmter Wert auf einer Dimension (wie Farbe) durch das Verhältnis der Aktivität verschiedener Neuronenpopulationen definiert wird; hierarchische Bindung (hierarchical binding, z.B. shape-defined Merkmale zu einem surface-defined Merkmal in ihrer Terminologie zu binden); Bedingungsbindung (conditional binding), wo die Interpretation einer Eigenschaft von einer anderen abhängig ist (z.B. Bewegungsrichtung von der Tiefe); sowie temporale Bindung (temporal binding) und Lokalisationsbindung (location binding). Eine ausführliche Behandlung des Themas liefert Treisman (1996, 1998). Treisman betrachtet den letzten Bindungstyp, also die Lokalisationsbindung, als Bindung von „Was“ zu „Wo“. In dieser lokalisationsbasierten Merkmalsintegration (vgl. Anschnitt 3.1.1) sah sie eine psychologische Lösung des „Bindungsproblems“, bei der auch gleich die Eigenschaften und Teile eines Objektes zu einem „Was” gebunden werden (Treisman, 1996). Eine andere Möglichkeit für die Teilbindung fand sie in der merkmalsbasierten Selektion. Durch diese Art von Selektion werden die irrelevanten Merkmale gehemmt (Treisman, 1993). Falls keine apriori-Information bezüglich der Lokalisation oder des(der) relevanten Merkmal(e) vorhanden ist, soll die Herangehensweise für die Bindung von verschiedenen Merkmalen nach Treisman in der Regel das serielle Scanning von Lokalisationen sein (ebd.).

Betrachtet man das Bindungsproblem aus neurophysiologischer Sicht, ist vor allem die Frage interessant, ob eine spezifische Struktur im Gehirn existiert, die diese Bindungsaufgabe ausführt. Die neurophysiologische Forschung an dem Bindungsproblem konzentriert sich in der letzten Zeit auf die Hypothese, dass Bindung durch die präzise Synchronisation der Aktionspotentiale derjenigen Nervenzellen, die die zusammengehörigen Teilinformation repräsentieren, realisiert werde. Diese Idee vom Zellverband (cell assembly) ist eigentlich nichts Neues (vgl. Hebb, 1949), sie gewinnt nun aber immer mehr an Popularität. Die weit 
verbreitete konnektionistische Sichtweise (z.B. Singer, 1994; Gray \& Singer, 1989) beinhaltet, dass die Antworten der Neuronen auf denselben Stimulus in Phasen zusammen oszillieren und durch die zeitgleiche Koordination die zusammengehörenden Repräsentationen in verschiedenen Regionen im Gehirn gebunden werden. Die von Neurowissenschaftlern beobachtete synchronisierte Aktivität bei einer Katze ist z.B. assoziiert mit einer Oszillation von etwa $40 \mathrm{~Hz}$ (Gray \& Singer, 1989). Um Objekte als Zellverbände im Gehirn repräsentieren zu können, müssen gewisse Basisanforderungen (vgl. Singer, 1994) erfüllt werden. Neuronen könnten durch eine temporale Kodierung (temporal code) in einen Zellverband organisiert werden (ebd.). Die ,binding by synchronous discharge” wird auch als ein möglicher Mechanismus für die Integration über Modalitäten hinweg angenommen (Damasio, 1990).

Ein spezielles Hirnareal für die „Bindungsaufgabe” wird in der konnektionistischen Sichtweise nicht vorgesehen. Dafür spricht unter anderem, dass unser Gehirn bei High-levelFunktionen nicht so spezialisiert ist, wie bei Low-level-Funktionen. Es scheint auch unmöglich zu sein, dass es für alles spezialisierte Neuronen gibt. Dennoch bleibt z.B. zu fragen: Wie kann eine solche einfache direkte Verbindung die Bedeutung oder ein Objekt spezifizieren, insbesondere bei der Repräsentation von abstrakten Informationen? Zumal es immer noch nicht klar ist, wie die zeitliche Kodierung (temporal code) und die Kodierung der Aktivierungsrate (rate code) von Neuronen, wodurch die Eigenschaften vom Objekt signalisiert werden sollen, kombiniert werden. Es gibt z.B. auch Studien mit Affen, in denen die Belege für Oszillation oder temporale Kodierung fehlen (Tovee \& Rolls, 1992, 1995). So scheint Kosslyns Hypothese nicht unbegründet zu sein. Er nimmt nämlich an, dass der Hippocampus eine wichtige Rolle für die Bindung von Verknüpfungen verschiedener Informationen spiele und ein associative memory für die Speicherung dieser gebundenen Informationen im posterioren, superioren temporalen Cortex (Kosslyn, 1994), bzw. in dem Areal 19 und im Gyrus angularis (Kosslyn \& Thompson, 2000), implementiert sei. Eine spezifische Struktur im Gehirn soll ihm zufolge also für die Integration und Zusammenfügung der getrennt verarbeiteten Merkmalsinformationen sorgen. Treisman dagegen hielt es nicht für notwendig, die ,functional instantiation” von der Objektdatei in eine bestimmte Gruppe von Neuronen implementieren zu müssen, sondern ,it could also be a temporary synchronization of activity in groups of cells located in different areas of the brain" (Treisman, 1992, S. 863).

\subsubsection{Kognitive neuropsychologische Betrachtung von visueller Aufmerksamkeit}

Die bisherige Forschung über Aufmerksamkeit teilte Posner (1993) in drei Phasen ein: anfänglich, in den 50er und 60er Jahren, konzentrierte sich die Forschungsarbeit auf human performance und auf das Konzept, in dem der Mensch als ein single channel processor 
betrachtet wurde. In den 70er Jahren und Anfang der 80er Jahre wurde die Forschung „kognitiv“, die meisten Arbeiten waren fokussiert auf die Untersuchung von (internalen) Repräsentationen, automatischen und kontrollierten Prozessen, sowie fokussierender und geteilter Aufmerksamkeit. Seit Mitte der 80er Jahre ist Cognitive Neuroscience das Schlagwort, und Psychologen bemühen sich zunehmend, biologische Aspekte in Betracht zu ziehen und neuropsychologische Befunde von Patienten zu berücksichtigen. Dieser Schwerpunkt und Trend der Aufmerksamkeitsforschung hält heute weiter an, und zwar mit zunehmender Tendenz.

In der neuropsychologisch orientierten Aufmerksamkeitsforschung setzt sich nicht nur die berühmte Diskussion zwischen Früh- und Spätselektion fort, die aktuelle Debatte kreist auch darum, ob es separate Hirnareale für die sensorische und gedächtnisspezifische Aufmerksamkeitskontrolle gibt (Posner \& Digirolamo, 2000). Weiterhin wird auch über den Sitz und die Quelle der Aufmerksamkeit debattiert (site versus source of attention; LaBerge, 1995; Posner \& Digirolamo, 2000). Site of attention ist die neuronale Basis, wo die Aufmerksamkeitsoperation stattfindet, während source of attention der Antrieb und die Ursache der Aufmerksamkeitsoperation sein soll. Auf die Frage, ob Aufmerksamkeit eine Funktion des ganzen Gehirns oder eine Funktion eines diskreten Aufmerksamkeitskontrollmoduls ist, gaben Posner und Dehaene (1994) als Antwort, dass das Aufmerksamkeitssystem weder eine Eigenschaft von einer single brain area noch vom ganzen Gehirn sei. Posner und Peterson (1990) schlagen zwei unabhängige, aber interagierende Aufmerksamkeitssysteme vor: ein anteriores Aufmerksamkeitssystem im Frontallappen und ein posteriores Aufmerksamkeitssystem innerhalb des Parietallappens. Nach ihrer Beobachtung ist das posteriore System auf verdeckte (covert) Orientierung zur Lokalisation spezialisiert; während das anteriore Aufmerksamkeitssystem in Aufgaben involviert ist, bei denen eine Selektion auf der Basis von andersartigen Hinweisreizen, wie z.B. Farben, durchgeführt wird. Die beiden Aufmerksamkeitssysteme können aber auch hierarchisch zueinander stehen, das anteriore präfrontale System kann nämlich das posteriore Aufmerksamkeitssystem kontrollieren (Posner \& Peterson, 1990). Im Zusammenhang mit der Frage nach der „Quelle der Aufmerksamkeit“ wurde diskutiert, ob der visuelle Aufmerksamkeitseffekt (top-down) durch ein neuronales Netzwerk einschließlich des posterioren Parietallappens, des Pulvinars und des Colliculus auf den ventralen object-recognition-pathway ausgeübt wird (LaBerge, 2000, 1995; Corbetta et al., 1995), oder ob der Effekt einfach auf Konkurrenz zwischen reizspezifischen neuronalen Aktivitäten innerhalb des object-recognition-pathway, vor allem im Areal V4, zurückgeht (Duncan, Humphreys \& Ward, 1997). 
Eine hilfreiche Klarstellung für diese Diskussion der neurophysiologischen Lokalisation der Aufmerksamkeit liefert LaBerge (2000). Er unterscheidet zwischen dem „Ausdruck“ (expression), dem „Modulations- bzw. Verstärkungsmechanismus“ sowie dem „Steuerungsmechanismus“ der Aufmerksamkeit, worauf gleich näher eingegangen wird.

Ebenso wie Posner und Dehaene (1994) hat LaBerge sich mit den neuronalen Aufmerksamkeitsnetzwerken beschäftigt. LaBerge stellte 1995 eine interessante kognitive neurowissenschaftliche Theorie der Aufmerksamkeit vor, die er später zur „DreiecksbahnTheorie der Aufmerksamkeit“ (triangular-circuit theory of attention, LaBerge, 2000) weiterentwickelt hat (s. Abb. 21.)

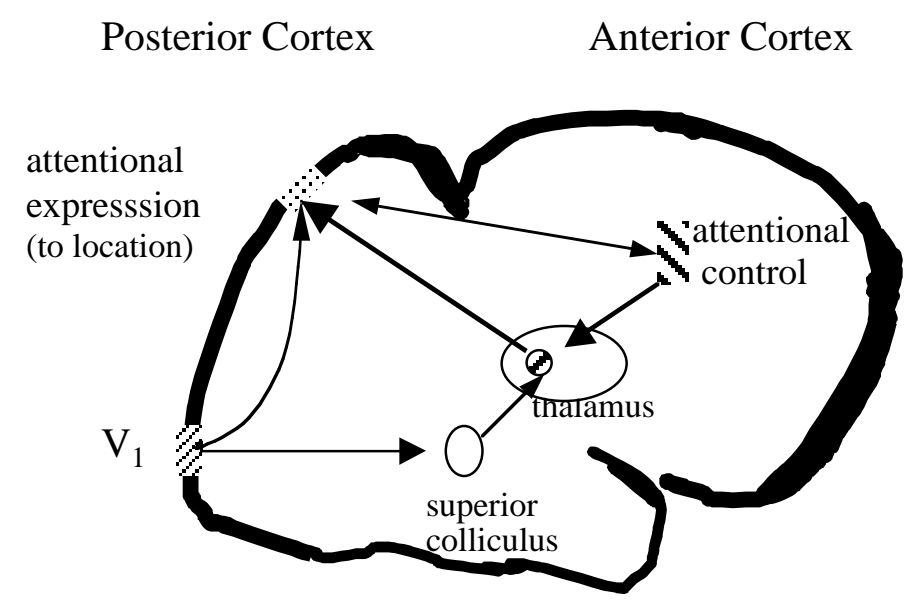

Abbildung 21: Die Dreiecksbahn-Theorie der Aufmerksamkeit (triangular-circuit of attention) von LaBerge (2000, S. 721).

LaBerge (1995) betrachtet zunächst die Aufmerksamkeit an ihrem Wirkungsort, den so genannten Aufmerksamkeitsausdruck (expression of attention) in den neuronalen Bahnen. Die Aufmerksamkeit kann in verschiedenen Hirnarealen simultan zum Ausdruck gelangen und zeigt sich in einer positiven Aktivitätsdifferenz zwischen dem aufmerksamkeitsaktiven (attended site) und dem aufmerksamkeitsinaktiven Areal (non-attended site). Der Ausdruck der Aufmerksamkeit kann in ihrer Intensität und Dauer variieren. Der selektive Aspekt der Aufmerksamkeit bedeutet einfach, das Verhältnis zwischen den Aktivitätsniveaus an dem aufmerksamkeitsaktiven und dem -inaktiven Areal zugunsten dem Niveau des aufmerksamkeitsaktiven Areals zu ändern. Diese Regulierung kann auf verschiedene Arten geschehen. Der Informationsfluss, der den Aufmerksamkeitsmodulationen unterliegt, kann LaBerge (1995) zufolge eine sensorische Herkunft haben oder aus dem Gedächtnis stammen.

Die Aufmerksamkeitsmechanismen (Modulations- bzw. Verstärkungsmechanismus) in LaBerges Verständnis (ebd.) modulieren direkt den Informationsfluss in cortikalen Bahnen, wo der „Ausdruck“ der Aufmerksamkeit gebildet wird, d.h., die Aufmerksamkeitsmechanismen 
produzieren also direkt dort den Aufmerksamkeitsausdruck. Für die visuelle Aufmerksamkeit kommen vor allem zwei Mechanismen in Frage: „neural circuits between the thalamus and cortical areas, and neural circuits involving the oculomotor regions of the superior colliculus and the posterior parietal cortex“ (LaBerge, 1995, S. 219).

Die Aufmerksamkeitsmechanismen sind aber nur Ausführungsinstanzen und nicht die Ursache für den Aufmerksamkeitsausdruck. Die Kontrolle darüber, was, wie intensiv und wie lange Aufmerksamkeit gespendet (attended) werden soll, kann nach LaBerge (2000) bottom-up (exogene, stimulus-driven) und top-down (endogene, goal-directed) geschehen. Vermutlich wird die thalamocortikale Schleife sowohl von sensorischer Kontrolle (bottom-up), als auch von willentlicher Kontrolle (top-down) gesteuert. Die Bottom-up-Aufmerksamkeitskontrolle geschieht LaBerge zufolge (ebd.) entweder durch Aufmerksamkeitsverschiebung oder dadurch, dass die Aufmerksamkeit auf bestimmte Lokalisationen im visuellen Gesichtsfeld gelenkt wird. Die Top-down-Kontrolle übernimmt nach LaBerge (ebd.) wahrscheinlich Areale in dem präfrontalen Cortex, die auch dem Arbeitsgedächtnis zugrunde liegen. Der dorsolaterale präfrontale Cortex (DLPFC) kontrolliert Lokalisationsattribute, der ventrolaterale präfrontale Cortex (VLPFC) dagegen Attribute wie Farbe und Form, und für eine Aktionskontrolle ist dann eventuell der anteriore cinguläre Cortex verantwortlich (LaBerge, 1995). Die Kontrollinstanzen der Aufmerksamkeit im präfrontalen Cortex haben sowohl eine direkte neuronale Verbindung zum posterioren parietalen Cortex, wo die Aufmerksamkeit ausgedrückt wird, als auch Verbindung zum Thalamus (Pulvinar), dieser steht wiederum in Verbindung zum posterioren cortikalen Areal (s. Abb. 21). Diese Verbindungen zwischen den drei Instanzen ergeben eine Dreiecksbahn ( triangular-circuit). In der „Dreiecksbahn-Theorie der Aufmerksamkeit“ (LaBerge, 2000) wird postuliert, dass die direkte Verbindung zwischen dem präfrontalen und posterioren Cortex primär dazu da ist, zu selektieren, in welcher Kolumne der Aufmerksamkeitsausdruck aktiviert werden soll. Die indirekte Verbindung durch den Thalamus dient eher dazu, die Aktivität der selektierten Kolumnen zu intensivieren. Die direkte Verbindung kann also als eine informatorische, die indirekte als eine modulatorische Verbindung betrachtet werden.

\subsubsection{Modellvorstellung}

Basierend auf den wesentlichen Gedanken der oben kurz dargestellten relevanten Theorien und unter Berücksichtigung von neurophysiologischen Erkenntnissen wird nun ein Modell (s. Abb. 22) zur visuellen Informationsverarbeitung im Zusammenhang mit dem ikonischen Gedächtnis aufgestellt. Das Anliegen dabei ist, einen geeigneten theoretischen Rahmen zu 
finden und letztendlich das Phänomen des ikonischen Gedächtnisses besser beschreiben und erklären zu können. Dieses Modell baut vor allem auf Kosslyns Ansatz (s. Abschnitt 3.1.2) auf, wobei der Gedanke der Objektdatei mit einem temporären Charakter von Treisman (s. Abschnitt 3.1.1) sowie die detaillierten Annahmen der präfrontalen Aufmerksamkeitssteuerung von LaBerge (s. Abschnitt 3.1.3) darin integriert werden.

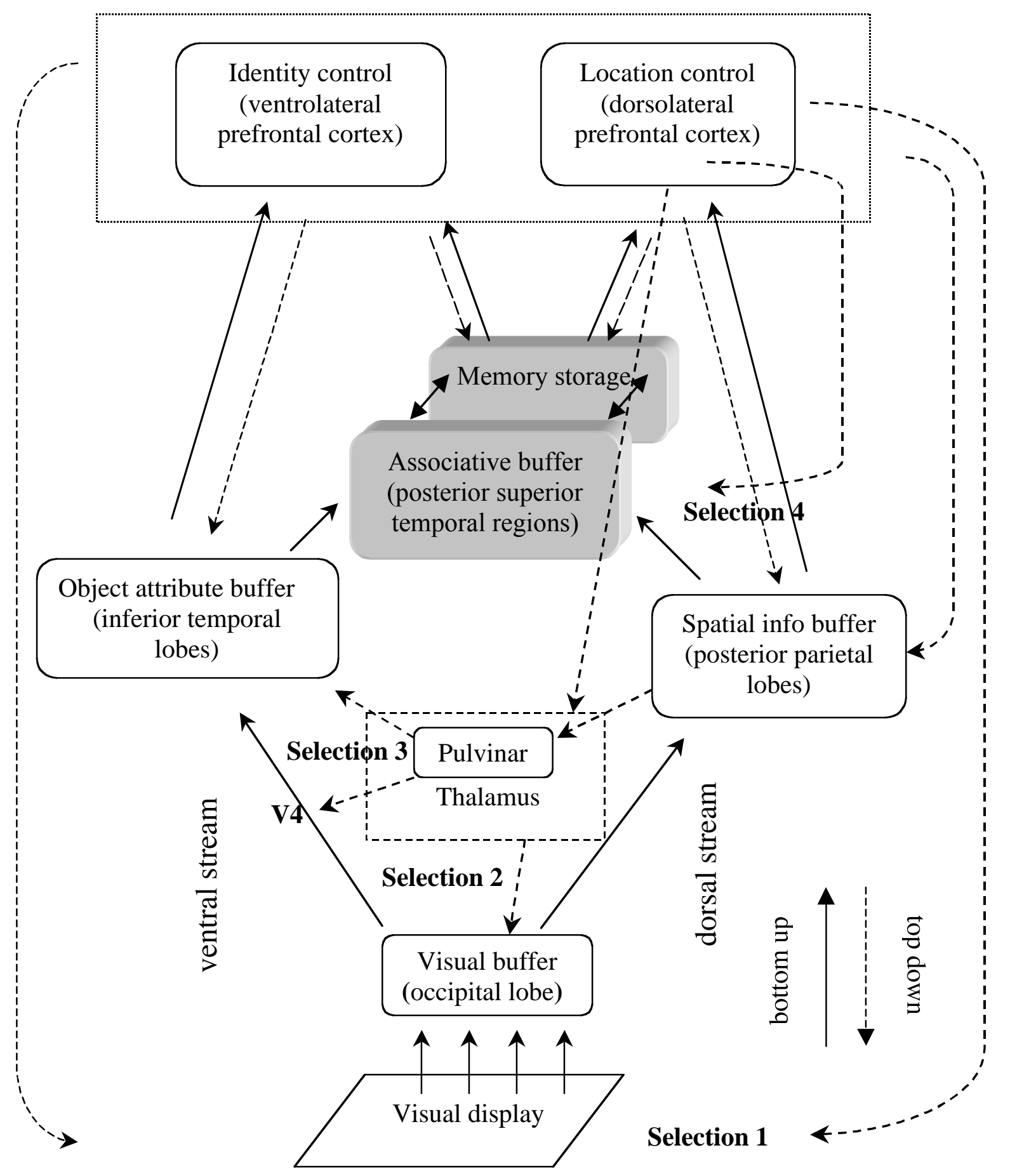

Abbildung 22: Ein neuropsychologisches Modell zur visuellen Informationsverarbeitung und zum ikonischen Gedächtnis (innerhalb der Top-down-Richtung werden die beschriebenen Selektionswege mit dick gestrichelten Linien gekennenzeichnet). 
Das Modell erhebt keinen Anspruch auf Vollständigkeit bezüglich des visuellen Informationsverarbeitungssystemes. Es wird z.B. die Informationsverarbeitung von Bewegung bzw. die Bewegungssteuerung und auch die Feedback-regulierte Informationsverarbeitung (vgl. Kosslyns Modell, Abb. 20) nicht berücksichtigt. Das Ziel der vorliegenden Arbeit besteht vor allem darin, für das Phänomen des ikonischen Gedächtnisses eine annähernd geeignete theoretische Beschreibung zu finden. Da die Bewegungsinformation für den Fall des ikonischen Gedächtnisses in der aktuellen Untersuchung nicht relevant ist, wird sie in dem Modell zunächst außer acht gelassen. Ebenso kann man davon ausgehen, dass die Feedbackregulierte Informationsverarbeitung in der spezifischen Aufgabenanforderung (z.B. der Sperling-Aufgabe) nicht ohne weiteres möglich ist.

Die wesentlichen Aspekte des neuropsychologischen Modells bestehen darin:

(1) eine getrennte Verarbeitung von räumlichen und objektbezogenen Informationen,

(2) ein Buffer für Kodierung von objektbezogenen Informationen mit perzeptueller Kapazitätsbeschränkung,

(3) ein Buffer für Kodierung von räumlichen Informationen mit exogener Charakteristik,

(4) ein Buffer mit zentraler (kognitiver) Kapazitätsbeschränkung für die Integration und Identifikation der Information von den getrennten Verarbeitungen,

(5) ein Abgleichsprozess (matching) mit den gespeicherten Repräsentationen (Langzeitgedächtnis),

(6) die Rolle der Aufmerksamkeit ausgedrückt in verschiedenen Selektionsebenen (Wege),

(7) die Steuerung der Aufmerksamkeit vom präfrontalen Cortex,

(8) die Modulierungs- und Verstärker-Rolle des Pulvinars (Thalamus) für die Aufmerksamkeitssteuerung.

Das Modell kann folgenderweise beschrieben werden:

Ebene 1: „Visual buffer“. Die visuellen Signale gelangen zunächst in den „visual buffer“. Sie werden hier entsprechend der realen Welt topographisch abgebildet. Die Registrierung der Information geschieht nahezu automatisch (präattentiv) und parallel. Die Verarbeitungsweise kann z.B. als ,spatial indexing” (vgl. Wright \& Ward, 1998) oder Figur-Grund-Unterscheidung beschrieben werden, es wird noch kein Merkmal extrahiert.

Neuroanatomisch betrachtet wird der Buffer vermutlich in den Occipitallappen zu finden sein, genauer gesagt, eventuell in den Arealen V1 bis V2, d.h. Areal 17 und 18, wo die Areale funktionell heterogen sind (Kolb \& Whishaw, 1996) und die beste räumliche Auflösung aufweisen (Kosslyn \& Thompson, 2000). Anatomisch gesehen sind heute mindestens sechs verschiedene occipitale Regionen bekannt: V1, V2, V3, V3A, V4 und V5 (MT). V1 ist das 
übergeordnete Areal, es erhält umfangreiche Informationen vom Corpus geniculatum laterale des Thalamus und projiziert in alle anderen occipitalen Regionen. Das V1-Areal ist funktional heterogen, weil die Zellen in diesen Regionen an unterschiedlichen Funktionen beteiligt sind, d.h. die Zellen in den Blob-Regionen an der Farbwahrnehmung, und die in den InterblobRegionen an der Wahrnehmung von Form und Bewegung. Im V2-Areal kann dieser Funktionsunterschied weiterhin in Form von dünnen und dicken Streifen manifestiert werden, so dass das V2-Areal ebenfalls funktional heterogen ist (Kolb \& Whishaw, 1996). Die funktionale Heterogenität der beiden Areale ermöglicht die Fortleitung aller relevanten Reizinformationen ohne Merkmalsextraktion.

Ebene 2: „Spatial info buffer” und „object-attribute buffer“. Vom „,visual buffer” aus werden Informationen in räumlicher und objektbezogener Art getrennt zu dem ,spatial info buffer” und dem ,object-attribute buffer” geschickt. Anatomisch gesehen verläuft der Informationsfluss zum einen dorsal von V1 durch V5 oder V3A in den posterioren Parietallappen, oder direkt von V2 zu dem posterioren parietalen Cortex, zum anderen ventral von V2 durch V3 (dynamische Form) oder V4 (Farbe und Form) in den inferioren Temporallappen (Goodale, 1993). Durch die dorsale Bahn bis in den „spatial info buffer” im posterioren Parietallappen (Areal 7a) wird räumliche Information wie Lokalisation, Größe und Orientierung übertragen. Dieser Verarbeitungsprozess verläuft vermutlich parallel und weist exogenen Charakter auf. Die objekteigenen Merkmale, wie Form und Farbe, werden durch die ventrale Bahn weitergeleitet, im „object-attribute buffer” verarbeitet und dort mit gespeicherten perzeptuellen Repräsentationen verglichen. Sie werden dann als Eigenschaftsinformation eines Objektes, wie z. B. Form, Muster, Farbe und Kategorie, kodiert. Es handelt sich hier wie bei Kosslyns Modell (1994; Kosslyn \& Thompson, 2000) um „Rekognition“, d.h., der Input wird mit vorhandenen modalitätsspezifischen, in diesem Fall visuellen Repräsentationen, verglichen und entsprechend kodiert. Allerdings wird hier im Unterschied zu der Position der strengen Lokalisationsdeterminierung von Treisman (vgl. oben) angenommen, dass die Verarbeitung (Rekognition, wie Formerkennung) in dem ,object attribute buffer” ohne Lokalisationsinformation möglich ist (vgl. Kosslyn, 1994, S. 176). Die Verarbeitung oder Kodierung in dem „object attribute buffer“ kann parallel erfolgen, dennoch ist es nicht auszuschließen, dass dieser Abgleichungsprozess auch top-down gesteuert wird, selbst wenn diese Top-down-Steuerung nur auf niedrigem perzeptuellen Niveau geschieht. Dies lässt sich zumindest bei vertrauten Objekten vermuten. Das image-based matching von Kosslyn (1994, S. 120) oder auch die merkmalsbasierte Selektion von Treisman (1993, vgl. oben) könnte als eine Top-down-Verarbeitung in Zusammenhang mit dem Rekognitionsprozess in diesem Buffer 
betrachtet werden. Selbst bei einer parallelen Verarbeitung unterliegt der „object attribute buffer” allgemein einer perzeptuellen Kapazitätsbeschränkung, die sich eventuell in einem Abgleichsverhältnis (trade-off) zwischen der Merkmalsqualität und der perzeptuellen Größe ausdrückt.

Ebene 3: „Associative buffer" und „memory storage“. Um ein visuelles Objekt identifizieren zu können, müssen die getrennt kodierten Objekt-Eigenschaftsinformationen und die räumlichen Informationen integriert oder zusammengefügt werden. Die Integration und Identifikation ereignen sich in dem Modell in einem ,associative buffer”. Bei dem ,,associative buffer" handelt es sich um eine Arbeitsinstanz mit temporärem Charakter (vgl. ,object file “ in Kahneman \& Treisman, 1984; Kahneman, Treisman \& Gibbs, 1992).

Anatomisch gesehen treffen die Informationsströme des ventralen und dorsalen Systems dann mindestens in zwei Stellen im Gehirn wieder zusammen: einmal an dem dorsolateralen Präfrontallappen (Goldman-Rakic, 1992; Wilson, O’Scalaidhe \& Goldman-Rakic, 1993), zum anderen in dem anterioren Teil vom Sulcus temporalis superior (Baizer, Ungerleider \& Desimone, 1991). Der zweite Verlaufsweg ist vielleicht die von Boussaoud, Ungerleider und Desimone (1990) postulierte dritte Bahn (neben der ventralen und dorsalen Bahn, vgl. Abschnitt 3.1.2). Diese dritte Bahn, die von V2 zum Sulcus temporalis superior verläuft, hat den Ursprung in Strukturen, die sowohl mit den parietalen als auch mit den temporalen Bahnen assoziiert sind. Sie zieht in eine Region des Temporallappens, die im Sulcus temporalis superior verborgen liegt. Dort kommen außer visuellen auch auditorische und somatische Afferenzen zusammen. Die Neuronen in dieser Region sind polysensorische, d.h., sie reagieren sowohl auf visuelle als auch auf auditive bzw. somatosensorische Informationen (Kolb \& Whishaw, 1996). So scheint diese Region der beste Kandidat dafür zu sein, wo der ,,associative buffer" seinen Sitz haben könnte. Andererseits, selbst wenn diese anatomische Lokalisation nicht zutreffend ist, muss in jedem Fall ein assoziativer Zustand für die weitere Informationsverarbeitung angenommen werden, da die Identifikation eines visuellen Objektes die Integration der verschiedenen Merkmalsinformationen voraussetzt. Dieser assoziative Zustand kann auch im Sinne von konnektionistischer Betrachtung, z.B. als temporäre Synchronisation der beteiligten Neuronen, verstanden werden.

In dem ,,associative buffer” kommen die kodierten Informationen aus dem „object attribute buffer” und dem ,spatial info buffer” zusammen, aber auch Informationen aus anderer modalitätsspezifischer Verarbeitung, z.B. auditiver oder somatischer Kodierung desselben Objektes. Alle diese Informationen werden zusammengefügt und integriert, eine Identifikation des Objektes wird zugleich in Gang gesetzt. Diese Integration und Identifikation geschieht in 
ständigem Austausch mit einem „memory storage”, d.h., die gesammelten Informationen werden mit gespeicherten Repräsentationen verglichen. Im Fall eines guten Abgleichs wird das Objekt identifiziert. Das identifizierte Objekt im ,associative buffer” erhält dann seinen Namen, seine Identität mit allen dazugehörigen temporären episodischen Beschreibungen und konzeptuellen Informationen. Wenn es sich um ein unbekanntes Objekt handelt, werden die Informationen anhand der Lokalisation integriert (vgl. Treismans location binding, 1996). Wenn es sich um mehrere Objekte handelt, kann dann nur Objekt für Objekt identifiziert werden, da diese Verarbeitung gerichtete Aufmerksamkeit erfordert (vgl. Treisman \& Gelade, 1980; Treisman, 1996). Eine kognitive Kapazitätsbeschränkung der Verarbeitung im „associative buffer” wird in dem Modell angenommen. Die Beschränkung kann darin begründet sein, dass der Identifikationsprozess im Austausch mit dem „,memory storage“ nur seriell erfolgt. Im Sinne einer konnektionistischen Betrachtungsweise kann aufgrund des Prinzips der temporalen Kodierung zu gleicher Zeit auch nur die assoziative Konnektion für ein Objekt aktiv sein, was auch für eine mögliche Kapazitätslimitation spricht.

Der von dem ,associative buffer“ in Anspruch genommene „,memory storage” als Instanz für Wissensrepräsentation ist vermutlich im medialen Temporallappen implementiert. Dieser Speicher kann dem konventionellen Langzeitgedächtnis gleichgesetzt werden, worauf später noch eingegangen wird. Die Annahme eines ,associative buffer” im Sulcus temporalis und die eines „memory storage” im medialen Temporallappen, sowie die Annahme des Austausches zwischen ihnen stimmen mit Beobachtungen aus Studien mit Affen überein, wo angenommen wurde, dass die Zellen im Sulcus temporalis inferior und im benachbarten Sulcus temporalis superior eine Rolle in „comparing current visual inputs with internal representation of recalled images” (Goodale, 2000, S. 373) spielten, welche vermutlich in anderen Regionen, wie z.B. benachbarten Regionen der medialen Temporallappen und limbischen Regionen, gespeichert sind (Goodale, 2000).

Ebene 4: „Identity control” und ,location control”. Der ,, associative buffer” ist auch mit zwei weiteren Instanzen im Präfrontallappen entweder in direkter oder indirekter Verbindung und wird von ihnen on-line gehalten. Die eine Instanz ist die „,identity control”, die sich vermutlich im ventrolateralen präfrontalen Cortex (VLPFC) befindet; die andere ist die „location control”, die ihren Sitz im dorsolateralen präfrontalen Cortex (DLPFC) haben könnte. Es wird in dem Modell angenommen, dass die Verbindung und der Austausch zwischen dem ,associative buffer” und dem „,memory storage” von den präfrontalen Instanzen gesteuert wird. Aber diese zwei Instanzen sollen in dem Modell vor allem bei der Aufmerksamkeitskontrolle bzw. Selektion eine wichtige Rolle spielen. 
„Top-down-Selektionen“. Anatomisch gesehen treffen die Informationen aus dem ventralen und dorsalen System, außer, wie oben bereits erwähnt wurde, im Sulcus temporalis superior noch in den dorsolateralen Präfrontallappen zusammen (Goldman-Rakic, 1992; Wilson, O’Scalaidhe \& Goldman-Rakic, 1993). Genauer gesagt: das dorsale System projiziert in das topographisch organisierte Areal 46, und das ventrale System projiziert zu einer mehr orbitaleren Region des Frontallappens. Die zwei präfrontalen Instanzen sind an der willentlichen Kontrolle beteiligt. Diese angenommenen reziproken Verbindungen in dem Modell zwischen dem „object attribute buffer” zum Frontallappen und dem „spatial info buffer" zum Frontallappen dienen zum einen (Bottom-up-Richtung) dazu, die für eine Entscheidung der frontalen Instanzen notwendige Information zu liefern; zum anderen (Topdown-Richtung) die Aufmerksamkeitskontrolle bzw. Selektion durchzuführen. Bei den Topdown-Prozessen können die zwei postulierten Aufmerksamkeitskontrollinstanzen anhand der Identitätsinformation oder der Lokalisationsinformation in den Verarbeitungsweg eingreifen und den dortigen Informationsfluss regulieren. Dieser Eingriff ist in verschiedenen Stadien möglich, und je nachdem, während welcher Verarbeitungsphase der Willen entsteht oder bewusst wird, entstehen verschiedene Selektionsarten. Es werden in dem Modell vor allem die Selektionsmöglichkeiten, die vom DLPFC ausgehen und auf Lokalisationsinformation basieren, betrachtet, da diese Selektionsmöglichkeiten für die vorliegende Arbeit von Interesse sind. Es sind mindestens vier Arten von Selektionen möglich. Bei der Selektion 1 in Abbildung 22 handelt es sich um vorbereitende Selektion im Sinne von LaBerge (2000) ${ }^{14}$. Man kann nämlich vorher bestimmen, wohin man die Augen richtet, was also gesehen werden soll. Diese Art von Selektion betrachtet LaBerge (2000) als eine Bottom-up-Aufmerksamkeitskontrolle, was aber in dem vorgestellten Modell eher als ein vom DLPFC ausgehender Top-down-Prozess zu verstehen ist. Die Selektion 2 erfolgt bei dem „,visual buffer”, es wird dabei die Entscheidung darüber getroffen, aus welchem topographischen Teil Signale weitergeleitet werden sollen. Der neurophysiologische Kontrollweg dafür ist allerdings nicht ganz klar, das Selektionssignal wird eventuell vom DLPFC aus durch den Thalamus an das V2 (V1) weitergegeben, ${ }^{15}$ zumal der Thalamus eigentlich mit fast jedem Areal des Cortex in Verbindung ist (Jones, 1985; LaBerge, 2000). Es wurde berichtet (s. Posner \& Gilbert, 1999), dass unter bestimmten Bedingungen bereits in V1 die Wirkung von Aufmerksamkeit zu beobachten sei. Ein weiterer Ort, wo aber ein Aufmerksamkeitseffekt gut nachgewiesen ist, ist das V4-Areal

\footnotetext{
${ }^{14}$ Er teilt die Funktion von Aufmerksamkeit in vorbereitende, selektierende und aufrechterhaltende ein.

${ }^{15}$ Dieser Selektionsweg betrifft eine oft diskutierte Frage: Kann Aufmerksamkeit das V1-Areal beeinflussen? Die Diskussion der Früh- oder Spätselektion drückt sich in dieser Hinsicht darin aus, wie früh sich die Aufmerksamkeit in dem Nervensystem auf den Stimulus-Input auswirken kann.
} 
(z.B. LaBerge, 2000; Duncan, Humphreys \& Ward, 1997). Der Kontrollweg dafür (Selektion 3 in dem Modell) geht sehr wahrscheinlich vom DLPFC durch den posterioren Parietallappen via Pulvinar an V4 (LaBerge, 1995; 2000). Möglich ist auch, dass diese Selektion durch den Pulvinar direkt den „object attribute buffer” beeinflusst, da der Pulvinar auch eine reziproke Verbindung mit IT hat bzw. eigentlich reziprok zu (allen) visuellen Regionen in dem Occipital, Temporal-, Parietal- und Frontallappen projiziert. Bei Menschen ist der Pulvinar der größte Nucleus des Thalamus, er macht ca. zwei Fünftel des thalamischen Volumens aus (LaBerge, 2000). Die Beteiligung des Pulvinars in der visuellen Aufmerksamkeit wurde in vielen Studien gut belegt (z.B. LaBerge, 1995, 2000; Olshausen, Anderson \& Van Essen, 1993). Durch die Modulation des Pulvinars beeinflusst also die Selektion 3 die V4-IT-Bahn, den Verarbeitungsweg für die Objekt-Eigenschaften und eventuell auch den „object attribute buffer”. Schließlich kann die identifizierte Information aus dem ,,associative buffer”, wo bereits das Objekt mit allen seinen Eigenschaften und Zugehörigkeiten erkannt wird, direkt mit Steuerung der präfrontalen Instanz selektiert werden. Das ist nämlich die vierte Selektionsmöglichkeit (Selektion 4).

Man könnte sich ebenso auch andere Top-down-Wege der Aufmerksamkeitskontrolle von dem VLPFC aus vorstellen, bei denen der visuelle Wahrnehmungsprozess eines Objektes von der vorhandenen Identitätsinformation beeinflusst wird. Diese Top-down-Art von Aufmerksamkeitskontrolle kann als objektbasierte Selektion im Sinne von Treisman (1993) betrachtet werden. Diese Selektionsart spielt aber in der aktuellen Untersuchung eine geringe Rolle, so dass auf sie nicht näher eingegangen wird.

Das hier vorgestellte Modell ist von den grundlegenden Ideen her gesehen Kosslyns Modell (Kosslyn, 1994; Kosslyn \& Thompson, 2000) sehr ähnlich. Teilweise wurde auch von diesem Modell ausgegangen, dennoch unterscheidet es sich vor allem in folgenden Annahmen von ihm, bzw. geht es darüber hinaus:

(1) Es wird in dem Modell über die Kapazitätsbeschränkung und die Verarbeitungsweise der Informationsverarbeitung in verschiedenen Stadien angenommen, dass Information in dem „object attribute buffer“ parallel verarbeitet wird und die Verarbeitung einer perzeptuellen Kapazitätsbeschränkung unterliegt. Im ,,associative buffer“ soll die Informationsverarbeitung nur seriell erfolgen können und die Verarbeitung einer kognitiven Kapazitätseinschränkung unterliegen. Diese Annahmen sowie ihre Begründung werden weiter unten diskutiert und überprüft.

(2) Es wird in dem Modell ein temporärer Zustand, nämlich der ,associative buffer“ als eine Art von „on-line-Speicher“ für die Informationszusammenfügung und 
Identifizierung postuliert. Dieser Speicher hält die Informationen aus zwei davorliegenden Buffern zusammen, dessen Inhalt wird mit dem des „memory storage“ verglichen, um letztendlich das Objekt identifizieren zu können. Das ,,associative memory“ von Kosslyn (1994) ähnelt dem klassischen Konzept des Langzeitgedächtnisses, und die Identifikation eines Objektes bedeutet Kosslyn zufolge die Aktivierung einer multimodalen Repräsentation darin. Eigentlich betrachtet Kosslyn das ,,associative memory“ als eine Art von amodalem Langzeitgedächtnis im Gegensatz zur modalitätsspezifischen Langzeitgedächtnisrepräsentation (Kosslyn, 1994, S. 325). Im hier vorgestellten Modell wird aber der Ort der aktuellen Verarbeitung, eine temporäre Instanz, von der dauerhaften Lagerung der Repräsentationen getrennt betrachtet. Anstelle des ,associative memory“ bei Kosslyn wird in dem Modell das „memory storage“ im Sinne des Langzeitgedächtnisses in herkömmlicher Betrachtung postuliert, das möglicherweise in den medialen Bereichen beider Temporallappen implementiert ist. Die möglichen Zusammenhänge zwischen den verschiedenen Prozessen innerhalb des Modells und den unterschiedlichen Gedächtnisformen des herkömmlichen Konzepts sind ein wichtiger Bestandteil der vorliegenden Arbeit, worauf im Folgende immer wieder zurückgegriffen wird.

(3) Kosslyn (1994) schreibt dem Hippocampus eine wichtige Rolle bei der Verknüpfungsbildung verschiedenartiger Informationen zu. In dem hier vorgestellten Modell wird angenommen, dass der präfrontale Cortex den Austausch zwischen dem „associative buffer“ und dem „memory storage“ steuert und letztendlich die Identifikation vornimmt. Darüber wird noch am Schluss der Arbeit im Zusammenhang mit dem Arbeitsgedächtnis diskutiert.

(4) Die Aufmerksamkeitssteuerungsfunktion des Präfrontalcortex wird in dem Modell stark betont. Dabei wird eine Domainspezifität innerhalb des Präfrontalcortex angenommen. Neben dem DLPFC wird dem VLPFC die Rolle der Selektionssteuerung anhand Objekteigenschaftsinformation zugeschrieben. Verschiedene Selektionswege für die Top-down-Verarbeitungen werden im Modell postuliert, vor allem der Weg über den posterioren Parietallappen (und zwar anhand Lokalisationsinformation) durch den Pulvinar. Die Funktionsweise der Selektion (Aufmerksamkeit) in dem vorgestellten Modell ist über das Kosslynsche (Kosslyn, 1994; Kosslyn \& Thompson, 2000) hinaus differenzierter und detaillierter, dabei stützen sich die theoretischen Annahmen vor allem auf den Ansatz LaBerges (LaBerge, 1995, 2000). Die 
Notwendigkeit der Annahme verschiedener Selektionsmöglichkeiten wird noch in der weiter unten folgenden genaueren Betrachtung der Sperling-Aufgabe deutlicher.

Abgesehen von den oben beschriebenen Punkten werden noch weitere kleine Unterschiede zwischen dem hier dargestellten und dem Kosslynschen Modell in den weiteren Ausführungen zum Vorschein kommen, die dann erst im jeweiligen Kontext angesprochen werden.

Nachdem das Modell unter allgemeinen Gesichtspunkten der visuellen Informationsverarbeitung vorgestellt wurde, geht es im Folgenden darum, das Phänomen des ikonischen Gedächtnisses nach dem vorgestellten Modell zu betrachten bzw. es zu lokalisieren.

\subsubsection{Ikonisches Gedächtnis im vorgestellten Modell}

In der neuropsychologischen Forschung wird angenommen, dass die hirnstrukturellen Grundlagen für verschiedene Gedächtnisformen ebenso verschieden sind, d.h., dass das Langzeitgedächtnis beispielsweise auf anderen neuronalen Strukturen als das Arbeitsgedächtnis basiert. Den medialen Bereichen beider Temporallappen und vor allem dem Hippocampus (z.B. McClelland, McNaughton \& O'Reilly, 1995) werden eine Schlüsselstellung für die Einspeicherung und die Konsolidierung deklarativer und episodischer Gedächtnisinhalte zugeschrieben (s. Rösler, 1997). Beobachtungen nach operativer Entfernung des medialen Temporallappens einschließlich des Hippocampus und der Amygdala sowie Beobachtungen bei der Alzheimer Krankheit legen nahe, dass der mediale temporale Cortex mit anterograder Amnesie zusammenhängt. Die medialen Temporallappen scheinen tatsächlich die Hirnstruktur für Einspeicherung und Konsolidierung des Langzeitgedächtnisinhalts zu sein. In dem oben vorgestellten Modell wird dieser Speicher für deklaratives Wissen als ,memory storage” bezeichnet.

Ein Zusammenhang zwischen Arbeitsgedächtnis und präfrontalem Cortex wird von vielen angenommen (z.B. Kolb \& Whishaw, 1996; LaBerge, 1995; Goldman-Rakic, Ó Scalaidhe \& Chafee, 2000). Der VLPFC wurde mit dem visuellen Objekterkennungssystem und der DLPFC mit dem visuellen räumlichen System im Arbeitsgedächtnis assoziiert (Kolb \& Whishaw, 1996). Die Domainspezifizität im Frontallappen scheint neuronal begründet zu sein, so dass es multiple Arbeitsgedächtnis-Domänen im Präfrontalcortex gibt (Goldman-Rakic, Ó Scalaidhe \& Chafee, 2000). Dem präfrontalen Cortex wird in dem vorgestellten Modell vor allem eine Steuerungsfunktion zugeschrieben, sowohl für die Aufmerksamkeitskontrolle als auch für den Identifikationsprozess im ,associative buffer”.

Für die vorliegende Arbeit ist insbesondere die Frage von zentraler Bedeutung, wo das ikonische Gedächtnis in diesem Modell zu platzieren ist. Betrachtet man die Verarbeitungswege von visuellen und auditiven Stimuli (bei Affen), gibt es vier Typen von 
intracortikalen Verbindungen. Der erste Projektionstyp besteht aus einer hierarchischen Anordnung von Faserzügen, die von primären und sekundären visuellen und auditorischen Regionen ausgehen und im temporalen Pol enden. Der zweite Typ umfasst eine ganze Serie paralleler Projektionen von den visuellen und auditorischen Assoziationsgebieten, die in den polymodalen Regionen des Sulcus temporalis superior enden. Der dritte Typ stammt aus auditorischen und visuellen Assoziationsgebieten und endet in medialen temporalen Regionen. Die Axone erreichen zunächst den entorhinalen Cortex und ziehen von dort in den Hippocampus und/oder in die Amygdala. Der vierte Projektionstyp wird durch eine Serie paralleler Faserzüge zum Frontallappen gebildet (Kolb \& Whishaw, 1996). Modalitätsspezifische sensorische Nervenbahnen für visuelle, auditorische und somatische Reize laufen anscheinend in drei multimodalen Regionen zusammen, und zwar in dem präfrontalen, dem limbischen und dem parietotemporalen Assoziationscortex. Neuronen in diesen Arealen sind polymodal bzw. amodal. Sie reagieren auf eine Kombination von Signalen aus verschiedenen Modalitäten (Kandel, Schwartz \& Jessell, 1995; 2000). Ist es in Anbetracht der intracortikalen Verbindungen berechtigt, die verschiedenen Gedächtnisformen mit diesem anatomischen Aufbau in Verbindung zu bringen und so zu interpretieren, dass in den drei Assoziationsfeldern drei unterschiedliche Gedächtnisformen lokalisiert sind? Man könnte annehmen, wenn die präfrontalen Assoziationsfelder dem Arbeitsgedächtnis und die limbischen Assoziationsfelder dem Langzeitgedächtnis zugrunde liegen, dann könnte in den parietotemporalen Assoziationsfeldern (Sulcus temporalis superior) die dritte Gedächtnisform implementiert sein, nämlich das, was in dem vorgestellten Modell als ,,associative buffer” bezeichnet wird, worin vielleicht auch das sensorische bzw. ikonische Gedächtnis zu lokalisieren ist.

Wenn man bei dem ,,associative buffer” unbedingt von Gedächtnis sprechen möchte, so ist „perzeptuelles Gedächtnis“ vielleicht eher angemessen, da es die zeitliche Prozessdynamik ausdrückt. ${ }^{16}$ Auch Treisman (1992) hat ihre Objektdatei mit einem perzeptuellen Gedächtnis in Verbindung gebracht. „An object file embodies a temporary perceptual memory that links the present state of an object to its immediately preceding history and integrates visual information across time ...“ (S. 865). Im Unterschied zu Treisman soll in dem vorliegenden Modell der „,associative buffer” jedoch als der Ort des Geschehens und das perzeptuelle Gedächtnis dann als dessen Produkt betrachtet werden. Es ist ähnlich wie in dem Konzept von Massaro und Loftus (1996), wo das perzeptuelle Gedächtnis als Output des sensorischen Speichers betrachtet

\footnotetext{
${ }^{16}$ Wobei das "perceptual memory" bei Kosslyn als "visual code" in dem vorderen Teil des ventralen Systems betrachtet wurde, da es nicht für den Input aus anderen Modalitäten zugänglich sein sollte (Kosslyn, 1994, S. 72).
} 
wird. In dem Sinne kann man das perzeptuelle Gedächtnis auch mit Treismans token (1992, 1996; Kahneman, Treisman \& Gibbs, 1992) vergleichen.

Sensorisches Gedächtnis und KZG in den herkömmlichen Konzepten können nach dem vorgestellten Modell als zwei verschiedene Ausprägungen des perzeptuellen Gedächtnisses betrachtet werden, und zwar für unterschiedliche qualitative Merkmale des ,associative buffer". Wie die beiden herkömmlichen Konzepte nach dem vorgestellten Modell zu betrachten sind, und wie ihre Beziehung zueinander aussieht, wird später noch detailliert diskutiert werden. Bei dem sensorischen Gedächtnis geht es darum, wie viele Objekte in den ,associative buffer“ „hinein“ identifiziert werden können, bei dem KZG darum, wie viele Objekte als Output ,heraus“ reproduziert werden können, und zwar unter der Bedingung, dass das System nicht genügend weiteren Input bekommt. Wenn der nächste Nachschub nicht da ist, verfällt die bereits existierende Repräsentation. Das ist aus evolutionsbiologischer Sicht ein sinnvoller Selbstschutzmechanismus, damit das System ökonomisch arbeiten kann.

Gegen die Platzierung des sensorischen Gedächtnisses in der ,,associative buffer”-Phase, könnte Folgendes eingewendet werden: Es ist bei dem ,associative buffer” nicht mehr angemessen, von sensorischem Gedächtnis zu sprechen, weil die modalitätsspezifische Verarbeitung bereits vorausgegangen ist. Es soll aber in dem Modell so verstanden werden, dass der Output des ,,associative buffer“ hier insofern sensorisch ist, als es schließlich um den Inhalt des Buffers geht, der immer einen bestimmten sensorischen Ursprung hat, d.h. einen visuellen, auditiven oder somatosensorischen Ursprung. Der ,associative buffer” arbeitet zwar auf gleiche Weise, aber die Qualität und die Eigenschaft von dessen Produkt sind von den Input-Eigenschaften abhängig, unter anderem von der sensorischen Herkunft des Input und der damit zusammenhängenden neuronalen Bahnen. So kann man sagen, dass das von dem ,associative buffer" aufgestellte perzeptuelle Gedächtnis von seiner Dauer, Größe oder Kapazität her in Abhängigkeit von der Modalität unterschiedlich ist. Es gibt somit ein visuelles perzeptuelles und ein auditives perzeptuelles Gedächtnis. Sie entsprechen damit dem ikonischen Gedächtnis und dem echoischen Gedächtnis im herkömmlichen Sinne. Das ikonische Gedächtnis ist also in dem vorgestellten Modell im ,associative buffer” zu lokalisieren.

\subsubsection{Partial-report-Aufgabe (Sperling-Paradigma) im Rahmen des Modells}

Angesichts der Bedeutung der PR-Aufgabe zur Untersuchung des ikonischen Gedächtnisses und für die vorliegende Arbeit soll die Informationsverarbeitung während der Bearbeitung einer PR-Aufgabe bzw. eines Sperling-Paradigmas noch genauer nach dem Modell betrachtet werden. Die folgende Analyse bezieht sich vor allem auf die verwendete Methode in 
der aktuellen Untersuchung, nämlich eine Variante des Sperling-Paradigmas. Da aber Buchstaben als Versuchsmaterial eingesetzt wurden, wird zunächst noch kurz auf die visuelle Verarbeitung von Buchstaben eingegangen.

(1) Visuelle Verarbeitung von Buchstaben

Was die Erkennung von Buchstaben betrifft, die hauptsächlich in dem $P R$-Experiment verwendet werden, wird in der Arbeit im Rahmen des vorgestellten Modells davon ausgegangen, dass bei der Buchstabenwahrnehmung im Normalfall zuerst die einzelnen elementaren Merkmale erkannt werden. Die Merkmale werden dann zu bekannten Buchstabenmustern in dem „object attribute buffer“ geformt oder als solche wieder erkannt (Rekognition) und schließlich im ,associative buffer“ identifiziert. Diese Integration und Identifikation des Buchstabens geschieht wahrscheinlich nur mit Hilfe der Aufmerksamkeit.

Bereits Wolford (1975) hat ein Modell zur Buchstabenidentifikation (perturbation model for letter identification) aufgestellt. Er nahm an, dass die Merkmale bei parallelen unabhängigen Kanälen registriert, dann gruppiert und seriell als Buchstaben identifiziert werden. Störungen bei der Identifikation entstehen seinem Modell zufolge beim räumlichen Anordnen (spatial ordering) von Merkmalen. In dem konnektionistischen PDP-Modell (Parallel Distributed Processing; McClelland \& Rumelhart, 1981) werden einzelne Merkmale (z.B. ein horizontaler und ein vertikaler Strich) zu Buchstaben und einzelne Buchstaben werden wieder zu Wörtern kombiniert, wobei aus einer konnektionistischen Sicht auch eine Top-downAktivation angenommen wird, die benutzt wird, um das Erkennen einzelner Buchstaben zu erleichtern.

Treisman und Gelade (1980) interessierten sich in ihrer Untersuchung zur MIT auch für den Fall der etwas vertrauteren Stimuli wie den Buchstaben des lateinischen Alphabets. Für sie (ebd.) können die Merkmale ebenfalls lokale Elemente der Buchstaben sein, z.B. ein horizontaler Balken oder ein vertikaler Strich. Die Autoren konnten in einem ihrer Experimente zeigen, dass die Pbn längere Zeit brauchten, um einen Buchstaben, z.B. ein $\mathrm{R}$ in einer ansonsten aus den Buchstaben P und Q bestehenden Menge, zu finden, und zwar im Vergleich dazu, ein „, $\mathrm{R}^{\prime}$ in einer ansonsten aus den Buchstaben „P“ und „B“ bestehenden Menge zu identifizieren. Im ersten Fall brauchten die Pbn länger, weil der Zielbuchstabe aus Merkmalen der anderen beiden Buchstaben kombiniert werden konnte. Dasselbe galt auch für eine negative Entscheidung. So stellten Treisman und Gelade fest: „It is interesting that our hypothesis about the role of focal attention in integrating separable features appears to hold not only with arbitrary pairing of colors and shapes, or with unfamiliar schematic faces (Treisman et al., 
1977), but also with highly familiar, potentially, 'unitized' stimuli like letters“ (Treisman \& Gelade, 1980, S. 119).

In der frühen MIT wurde vor allem die lokalisationsbasierte Merkmalsintegration in den Vordergrund gestellt, wobei für Wahrnehmung von vertrauten Objekten oder Reizen auch der „Top-down-Abgleich“ zugelassen wurde (Treisman \& Schmidt, 1982; Treisman, 1986). In der weiteren Entwicklung der MIT ändert Treisman ihre Position von der lokalisationsdeterminierenden Bottom-up-Verarbeitung zugunsten der Top-down-Verarbeitung. So lässt sie in ihrer späteren Version der MIT (1993) eine Wahrnehmung zu, die entweder durch eine Objektdatei oder durch eine Merkmalskarte gesteuert wird.

In der Tat betrachten viele Modelle die Objektwahrnehmung nicht mehr als einen unidirektionalen, sondern vielmehr als einen interaktiven Prozess. Dabei konfrontieren die sensorischen Informationen auf einer oder mehreren Verarbeitungsebenen ständig mit der Topdown-Hypothese, um herauszufinden, was das zu identifizierende Objekt ist. Diese Top-downHypothese kann wiederum auf verschiedenen Niveaus sein.

Was vertrautes Material wie Buchstaben betrifft, kann die Top-down-Hypothese auf niedrigem Niveau z.B. ein gewisses orthographisches Wissen der Buchstaben enthalten. Auf einer höheren Ebene kann dann die Top-down-Hypothese die Identität der Buchstaben mit Aussprache usw. betreffen. Da das Ziel im „object attribute buffer“ in dem vorgestellten Modell ist, den Input in vertraute Muster (vgl. familar packet bei Kosslyn, 1994) zu organisieren und zu formen, ist es plausibel, anzunehmen, dass eine aktive Suche (top-down processing) nach vermuteten Elementen bei so vertrautem Material wie dem Alphabet im Spiel ist. In diesem Fall ist ein aktives Gestalten bzw. Organisieren der einzelnen Elemente nach vorhandenem orthographischen Wissen usw. in der „Rekognition“ in dem „object attribute buffer“ involviert. In dem ,associative buffer“ können dann alle die zu der Identität beitragenden Informationen höherer Ordnung, wie z.B. Aussprache, Kategorie, bei der Identifikation eines Buchstabes aktiv mitwirken.

Zusammenfassend wird in dem Modell die Ansicht vertreten, dass die Buchstabenerkennung einem vergleichbaren Verarbeitungsprinzip oder Verarbeitungsweg wie bei der Objektwahrnehmung folgt. Der Buchstabe wird nicht unitär wahrgenommen, sondern für die Buchstabenidentifikation müssen die elementaren Merkmale zunächst einzeln verarbeitet und dann integriert werden. Integration und Identifikation erfordert Aufmerksamkeit. In der Verarbeitung von Buchstaben kann der Top-down-Prozess eine große Rolle spielen. Zum einen kann die Rekognition in dem „object attribute buffer“, also da, wo die Buchstaben nach dem Modell ihre Gestalt oder Form annehmen, von Vorwissen (wie 
orthographischem Wissen) auf einem niedrigen Niveau top-down beeinflusst werden. Zum anderen kann das vorhandene Identitätswissen über die Buchstaben die Identifikation der Buchstaben in dem ,associative buffer“ aktiv mitgestalten.

(2) Verarbeitungseinschränkung im Sperling-Paradigma nach dem vorgestellten Modell

Im Sperling-Paradigma werden normalerweise mehrere Buchstaben gleichzeitig in einer Matrixform dargeboten. Bei Verarbeitung einer solchen Buchstabenmatrix können die Buchstaben entweder als einzelne Objekte, also als mehrere Objektdateien im Sinne von Treisman, oder als ein komplexes Objekt mit mehreren Teilobjekten wahrgenommen werden. Im zweiten Fall gibt es dann nur eine große Objektdatei. Was die experimentelle Aufgabe in der aktuellen Untersuchung betrifft, wird postuliert, dass für die gesamte Matrix nur ein einziger „associative buffer“ (bzw. eine einzige Objektdatei) zur Verfügung steht, da die Buchstaben gleichzeitig dargeboten worden sind, d.h., dass sie auch zur gleichen Zeit die gemeinsamen Verarbeitungswege beanspruchen. Dadurch kann es bei der Verarbeitung möglicherweise zu Kapazitätsproblemen kommen.

Was die Verarbeitungskapazität des „object attribute buffer“ und des ,,associative buffer“ bei der Sperling-Aufgabe angeht, ist nach dem vorgestellten Modell mit einer Überlastung zu rechnen: Sie kann zum einen die Wiedererkennung im „object attribute buffer“, zum anderen die Identifikation in dem ,,associative buffer“ betreffen.

Die Einschränkung im „object attribute buffer“ besteht darin, dass nur eine bestimmte Menge von Merkmalen gleichzeitig richtig zu einem Muster geformt bzw. als solches wieder erkannt werden kann. Kosslyn (1994) nahm ebenfalls an, dass nur eine begrenzte Menge von Outputs aus dem ,visual buffer“ in seinem „object properties subsystem“ auf einmal verarbeitet werden kann: „only a limited number of outputs from the visual buffer can be monitored at once“ (Kosslyn, 1994, S. 184). Der Grund für die Beschränkung im „object attribute buffer“ ist wahrscheinlich, dass das System an dieser Stelle perzeptuell nur eine bestimmte Kapazität hat und dass es für den ,perceptual load“ im Sinne von Lavie (1994, 1995) eine gewisse Grenze gibt. Allerdings sollte man hier vielleicht nicht von einer fixen Kapazität mit Mengenangaben sprechen, sondern es als ein Abgleichsverhältnis (trade-off) zwischen Qualität und Menge betrachten. Das perzeptuelle Feld hier ist wie ein variables Fenster, das kleiner oder größer eingestellt werden kann. Je größer es wird, desto weniger präzise und detailgetreu ist das Bild; je kleiner es wird, desto weniger passt hinein. Wenn der Input aus dem ,visual buffer“ in den „object attribute buffer“ die perzeptuelle Belastbarkeit übersteigert, können entweder durch Verwechslung falsche Muster geformt oder eben nur ein Teil des Input zu Mustern geformt werden, so dass es, egal in welchem Fall, zu wenigen richtig geformten oder wieder erkannten 
Mustern kommt. Wenn Buchstaben als Versuchsmaterial eingesetzt werden, wie in der Sperling-Aufgabe bzw. in der aktuellen Untersuchung, ist eine perzeptuelle Überlastung hoch wahrscheinlich. Außerdem kann eine Kapazitätseinschränkung der Verarbeitung im „object attribute buffer“ im Fall von vertrautem Material noch dadurch zustande gekommen sein, dass bei der Wiedererkennung im „object attribute buffer“ ein Top-down-Prozess im Sinne einer Anwendung von Wissen auf niedrigem Niveau involviert ist. Dabei wird möglicherweise eine gewisse Aufmerksamkeit gefordert werden, so dass bei der Verarbeitung mit einem Engpass zu rechnen ist.

Die zweite Kapazitätseinschränkung in dem vorgestellten Modell im Zusammenhang mit der Sperling-Aufgabe betrifft die Integrations- bzw. Identifikationsphase in dem ,associative buffer“, wo der Input aus den davor liegenden „object attribute buffer“ und „spatial info buffer“ zu einer Einheit vereinigt werden sollen. Wie oben bereits beschrieben wurde, verlangt dieser Integrations- bzw. Identifikationsprozess in dem ,associative buffer“ im ständigen Austausch mit dem ,memory storage“ gerichtete Aufmerksamkeit, und der Prozess erfolgt nur seriell, so dass jeweils nur ein Objekt identifiziert werden kann. Innerhalb gegebener Zeit, d.h. ohne weiteren Input aus den beiden vorgeschalteten Buffern, kann nur ein Teil des vorhandenen Inputs integriert und identifiziert werden.

(3) Die Rolle des Hinweisreizes in der PR-Aufgabe bzw. dem Sperling-Paradigma

Im Original-Sperling-Paradigma wurden auditive Hinweisreize verwendet. In der aktuellen Untersuchung sind sowohl auditive als auch visuelle Hinweisreize im Einsatz. In der heutigen Forschung mit der PR-Methode wird oft ein visueller Hinweisreiz benutzt. Die Frage ist: Wo setzt der Hinweisreiz an, bzw. wo wird der „Befehl“ des Hinweisreizes umgesetzt?

Im Rahmen des vorgestellten Modells kann angenommen werden, dass sich der visuelle und auditive Hinweisreiz in der PR-Aufgabe auf unterschiedliche Phasen der Informationsverarbeitung auswirken. Da dem Modell zufolge der auditive Hinweisreiz erst in dem „associative buffer“ (also in polymodalen Regionen) auf die visuell verarbeiteten Buchstaben treffen kann, ist es nahe liegend anzunehmen, dass die Botschaft des Hinweisreizes direkt dort, also in dem ,associative buffer“, umgesetzt wird. Es gibt durch die Steuerungsfunktion der präfrontalen Lokalisationskontrolle theoretisch auch die Möglichkeit, die Botschaft des auditiven Hinweisreizes in den „spatial info buffer“ zurückzuübersetzen, falls die Verarbeitung der Buchstaben sich noch auf dem Weg zum ,,associative buffer“ befindet. In diesem Fall wird dann mit Hilfe des thalamischen Aufmerksamkeitsmanipulationssystems, vor allem des Pulvinars, eine Verstärkung der Informationsverarbeitung des Stimulus-Inputs auf der ausgewählten Position in der ventralen Bahn in Gang gesetzt, d.h., es erfolgt eine 
positionsbasierte Selektion, die auf V4 und eventuell bis in den „object attribute buffer“ wirkt. Es ist sogar hypothetisch möglich, dass das Selektionssignal des auditiven Hinweisreizes auch schon auf den ,visual buffer“ wirken kann, was aber aus zeitlichem Grund auszuschließen ist. Die visuelle Vorlage wurde in den meisten Untersuchungen mindestens schon $50 \mathrm{~ms}$ vor dem auditiven Hinweisreiz dargeboten, es wird daher für die Selektion nicht reichen, den Stimulusinhalt noch im ,visual buffer“ zu beeinflussen, selbst wenn man von der weitaus schnelleren Verarbeitung des auditiven Hinweisreizes ausgeht. Denn die Top-downSelektionsmöglichkeiten aufgrund eines auditiven Hinweisreizes setzen voraus, dass der auditive Hinweisreiz an sich bereits soweit verarbeitet worden ist, d.h., dass er sich schon in dem ,,associative buffer“ mit seiner Botschaft befindet, während die anderen Zielreiz-Inputs auf dem Weg dorthin unterwegs sind. Aus dem vorangegangenen Experiment 2 weiß man, dass in der aktuellen Untersuchung der auditive Hinweisreiz viel später als der visuelle in dem „,associative buffer“" ankommt.

Was den visuellen Hinweisreiz betrifft, kann eine durch ihn hervorgerufene Selektion der Informationsverarbeitung der visuellen Matrix begleitend sein, weil die Verarbeitung des visuellen Hinweisreizes auf denselben Bahnen geschieht. Das heißt, eine Selektion kann sich in diesem Fall auf den „,visual buffer“, auf dem Weg in den „object attribute buffer“, direkt auf den „object attribute buffer“ oder auf den ,associative buffer“ auswirken, und zwar je nachdem, wann der Hinweisreiz dargeboten wird. Auf den genaueren Wirkungsort des visuellen Hinweisreizes in Abhängigkeit des Darbietungszeitpunkts wird im nächsten Abschnitt noch eingegangen. Die allgemeine Frage nach dem Selektionsort lässt sich folgendermaßen beantworten: Die Selektion aufgrund eines visuellen Hinweisreizes in der PR-Aufgabe kann in Abhängigkeit des Zeitintervalls zur Reizvorlage auf verschiedenen Ebenen geschehen. Das heißt, sie ist in allen Phasen möglich. Aber der Wirkungsort des auditiven Hinweisreizes befindet sich wahrscheinlich nur in späteren Phasen.

Es wurde zuvor bereits belegt, dass es einen stabilen Modalitätseffekt des Hinweisreizes in der Untersuchung zum visuellen sensorischen Gedächtnis gibt. Auf die Frage, wo und wie der Modalitätseffekt in dem vorgestellten Modell ausgemacht wird, wird gleich bei der Modellprüfung näher eingegangen.

\subsection{Experimente zur Prüfung des Modells}

\subsubsection{Experiment 5 zur Lokalisierung des Modalitätseffektes: Modellprüfung}

Im vorangegangenen empirischen Teil wurde demonstriert, dass die Modalität des Hinweisreizes in der Sperling-Aufgabe darin besteht, dass ein visueller Hinweisreiz generell zu 
einer schlechteren Leistung im Vergleich zu einem auditiven Hinweisreiz führt. Darüber hinaus gab es noch ein Phänomen, das bis jetzt rätselhaft geblieben ist. Beim Teilbericht in der 0-msISI-Bedingung unterschieden sich die Leistungen in den beiden Hinweisreizbedingungen nicht; der visuelle Hinweisreiz stellte sogar eine etwas günstigere Bedingung dar. Wie kann man den Modalitätseffekt des Hinweisreizes nach dem vorgestellten Modell erklären? Was läuft bei der 0-ms-ISI-Bedingung anders ab?

Durch die Experimente 2 bis 4 wurde gezeigt, dass der Modalitätseffekt auf eine intramodale Interferenz zwischen dem Zielreiz und dem Hinweisreiz zurückzuführen ist. Allerdings sagt dies wenig darüber aus, wo und wie die Interferenz zustande kommt.

Gemäß dem vorgestellten Modell kann der Unterschied nur bei der visuellen Informationsverarbeitung des Zielreizes auf dem Weg in den ,associative buffer“ durch den ebenfalls visuell zu verarbeitenden Hinweisreiz hervorgerufen worden sein. Denn in dem „,associative buffer“ müssen die beiden Hinweisreize auf gleiche Weise wirken. Ab diesem Moment müssen die Verarbeitungen in beiden Fällen ähnlich verlaufen.

Aus Experiment 3 wissen wir, dass der visuelle Hinweisreiz in dem aktuellen experimentellen Design sogar schneller verarbeitet bzw. identifiziert werden kann. Das bedeutet, dass die Selektion mit gleichem ISI im Falle eines visuellen Hinweisreizes im Grunde früher einsetzen sollte als bei einem auditiven Hinweisreiz, was wiederum eigentlich einen Vorteil bringen sollte (s.o. Modellbeschreibung: je früher die Selektion, desto präzisere und bessere Verarbeitung der ausgewählten Position). Aber der Vorteil tritt anscheinend nicht immer zutage, es müssen daher noch andere Faktoren im Spiele sein.

Nach dem vorgestellten Modell können in der Sperling-Aufgabe zumindest zwei Stellen unter Kapazitätseinschränkung leiden: zum einen betrifft es die Verarbeitung (Wiedererkennung) im „object attribute buffer“, zum anderen betrifft es die Verarbeitung (Identifikation) im ,associative buffer“. Die erste Einschränkung entsteht dadurch, dass bei einer perzeptuellen Überlastung des Systems nur ein Teil der Inputs im „object attribute buffer“ zu Mustern geformt oder als solche wieder erkannt werden kann. Die zweite Einschränkung im ,,associative buffer“ geht darauf zurück, dass die Inputs in dem Buffer nur seriell verarbeitet werden können, wenn mehrere Objekte innerhalb einer bestimmten Zeit zu identifizieren sind und zwar ohne weitere Reizinputs und bevor die Inputs verblassen -, so dass nur eine bestimmte Menge von Objekten identifiziert werden kann. Wenn mehrere Buchstaben wie in der aktuellen Untersuchung in Matrixform zeitgleich als visuelle Vorlage dargeboten werden, und alle wiedergegeben werden müssen, ist wahrscheinlich mit beiden Arten von Engpässen zu rechnen. 
Der Leistungsunterschied (Modalitätseffekt) zwischen visuellen und auditiven Hinweisreizbedingungen in den vorausgehenden Experimenten trat sowohl beim Ganzbericht als auch beim Teilbericht auf. Dem Modell zufolge könnte es sich hier um zwei Arten von Leistungsunterschieden handeln, die verschiedene Ursachen haben. Der Leistungsunterschied in der Ganzberichtsbedingung und der in der Teilberichtsbedingung zeigt wahrscheinlich die zwei postulierten Kapazitätsbeschränkungen in dem dargestellten Modell an. Die schlechtere Leistung beim Ganzbericht mit visuellem Hinweisreiz im Vergleich zum auditiven Hinweisreiz könnte durch die perzeptuelle Kapazitätsbeschränkung in dem „object attribute buffer“ zu erklären sein. Denn in der aktuellen Untersuchung erscheint beim Ganzbericht der visuelle Hinweisreiz mit größerem physischen Ausmaß (Doppelpfeile in Experiment 1 oder Doppelecke in Experiment 3) fast zeitgleich wie die Matrix. In diesem Fall muss das „Aufmerksamkeitsfenster“ im „object attribute buffer“ entweder größer eingestellt werden, so dass weniger auf Detail geachtet wird, oder es muss verkleinert werden, so dass nur ein bestimmter Teil berücksichtigt werden kann. Daraus kann nur resultieren, dass hier falsche oder wenige Muster von Buchstaben geformt werden, so dass in beiden Fällen weniger korrekte Buchstaben wiedergegeben werden können.

Beim Teilbericht könnte die schlechtere Leistung mit den visuellen Hinweisreizen nach dem vorgestellten Modell aber eine andere Ursache haben. Die ,perceptual load“ im „object attribute buffer“ ist beim Teilbericht zwar nicht überlastet, aber in dem ,associative buffer“ kommt es bei der Objektidentifikation zur Interferenz, da der Hinweisreiz ebenfalls identifiziert, also kognitiv interpretiert werden muss, und dieses sogar vorrangig geschehen muss. In diesem ,,associative buffer“ ist aber leider nur serielle Verarbeitung möglich und unter diesem Umstand kann daher nur eine bestimmte Menge identifiziert werden.

Bei der 0-ms-ISI-Teilberichtsbedingung handelt sich um einen Spezialfall. Nach der 50ms-Reizdarbietung erschien in Experiment 1 fast zeitgleich der visuelle Hinweisreiz (Pfeil) und zu dieser Zeit soll sich die Reizinformation nach dem vorgestellten Modell noch in der Phase des „visual buffer“ befinden. Da der visuelle Hinweisreiz und die visuellen Zielreize (Buchstabenmatrix) die gleichen Verarbeitungswege beanspruchen, ist eine vollständige Verarbeitung des Hinweisreizes nicht notwendig. Die gefragte Zeile wird bottom-up direkt aus dem „,visual buffer“, wo sie topographisch organisiert ist, „,selektiert“. Das ist aber eigentlich nicht die vom Präfrontalcortex gesteuerte Top-down-Selektion (Selektion 2 in dem Modell, s. Abb. 22), sondern sie ist eine automatische Bottom-up-Selektion (,Stimulus-driven“-Selektion; vgl. LaBerge, 2000), da der Hinweisreiz noch nicht interpretiert ist. Ab dieser Stufe wird dann nur die Reizinformation von der gefragten Zeile in den „object attribute buffer“ und den 
„spatial info buffer“ weitergeleitet. Bei einem auditiven Hinweisreiz mit einer 0-ms-ISIBedingung im Teilbericht muss die Selektion durch den Top-down-Weg via „spatial info buffer“ in den ,visual buffer“ eingreifen, was aber unwahrscheinlich ist, oder sie wirkt erst auf die späteren Phasen der Verarbeitung ein. Der Selektionsprozess beim auditiven Hinweisreiz dauert in diesem Fall etwas länger, er kann nur einigermaßen mit dem Selektionsprozess in der visuellen Hinweisreizbedingung mithalten, daher besteht tendenziell ein Vorteil für die visuelle Hinweisreizbedingung, aber der Unterschied in der Leistung ist nur minimal. Denkbar wäre, dass bei der visuellen Hinweisreizbedingung mit einem 0-ms-ISI in Experiment 1 und 3 eine automatisierte Selektion aufgrund der unmittelbaren Hinweisreiz-Darbietung stattgefunden hat, wofür die kognitive Interpretation des Hinweisreizes nicht vorausgesetzt werden muss. Dieser Vorteil durch frühe Selektion eliminierte den möglichen aufzutretenden Nachteil für die visuelle Hinweisreizbedingung in den folgenden Verarbeitungsphasen, so dass kein Leistungsunterschied zwischen den beiden Hinweisreizbedingungen auftrat, wenn das ISI zwischen dem Offset der visuellen Vorlage und dem Onset des Hinweisreizes 0 ms betrug.

In der aktuellen Untersuchung wurde beim Ganzbericht nur eine ISI-Bedingung realisiert und der Hinweisreiz für den Ganzbericht wurde immer unmittelbar nach dem Offset der Reizvorlage dargeboten. Die Frage bei der Betrachtung der obigen Analysen ist, warum die visuelle Ganzberichtsbedingung nicht von der unmittelbar folgenden Hinweisreiz-Darbietung profitiert hat, sondern ebenfalls schlechtere Leistung gegenüber der auditiven Bedingung aufwies. Dem vorgestellten Modell zufolge liegt die Erklärung darin, dass der Hinweisreiz an sich für den Ganzbericht keine richtige Selektion hervorrufen konnte. Selbst wenn der visuelle Hinweisreiz in diesem Fall in dem ,visual buffer“ bottom-up wirkte, hatte dieses aber keine Aktivität der neurophysiologischen Aufmerksamkeitsmodulation zufolge, weil der Hinweisreiz eigentlich keine Selektion zu bedeuten hatte.

Bei den anderen ISI-Bedingungen mit visuellen Hinweisreizen musste der visuelle Hinweisreiz erst vollständig verarbeitet, d.h., in dem ,associative buffer“ identifiziert und mit seiner Botschaft verstanden werden. Diese Verarbeitung interferierte aber mit der Verarbeitung der Zielreize (Buchstaben in der Matrix). In dem vorgestellten Modell wird postuliert, dass die Zusammenfügung der Eigenschaften bzw. die Stimulus-Identifikation Aufmerksamkeit erfordert und nur seriell durchgeführt werden kann. Die Identifikation des Hinweisreizes konkurriert mit der Identifikation der Buchstaben im ,associative buffer“, wobei die Hinweisreiz-Interpretation sogar einen Vorrang hat, denn um die Aufgabe erledigen zu können, muss der Hinweisreiz zuerst interpretiert werden. Somit entstand ein Verlust bei der Identifikation der Zielbuchstaben. 
Um den Modalitätseffekt näher zu betrachten, ihn zu lokalisieren, und noch wichtiger, um die obigen abgeleiteten Hypothesen als Modellprüfung zu testen, werden im Experiment 5 folgende Vorhersagen nach diesem Modell aufgestellt:

Vorhersage 1: Wenn der gefundene Modalitätseffekt beim Teilbericht auf eine Interferenz im ,associative buffer“ durch den Verarbeitungsengpass bei der Objektidentifikation zurückzuführen ist, tritt er beim Teilbericht in der aktuellen Untersuchung nur dann auf, wenn der visuelle Hinweisreiz kognitiv verarbeitet werden muss, er also im ,associative buffer“ interpretiert werden muss.

Vorhersage 2: Wenn der gefundene Modalitätseffekt beim Ganzbericht auf eine perzeptuelle Interferenz im „object attribute buffer“ durch perzeptuelle Überlastung zurückzuführen ist, tritt er beim Ganzbericht auch auf, selbst wenn der visuelle Hinweisreiz nicht kognitiv verarbeitet werden muss, d.h., nicht in dem ,,associative buffer“ interpretiert werden muss.

\subsubsection{Methode}

Die „kognitive Verarbeitung“ des visuellen Hinweisreizes wurde dadurch gewährleistet, dass die Pbn in der entsprechenden Bedingung gezwungen wurden, den Hinweisreiz zu interpretieren, um die Aufgabe überhaupt bearbeiten zu können.

In Experiment 5 wurde ein ähnliches Design wie in Experiment 1 realisiert, allerdings wurde eine verbale Anweisung über die zu berichtende Zeile der Matrix kurz vor dem Tastendruck (Start) gegeben. Die Anweisungen hießen: „oben“, „unten“ und „ganz“, womit jeweils die obere bzw. untere Zeile oder beide Zeilen zu berichten gemeint war.

Zwei Bedingungen wurden in das Experiment eingebaut: Bedingung A und Bedingung $\mathbf{B}$ (zum Ablauf: s. Abb. 23):

Bedingung A: gleiches experimentelles Programm wie in Experiment 1, der ursprüngliche Hinweisreiz wurde zwar dargeboten, aber seine Funktion wurde durch eine vorherige verbale Anweisung ersetzt und war damit aufgabenirrelevant.

Bedingung B: gleicher Versuchsablauf wie in der Bedingung A, aber die Anweisung und der Hinweisreiz mussten gleichermaßen beachtet werden.

Die wichtige Unterscheidung zwischen Bedingung A und Bedingung B lag darin, dass der Hinweisreiz unter der Bedingung A für die Aufgabe als nicht relevant galt, während er unter der Bedingung B relevant war. Die Pbn unter Bedingung A sollten nur der verbalen Anweisung folgen und den ursprünglichen Hinweisreiz ignorieren, während sie in der Bedingung B sowohl die Anweisung beachten, als auch den Hinweisreiz interpretieren mussten. In der Bedingung B wird eine kognitive Verarbeitung des Hinweisreizes angenommen, während in der Bedingung A der ursprüngliche Hinweisreiz nur peripher verarbeitet werden soll. 


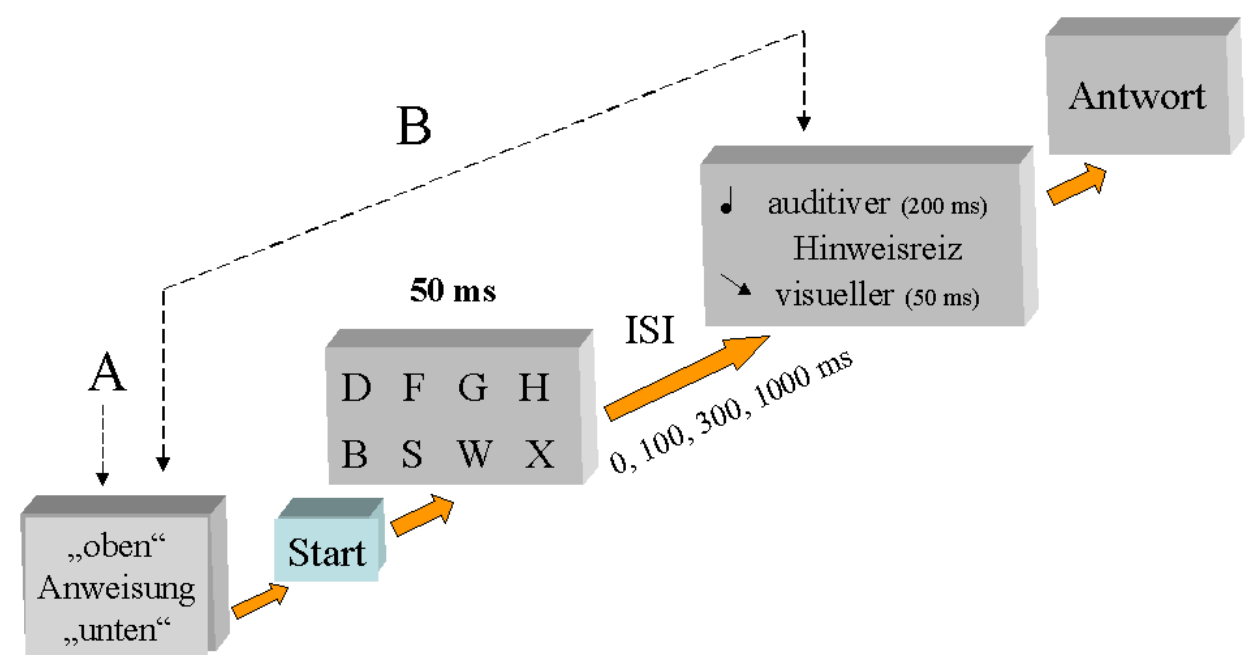

Abbildung 23: Ablauf eines Durchgangs in der Bedingung A und B in Experiment 5.

Probanden. 24 Studierende der Universität Göttingen haben an dem Versuch teilgenommen. Der Altersdurchschnitt betrug 22.5 Jahre (Range 19-31, SD = 3.01).

Apparate und Versuchsraum. Die Apparaturen und der Versuchsraum waren die gleichen wie in Experiment 1. Eine Sondertaste wurde mit rot und groß geschriebenem Buchstaben „A“ beklebt, sie diente für die Sondereintragung (s. Aufgabenanforderung).

Versuchsmaterial. Das verwendete Reizmaterial ist dasselbe wie in Experiment 1. Für jede Bedingung wurde eine gesonderte Instruktion (A und B) eingesetzt. Eine Liste mit Anweisungen, die zwischen (ursprünglichen) Hinweisreizen und Berichtsarten variiert worden sind, wurde für den/die Versuchsleiter/Versuchsleiterin (VL) bereitgestellt.

Aufgabenanforderung und Versuchsablauf (Abb. 23).

Bedingung A: Der/die $\mathrm{Pb}$ sollte seine/ihre Aufmerksamkeit zunächst auf die Mitte des Fixationskreuzes richten. Nach der bündigen Anweisung von dem/der VL (,oben“, ,unten“ oder „ganz“) konnte der/die Pb die Reizdarbietung sofort per Eingabetaste initiieren. Die 2x4Matrix wurde unmittelbar für 50 ms präsentiert. Per Zufall wurde(n) der Pfeil (die Pfeile) für 50 ms und der Ton (auch der Doppelton) für $200 \mathrm{~ms}$ dargeboten, und zwar nach einem Zeitintervall (ISI) von 0, 100, 300 oder 1000 ms, das wiederum variiert wurde. Danach folgte die Antworteintragung. Die Pbn sollten nun eintragen, was die jeweilige Anweisung forderte, d.h., wenn „oben“ genannt wurde, die obere Zeile, wenn „unten“ genannt wurde, die untere Zeile, und bei der Ansage „ganz“ beide Zeilen.

Bedingung B: Die Hinweisreize wurden als solche vorgeführt und dann in den Übungsdurchgängen in ihrer Funktion geübt. Ansonsten war der Ablauf des Durchgangs der gleiche wie in der Bedingung A, die Pbn sollten in der Bedingung aber nur die von der Anweisung und dem Hinweisreiz gemeinsam erfragte Zeile wiedergeben. Das heißt, nur wenn 
der Hinweisreiz mit der Anweisung übereinstimmt, sollten die erfragte Zeile oder die erfragten Zeilen wiedergegeben werden. Wenn die beiden nicht miteinander übereinstimmten, dann sollten die Pbn mit der rot gekennzeichneten Taste „A“ das Antwortgitter füllen, damit das experimentelle Steuerungsprogramm fortfahren konnte.

Versuchsdurchführung. Der Versuch dauerte ca. 1.5 Stunden. Die Reihenfolge zwischen Bedingung A und B wurde permutiert. Für jede Bedingung wurden 160 Durchgänge getestet, wobei sie in vier Blöcke eingeteilt waren. Im Unterschied zu den Experimenten zuvor wurden die auditiven Töne und die visuellen Pfeile innerhalb eines Blocks per Zufall gemischt dargeboten, die ISI wurden wie in Experiment 1 variiert.

\subsubsection{Ergebnisse}

Bedingung A: Abbildung 24a veranschaulicht die Ergebnisse des Teilberichts (aus beiden Teilberichtsarten zusammen ermittelt) und des Ganzberichts für jede Bedingung, wo in der einen der ursprüngliche visuelle Hinweisreiz und in der anderen der auditive Hinweisreiz dargeboten wurde.
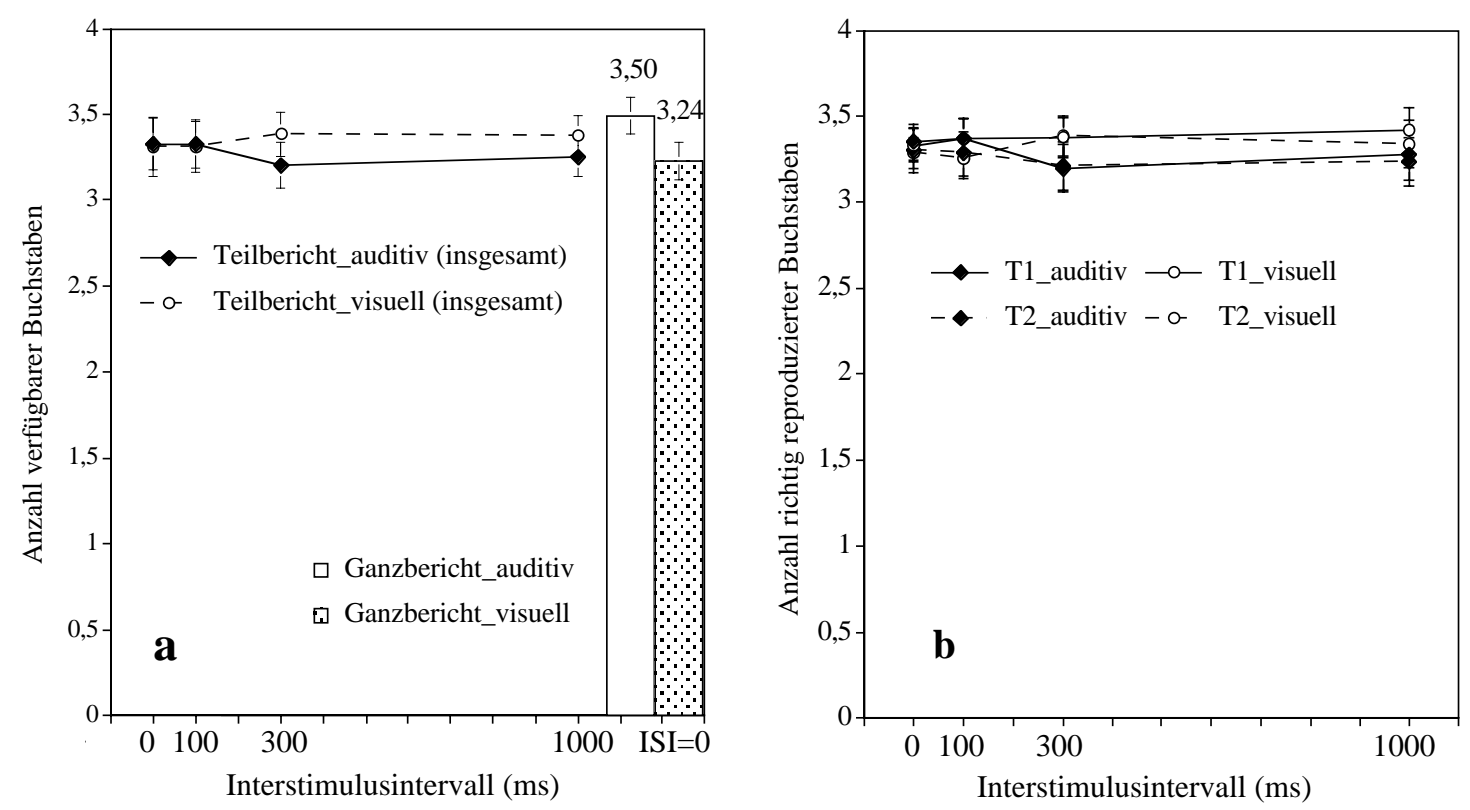

Abbildung 24: Ergebnisse in Experiment 5A; dargestellt in Abhängigkeit von ISI und (ursprünglicher) Hinweisreizart; $\mathrm{N}=24$.

a: Mittelwerte und Standardfehler für die Anzahl richtig reproduzierter Buchstaben im Ganzbericht und im Teilbericht. Das ISI zwischen dem Offset der Buchstabenmatrix und dem Onset des Hinweisreizes variierte in der Teilberichtsbedingung zwischen 0 und $1000 \mathrm{~ms}$. Beim Ganzbericht betrug das ISI $0 \mathrm{~ms}$.

b: Mittelwerte und Standardfehler für die Anzahl richtig reproduzierter Buchstaben im Teilbericht je Berichtsart (T1: Reproduktion der oberen Zeile; T2: Reproduktion der unteren Zeile) und je ISI.

Der Hinweisreiz war in der Bedingung A nur ein visuelles oder auditives Begleit-Ereignis und hatte keinen Instruktions-Charakter. Die Leistung des Teilberichts wurde nicht wie in den vergangenen Experimenten hochgerechnet. Denn die Pbn wussten bereits vor der Matrix- 
Darbietung über die Aufgabe, welche Zeile zu reproduzieren war, Bescheid. Damit ist die Voraussetzung für eine Hochrechnung nicht mehr gegeben. Deshalb war wie erwartet auch keine Abnahme der Leistung in Abhängigkeit vom ISI und ebenso keine Teilberichtsüberlegenheit mehr gegenüber dem Ganzbericht in den Daten zu beobachten. Das gleiche galt auch bei einer getrennten Betrachtung der Teilberichtsleistung (s. Abb. 24b).

Eine dreifaktorielle MANOVA mit den Innersubjekt-Faktoren „Hinweisreizmodalität“ (zwei Stufen: auditiv und visuell), „ISI“ (vier Stufen: 0, 100, 300, 1000 ms Bedingung) und „Berichtsart“ (zwei Stufen: Teilbericht 1 und Teilbericht 2) wurde mit den Teilberichtsdaten berechnet. Es ergab sich kein signifikanter Haupteffekt der „Hinweisreizmodalität“ $[F(1,23)=$ 2.69, $\left.\Lambda(1,23)=.90, p=.115, \eta^{2}=.11\right]$, ebenfalls kein signifikanter Haupteffekt des ,ISI“ [F(3, 21) $\left.=0.14, \Lambda(3,21)=.98, p=.937, \eta^{2}=.019\right]$ und kein signifikanter Haupteffekt der „Berichtsart“ $\left[F(1,23)=1.73, \Lambda(1,23)=.93, p=.201, \eta^{2}=.070\right]$. Keine Wechselwirkung zwischen den Faktoren war bedeutsam.

In Tabelle 7 sind die statistischen Testergebnisse der Einzelvergleiche zusammengestellt.

Tabelle 7. Ergebnisse der Mittelwertsvergleiche zwischen den Leistungen in der auditiven und der visuellen (ursprünglichen) Hinweisreizbedingung in den einzelnen Bedingungskombinationen in Experiment 5A

\begin{tabular}{|c|c|c|c|c|c|c|c|c|}
\hline \multirow{3}{*}{ Berichtsart } & \multicolumn{7}{|c|}{ Hinweisreiz $^{a}$} & \multirow{3}{*}{$\varepsilon$} \\
\hline & \multirow[t]{2}{*}{$\mathrm{ISI}^{\mathrm{b}}$} & \multicolumn{2}{|c|}{ auditiv } & \multicolumn{2}{|c|}{ visuell } & \multirow[t]{2}{*}{$t$} & \multirow[t]{2}{*}{$p$} & \\
\hline & & $M$ & $S D$ & $M$ & $S D$ & & & \\
\hline Ganzbericht & 0 & 3.50 & 0.53 & 3.24 & 0.52 & 4.52 & $<.001$ & 2.53 \\
\hline \multirow[t]{4}{*}{ Teilbericht $^{\mathrm{c}}$} & 0 & 3.33 & 0.48 & 3.31 & 0.40 & 0.33 & .748 & 0.14 \\
\hline & 100 & 3.33 & 0.57 & 3.31 & 0.50 & 0.15 & .884 & 0.00 \\
\hline & 300 & 3.20 & 0.55 & 3.38 & 0.50 & -2.18 & .040 & -0.88 \\
\hline & 1000 & 3.26 & 0.64 & 3.38 & 0.63 & -1.10 & .283 & -0.44 \\
\hline \multirow[t]{4}{*}{ Teilbericht 1} & 0 & 3.35 & 0.51 & 3.33 & 0.45 & 0.21 & .834 & 0.07 \\
\hline & 100 & 3.37 & 0.57 & 3.37 & 0.57 & 0.01 & .993 & 0.00 \\
\hline & 300 & 3.20 & 0.67 & 3.38 & 0.57 & -1.42 & .171 & -0.40 \\
\hline & 1000 & 3.28 & 0.73 & 3.42 & 0.67 & -0.94 & .358 & -0.26 \\
\hline \multirow[t]{4}{*}{ Teilbericht 2} & 0 & 3.30 & 0.65 & 3.28 & 0.45 & 0.17 & .868 & 0.05 \\
\hline & 100 & 3.28 & 0.62 & 3.26 & 0.58 & 0.19 & .851 & 0.05 \\
\hline & 300 & 3.21 & 0.69 & 3.38 & 0.54 & -1.22 & .236 & -0.32 \\
\hline & 1000 & 3.23 & 0.67 & 3.34 & 0.67 & -1.01 & .325 & -0.40 \\
\hline
\end{tabular}

Anmerkungen. M: Mittelwert, SD: Standardabweichung der Mittelwerte, $\varepsilon$ : Effektgröße.

${ }^{\text {a }}$ In dieser Bedingung hat der ursprüngliche Hinweisreiz aber nicht die wirkliche Hinweisreiz-Funktion.

${ }^{\mathrm{b}}$ Interstimulusintervall in ms.

${ }^{\mathrm{c}}$ Aus Teilbericht 1 und Teilbericht 2 zusammen ermittelter Mittelwert für Teilbericht insgesamt.

Teilbericht 1: Reproduktion der oberen Zeile.

Teilbericht 2: Reproduktion der unteren Zeile. 
Wenn man die statistischen Testergebnisse (t-Test) der Einzelvergleiche (s. Tabelle 7) betrachtet, war vor allem kein bedeutsamer Unterschied zwischen den beiden HinweisreizBedingungen beim Teilbericht mehr da, d.h. nur mit Ausnahme bei der Gesamtbetrachtung der Teilberichtsbedingung mit einem ISI von $300 \mathrm{~ms}[t(23)=-2.18, p=.040<.05, \varepsilon=-0.88]$, wobei es hier eine etwas bessere Leistung für die visuelle Hinweisreizbedingung gab. Der robuste Leistungsvorteil unter der auditiven Hinweisreizbedingung in den vergangenen Experimenten verschwand auch bei einer getrennten Betrachtung der Teilberichtsleistung. Die Leistungen unter den beiden Hinweisreizbedingungen beim Ganzbericht unterschieden sich interessanterweise aber nach wie vor hochsignifikant voneinander $[t(23)=4.52, p<.001, \varepsilon=$ 2.53], dies kann man aus der Abbildung 24a und der Tabelle 7 entnehmen.

Bedingung B: Die Abbildung 25a und 25b veranschaulichen die Ergebnisse der Bedingung 5B. Was den Modalitätseffekt betrifft, ergab sich ein ähnliches Bild wie in Experiment 1. Sowohl beim Ganzbericht als auch beim Teilbericht zeigten sich fast überall wieder schlechtere Leistungen bei den visuellen Hinweisreizen.
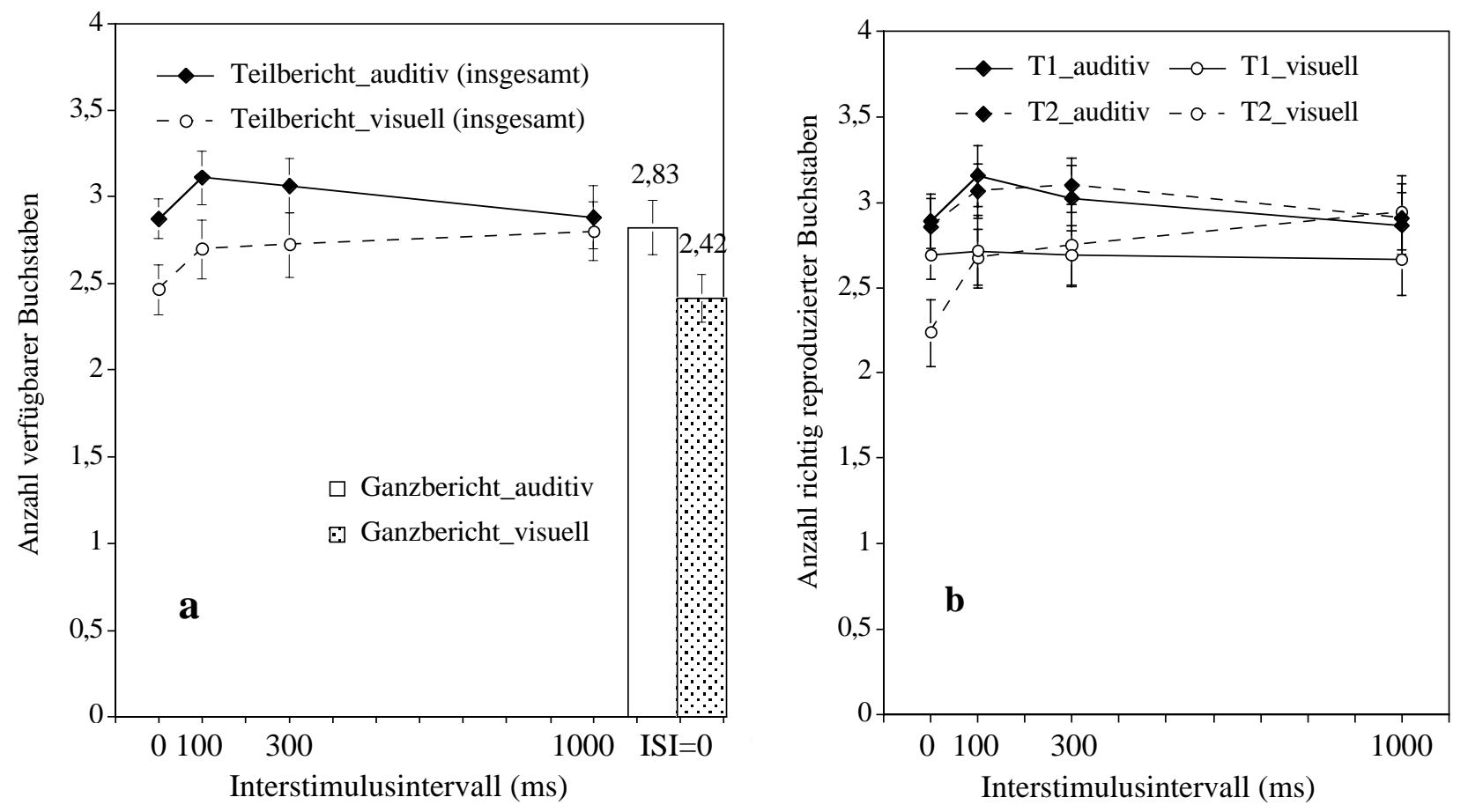

Abbildung 25: Ergebnisse in Experiment 5B; dargestellt in Abhängigkeit von ISI und Hinweisreizart; $\mathrm{N}=24$.

a: Mittelwerte und Standardfehler für die Anzahl richtig reproduzierter Buchstaben im Ganzbericht und im Teilbericht. Das ISI zwischen dem Offset der Buchstabenmatrix und dem Onset des Hinweisreizes variierte in der Teilberichtsbedingung zwischen 0 und 1000 ms. Beim Ganzbericht betrug das ISI 0 ms.

b: Mittelwerte und Standardfehler für die Anzahl richtig reproduzierter Buchstaben im Teilbericht je Berichtsart (T1: Reproduktion der oberen Zeile; T2: Reproduktion der untere Zeile) und je ISI. 
Eine dreifaktorielle MANOVA mit den Innersubjekt-Faktoren „Hinweisreizmodalität“ (zwei Stufen: auditiv und visuell) , „ISI“ (4 Stufen: 0, 100, 300, 1000 ms Bedingung) und „Berichtart“ (zwei Stufen: Teilbericht 1 und Teilbericht 2) von den Teilberichtsdaten unter der Bedingung B ergab einen hoch signifikanten Haupteffekt der „Hinweisreizmodalität“ $[F(1,23)=$ $\left.35.98, \Lambda(1,23)=.39, p<.001, \eta^{2}=.61\right]$. Außer diesem bedeutsamen Effekt war kein anderer Haupteffekt oder Interaktion signifikant.

Der Leistungsunterschied zwischen den beiden Hinweisreizbedingungen trat signifikant bei fast allen Bedingungen bis auf die Bedingung mit ISI von $1000 \mathrm{~ms}$ auf (s. Tabelle 8). Beim Ganzbericht wurde signifikant schlechtere Leistung unter der visuellen Hinweisreizbedingung erbracht $[t(23)=3.46, p=.002<.05, \varepsilon=1.26]$.

Tabelle 8. Ergebnisse der Mittelwertsvergleiche zwischen den Leistungen in der auditiven und der visuellen Hinweisreizbedingung in den einzelnen Bedingungskombinationen in Experiment $5 \mathrm{~B}$

\begin{tabular}{|c|c|c|c|c|c|c|c|c|}
\hline \multirow{3}{*}{ Berichtsart } & \multirow{3}{*}{$\mathrm{ISI}^{\mathrm{a}}$} & \multicolumn{4}{|c|}{ Hinweisreiz } & \multirow{3}{*}{$t$} & \multirow{3}{*}{$p$} & \multirow{3}{*}{$\varepsilon$} \\
\hline & & \multicolumn{2}{|c|}{$\underline{\text { auditiv }}$} & \multicolumn{2}{|c|}{ visuell } & & & \\
\hline & & $M$ & $S D$ & $M$ & $S D$ & & & \\
\hline Ganzbericht & 0 & 2.83 & 0.77 & 2.42 & 0.68 & 3.46 & .002 & 1.26 \\
\hline \multirow[t]{4}{*}{ Teilbericht $^{\mathrm{b}}$} & 0 & 2.87 & 0.58 & 2.46 & 0.72 & 3.45 & .002 & 1.14 \\
\hline & 100 & 3.11 & 0.75 & 2.69 & 0.83 & 3.41 & .002 & 1.32 \\
\hline & 300 & 3.06 & 0.78 & 2.72 & 0.91 & 2.44 & .023 & 0.88 \\
\hline & 1000 & 2.88 & 0.89 & 2.80 & 0.82 & 0.73 & .474 & 0.55 \\
\hline \multirow[t]{4}{*}{ Teilbericht 1} & 0 & 2.89 & 0.78 & 2.69 & 0.71 & 1.45 & .162 & 0.46 \\
\hline & 100 & 3.15 & 0.88 & 2.72 & 1.01 & 2.28 & .032 & 0.67 \\
\hline & 300 & 3.02 & 0.93 & 2.69 & 0.86 & 2.22 & .045 & 0.72 \\
\hline & 1000 & 2.86 & 0.97 & 2.66 & 0.99 & 0.90 & .376 & 0.24 \\
\hline \multirow[t]{4}{*}{ Teilbericht 2} & 0 & 2.85 & 0.83 & 2.23 & 0.96 & 3.10 & .005 & 0.83 \\
\hline & 100 & 3.06 & 0.78 & 2.67 & 0.83 & 2.75 & .011 & 0.92 \\
\hline & 300 & 3.10 & 0.78 & 2.75 & 1.18 & 1.91 & .069 & 0.65 \\
\hline & 1000 & 2.90 & 1.01 & 2.94 & 1.06 & -0.23 & .821 & -0.09 \\
\hline
\end{tabular}

Anmerkungen. M: Mittelwert, $S D$ : Standardabweichung der Mittelwerte, $\varepsilon$ : Effektgröße.

${ }^{\mathrm{a}}$ Interstimulusintervall in ms.

${ }^{\mathrm{b}}$ Aus Teilbericht 1 und Teilbericht 2 zusammen ermittelter Mittelwert für Teilbericht insgesamt. Teilbericht 1: Reproduktion der oberen Zeile.

Teilbericht 2: Reproduktion der unteren Zeile.

Die Leistungen in der Bedingung B waren insgesamt schlechter als in der Bedingung A. Sie nahmen auch nicht mit zunehmendem Zeitintervall ab. Bei der Bedingung mit einem ISI von $0 \mathrm{~ms}$ scheint die Leistung sogar schlechter als in den anderen ISI-Bedingungen zu sein. Aber der Unterschied zwischen der 0-ms-ISI-Bedingung und der 100-ms-ISI-Bedingung beim 
Teilbericht (insgesamt) war sowohl bei auditiven als auch bei visuellen Hinweisreizen nicht signifikant. Nur wenn die Teilberichtsarten getrennt betrachtet wurden, ergab sich ein signifikanter Unterschied bei Teilbericht 2 mit dem visuellen Hinweisreiz $[t(23)=2.20, p=.038$ $<.05, \varepsilon=-0.65]$.

\subsubsection{Diskussion}

Die Ergebnisse in der Bedingung A zeigen, dass sich die Leistungen unter beiden Hinweisreizbedingungen nicht unterschieden, wenn in der Teilberichtsbedingung der (ursprüngliche) Hinweisreiz nur begleitend dargeboten bzw. peripher verarbeitet wurde. Das heißt, dass die periphere Verarbeitung des visuellen Hinweisreizes keinen Einfluss auf die Verarbeitung der visuellen Matrix hat. Wenn dagegen in der Bedingung B der Hinweisreiz kognitiv verarbeitet werden musste, trat anscheinend eine Interferenz zwischen der Verarbeitung der visuellen Zielreize (Buchstaben) und des visuellen Hinweisreizes auf. Als Folge wurde dadurch die Reproduktion der Buchstaben beeinträchtigt, so dass im Vergleich zu der auditiven Hinweisreizbedingung eine schlechtere Leistung auftrat. Beim Ganzbericht scheint es aber so zu sein, dass es, sobald der visuelle Hinweisreiz dargeboten wird, zu einer Störung kommt, egal ob der visuelle Hinweisreiz aufgabenrelevant ist. Das heißt, diese Störung des visuellen Hinweisreizes in der Ganzberichtsbedingung ist nicht kognitiv bedingt.

Die kognitive Interpretation des visuellen Hinweisreizes in der Teilberichtsbedingung ereignet sich nach dem oben vorgestellten Modell in dem ,associative buffer“, nämlich dort, wo die einzelnen Objekte (Buchstaben) identifiziert werden müssen. Die Merkmalsintegration und Identifikation ist ein kognitiver Verarbeitungsprozess, der seriell verläuft und die mentale Steuerung durch Instanzen im präfrontalen Cortex und die Aktivierung der gespeicherten Wissensrepräsentationen beansprucht. Wenn der Hinweisreiz nicht kognitiv verarbeitet werden muss, bedeutet dies, dass für ihn nur eine perzeptuelle Wahrnehmung bis in den ,object attribute buffer“ notwendig ist. Da in dem „object attribute buffer“ bei der Teilberichtsaufgabe keine perzeptuelle Überlastung zu erwarten ist und der visuelle Hinweisreiz in diesem Fall auch keine Verarbeitungskapazität im ,associative buffer“ beansprucht, findet somit keine Konkurrenz statt. Das ist ähnlich wie in der Bedingung, in der ein auditiver (ursprünglicher) Hinweisreiz dargeboten wird. Deshalb lässt sich zwischen den beiden BegleitereignisBedingungen kein Leistungsunterschied im Teilbericht feststellen.

Beim Ganzbericht trat (fast) immer ein Leistungsunterschied auf. Es sieht so aus, dass die Interferenz, die durch den visuellen Hinweisreiz verursacht wird, rein perzeptueller Natur ist. Denn sobald der Hinweisreiz auftritt, gibt es eine Störung, egal, ob der Hinweisreiz überhaupt eine Bedeutung für die Aufgabe hat, bzw. ob er als solcher fungiert. Diese Interferenz zwischen 
der Verarbeitung der visuellen Matrix und des visuellen Hinweisreiz ereignet sich nach dem vorgestellten Modell in dem „object attribute buffer“, nämlich genau dort, wo im Falle des Ganzberichts das System durch die Darbietung des visuellen Hinweisreizes (der Pfeile) perzeptuell immer überlastet ist.

In den Ergebnissen ist es ebenfalls interessant zu sehen, wie sich die Leistung unter schwierigen Bedingungen verhält. In der Bedingung B, wo eine Rückkopplung des Hinweisreizes auf die verbale Anweisung zuvor notwendig war, wurde die Leistung viel schlechter. Die verbale Anweisung rief einen mentalen Vorbereitungszustand hervor; diese vorbereitende Aufmerksamkeit (vgl. preparatory attention bei LaBerge, 1995, 2000) muss von den präfrontalen Instanzen aufrechterhalten werden. Der später eintreffende Hinweisreiz muss auch identifiziert werden. Dies alles führt dazu, dass die Steuerungsinstanzen im präfrontalen Lappen mehr oder zu sehr beansprucht werden, so dass nur wenige Ressourcen noch verfügbar sind, um den ,,associative buffer“" aufrechtzuerhalten. Somit stehen innerhalb der kurzen Zeit nur weniger Ressourcen für die Verarbeitung der Buchstaben zur Verfügung, was dann wiederum eine schlechtere Leistung zur Folge haben muss.

Interessant ist auch das Leistungsverhalten bei der visuellen Hinweisreizbedingung mit ISI $=0 \mathrm{~ms}$ in der Bedingung B. Die Leistung war dort zwar nicht signifikant schlechter als die anderen ISI-Bedingungen, wies aber eine statistische Tendenz auf. Es sieht so aus, dass der Hinweisreiz in den Experimenten zuvor (Experiment 1 und 3) tatsächlich nicht kognitiv verarbeitet wurde. Denn wenn der Hinweisreiz jetzt ebenfalls interpretiert werden muss, um mit der Anweisung verglichen werden zu können, scheint dessen Verarbeitung in dem Fall gelitten zu haben — die Leistung machte nämlich dort einen Knick. Dies deutet auf eine „bottom-up“ und nicht kognitiv gesteuerte Frühselektion in den alten Experimenten hin, was ebenfalls durch des Modell postuliert wurde.

Die in Experiment 5 verwendete Methode ist nicht das klassische Verfahren des SperlingParadigmas. Die Verwendung einer verbalen Anweisung hat die Funktion des Hinweisreizes ersetzt (in der Bedingung A) oder abgeschwächt (in der Bedingung B). Die Pbn wussten bereits vor der Reizdarbietung darüber Bescheid, welche Zeile(n) zu reproduzieren ist (sind). Ein möglicher Einwand ist, dass der Untersuchungsgegenstand nicht mehr derselbe wie in den vergangenen Experimenten sei. Der Gegenstand soll aber hier im Rahmen der visuellen Informationsverarbeitung betrachtet werden. In der vorliegenden Arbeit wird die Ansicht vertreten, dass die blitzartige (tachistoskopische) Darbietungszeit der Reizvorlage entscheidend dafür ist, ob die erhobenen Verhaltensdaten einen ähnlichen Zustand widerspiegeln wie im klassischen Sperling-Paradigma. Aus der gleichen Überlegung heraus wird deshalb nicht davon 
ausgegangen, dass in der aktuellen Untersuchung der Teilberichts- und der Ganzberichtsbedingung zwei unterschiedliche Gedächtnisprozesse zugrunde liegen, da die Matrix in Experiment 5 weiterhin nur für $50 \mathrm{~ms}$ präsentiert wurde. Wie viel Information von der kurz dargebotenen Matrix noch vorhanden oder verfügbar ist, bezieht sich nach diesem Modell immer auf den Fall, in dem der ,associative buffer“ nicht genügend weiteren Input von den davor liegenden Buffern bekommen kann, um alle Informationen (hier: Buchstaben) identifizieren zu können. Durch die Anordnung der vorgezogenen verbalen Anweisung konnte diesem Modell zufolge jedoch die vorbereitende Aufmerksamkeit ins Spiel kommen und auf die Zuteilung der Verarbeitungsressourcen einen Einfluss ausüben, so dass von vorhinein nur einem Teil der Matrix bewusst mehr Aufmerksamkeit geschenkt wurde. Das äußerte sich auch darin, dass sich die Leistungen der einzelnen Teilberichtsbedingungen (nicht hochgerechnet) von der Ganzberichtsleistung in der Bedingung A nicht unterschieden. Dies ist ein Beleg dafür, dass den beiden Leistungen die gleichen Verarbeitungsmechanismen zugrunde liegen und die Leistungen in beiden Fällen eine Kapazitätsbeschränkung in dem ,associative buffer“ anzeigten. Die Leistungen in beiden Bedingungen nahmen nicht mit dem zunehmenden ISI zwischen Offset der Matrix und Onset des auditiven und visuellen Ereignisses (ursprünglicher Hinweisreiz) ab. Dies bedeutet, dass das zeitliche Geschehen des Ereignisses keinen Einfluss auf die Leistung hatte und dass die Selektion der Reizverarbeitung bereits stattgefunden hat. Das ist, was nach dem Modell ebenfalls angenommen werden kann.

Insgesamt erwiesen sich die Ergebnisse als hypothesenkonform und die auf dem Modell basierenden Vorhersagen sind eingetroffen. Das Modell mit seinen Annahmen kann das Phänomen des Modalitätseffektes des Hinweisreizes in der Sperling-Aufgabe plausibel und differenziert erklären. Nach dem Modell ist der Modalitätseffekt zum einen in der Ganzberichtsbedingung durch perzeptuelle Kapazitätslimitation in dem „object attribute buffer“, zum anderen in der Teilberichtsbedingung durch kognitive Kapazitätsbeschränkung in dem ,associative buffer“" zustande gekommen.

\subsubsection{Post-hoc-Analyse zwecks Modellprüfung}

In dem vorgestellten Modell wird von der inzwischen weit akzeptierten theoretischen Annahme ausgegangen, dass die objekteigenen Merkmale wie Form und Farbe in der ventralen Bahn verarbeitet werden, während die Informationen über dessen Lokalisation, Größe und Orientierung in der dorsalen Bahn kodiert werden. In dem vorgestellten Modell werden die Merkmale in einem „object attribute buffer“ in der ventralen Bahn zu bekannten Formen oder Mustern gebündelt. Im ,associative buffer“ werden die Formen oder Muster mit anderen dazugehörenden Reizeigenschaften wie z.B. Lokalisationsinformation zusammengefügt, mit 
gespeicherten Repräsentationen verglichen und dann identifiziert. Eine Möglichkeit, die Annahmen bezüglich der Verarbeitungsmechanismen (Verarbeitungsweise) in verschiedenen Stadien der Informationsverarbeitung zu überprüfen, bietet die Datenanalyse der Fehlerarten in den entsprechenden Experimenten.

Wie in Kapitel 1 bereits beschrieben, kann man bei den Fehlern, die in der PR-Aufgabe gemacht werden, zwei Arten unterscheiden:

1) Identitätsfehler: Das reproduzierte oder wieder erkannte Item war nicht in der Reizvorlage enthalten;

2) Lokalisationsfehler: Das reproduzierte oder wieder erkannte Item war zwar in der Reizvorlage enthalten, aber nicht in der gefragten Position.

Durch das obige Experiment konnte gezeigt werden, dass sowohl der „object attribute buffer“ als auch der „,associative buffer“ einer Kapazitätsbeschränkung unterliegt. Allerdings handelt es sich beim Ersten um eine perzeptuelle, beim Zweiten aber um eine kognitive Kapazitätsbeschränkung. Die Kapazitätsbeschränkung in verschiedenen Phasen der Informationsverarbeitung kann sich aufgrund der unterschiedlichen Verarbeitungsmechanismen in unterschiedlichen Fehlerarten ausdrücken. Der „object attribute buffer“ hat nur eine begrenzte perzeptuelle Kapazität, die zwischen der Präzision und der Quantität abgeglichen werden muss, um die Inputs zu bekannten Mustern $\mathrm{zu}$ formen. Bei einer perzeptuellen Überlastung wird sich das „Aufnahmefenster“ entweder erweitern oder verkleinern müssen. Bei einem erweiterten Aufnahmefenster geht die Verarbeitung auf Kosten der Präzision, in diesem Fall ist zu erwarten, dass dadurch (mehr) Identitätsfehler gemacht werden gegenüber der Bedingung ohne die perzeptuelle Überbeanspruchung, da z.B. Merkmale zu falschen Mustern geformt werden können. Wenn das „Aufnahmefenster“ nur auf einen Teil der Inputs konzentriert ist, werden auch nur weniger Muster als erwartet geformt oder wieder erkannt. Wenn die restlichen Items geraten werden müssen, was in den vergangenen Experimenten der Fall war, resultieren daraus ebenfalls mehr Identitätsfehler im Vergleich zu einer Bedingung, wo die Verarbeitung perzeptuell wenig Ressourcen beansprucht (hier in der auditiven Hinweisreizbedingung). Die Folge des Verarbeitungsengpasses im ,associative buffer“ drückt sich dagegen entweder in einer höheren Anzahl von Identifikationsfehlern aus, weil wenige Items identifiziert werden können (und die restlichen Items geraten werden müssen), oder in einer höheren Anzahl von Lokalisationsfehlern, weil die identifizierten Items mit vorhandenen Lokalisationsinformationen falsch zusammengebunden wurden.

Zusammenfassend kann man in diesem Zusammenhang postulieren, dass eine perzeptuelle Überbeanspruchung im „object attribute buffer“ im Vergleich zum Fall mit geringerer 
Beanspruchung zu mehr Identitätsfehlern führt, während eine Konkurrenz um Verarbeitungsressourcen im ,associative buffer“ sowohl mehr Identifikationsfehler als auch mehr Lokalisationsfehler verursachen kann, und zwar im Vergleich zu dem Fall ohne Verarbeitungskonkurrenz.

In der vorangegangenen empirischen Untersuchung wurde bereits belegt, dass der Modalitätseffekt des Hinweisreizes auf eine Interferenz zwischen der Verarbeitung der visuellen Vorlage und der des visuellen Hinweisreizes zurückzuführen ist, und zwar dass eine Interferenz entweder auf perzeptuelle (beim Ganzbericht) oder auf kognitive (beim Teilbericht) Weise geschehen kann. Nach dem vorgestellten Modell geschieht diese Interferenz beim Ganzbericht in der ventralen Bahn bzw. in dem „object attribute buffer“. Beim Teilbericht (mit Ausnahme in der Bedingung mit einem ISI von $0 \mathrm{~ms}$ ) gibt es eine Interferenz aufgrund des Identifikationsengpasses in dem ,associative buffer“, weil der visuelle Hinweisreiz ebenfalls wie die Buchstaben identifiziert und mit seiner Lokalisationsinformation integriert werden muss. Entsprechend dieser Überlegungen kann man bei dem Modalitätseffekt in der SperlingAufgabe folgende Vorhersagen aufstellen:

Vorhersage 1: Beim Ganzbericht in der visuellen Hinweisreizbedingung werden mehr Identitätsfehler gegenüber der auditiven Hinweisreizbedingung gemacht .

Vorhersage 2: Beim Teilbericht in der visuellen Hinweisreizbedingung werden sowohl mehr Identifikationsfehler als auch mehr Lokalisationsfehler gegenüber der auditiven Hinweisreizbedingung gemacht.

Im Folgenden werden anhand der Daten aus Experiment 1, wo ein Modalitätseffekt nachgewiesen wurde, die Fehlerarten unter beiden Hinweisreizbedingungen analysiert, um die Modellannahmen zu überprüfen.

\subsubsection{Methode bei der Fehleranalyse von Experiment 1}

Definition (Operationalisierung) der Fehlerarten in Experiment 1: Eigentlich gehen die Identitätsfehler und die Identifikationsfehler laut der obigen Analyse auf unterschiedliche Verarbeitungsmechanismen zurück. Da sie in den Verhaltensdaten aber nicht auseinander gehalten werden können, werden sie hier über den gleichen Indikator erfasst.

1) Identitätsfehler und Identifikationsfehler: Bericht von Buchstaben, die nicht in der zuvor dargebotenen Matrix vorhanden waren.

2) Lokalisationsfehler: Bericht von Buchstaben, die zwar in der zuvor dargebotenen Matrix enthalten waren, aber in der falschen Position wiedergegeben werden. 
Als abhängige Variablen dient die Anzahl der Identitätsfehler (Identifikationsfehler) und die Anzahl der Lokalisationsfehler. Unter dieser neuen Perspektive wurden die Datenprotokolle von Experiment 1 neu analysiert und ausgewertet.

\subsubsection{Ergebnisse der Datenanalyse und statistischen Tests}

Beim Ganzbericht wurden im Durchschnitt 3.13 Identitätsfehler unter der auditiven Hinweisreizbedingung und 3.28 Identitätsfehler in der visuellen Hinweisreizbedingung gemacht. Die Mittelwerte unterschieden sich signifikant voneinander $[t(47)=3.55, p=.001<$ .05, $\varepsilon=0.86]$. Dagegen unterschied sich die Menge der Lokalisationsfehler unter beiden Hinweisreizbedingungen beim Ganzbericht nicht $[t(47)=1.29, p=.203, \varepsilon=0.31]$, der Mittelwert betrug für auditive und visuelle Hinweisreizbedingungen jeweils 1.49 und 1.55, d.h., beim Ganzbericht wurden signifikant mehr Identitätsfehler aber nicht signifikant mehr Lokalisationsfehler unter der visuellen Hinweisreizbedingung gemacht. Dies kann man der Abbildung 26 entnehmen.

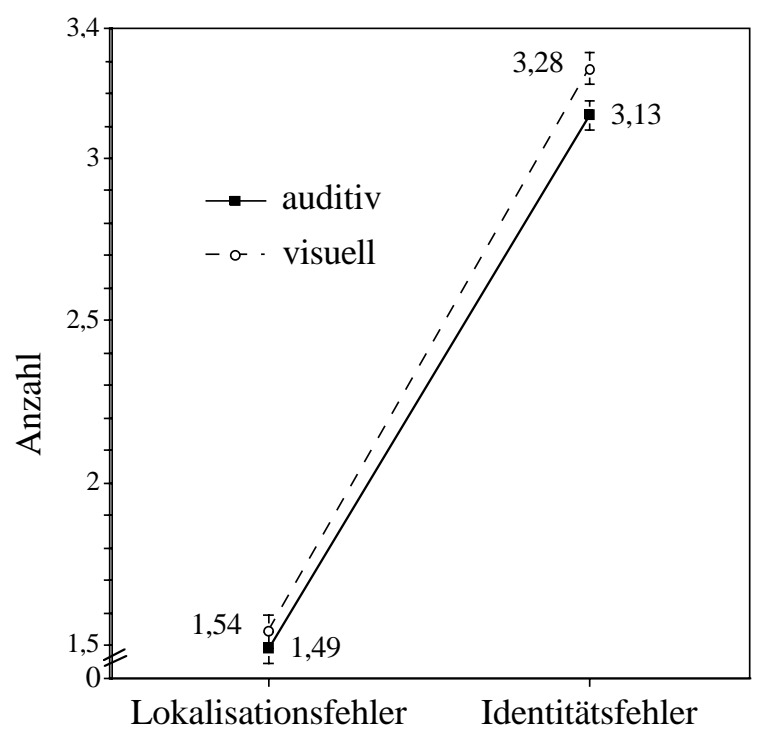

Abbildung 26: Mittelwerte und Standardfehler der Identitätsfehler und Lokalisationsfehler unter den beiden Hinweisreizbedingungen beim Ganzbericht in Experiment 1.

Für den Teilbericht wurde mit den Daten aus den drei ISI-Bedingungen eine MANOVA mit drei Innersubjekt-Faktoren „Hinweisreizmodalität“ (zwei Stufen: auditiv und visuell), „Fehlerart“ (zwei Stufen: Identitätsfehler und Lokalisationsfehler) und „ISI“ (vier Stufen: 0, 100, 300, 1000 ms Bedingung) berechnet. Wie erwartet, gab es einen hoch signifikanten Haupteffekt des Faktors der „Hinweisreizmodalität“ $[F(1,47)=16.57, \Lambda(1,47)=.74, p<.001$, $\left.\eta^{2}=.26\right]$, da mehr Fehler unter den visuellen Hinweisreizbedingungen gemacht worden sind. Es ergab sich für „Fehlerart“ auch ein signifikanter Haupteffekt $[F(1,47)=4.89, \Lambda(1,47)=.91$, $\left.p=.032<.05, \eta^{2}=.09\right]$, weil generell mehr Lokalisationsfehler als Identifikationsfehler 
gemacht wurden. Der Faktor „ISI“ erwies sich ebenfalls als hoch signifikant $[F(3,45)=70.23$, $\left.\Lambda(3,45)=.18, p<.001, \eta^{2}=.82\right]$. Außerdem nahmen die beiden Fehlerarten mit zunehmendem ISI zu, daher war die Interaktion zwischen der „Fehlerart“ und dem „ISI“ hoch signifikant [F(3, $\left.45)=7.53, \Lambda(3,45)=.67, p<.001, \eta^{2}=.33\right]$. Ebenfalls hoch signifikant war die Interaktion zwischen der „Hinweisreizmodalität“ und dem „ISI“ $[F(3,45)=23.65, \Lambda(3,45)=.39, p<.001$, $\left.\eta^{2}=.61\right]$. Die Wechselwirkung zwischen der „Hinweisreizmodalität“ und der „Fehlerart“ war statistisch aber nicht bedeutsam $\left[F(1,47)=0.02, \Lambda(1,47)=1.00, p=.882, \eta^{2}=.00\right]$.

Beim Teilbericht wurde die Fehleranzahl der jeweiligen Fehlerart in den beiden Hinweisreizbedingungen miteinander verglichen, und zwar getrennt für jede ISI-Bedingung. Die Ergebnisse der statistischen Einzelvergleiche kann man der Tabelle 9 entnehmen.

Tabelle 9. Ergebnisse der Mittelwertsvergleiche der Lokalisations- und Identifikationsfehler zwischen der auditiven und visuellen Hinweisreizbedingung beim Teilbericht (Teilbericht 1 und Teilbericht 2 zusammen betrachtet) je ISI in Experiment 1

\begin{tabular}{|c|c|c|c|c|c|c|c|c|}
\hline \multirow{3}{*}{ Fehlerart } & \multirow{3}{*}{$\mathrm{ISI}^{\mathrm{a}}$} & \multicolumn{4}{|c|}{ Hinweisreiz } & \multirow{3}{*}{$t$} & \multirow{3}{*}{$p$} & \multirow{3}{*}{$\varepsilon$} \\
\hline & & \multicolumn{2}{|c|}{ auditiv } & \multicolumn{2}{|c|}{ visuell } & & & \\
\hline & & $M$ & $S D$ & $M$ & $S D$ & & & \\
\hline \multirow{4}{*}{$\begin{array}{l}\text { Lokalisations- } \\
\text { fehler }\end{array}$} & 0 & 1.70 & 0.62 & 1.55 & 0.77 & 2.07 & .044 & 0.61 \\
\hline & 100 & 1.77 & 0.67 & 2.03 & 0.76 & -3.24 & .002 & -0.88 \\
\hline & 300 & 1.94 & 0.71 & 2.21 & 0.75 & -3.21 & .002 & -0.84 \\
\hline & 1000 & 2.00 & 0.62 & 2.21 & 0.78 & -2.55 & .014 & -0.68 \\
\hline \multirow{4}{*}{$\begin{array}{l}\text { Identifikations- } \\
\text { fehler }\end{array}$} & 0 & 1.26 & 0.67 & 1.24 & 0.74 & 0.47 & .637 & 0.18 \\
\hline & 100 & 1.36 & 0.65 & 1.59 & 0.78 & -3.02 & .004 & -0.88 \\
\hline & 300 & 1.60 & 0.70 & 1.76 & 0.78 & -2.19 & .034 & -0.63 \\
\hline & 1000 & 1.96 & 0.73 & 2.22 & 0.85 & -3.11 & .003 & -0.88 \\
\hline
\end{tabular}

Anmerkungen. M: Mittlere Anzahl von Fehlern, SD: Standardabweichung der Mittelwerte.

$\varepsilon$ : Effektgröße.

${ }^{a}$ Interstimulusintervall in ms.

Es wurden beim Teilbericht in den visuellen Hinweisreizbedingungen insgesamt sowohl signifikant mehr Identifikationsfehler als auch signifikant mehr Lokalisationsfehler gegenüber den auditiven Hinweisreizbedingungen gemacht. Diese signifikanten Unterschiede werden in der Abbildung 26a, 26b und 26c veranschaulicht. Da der Modalitätseffekt in der Teilberichtsbedingung nicht bei der ISI-Bedingung von $0 \mathrm{~ms}$ auftritt, wurde bei der Darstellung (Abb. 26b und 26c) hauptsächlich die Fehleranalyse für die ISI-Bedingungen von 100, 300 und $1000 \mathrm{~ms}$ betrachtet. Es wurde in allen drei ISI-Bedingungen ein signifikanter Unterschied zwischen den beiden Hinweisreizbedingungen bei beiden Fehlerarten festgestellt. 

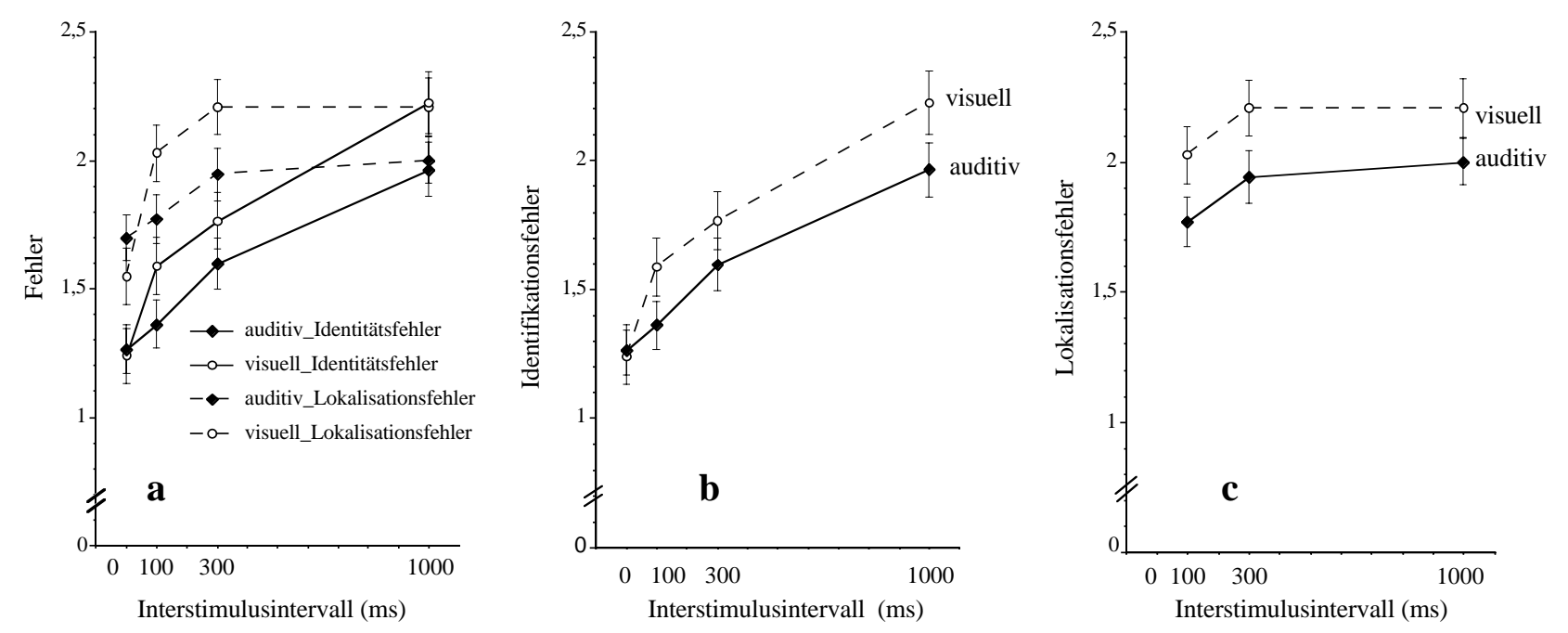

Abbildung 27: Fehlervergleich zwischen auditiven und visuellen Hinweisreizbedingungen beim Teilbericht in Experiment 1.

a. Gesamtdarstellung der beiden Fehlerarten.

b. Mittelwertvergleich und Standardfehler der Identifikationsfehler zwischen auditiven und visuellen Hinweisreizbedingungen.

c. Mittelwertvergleich und Standardfehler der Lokalisationsfehler zwischen auditiven und visuellen Hinweisreizbedingungen.

\subsubsection{Diskussion}

Bei der Datenanalyse sind folgende Vorhersagen eingetroffen: Beim Ganzbericht in der visuellen Hinweisreizbedingung wurden mehr Identitätsfehler als in der auditiven Hinweisreizbedingung gemacht, während sich die Lokalisationsfehler in den beiden Hinweisreizbedingungen nicht voneinander unterschieden. Beim Teilbericht in der visuellen Hinweisreizbedingung wurden sowohl mehr Identifikationsfehler als auch mehr Lokalisationsfehler gegenüber der auditiven Hinweisreizbedingung gemacht.

Die obigen Experimente ergaben, das: $\mathbf{b}$ Modalitätseffekt in der Sperling-Aufgabe darauf zurückzuführen ist, dass 1) bei der Ganzberıcntsbedingung mit visuellem Hinweisreiz, wo eine perzeptuelle Kapazitätskonkurrenz in dem „object attribute buffer“ nachgewiesen ist, mehr Identitätsfehler gemacht worden sind; 2) beim Teilbericht in den visuellen Hinweisreizbedingungen, wo eine kognitive Verarbeitungsinterferenz in dem ,associative buffer“ zu erwarten ist, sowohl mehr Identifikationsfehler als auch mehr Lokalisationsfehler gemacht worden sind. Diese Befunde sprechen für die Modellannahmen über die unterschiedlichen Verarbeitungsmechanismen (oder Verarbeitungsweisen) in den verschiedenen Buffer. In dem „object attribute buffer“ werden die Merkmale zu bekannten Mustern oder Formen gebündelt. Die Identitätsfehler beim Ganzbericht in der visuellen Hinweisreizbedingung sind durch Merkmalskonfundierung bei der Mustererkennung der Buchstaben in dem „object attribute buffer“ entstanden. In dem ,,associative buffer“ werden die 
Inputs, also die Muster oder Formen, mit allen anderen dazugehörenden Informationen wie der Lokalisationsinformation integriert und identifiziert. Wenn es zu einer Konkurrenz um die Verarbeitungsressourcen kommt, werden als Folge entweder weniger Objekte identifiziert oder die Objektrepräsentationen mit falschen Positionsinformationen verknüpft. Daher kommt es beim Teilbericht in der visuellen Hinweisreizbedingung zu Identifikationsfehlern oder Lokalisationsfehlern.

Die Fehleranalyse hat die vom Modell abgeleiteten Vorhersagen bestätigt, die Ergebnisse sprechen somit für die Modellannahmen über die Verarbeitungsweise in den verschiedenen Verarbeitungsphasen.

\subsubsection{Experiment 6 zum Darbietungsdauereffekt des Hinweisreizes zwecks Modellprüfung}

Bis jetzt haben wir uns hauptsächlich mit der ventralen Verarbeitungsbahn in dem vorgestellten Modell beschäftigt, nämlich damit, wie die Objekteigenschaftsinformationen durch den „object attribute buffer“ in den ,associative buffer“ weitergeleitet und dort identifiziert werden. Es konnte demonstriert werden, welche Stellen in dem Verarbeitungsprozess kapazitätsanfällig sein könnten und wie die Verarbeitungsweise in dem „object attribute buffer“ und ,associative buffer“ aussieht. Die Ursache für den Modalitätseffekt des Hinweisreizes wurde herausgefunden, und zwar zum einen durch perzeptuelle Konkurrenz in dem „object attribute buffer“, und zum anderen durch kognitive Verarbeitungsinterferenz im ,,associative buffer“. Welcher Gesetzmäßigkeit aber unterliegt der dorsale Verarbeitungsweg? Was kann die Verarbeitung dieser Bahn beeinflussen bzw. wie wird sie beeinflusst? Von welcher Art ist die Verarbeitungsweise in dem ,spatial info buffer“?

Wir nehmen an, dass die ventrale Bahn nicht nur zeitabhängig, sondern zugleich auch für Kapazitätsaspekte sensibel ist. Die dorsale Bahn dagegen ist für Kapazitätsaspekte unempfindlich, aber sehr sensibel für zeitliche Aspekte. Neurophysiologisch gesehen sind in der Tat viel mehr Neuronen für die Verarbeitung von Objekteigenschaften in dem inferioren Temporallappen zuständig als für die Verarbeitung der räumlichen Information im parietalen Cortex (vgl. Van Essen, 1985). Die Form eines Objektes zu kodieren ist sicherlich viel schwieriger und aufwändiger, als seine Lokalisation zu kodieren.

Posner (1980) postulierte zwei Wege, wie sich Aufmerksamkeit auf einen Stimulus ausrichtet. Bei der exogenen Aufmerksamkeit wird der Aufmerksamkeitsfokus automatisch reflexartig auf neu auftretende, periphere Reize gelenkt, während bei der endogenen Aufmerksamkeit die Aufmerksamkeitszuwendung willentlich erfolgt. Das endogene System ist von subjektiver Intention kontrolliert, wohingegen die exogene Aufmerksamkeitszuwendung geschieht, wenn die Aufmerksamkeit automatisch ohne subjektive Kontrolle auf einen 
Umweltstimulus gelenkt wird. Müller und Rabbitt (1989) nannten das endogene ein voluntary und das exogene ein reflexive System. Es wurde lange Zeit debattiert, ob es sich dabei um zwei separate Systeme handelt (s. Posner, 1980; Jonides, 1981; Müller \& Rabbitt, 1989; Briand \& Klein, 1987).

Posner und Peterson (1990) bringen die exogene Aufmerksamkeit mit dem von ihnen angenommenen posterioren Aufmerksamkeitssystem in Verbindung. Es sieht so aus, als ob ein peripherer Hinweisreiz zu einer automatischen Verschiebung der Aufmerksamkeit im Sinne exogener Aufmerksamkeit - oft verbunden mit Augenbewegungen - führt. Dies stimmt auch mit neurobiologischen Erkenntnissen überein, die besagen, dass die posterior-parietalen Regionen eine wichtige Rolle bei der visuomotorischen Steuerung spielen (s.o. Milner \& Goodale, 1995; Goodale \& Milner, 1992; Goodale, 2000). Sie sind bei der Steuerung von Bewegung und bei der Ortung von Reizen von wichtiger Bedeutung. Ein gemeinsames Charakteristikum aller posterior-parietalen Neuronen ist die Reaktivität auf die Bewegung der Augen und auf die Position der Augenhöhlen (Kolb \& Whishaw, 1996). Die Beteiligung des posterior-parietalen Cortex an sakkadischer und Blickfolgebewegung sowie Fixationen ist an sich gut belegt (Milner \& Goodale, 1995; Kolb \& Whishaw, 1996). Kurz gesagt, die so genannte exogene Aufmerksamkeit ist wahrscheinlich eine Funktion des posterior-parietalen Cortex. Die dominante Mediator-Funktion des posterioren Parietallappens an der räumlichen Aufmerksamkeit ist allgemein anerkannt. Darüber hinaus fand Jonides (1981) heraus, dass die endogene Aufmerksamkeitsselektion von processing load beeinflusst und durch kognitive Interpretation vermittelt wird, während die exogene Aufmerksamkeitsverschiebung anstrengungslos und obligatorisch ist. Den Unterschied zwischen den beiden hier behandelten Aufmerksamkeitssystemen könnte man mit den möglichen unterschiedlichen Eigenschaften der zwei Informationsverarbeitungsbahnen in dem vorgestellten Modell in Verbindung bringen, dass nämlich die ventrale Bahn einer perzeptuellen Kapazitätseinschränkung unterliegt und von kognitiver Interpretation in einer späteren Phase vermittelt ist (s. Experiment 5), dass die dorsale Bahn aber vermutlich eine automatische und mühelose parallele Verarbeitung durchführt, die zugleich durch einen zusätzlichen oder neuartigen (peripheren) Reiz leicht ablenkbar ist.

Es wird davon ausgegangen bzw. wurde bereits bei der Planung des Experiments 3 angenommen, dadurch, dass die visuellen Hinweisreize in Experiment 1 peripher dargeboten wurden, dass eine automatische Aufmerksamkeitsverschiebung (Augenbewegung) in diesem Fall unvermeidlich war. In Experiment 3 konnte aber kein bedeutsamer Einfluss der Exzentrizität des visuellen Hinweisreizes bzw. der Distanz zwischen dem Fixationspunkt und 
dem visuellen Hinweisreiz auf den Modalitätseffekt festgestellt werden, denn die neue Manipulation der Größe und Exzentrizität des visuellen Hinweisreizes konnte den Leistungsunterschied zwischen den beiden Hinweisreizbedingungen nicht eliminieren. Wenn nun einige Eigenschaften des visuellen Hinweisreizes, wie Größe und Exzentrizität, in dem aktuellen experimentellen Design bei einer vermuteten Aufmerksamkeitsverschiebung keinen Einfluss haben können, so können doch andere Eigenschaften des visuellen Hinweisreizes, wie z.B. „die Darbietungsdauer“ einen solchen Einfluss ausüben. Es wurde in einigen Arbeiten von „,inhibition effects following peripheral cues“ (Mayor, 1985; Mayor \& Hockey, 1985; Posner \& Cohen, 1984) berichtet. Der Effekt verhindert, dass die Aufmerksamkeit nach der Verschiebung wieder in die alte Position zurückkehrt.

Wenn diese exogene Aufmerksamkeit „posterior parietal“ ausgeführt wird und der Augenbewegung vorausgeht bzw. die Augenbewegung steuert und begleitet, könnte man annehmen, dass sie an der Expositionszeit des peripheren Hinweisreizes (zumindest innerhalb eines bestimmten Zeitintervalls) gebunden ist. Auf die $P R$-Untersuchung übertragen, heißt das, dass der visuelle Hinweisreiz exogene Aufmerksamkeit auf sich zieht, solange er dargeboten wird (eine ähnliche Annahme machen Dixon, Gordon, Leung \& Di Lollo, 1997, s. unten). Schon Townsend vermutet ,that S[ubject] continues to process the cue until it is terminated“ (1973, S. 117). Zu der Ablenkungszeit kommt noch die Wirkungsdauer des Inhibitionseffekts, innerhalb der das Aufmerksamkeitssystem nicht zu der ursprünglichen Position zurückkehren kann und innerhalb der keine Verarbeitung des Zielreizes möglich ist. Alle diese zeitlichen Kosten müssten sich eigentlich bemerkbar machen, und zwar in der Verarbeitung der räumlichen Information, da die Verarbeitung der räumlichen Information in dem ,spatial info buffer“ ebenfalls in dem posterior-parietalen Cortex geschieht. Deshalb lautet die Annahme in dem Modell: Je länger der visuelle Hinweisreiz dargeboten wird, desto schlechter oder weniger gründlich wird die Lokalisationsinformation verarbeitet.

Über diesen Effekt der Darbietungsdauer des Hinweisreizes in der PR-Aufgabe wurde bereits in der Literatur berichtet. Townsend (1973) hat als Erster den Darbietungsdauereffekt des Hinweisreizes untersucht. Sie verwendete in einer $P R$-Aufgabe visuelle Hinweisreize mit einer Dauer von 50 ms oder 1000 ms, und sie fand eine schlechtere Leistung unter der längeren Hinweisreizbedingung. Dixon (1985) fand eine generell schlechtere Leistung mit einem 50-msHinweisreiz als mit einem 17-ms-Hinweisreiz. Dixon et al. (1997) variierten die Darbietungsdauer des Hinweisreizes in zwei Stufen, $30 \mathrm{~ms}$ und $330 \mathrm{~ms}$. Ihre Überlegungen waren ebenfalls, dass bei einem kurzzeitig dargebotenen Hinweisreiz die Aufmerksamkeit nur kurzzeitig abgelenkt wird, während der länger dargebotene Hinweisreiz das exogene 
Aufmerksamkeitssystem dazu veranlasst, die Aufmerksamkeit für längere Zeit abzulenken. Ihre zentrale Annahme beruht darauf, dass die Aufmerksamkeit am Ort des Hinweisreizes so lange fixiert bleibt, bis dieser ausgeblendet wird: ,... attention would not be shifted from the cued location if the cue remains in the visual field“ (Dixon et al., 1997, S. 1268). Ihre Befunde waren ebenfalls, dass die Leistung mit zunehmender Darbietungsdauer des (visuellen) Hinweisreizes abnimmt. Interessant ist aber vor allem, dass die schlechteren Leistungen in den oben genannten Untersuchungen mit der $P R$-Methode alle auf Lokalisationsfehler zurückzuführen waren.

Diese in der Literatur berichteten Untersuchungen bezüglich des Darbietungsdauereffekts wurden allerdings mit unterschiedlichen Methoden durchgeführt. Townsend (1973) verwandte eine aus acht Buchstaben bestehende einzeilige Anordnung, während Dixon et al. (1997) eine kreisförmige Buchstabenanordnung wählten. Nach Hagenaar und Van der Heijden (1997) sind wahrscheinlich zwei Einflussfaktoren für die auf der Fehleranalyse basierenden widersprüchlichen Ergebnisse in den $P R$-Untersuchungen verantwortlich: 1) Die Anordnungsformen, d.h., ob die Buchstaben linear oder kreisförmig angeordnet sind, und 2) die Buchstabenauswahl, d.h., ob das Versuchsmaterial aus dem ganzen Bestand oder nur aus einem beschränkten Teil des Alphabets besteht. Diese beiden Faktoren wirken sich ihnen zufolge darauf aus, inwieweit die Lokalisationsschwierigkeit und Identifikationsschwierigkeit als solche beobachtet bzw. erkannt werden können. Da die beiden oben erwähnten Untersuchungen nur die $P R$-Methode verwendet haben, worin ein Item erfragt wird, scheint hier eine Untersuchung des Darbietungseffektes des Hinweisreizes mittels Sperling-Paradigma für die einschlägige Forschung ergänzend und validierend zu sein. Nicht zuletzt soll diese experimentelle Untersuchung auch dem Zweck der Modellprüfung dienen.

Nach der zugrunde liegenden Modellvorstellung wird in dem geplanten Versuch erwartet, dass die Darbietungsdauer des visuellen Hinweisreizes einen Einfluss auf die exogene Aufmerksamkeit und somit auf die Verarbeitung der Lokalisationsinformation ausübt, und zwar je länger der Hinweisreiz dargeboten wird, desto mehr wird die Verarbeitung der Lokalisationsinformation beeinträchtigt. Die Verarbeitung der Identitätsinformation soll dagegen nicht davon betroffen sein.

Darüber hinaus wird in dem Modell angenommen, dass die Verarbeitung in dem ,spatial info buffer“ quasi parallel ist. Wenn die Verarbeitungsressource nicht gleich abgelenkt wird, dann könnte eine spätere Ablenkung keinen Einfluss mehr ausüben. Das bedeutet, dass eine längere Darbietungszeit des Hinweisreizes bei längerer Verzögerung (größerem ISI) die Verarbeitung der räumlichen Information des Zielreizes nicht mehr oder nur wenig 
beeinträchtigen kann. Kurz gesagt, der Darbietungsdauereffekt tritt bei unmittelbarer Darbietung des Hinweisreizes am stärksten auf. In der Tat trat der Effekt in der Untersuchung von Townsend (1973) bei der Verwendung des Designs von Averbach und Coriell (1961) mit variierter Darbietungsdauer des Hinweisreizes nur bei einer Hinweisreiz-Verzögerung (ISI) von $0 \mathrm{~ms}$ auf.

\subsubsection{Methode}

Der Darbietungsdauereffekt des Hinweisreizes in den oben berichteten Untersuchungen war nur mit Blick auf den partial report (das entspricht der Teilberichtsbedingung in der aktuellen Untersuchung) untersucht worden. Da den Teilberichts- und Ganzberichtsaufgaben in der aktuellen Untersuchung, wie oben begründet, der gleiche Prozess zugrunde liegt, muss der beim Teilbericht gefundene Effekt nach dem vorgestellten Modell gleichermaßen beim Ganzbericht auftreten. Deshalb geht es im folgenden Experiment hauptsächlich um den Ganzbericht. Was die Variation des ISI betrifft, erfolgt nur die Bedingungskombination Ganzbericht mit ISI $=0 \mathrm{~ms}$, da vermutet wird, dass der Darbietungsdauereffekt nur (oder am stärksten) bei unmittelbarer Hinweisreiz-Darbietung auftritt. Nur wegen eines programmtechnischen Grundes, nämlich damit die Ganzberichtsaufgabe per Zufall generiert werden kann, wird noch der Teilbericht mit einer Hinweisreiz-Verzögerung von 100 ms eingebaut. Das Interesse zielt hier vor allem auf das Leistungsverhalten bei der visuellen räumlichen Informationsverarbeitung (auf die dorsale Bahn) unter dem Einfluss von zeitlicher Ablenkung durch Hinweisreiz-Darbietung ab. Der Vergleich zwischen auditiven und visuellen Hinweisreizbedingungen steht diesmal nicht im Vordergrund, da in der vergangenen Untersuchung bereits gezeigt wurde, dass der Modalitätseffekt auf gewisse Engpässe in der ventralen Verarbeitungsbahn bzw. in dem ,,associative buffer“ zurückzuführen ist. Daher dient die Bedingung mit dem auditiven Hinweisreiz nur als Kontrolle.

Probanden. 30 Studierende haben an dem Versuch teilgenommen. Das Durchschnittsalter lag bei 20.83 Jahren (Range 19-24, SD = 1.94).

Apparate und Versuchsraum. Das Experiment wurde mit den gleichen Apparaten und in demselben Raum wie in Experiment 1 durchgeführt.

Versuchsmaterial. Das gleiche Versuchsmaterial wie in Experiment 1 wurde verwendet. Für dieses Experiment war der Hinweisreiz von zentraler Bedeutung. Gleiche Hinweisreize wie in Experiment 1 wurden verwendet. Der visuelle Hinweisreiz wurde links neben der Buchstabenmatrix präsentiert, die Dauer der Darbietung betrug jeweils 20, 170 oder 320 ms. Der auditive Hinweisreiz wurde über Kopfhörer für 200 ms präsentiert. 
Aufgabenanforderung und Versuchsablauf. Ähnlich wie in Experiment 1 wurde die Aufgabenanforderung realisiert. Jeder Durchgang hatte den gleichen Ablauf wie in Experiment 1. Nur beim Ganzbericht tauchten der Hinweisreiz, d.h. der Doppelpfeil oder der Doppelton, immer unmittelbar nach dem Offset der Matrix auf, dagegen wurden die Hinweisreize beim Teilbericht erst nach einem ISI von $100 \mathrm{~ms}$ dargeboten. Je nach Versuchsbedingung dauerte die Darbietung des Pfeils 20, 170 oder 320 ms, während in der auditiven Bedingung der Ton immer für 200 ms ertönte. Gemessen vom Onset des Hinweisreizes erschien nach einer Dauer von 1000 ms ein Gitter, das anschließend für das Eintragen der Antwort von Pbn per Tastatur diente. Erst nachdem alle Zellen des Gitters ausgefüllt waren, konnten die Pbn ihre Antwort durch das Drücken der Eingabetaste abgeben. Ein Feedback wie in Experiment 1 wurde direkt nach Antwortabgabe gegeben. Anschließend erschien wieder das Fixationskreuz für den nächsten Durchgang.

Design und Versuchsdurchführung. Der Versuch bestand aus 4 Teilversuchen mit jeweils einer Hinweisreizbedingung: auditiv 200 ms, visuell 20 ms, visuell 170 ms, visuell 320 ms. Die Reihenfolge der Teilversuche wurde nach einem Balancierungsplan nach dem lateinischen Quadrat festgelegt. Jeder Teilversuch enthielt 48 Durchgänge in zwei Blöcken à 24 Durchgänge. So bearbeiteten die Pbn insgesamt 48 x 4 = 192 Durchgänge.

\subsubsection{Ergebnisse}

Die Ergebnisdarstellung und Interpretation konzentriert sich nur auf die Ganzberichtsbedingung, und zwar aus den oben bereits erwähnten Überlegungen:

1) Die Leistung im Ganzbericht ist ebenso wie die Leistung aus der Teilberichtsbedingung dem ikonischen Gedächtnis zuzuschreiben. An der Ganzberichtbedingung kann man ebenso die Eigenschaften des ikonischen Gedächtnisses erforschen.

2) Der Darbietungsdauereffekt des Hinweisreizes in der Teilberichtsbedingung ist bereits mit der Bar-probe-Methode untersucht worden (vgl. Dixon et al., 1997; Townsend, 1973).

3) Der bestehende Zeileneffekt (Leistungsunterschied) bei den Teilberichtsbedingungen in der aktuellen Untersuchung erschwert eine eindeutige Interpretation eines möglichen Darbietungsdauereffekts.

Die Reproduktionsleistung im Ganzbericht unter den einzelnen Bedingungen der visuellen Hinweisreizdauer kann man der Abbildung 28 und der Tabelle 10 entnehmen. 


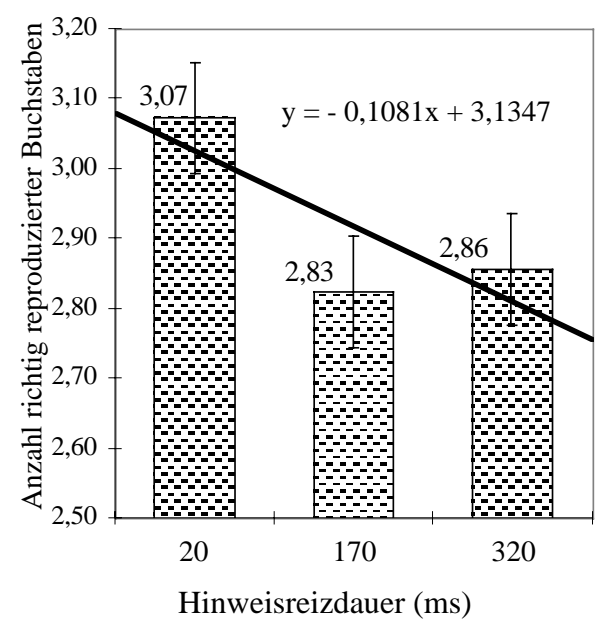

Abbildung 28: Mittelwerte und Standardfehler für die Anzahl richtig reproduzierter Buchstaben im Ganzbericht mit verschiedener visueller Hinweisreizdauer in Experiment 6 sowie Regressionsgerade.

Tabelle 10. Versuchsergebnisse für die einzelnen Bedingungen der visuellen Hinweisreizdauer im Ganzbericht in Experiment 6 (Anzahl richtig reproduzierter Buchstaben)

\begin{tabular}{cccc}
\hline $\begin{array}{c}\text { Darbietungsdauer des } \\
\text { Hinweisreizes in ms }\end{array}$ & $M$ & $S D$ & $S E$ \\
\hline 20 & 3.07 & 0.74 & 0.14 \\
170 & 2.83 & 0.90 & 0.16 \\
320 & 2.86 & 0.75 & 0.14 \\
\hline
\end{tabular}

Anmerkungen.

$M$ : Mittlere Wiedergabeleistung.

$S D$ : Standardabweichung der jeweiligen Bedingung.

$S E$ : Standardfehler der Mittelwerte der jeweiligen Bedingung.

Durch einen Vergleich der Mittelwerte der 20-ms- und 320-ms-DarbietungsdauerBedingung (3.07 vs. 2.86) ist erkennbar, dass die Leistung insgesamt mit steigender Hinweisreizdauer von $20 \mathrm{~ms}$ auf $320 \mathrm{~ms}$ abnahm. Selbst wenn der letzte Mittelwert unter der Bedingung mit einer Darbietungsdauer von 320 ms $(M=2.86)$ etwas höher als der von der 170ms-Bedingung $(M=2.83)$ ist, liegt dies aber nur optisch nahe, dass der Trend u-förmig sein könnte. Die Trendanalyse zeigte nämlich, dass die linearen Anteile überwogen und in diesem Fall ein linearer Trend vorlag. Der empirische $t$-Wert für die lineare Komponente des Trends war signifikant $[t(58)=2.63, p<.05, \varepsilon=1.06]$. Kein anderer Trend, d.h. kein nichtlinearer Trend wie beispielsweise ein quadratischer, könnte diesen Datenverlauf besser beschreiben $\left[F_{\text {emp, NONLIN }}=1.78<F_{\text {krit }}=4.00, d f=58, \alpha=.05\right]^{17}$. Für die Berechnung des Treatment wurde in

\footnotetext{
${ }^{17} \mathrm{~F}_{\text {emp, NONLIN }}$ : empirischer F-Wert für die nichtlineare Trendkomponente.

$\mathrm{F}_{\text {krit }}:$ kritische F-Wert bei einem $\alpha$-Wert von .05.
} 
diesem Fall als Testvarianz die Residualvarianz verwendet, denn sie liefert nach Bortz (1993, S. 309) einen genaueren Schätzer.

Um die aufgestellte Hypothese für dieses Experiment überprüfen zu können, wurden die aufgetretenen Fehler noch differenzierter betrachtet. Wie in der Datenanalyse zuvor, wurden die gesamten Fehler in Identitätsfehler und Lokalisationsfehler unterschieden. Abbildung 29a und $29 \mathrm{~b}$ veranschaulichen die Ergebnisse.
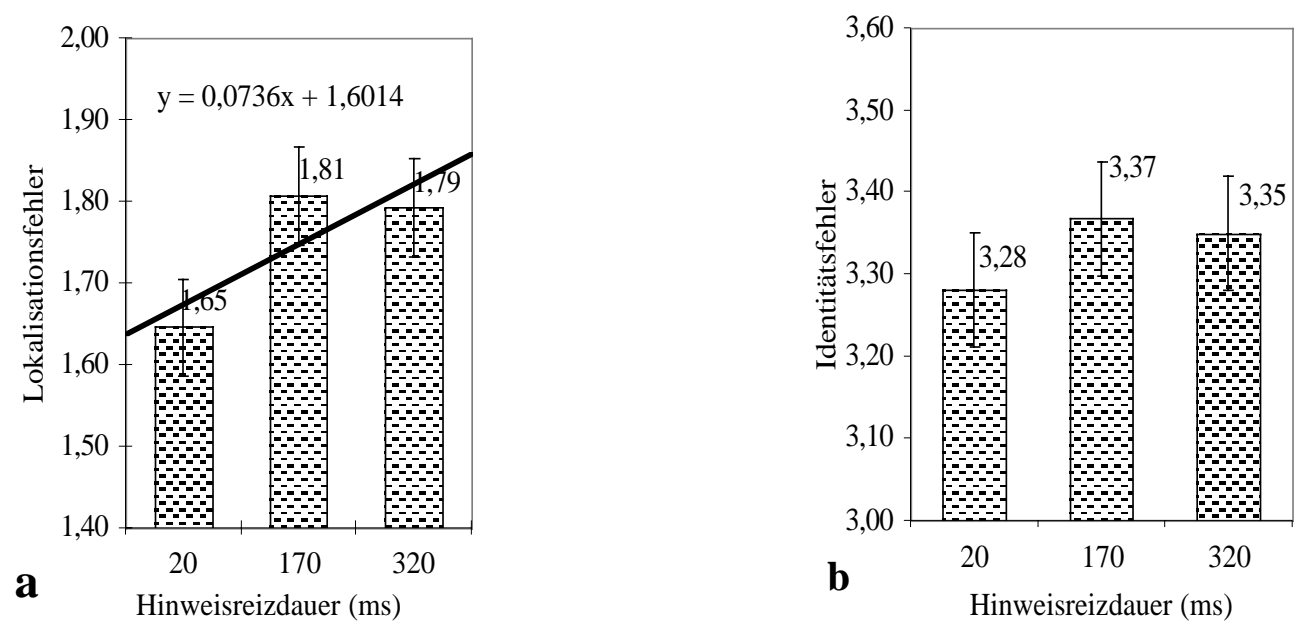

Abbildung 29: Ergebnisse in Experiment 6, dargestellt nach Fehlerarten; $\mathrm{N}=30$.

a. Mittelwerte und Standardfehler der Anzahl von Lokalisationsfehlern im Ganzbericht mit verschiedener visueller Hinweisreizdauer sowie mit Regressionsgerade.

b. Mittelwerte und Standardfehler der Anzahl von Identitätsfehlern im Ganzbericht mit verschiedener visueller Hinweisreizdauer.

Die Datenanalyse zeigte, dass die Lokalisationsfehler tendenziell mit zunehmender Hinweisreizdauer anstiegen (s. Abb. 29a und Tabelle 11).

Tabelle 11. Versuchsergebnisse bezüglich der Lokalisationsfehler für die einzelnen Bedingungen der visuellen Hinweisreizdauer im Ganzbericht in Experiment 6.

\begin{tabular}{cccc}
\hline $\begin{array}{c}\text { Darbietungsdauer des } \\
\text { Hinweisreizes in ms }\end{array}$ & $M$ & $S D$ & $S E$ \\
\hline 20 & 1.65 & 0.48 & 0.09 \\
170 & 1.81 & 0.55 & 0.10 \\
320 & 1.79 & 0.56 & 0.10 \\
\hline
\end{tabular}

\section{Anmerkungen.}

$M$ : Mittlerer Lokalisationsfehler.

$S D$ : Standardabweichung der jeweiligen Lokalisationsfehler.

$S E$ : Standardfehler der Mittelwerte der jeweiligen Lokalisationsfehler.

Die Lokalisationsfehler stiegen von einer 20-ms-Darbietungsdauer zu einer von $320 \mathrm{~ms}$ monoton an, und zwar linear. Die Trendanalyse ergab einen signifikanten empirischen $t$-Wert 
für die lineare Komponente des Trends $[t(58)=2.48, p<.05, \varepsilon=1.39]$. Kein anderer Trend, also kein nicht-linearer Trend wie beispielsweise ein quadratischer, konnte in diesem Fall den Datenverlauf besser beschreiben $\left[F_{\text {emp, NONLIN }}=1.44<F_{\text {krit }}=4.00, d f=58, a=.05\right]$.

Wie sich Identitätsfehler mit zunehmender Darbietungsdauer verhielten, veranschaulicht die Abbildung 29b. Die deskriptive statistischen Ergebnisse werden in Tabelle 12 dargestellt.

Tabelle 12. Ergebnisse bezüglich der Identitätsfehler für die einzelnen Bedingungen der Hinweisreizdauer im Ganzbericht in Experiment 6

\begin{tabular}{cccc}
\hline $\begin{array}{c}\text { Darbietungsdauer des } \\
\text { Hinweisreizes in ms }\end{array}$ & $M$ & $S D$ & $S E$ \\
\hline 20 & 3.28 & 0.38 & 0.07 \\
170 & 3.37 & 0.43 & 0.08 \\
320 & 3.35 & 0.34 & 0.06 \\
\hline
\end{tabular}

Anmerkungen.

$M$ : Mittlerer Identitätsfehler.

$S D$ : Standardabweichung der jeweiligen Identitätsfehler.

$S E$ : Standardfehler der Mittelwerte der jeweiligen Identitätsfehler.

Die Mittelwerte der 20-ms-Bedingung $(M=3.28)$, der 170-ms-Bedingung $(M=3.37)$ und der 320-ms-Bedingung $(M=3.35)$ lagen sehr nahe beieinander, und es wird erkennbar, dass sich der Identitätsfehler in den Bedingungen nur geringfügig verändert hat. Die Einzelvergleiche zwischen den Bedingungen mit einer Darbietungsdauer von $20 \mathrm{~ms}$ und 170 ms $[t(29)=1.14, p=.263, \varepsilon=0.29]$, den Bedingungen mit einer Darbietungsdauer von $170 \mathrm{~ms}$ und $320 \mathrm{~ms}[t(29)=0.30, p=.768, \varepsilon=0.09]$, und den Bedingungen mit einer Darbietungsdauer von $20 \mathrm{~ms}$ und $320 \mathrm{~ms}[t(29)=0.95, p=.352, \varepsilon=0.22]$ ergaben keinen signifikanten Unterschied. Es sieht so aus, dass der Identitätsfehler tatsächlich konstant blieb.

\subsubsection{Diskussion}

Die auf dem vorgestellten Modell basierende Hypothese konnte in Experiment 6 bestätigt werden, nämlich dass die Darbietungsdauer des verwendeten visuellen Hinweisreizes einen Einfluss auf die Informationsverarbeitung des Zielreizes hat, genauer gesagt, dass die Verarbeitung der räumlichen Information durch die Ablenkung des Hinweisreizes gestört wird. Das Ausmaß der Ablenkung richtet sich nach der Darbietungsdauer des Hinweisreizes. Solange der Hinweisreiz andauert, ist keine räumliche Informationsverarbeitung des Zielreizes möglich. Darüber hinaus deuten die Ergebnisse des Experiments 6 darauf hin, dass die Verarbeitung der Identitätsinformation nicht durch derartige periphere Faktoren zu beeinflussen ist. 
Diese Ergebnisse unterstützen somit die Modellannahme der getrennten visuellen Informationsverarbeitung, dass nämlich eine ventrale Bahn für die Identitätsinformationsverarbeitung und eine dorsale Bahn für die räumliche Informationsverarbeitung zuständig ist, und dass der ventrale Verarbeitungsweg eher kognitiv angelegt ist und einer Kapazitätseinschränkung unterliegt, während der dorsale Weg kapazitätsuneingeschränkt, aber für zeitliche Aspekte sensibel und von peripheren Faktoren zu beeinflussen ist. Der „spatial info buffer“ in der dorsalen Bahn, der in dem Modell für die Kodierung von räumlicher Information zuständig ist, weist ein exogenes Charakteristikum auf und ist durch einen neuartigen Stimulus im visuellen Gesichtsfeld leicht ablenkbar.

\subsubsection{Zusammenfassung}

Durch die obigen experimentellen Untersuchungen und Datenanalysen wurden einige aus dem vorgestellten Modell abgeleitete Hypothesen anhand des Beispiels des Modalitätseffektes überprüft. Insgesamt erwiesen sich die experimentellen Ergebnisse im Sinne der Modell(annahme)prüfung mit Verhaltensdaten als hypothesenkonform und die auf dem vorgestellten Modell basierenden Vorhersagen sind eingetroffen. Das Modell kann die visuelle Informationsverarbeitung in dem Sperling-Paradigma gut beschreiben und das spezifische Phänomen des Modalitätseffektes differenziert erklären. Die Ergebnisse der Experimente bestätigen die Modellannahmen, dass die visuelle Informationsverarbeitung getrennten Wegen folgt, dass ein Weg (ventrale Bahn) für die Verarbeitung der Objekt-Identitätsinformation und der andere (dorsale Bahn) für die Verarbeitung der räumlichen Information zuständig ist. Die beiden Verarbeitungswege scheinen nach den Verhaltensdaten unterschiedliche Charakteristika aufzuweisen. Die ventrale Bahn unterliegt einer Kapazitätsbeschränkung, die dorsale Bahn ist dagegen nicht für Kapazitätsaspekte empfindlich aber für zeitliche Aspekte sehr sensibel. Der in dem Modell postulierte „object attribute buffer“ in der ventralen Bahn unterliegt einer perzeptuellen Kapazitätsbeschränkung, während die Verarbeitung (Identifikation) in dem ,associative buffer“ nur seriell durchgeführt werden kann, da dort nur gewisse kognitive Verarbeitungsressourcen vorhanden sind. Die Verarbeitung in dem ,spatial info buffer“ ist leicht ablenkbar und das exogene Charakteristikum spricht für einen nahezu automatischen Verarbeitungsprozess in dieser dorsalen Bahn bzw. in diesem Buffer. Insgesamt scheint das Modell ein plausibler Ansatz zu sein, der den visuellen Informationsverarbeitungsprozess adäquat beschreibt und auch in der Lage ist, den empirischen Phänomenen und Daten Rechnung zu tragen. 


\section{Kapitel 4 Allgemeine Diskussion: Ikonisches Gedächtnis und PR-Methode neu betrachtet}

Ausgehend von dem oben dargestellten Modell sowie seinen theoretischen Annahmen kann das Phänomen des ikonischen Gedächtnisses - zumindest das, was herkömmlicherweise als das ikonische Gedächtnis bezeichnet und mit den entsprechenden Methoden untersucht wird - im Zusammenhang mit den anfangs geschilderten Kontroversen und offenen Fragen bezüglich der Thematik neu betrachtet werden.

\subsection{Ikonisches Gedächtnis und seine Problematik neu betrachtet}

Im Folgenden werden die Platzierung des ikonischen Gedächtnisses im Informationsverarbeitungssystem, die Repräsentationsart, die Verarbeitungsweise sowie Kapazitätsaspekte des ikonischen Gedächtnisses diskutiert.

\section{Platzierung des ikonischen Gedächtnisses im Informationsverarbeitungssystem} (Zusammenhang mit anderen Gedächtnisformen)

Wie oben bereits dargestellt, wird angenommen, dass neurophysiologisch betrachtet die strukturellen Grundlagen für verschiedene Gedächtnisformen auch unterschiedlich sind. Den medialen Bereichen beider Temporallappen und insbesondere dem Hippocampus werden eine Schlüsselstellung für die Einspeicherung und Konsolidierung deklarativer und episodischer Gedächtnisinhalte zugeschrieben (Squire \& Knowlton, 2000; Rösler, 1997). Diese Regionen scheinen die Hirnstruktur für das herkömmliche Konzept des Langzeitgedächtnisses zu sein. Inzwischen geht man auch davon aus, dass unterschiedliche Komponenten des medialen Temporallappens zu diesem Gedächtnis unterschiedlich beitragen. Für die deklarative Speicherung sind vor allem der Hippocampus, der entorhinale Cortex, der parahippocampale Cortex und der perirhinale Cortex zuständig, während die Amygdala nicht für deklaratives Gedächtnis an sich, aber für das emotionale Lernen und die Verstärkung des deklarativen Gedächtnisses verantwortlich ist (vgl. Squire \& Knowlton, 2000). In dem oben dargestellten Modell wird dieser Speicher für deklaratives Wissen als „,memory storage” implementiert.

Das Arbeitsgedächtnis wird oft mit dem präfrontalen Cortex assoziiert (z.B. LaBerge, 1995; Goldman-Rakic, Ò Scalaidhe \& Chafee, 2000). Weiterhin wird angenommen, dass es multiple Arbeitsgedächtnis-Domänen (working memory domains) im Präfrontalcortex gibt, die neuronal begründet sind (Goldman-Rakic, Ó Scalaidhe \& Chafee, 2000).

Die Hirnstruktur einer dritten Gedächtnisform wird in der vorliegenden Arbeit im parietotemporalen Assoziationsfeld vermutet, und diese dritte Gedächtnisverarbeitungsinstanz 
wird in dem vorgestellten Modell als der ,,associative buffer” implementiert, dessen Produkt das perzeptuelle Gedächtnis ist. Das herkömmliche Konzept des „,sensorischen Gedächtnisses“ und ebenso des KZG wären nach dem Modell hier zu platzieren. Beide können als zwei unterschiedliche Ausprägungen des perzeptuellen Gedächtnisses bzw. als unterschiedliche qualitative Ausdrücke des ,,associative buffer" ${ }^{18}$ betrachtet werden. Der zeitliche Aspekt, die so genannte Gedächtnisdauer der beiden Gedächtnisformen in der traditionellen Forschung, kann in diesem Modell wie folgt interpretiert werden: Bei dem sensorischen Gedächtnis bedeutet die Gedächtnisdauer, wie lange eine Repräsentation oder Merkmalskonfiguration eines Objektes ohne weiteren Reizinput in dem ,associative buffer” gehalten werden kann, bevor sie identifiziert wird. Die Dauer des KZG (bzw. Arbeitsgedächtnis) bedeutet, wie lange die identifizierte Repräsentation eines Objektes ohne weiteren Reizinput noch in dem ,,associative buffer" gehalten werden kann, bevor sie in entsprechende Handlung (output) umgesetzt wird. Der inhaltliche Aspekt des Gedächtnisses, die so genannte Gedächtnisspanne, kann so interpretiert werden: bei dem sensorischen Gedächtnis zeigt die gemessene Kapazität an, wie viele Objekte (Items) von kurzer Erscheinung ohne weiteren Reizinput in dem ,associative buffer" identifiziert werden können, bevor die Repräsentationen verblassen. Die herkömmliche Kurzzeitgedächtnisspanne drückt aus, wie viele identifizierte Repräsentationen von Objekten in Handlung umgesetzt (z.B. wiedergegeben) werden können, bevor sie verfallen, weil der „,associative buffer” ohne Reiz-Nachschub nicht mehr aufrechterhalten werden kann. Es geht also bei dem einen darum, wie viele „herein“ (identifiziert werden) können, bei dem anderen darum, wie viele „hinaus“ (reproduziert werden) können, und zwar unter der Bedingung, dass das System nicht genügend weiteren Input desselben Reizes bekommt. Das sensorische Gedächtnis in der ,,associative buffer”-Phase, d.h. in einer polymodalen Region, zu platzieren, wird damit begründet, dass es schließlich um Speicherinhalt geht, der immer einen bestimmten sensorischen, d.h. visuellen, auditiven und somatosensorischen Ursprung hat. Der ,,associative buffer" arbeitet zwar auf die gleiche Weise, aber die Qualität und Eigenschaft dessen Produktes sind von den Input-Eigenschaften abhängig, unter anderem von dessen sensorischer Herkunft und der damit zusammenhängenden neuronalen Bahn. So kann man sagen, dass das von dem „,associative buffer“ produzierte perzeptuelle Gedächtnis von seiner Dauer, Größe oder Kapazität her modalitätsbedingt unterschiedlich ist. Es gibt daher mehrere modalitätsspezifische Gedächtnissysteme, wie das visuelle perzeptuelle Gedächtnis (es

\footnotetext{
${ }^{18}$ Vgl. das „object file“ von Treisman, das auf mehr als einem Niveau geformt werden kann (Treisman \& DeSchepper, 1996) und Information auf verschiedenen Niveaus enthalten kann (Treisman, 1992).
} 
entspricht dem ikonischen Gedächtnis) und das auditive perzeptuelle Gedächtnis (es entspricht dem echoischen Gedächtnis).

Diese unlösliche Verflechtung zwischen dem sensorischen Gedächtnis und dem KZG wird damit in einem perzeptuellen Gedächtnis vereint und die beiden Gedächtnisformen werden als dessen unterschiedliche Ausprägungen betrachtet. Die Grenze zwischen dem ikonischen Gedächtnis und dem KZG im herkömmlichen Sinne ist in diesem Modell nur graduell bzw. quantitativ.

Mit der obigen Lokalisierung des Phänomens dessen, was man sonst unter dem ,ikonischen Gedächtnis" verstanden hat, wird auch die Frage in Bezug auf peripher vs. zentral (kognitiv) beantwortet: Das ikonische Gedächtnis, zumindest das Phänomen, was mit den herkömmlichen $(P R$-)Methoden gemessen wird, ist kein rein sensorisches peripheres Phänomen. Es bezieht sich nicht nur auf die Informationsverarbeitung auf der Netzhautebene, sondern schließt sowohl die neuronalen Aktionen in etwas späteren sensorischen Bahnen (vom primären Cortex über den ventralen und dorsalen Weg) als auch die kognitive Verarbeitung bis in die multimodalen Assoziationsfelder hin ein, und geschieht unter kognitiver Steuerung des präfrontalen Cortex. Das ikonische Gedächtnis ist kein rein sensorisches Phänomen, denn bereits in dem ,object attribute buffer" in der ventralen Bahn kann die Verarbeitung (Rekognition) top-down beeinflusst werden, selbst wenn es sich bei dem Vorwissen um vorhandene Repräsentationen auf niedrigem Niveau handelt. Damit wäre auch die Frage bezüglich präkategorial oder kategorial indirekt beantwortet, da selbst in dem „object attribute buffer” die Reizinformation schon anhand kategorialen „Vorwissens” zu bekannten Mustern (vgl. das familar packet bei Kosslyn, 1994) geformt werden können, was zumindest bei vertrautem Material wie Buchstaben der Fall ist.

\section{$\underline{\text { Repräsentationsart }}$}

Außer der obigen Diskussion zum Thema präkategorial vs. kategorial bleibt bezüglich des Inhalts des ikonischen Gedächtnisses noch die Frage offen, ob es sich bei dem ikonischen Gedächtnis um sichtbare Persistenz oder informatorische Persistenz handelt. Es ist eigentlich nicht vorstellbar, dass es zwei getrennte oder unterschiedliche neuronale Verarbeitungswege für zwei als verschieden betrachtete Persistenzformen gibt, die beide visueller Natur sind. Nach dem Modell kann es sich zwischen den beiden Persistenzformen nur um einen zeitlichen und qualitativen Unterschied handeln. In gewissem Sinne kann man es so betrachten, dass die sichtbare Persistenz den Zustand des ,visual buffer” widerspiegelt, während die informatorische Persistenz die Eigenschaft des „object attribute buffer” anzeigt. Da man aber die Auskunft über die verschiedenen Zustände oder Eigenschaften nur aus dem ,,associative 
buffer" bekommen kann, ist unter bestimmten Umständen das visuelle perzeptuelle Gedächtnis in dem ,associative buffer" die sichtbare Persistenz des Objektes und in anderen Fällen dann die informatorische Persistenz. Der Inhalt in dem ,,associative buffer“ spiegelt den Zustand oder die Eigenschaft des „visual buffer”, nämlich die visuelle Persistenz, wider, wenn die relevanten Informationen vom ,visual buffer” ohne Aufwand und Einschränkung durch den „object attribute buffer“ und den „spatial info buffer“ weitergeleitet werden, und in den ,associative buffer” gelangen, und dann dort auch ohne Aufwand und Einschränkung integriert und identifiziert werden. Die sich im ,,associative buffer" befindende Information ist dann die informatorische Persistenz, wenn der ,object attribute buffer“ überlastet ist und die verbliebenen Reizsignale (bzw. der dort verarbeitete Teil der Reizsignale) ohne Einschränkung im ,associative buffer” bearbeitet bzw. kodiert werden, solange die Repräsentationen noch ohne Nachschub aufrechterhalten werden können. Diese Sichtweise, d.h. die sichtbare Persistenz und informatorische Persistenz als unterschiedliche Stufen der visuellen Informationsverarbeitung zu betrachten, hat in diesem Zusammenhang mit dem Gedanken von Cowan (1993), dass das ikonisches Gedächtnis aus zwei Phasen bestehe, etwas gemeinsam: eine Phase auf der Rezeptorebene und die andere in der Informationsverarbeitung des höheren zentralen Nervensystems. Diese Ansicht ist ebenfalls vergleichbar mit dem theoretischen Ansatz von Massaro und Loftus (1996), worin versucht wurde, die beiden Persistenzformen mit derselben sensorischen Reaktionsfunktion zu beschreiben. Massaro und Loftus (1996) betrachteten die phänomenologische Erscheinung und Informationsextraktion ebenfalls als zwei Aspekte desselben Sachverhaltes, nämlich der visuellen Informationsverarbeitung.

\section{Verarbeitungsweise während des ikonischen Gedächtnisprozesses}

Gemäß dem vorgestellten Modell wird angenommen, dass in den visuellen Informationsverarbeitungsprozessen mindestens zwei Stellen kapazitätsempfindlich sind. Erstens unterliegt die Verarbeitung im „object attribute buffer” einer perzeptuellen Kapazitätseinschränkung, zweitens kann im ,associative buffer” nur eine bestimmte Menge von Objekten innerhalb einer bestimmten Zeit identifiziert werden. Was die Verarbeitung der räumlichen Information betrifft, wird aber angenommen, dass der „spatial info buffer” relativ kapazitätsunempfindlich ist.

Was die Verarbeitungsweise angeht, fängt die Informationsübertragung sofort an, und zwar sobald der Reiz da ist. Die Informationsübertragung ist zeitgebunden zum Stimulus-Onset. Die Informationsinputs eines Objektes werden im „,visual buffer“ parallel aufgenommen, diese Aufnahme, bzw. diese Informationsübertragung, geschieht nahezu automatisch. Ebenso parallel werden die Inputs im ,spatial info buffer” und vielleicht auch parallel im „object attribute 
buffer” verarbeitet (vgl. Kosslyn, 1994). (Im „object attribute buffer” gibt es allerdings eine perzeptuelle Einschränkung.) Aber spätestens von dort aus kann die Informationszusammenfügung oder Objektidentifikation im ,,associative buffer” nur seriell durchgeführt werden. Dies hat zur Folge, dass z.B. nur eine bestimmte Menge von Objekten innerhalb einer bestimmten Zeit identifiziert werden kann, was vor allem in Aufgaben wie im Sperling-Paradigma offensichtlich der Fall ist. Damit kommt man zur Kapazitätsfrage des ikonischen Gedächtnisses.

\section{$\underline{\text { Kapazitätsaspekte }}$}

Die Kapazitätsgröße ist eigentlich abhängig von der Reizart. Es werden hier einfach Buchstaben (Konsonanten) als Beispiel genommen. Im Zusammenhang mit dem ikonischen Gedächtnis wird aus dem Standard-Experiment eine Angabe von vier bis fünf Items gemacht (vgl. Sperling, 1960). Wie oben diskutiert wurde, wird nach dem Modell davon ausgegangen, dass der Unterschied zwischen dem ikonischen Gedächtnis und dem KZG (wie sie nach den herkömmlichen Konzepten genannt werden) nur graduell ist. In einem typischen KZGExperiment erhält man aber in der Regel eine etwas größere Kapazität, Cavanagh (1972) gab z.B. eine Gedächtnisspanne von 6.4 Items für Buchstaben an. Offensichtlich hat man es hier mit zwei unterschiedlichen Maßen zu tun. Ist dies überhaupt mit der Annahme vereinbar, dass das ikonische Gedächtnis und das KZG nur verschiedene Niveaus des perzeptuellen Gedächtnisses sind? Man kann sie in der Tat als zwei Maße betrachten, die unterschiedliche Qualitäten des perzeptuellen Gedächtnisses ausdrücken. Die zwei Kapazitäten können vielleicht als Ein- und Aus-Kapazität (oder auch als Geschwindigkeit) des ,associative buffer“ bezeichnet werden. Das erste Kapazitätsmaß (von dem ikonischen Gedächtnis) ist die Antwort auf die Frage, wie viele von den Objektrepräsentationen in dem ,associative buffer“ unter schlechter Wahrnehmungsbedingung, wie beispielsweise zu kurzer Darbietungsdauer, ausgearbeitet und identifiziert werden können. Das zweite Maß (von dem KZG) gibt an, wie viele von den identifizierten Objektrepräsentationen innerhalb einer bestimmten Zeit als Output reproduziert werden können. Diese zwei Konstanten sind also Maße für verschiedene Leistungen des ,associative buffer“.

Nachdem man die Stellung des ikonischen (sensorischen) Gedächtnisses in dem Informationsverarbeitungssystem neu betrachtet und dessen Beziehung zu den anderen Gedächtnisformen in dem klassischen Konzept nach dem Modell neu interpretiert hat, bleibt zu fragen: Sind die anderen Phänomene in der Untersuchung zum ikonischen Gedächtnis auch vereinbar mit dem neuen vorgestellten Konzept? Können die typischen Effekte in den einschlägigen Untersuchungen mit dem Modell erklärt werden? 


\subsection{Partial-report-Methode (Sperling-Paradigma) bzw. deren Phänomene neu betrachtet}

Basierend auf der neuen Betrachtungsweise bezüglich des ikonischen Gedächtnisses sollen im Folgenden noch die typischen Phänomene und Effekte in der Untersuchung zum ikonischen Gedächtnis, vor allem in der $P R$-Methode, unter dem neuen Gesichtspunkt betrachtet und erklärt werden.

(1) Teilberichtsüberlegenheit und Cue-delay-Effekt.

In der klassischen Ansicht wurde davon ausgegangen, dass in dem Sperling-Paradigma die Ganzberichtsleistung dem KZG zuzuschreiben sei, und dass der Teilbericht die Leistung des ikonischen Gedächtnisses widerspiegeln solle. Die vorliegende Arbeit vertritt die Position, dass den beiden Berichtsarten die gleichen Verarbeitungsprozesse und Verarbeitungswege zugrunde liegen. Mit den beiden Prozeduren wird das Leistungsmerkmal desselben Sachverhaltes gemessen, d.h., es wird der gleiche Gegenstand untersucht. Das ist zumindest in unserem Versuchsdesign der Fall, da die Ganzberichtsbedingung zusammen mit Teilberichtsbedingungen variiert wird. Entscheidend dafür, ob sie ein gleiches Niveau der Informationsverarbeitung widerspiegeln, ist in diesem Fall die Darbietungsdauer.

$\mathrm{Ob}$ der Teilbericht tatsächlich dem Ganzbericht überlegen ist, war eine zeitlang ein Gegenstand der Diskussion. Es wurde oft als Gegenargument angeführt, dass diese Überlegenheit durch „Output-Interferenz“ zu erklären sei (z.B. Holding, 1975; Dick, 1971). Schulz und Lamann-Lison (1985) schlugen noch die „Antwortvorbereitungsinterferenz“ als Ursache für die oft vorgefundene Teilberichtsüberlegenheit vor. Sie stellten die Hypothese auf, dass der Teilbericht weniger von der Antwortinterferenz belastet sei als der Ganzbericht, und dass es dieser Vorteil sei, der die Teilberichtsüberlegenheit ausmache und mit der Verarbeitungszeit abnehme. Die Teilberichtsüberlegenheit ist ihnen zufolge ein „Lese“- Effekt (ebd.). Nach Schulz (1981/1982) soll der Effekt sogar nur im Fall von Buchstaben in klarer Form und außerdem erst nach einer Reproduktionsmenge von drei bis vier Items auftreten.

Wie in dem theoretischen Teil bereits erwähnt, wird diese „Output-Interferenz“Begründung der Teilberichtsüberlegenheit gegenüber dem Ganzbericht oft mit dem Cue-delayEffekt, also dem Effekt der Abnahme der Überlegenheit mit zunehmenden Zeitintervallen, entkräftet (z.B. Coltheart, 1975). Nach dem vorgestellten Modell könnte die Erklärung für die Teilberichtsüberlegenheit im Zusammenhang mit dem Cue-delay-Effekt in den Selektionsmechanismen bzw. dem Selektionszeitpunkt liegen. Betrachtet man den Fall des klassischen Sperling-Paradigmas mit auditiven Hinweisreizen, kann die Teilberichtsüberlegenheit auf die von dem Hinweisreiz verursachte (Früh)Selektion in der Teilberichtsbedingung zurückzuführen sein. In der $P R$-Aufgabe wird die Information 
nichtselektiv verarbeitet und weitergeleitet, bevor der Hinweisreiz kommt (vgl. Gegenfurtner \& Sperling, 1993; Averbach \& Coriell, 1961). Je früher der Hinweisreiz dargeboten wird, desto früher setzt die Selektion ein. Dies hat den Vorteil, dass die in dem Modell (s. Abb. 21) postulierten Selektionen 2, 3 oder 4 in Gang gesetzt werden. Als Folge bekommt die von dem Hinweisreiz signalisierte Zeile der Matrix, oder besser gesagt, die Lokalisation der Zeile, in dem „spatial info buffer“, mehr Aufmerksamkeit. Mit Hilfe des thalamischen Modulationsmechanismus (des Pulvinars) wird die Verarbeitung der ausgewählten Items (Positionen) in der ventralen Bahn auf dem Weg zum „object attribute buffer“ oder direkt im „object attribute buffer“ bis hin zum „,associative buffer“ verstärkt. Der Informationsfluss an der signalisierten Position (Lokalisation) wird dabei erhöht (vgl. LaBerge, 1995). Somit werden die Merkmalsinformationen der ausgewählten Buchstaben besser zu Mustern geformt und als Buchstaben oder ähnliches identifiziert. Je früher die Selektion einsetzt, desto früher wird sich die Verarbeitung auf die Zielreize konzentrieren und desto besser ist die Leistung. Je später die Selektion erfolgt, desto mehr nimmt dieser Vorteil ab. Allerdings ist beim Ganzbericht der Darbietungszeitpunkt des Hinweisreizes irrelevant, da der Hinweisreiz an sich für den Ganzbericht keine Selektion im eigentlichen Sinne hervorruft, selbst dann nicht, wenn der Hinweisreiz für den Ganzbericht und die Hinweisreize für den Teilbericht variiert werden. Diese Leistung beim Ganzbericht stammt aus dem ,associative buffer“, sie ist einfach alles, was das System unter schlechter Wahrnehmungsbedingung noch zu leisten in der Lage ist. Der Vorteil durch frühe Selektion beim Teilbericht nimmt soweit mit dem verzögerten Hinweisreiz ab, bis der Zeitpunkt erreicht wird, wo eben keine Selektion mehr vor dem Identifikationsprozess im ,,associative buffer“ stattfinden kann. Die Situation ist dann mit der des Ganzberichtes gleichgestellt. Daher bewegen sich die Leistungen von den beiden Berichtsarten auf dem gleichen Niveau. Eigentlich muss man anzweifeln, ob es als Überlegenheit des Teilberichts bezeichnet werden darf und ob die Hochrechnung der Teilberichtsleistung für den Vergleich mit dem Ganzbericht überhaupt legitim ist. Denn durch die frühe Selektion kann von gleicher Aufmerksamkeit (,equal attention“ von Sperling, 1960) für alle Positionen (inkl. der nicht selektierten Positionen) nicht die Rede sein. Damit ist die Voraussetzung für die Hochrechnung eigentlich nicht gegeben. Über dieses Problem wird gleich noch im Zusammenhang mit dem möglichen Einfluss der „Strategie“ in der PR-Aufgabe diskutiert.

(2) Inverser Reizdauereffekt und inverser Helligkeitseffekt

Im Zusammenhang mit den beiden Effekten hat Coltheart (1980) die Trennung zwischen informatorischer und sichtbarer Persistenz begründet (s. Abschnitt 1.3.2). Dass die Effekte nur 
in bestimmten Methoden, nämlich in direkten Methoden auftreten, hat nach dem vorgestellten Modell tatsächlich mit den Aufgabenarten zu tun. Der inverse Reizdauereffekt und der inverse Helligkeitseffekt treten nur bei einem bestimmten Zustand der Informationsverarbeitung und bis zu einer gewissen Schwierigkeit der Aufgabe auf. Bei den direkten Methoden (Aufgaben), wo die phänomenologische Schätzung gefragt wird, ist das System perzeptuell nicht überlastet. Die Reizinformation gelangt problemlos vom ,,visual buffer“ in die nächsten Stufen (,object attribute buffer“ und ,spatial info buffer“), sie wird in den ,,associative buffer“ weitergeleitet und dort integriert und identifiziert. Die Leistung, die erbracht werden kann, ist nur abhängig von der Qualität und den physischen Eigenschaften des Stimulus, wie z.B. Helligkeit und Darbietungsdauer. Die genannten physischen Eigenschaften sind Faktoren, die die Aktivität der Neuronen in dem Übertragungsprozess von der Netzhaut zum visuellen Cortex oder zu den weiteren Nervenbahnen beeinflussen könnten, so dass beim Übertragungsprozess ein Inhibitionseffekt entsteht. Da bei weiterer Übertragung keine weitere Schwierigkeit auftritt, treten diese Wirkungen dann auch in dem ,associative buffer“ zutage, d.h., die Effekte werden beobachtbar. In Untersuchungen mit den indirekten Methoden werden diese Einflüsse von Helligkeit und Darbietungsdauer aber durch weitere dominierende Einschränkungen eliminiert bzw. überdeckt. Beispielsweise ist in der Sperling-Aufgabe das System offensichtlich perzeptuell überlastet (vor allem in der Phase des „object attribute buffer“) und die Integration und Identifikation der Reizinformation sind kognitiv viel aufwendiger und viel zeitraubender, so dass die minimalen peripheren Effekte in den frühen Phasen der Informationsverarbeitung nicht zutage treten können. Jedenfalls scheint es angebracht zu sein, die Leistung in der $P R$ Aufgabe besser als multipel determiniert zu betrachten.

\section{(3) Hinweisreiz-Kriterien-Effekt (cueing criteria effect)}

Die Wirksamkeit von verschiedenen Hinweisreizen kann unterschiedlich sein. Dass die Lokalisation als Selektionskriterium viel effektiver ist als andere Selektionskriterien, wie Farbe oder Form, kann mit der Unterschiedlichkeit der Hirnareale erklärt werden, die in den auf unterschiedlichen Stimulus-Attributen basierenden Selektionen involviert sind (vgl. Posner, 1993). In den von Posner und Peterson (1990) vorgeschlagenen Aufmerksamkeitssystemen ist das posteriore Aufmerksamkeitssystem im Frontallappen auf lokalisationsbasierte Selektion spezialisiert, während das anteriore Aufmerksamkeitssystem in Aufgaben involviert ist, wo eine Selektion auf Basis von andersartigen Hinweisreizen, wie z.B. Farben, durchgeführt werden soll. Warum die physikalischen Dimensionen der Reize, wie Lokalisation und Farbe, als cueing criteria effektiver sind als kategoriale Information, wie Klasse oder „sound“ (z.B. Sperling, 1960; von Wright, 1972; Coltheart, Lea \& Thompson, 1974), ist nach dem 
vorgestellten Modell damit zu erklären, dass die physikalischen Attribute der Reize als Selektionskriterien bereits auf frühe Phasen der Informationsverarbeitung wirken können. Die kategorische Information dagegen kann erst in dem ,associative buffer“ übersetzt und von dort aus angewendet werden.

(4) Einfluss der Hinweisreiz-Antizipation (guessing) und der Strategie

Sperlings „Equal attention“-Vorstellung (1960), aus der er die Hochrechnung der Teilberichtsleistung als Schätzung für die verfügbare Kapazität abgeleitet hat, und die besagt, dass der/die $\mathrm{Pb}$ in der $P R$-Aufgabe seine/ihre Aufmerksamkeit auf alle Positionen gleich verteilt, scheint nicht immer zutreffend zu sein. Es ist nämlich nicht auszuschließen, dass in der Aufgabenbewältigung eine subjektive mentale Vorbereitung vorausgeht und dass der Hinweisreiz antizipiert wird oder gar eine Strategie im Spiel ist (vgl. Holding, 1970, 1971, 1975).

Eine Selektionsmöglichkeit in dem vorgestellten Modell wurde bis jetzt außer acht gelassen. Das ist nämlich die von der Lokalisationssteuerung im präfrontalen Cortex ausgehende Selektion 1 (s. Abb. 22), um das visuelle Gesichtsfeld zu bestimmen. Anders ausgedrückt: Der Mensch hat im Voraus die Möglichkeit, zu entscheiden, was er sehen und beachten will, und zwar aufgrund bestimmter Interessen, bestimmten Vorwissens und bestimmter Erwartung. In der $P R$-Aufgabe bedeutet dies konkret, dass der/die $\mathrm{Pb}$ seine/ihre Aufmerksamkeit aufgrund seiner/ihrer Erwartung, aufgrund Erratens oder einfach als Strategie auf bestimmte Regionen lenken oder fixieren kann. Das ist die so genannte vorbereitende Aufmerksamkeit (vgl. preparatory attention von LaBerge, 1995). Der/die Pb kann vor jeder Testaufgabe (Durchgang) in der $P R$-Methode beispielsweise einfach spekulieren, was als nächstes kommen wird; oder er/sie kann sich dafür entscheiden, jedes Mal die mittlere (vgl. Holding, 1970; Gegenfurtner \& Sperling, 1993) oder die obere Reihe der Buchstaben-Matrix stärker zu beachten. Dies könnte zur Folge haben, dass die Teilberichtsleistung für verschiedene Zeilen unterschiedlich ausfällt.

\section{(5) Zeileneffekt}

Allerdings ist der beobachtete Zeileneffekt in der aktuellen Untersuchung nicht durch den oben beschriebenen Einfluss der Hinweisreiz-Antizipation bzw. den Einfluss der Strategie zu erklären. Es ist zwar nahe liegend, zu vermuten, dass der Zeilenunterschied bereits von Anfang an auf der untersten Ebene der Informationsaufnahme entstanden ist, da die Pbn von vornhinein subjektiv stärker auf die obere Zeile als die untere geachtet haben könnten. Es konnte aber gezeigt werden, dass es sich bei dem Zeileneffekt viel mehr um eine Lesegewohnheit, die 
schwer zu unterdrücken ist, als um ein Strategieproblem handelt (mehr dazu, s. Lass et al., 2001). In einigen Experimenten (ebd.) konnte gezeigt werden, dass der Zeileneffekt zum einen nicht durch Änderung der Cursorrichtung für die Antworteingabe von ursprünglich links oben nach rechts unten in die rückläufige Richtung berührt wurde, und dass der Zeileneffekt zum anderen auch nicht durch eine bewusste Instruktion, „den Aufmerksamkeitsfokus zu erweitern“ und ,auch auf die zweite Zeile zu achten“, eliminiert werden konnte. Anscheinend ist die Herangehensweise, die obere Zeile besser zu verarbeiten als die untere und links dargebotene Items besser als rechts dargebotene Items, ein nahezu automatisierter Prozess.

Eine mögliche Erklärung nach dem Modell wäre, dass das Formen der elementaren Merkmale zu bekannten Mustern ein erlernter Prozess ist, und dass die Leserichtung im Alltag soweit verinnerlicht ist, dass der Verarbeitungsprozess in dem „object attribute buffer“ unter dem Einfluss der Lesegewohnheit ist. Es ist auch anzunehmen, dass sogar der Integrations- und Identifikationsprozess im ,associative buffer“ dieser Gewohnheit folgt (d.h. nach einer bestimmten Reihenfolge seriell zu identifizieren), solange die Selektionsinformation noch nicht vorliegt. Ein Einwand gegen diese Erklärung ist möglicherweise der Folgende: Warum wird der Zeileneffekt bei kleinen ISI (s. Experiment 1 und 3) immer noch beobachtet, wenn in diesem Fall die Selektion früher eingreifen kann, z.B. vor dem ,,associative buffer“? Es handelt sich hier wahrscheinlich um den Informationsanteil, der nichtselektiv vor dem Hinweisreiz weitergeleitet wird, welcher diesem Lesegewohnheitseinfluss unterliegt. Wenn man die Daten von Experiment 1 noch einmal genauer betrachtet, zeichnet sich eine Vergrößerung des Zeileneffektes mit zunehmenden ISI $a b,{ }^{19}$ was so interpretiert werden kann: Da der Informationsanteil vor der Selektion, der nach der automatisierten Lesegewohnheit im „object attribute buffer“ verarbeitet wird, mit zunehmender Verzögerung des Hinweisreizes immer größer wird, wird auch der Zeileneffekt immer größer.

\section{(6) Spracheffekt}

Ein Einfluss von Sprache auf die Leistung in dem Sperling-Paradigma wurde nachgewiesen (mehr dazu s. Lass et al., 2001). Lass et al. (ebd.) haben in ihrer Untersuchung zeigen können, dass deutschen Pbn mit Konsonanten als Versuchsmaterial bessere Leistung erbracht haben als die Vergleichgruppe chinesischer Pbn, die mit dem Alphabet nicht so vertraut waren, wie die Deutschen. Nach dem vorgestellten Modell kann dieser Leistungsunterschied durch einen sprachlich bedingten Unterschied in dem Top-down-Prozess im „object attribute buffer“ erklärt werden. Bei dem Top-down-Prozess handelt es sich um die implizite Anwendung von

\footnotetext{
${ }^{19} \mathrm{Vgl}$. den Ergebnisteil von Experiment 1: Eine signifikante Interaktion zwischen den zwei Faktoren „Berichtsart“ und ,ISI“ $\left[F(3,45)=15.69, \Lambda(3,45)=.619, p<.001, \eta^{2}=.51\right]$.
} 
vorhandenem Wissen, was im Laufe der Zeit erlernt wird und durch individuelle Erfahrung, gesellschaftliche und kulturelle Gegebenheiten bedingt ist. Was diesen speziellen Fall betrifft, haben Deutsche im Laufe der sprachlichen Erziehung ein viel vertrauteres Verhältnis mit dem Alphabet entwickelt. Sie können deshalb im Vergleich zu den Chinesen bei dem Wiedererkennungsprozess im „object attribute buffer“ nahezu ,automatisch“ viel schneller und kompakter die Elemente von Buchstaben zu bekannten Mustern formen. Das erleichtert folglich auch das ,perceptual load“, so dass schneller und mehr Outputs zu dem ,,associative buffer“"geliefert werden können und dadurch insgesamt eine bessere Leistung erbrachtet wird.

\subsection{Schlussdiskussion und Ausblick}

Das Anliegen der Arbeit war, nach einem neuen Konzept zu suchen, um das Phänomen des so genannten ikonischen Gedächtnisses besser zu beschreiben und zu erklären, und unterschiedliche Befunde, Beobachtungen, Kontroversen und Diskussionen bezüglich des Gegenstandes und der Forschungsmethode in Einklang zu bringen. Es wurde dabei angestrebt, das Ganze eingebettet in ein gesamtes visuelles Informationsverarbeitungssystem zu betrachten.

Unter Berücksichtigung der relevanten Literatur aus verwandten Bereichen der psychologischen und neuropsychologischen Forschung wurde in der vorliegenden Arbeit ein neuropsychologisches Modell zur visuellen Informationsverarbeitung, vor allem aber zum (visuellen) sensorischen Gedächtnisphänomen aufgestellt. Neben der neurophysiologischen Fundierung wurden einigen Annahmen des Modells anhand des Beispiels des Modalitätseffektes in der Sperling-Aufgabe überprüft. Die empirischen Daten unterstützten die bereits allgemein akzeptierte Grundannahme, dass die visuelle Informationsverarbeitung getrennten Wegen folgt, d.h., dass ein Weg (ventrale Bahn) die Information der ObjektIdentität und der andere (dorsale Bahn) für die Verarbeitung der räumlichen Information zuständig ist, und dass die Informationen aus beiden Verarbeitungsbahnen in einem temporären Zustand zusammengefügt und integriert werden. Darüber hinaus konnte in der Arbeit demonstriert werden, dass die beiden Verarbeitungswege unterschiedliche Charakteristika besitzen. Die ventrale Bahn unterliegt einer Kapazitätsbeschränkung, die dorsale Bahn dagegen ist nicht sehr kapazitätsempfindlich, dafür aber für zeitliche Aspekte sehr sensibel. Ebenfalls konnte gezeigt werden, dass mindestens zwei Stellen im visuellen Informationsverarbeitungsprozess kapazitätsanfällig sind, wobei ihre Kapazitätslimitationen unterschiedlicher Natur sind. Die Objekterkennung (Rekognition) in der ventralen Bahn (in 
dem „object attribute buffer“ des vorgestellten Modells) unterliegt einer perzeptuellen Kapazitätsbeschränkung, während der Identifikationsprozess in einem assoziativen Zustand (dem ,associative buffer“ des Modells), wo die Informationen von den getrennten Verarbeitungen zusammenkommen, mit einer kognitiven Verarbeitungslimitation konfrontiert ist, da die Identifikation nur seriell durchgeführt werden kann und dort nur bestimmte kognitive Verarbeitungsressourcen vorhanden sind. Die räumliche Informationsverarbeitung in der dorsalen Bahn (im „spatial info buffer“ des Modells) ist leicht ablenkbar. Das exogene Charakteristikum der Verarbeitung spricht für einen nahezu automatischen Verarbeitungsprozess der dorsalen Bahn bzw. in diesem Buffer. Das Modell kann nicht nur das spezifische Phänomen des Modalitätseffektes in der PR-Aufgabe plausibel erklären, es liefert ebenso einen geeigneten Ansatz dafür, das ikonische Gedächtnis mit allen dazugehörigen Phänomenen gut zu beschreiben und zu erklären. Insgesamt scheint das Modell ein plausibler Ansatz zu sein, der den visuellen Informationsverarbeitungsprozess adäquat beschreibt und auch in der Lage ist, den empirischen Phänomenen und Daten Rechnung zu tragen.

Das vorgestellte Modell betont den Prozess-Charakter der Informationsverarbeitung. Durch die empirische Untersuchung konnte gezeigt werden, dass der Gegenstand des ikonischen Gedächtnisses in der temporären integrativen Phase der Informationsverarbeitung verankert ist, und dass ihm die gleichen Verarbeitungsprozesse zugrunde liegen wie anderen visuellen Phänomenen. Damit kann die einschlägige Forschung auf dem Hintergrund des gesamten Forschungsnetzwerks der visuellen Informationsverarbeitung betrachtet werden und somit ist die Kritik wegen des zu „speziellen“ Gegenstandes (vgl. Haber, 1983) aus dem Weg geräumt.

Das herkömmliche Konzept des sensorischen Gedächtnisses und das des KZG wurden in dem Modell in einem perzeptuellen Gedächtnis vereint. Die beiden Gedächtnisformen werden nur als verschiedene Ausdrücke des perzeptuellen Gedächtnisses betrachtet, welches in Form von episodischen Repräsentationen verkörpert ist. Das perzeptuelle Gedächtnis ist das Produkt eines aktiven kognitiven Verarbeitungsmechanismus, der von den präfrontalen Instanzen gesteuert wird, die eine ähnliche Funktion wie die zentrale Exekutive (central executive) in Baddeleys Arbeitsgedächtnis-Modell haben. Hier ist auch der Zeitpunkt, das „Workingmemory"-Modell von Baddeley $(1986$, 1990) unter die Lupe zu nehmen. Das Arbeitsgedächtnis besteht nach Baddeley aus einem Aufmerksamkeitskontrollsystem (controlling attentional system, 1990, S. 71) und einer Menge von Hilfssystemen (slave systems). Die wichtigen Hilfssysteme sind vor allem die phonologische Schleife und der räumlich-visuelle Notizblock. Das Aufmerksamkeitskontrollsystem, das die Hilfssysteme 
überwacht und koordiniert, nannte Baddely „,zentrale Exekutive“. Baddeley (1990) hat bereits die Rolle des Frontallappens beim Vergleich seiner ,zentralen Exekutive“ mit dem SASModell (supervisory attentional system) von Norman und Shallice (1986) erkannt, nämlich die Rolle, die Planung, Organisation und Kontrolle von Aktionen durchzuführen. Baddeley (1990) nimmt einen eigenen Übergangsspeicher der zentrale Exekutive an und darin sollen ihm zufolge benötigte Informationen gespeichert werden, um Entscheidungen über die Kontrolle der Hilfssysteme treffen zu können. Untersuchungen an Primaten weisen darauf hin, dass unterschiedliche Areale des frontalen Cortex dafür verantwortlich sind, unterschiedliche Arten von Informationen im Arbeitsgedächtnis aufrechtzuerhalten (Goldman-Rakic, Ó Scalaidhe \& Chafee, 2000). Die Frage ist hier, wo sich dieser eigene Speicher für die ,zentrale Exekutive“ befindet und wo das Aufrechtzuerhaltende gelagert ist. Im Zusammenhang mit dem vorgestellten Modell kann man dies so betrachten, dass Baddeleys Arbeitsgedächtnis eigentlich aus den Kontrollinstanzen im Präfrontallappen und dem ,associative buffer” besteht. Der „,associative buffer” übernimmt quasi die Rolle eines on-line-aktiv-gehaltenen Speichers. Die „zentrale Exekutive“ im Präfrontallappen ist dann diejenige, die handelt. Sie speist aktiv die Information aus verschiedenen sensorischen Modalitäten ein oder nimmt passiv Informationen an, sie verknüpft und integriert die Informationen, vergleicht sie mit vorhandene Informationen oder Repräsentationen im Langzeitgedächtnis, um sie letztendlich zu identifizieren. Der Austausch zwischen dem aktuellen On-line-Speicher (,associative buffer“) und dem Langzeitgedächtnis (vielleicht der Austausch, den Kosslyn als „swapping process” bezeichnete, s. Kosslyn, 1994, S. 324) ist wahrscheinlich eine der wichtigsten Aufgaben des Arbeitsgedächtnisses, genauer gesagt, der ,zentralen Exekutive“. Diese Instanz in dem Präfrontallappen trifft dann auch die Entscheidung darüber, wie reagiert und gehandelt werden soll, und bei Bedarf gibt diese ,zentrale Exekutive“ entsprechende Anweisungen für die Motorik, um die Handlung in Gang zu setzen. Somit kann man das Arbeitsgedächtnis-Konzept fast nur auf die ,zentrale Exekutive“ reduzieren.

Letztendlich kann man das menschliche Informationsverarbeitungssystem als einen Apparat betrachten, der für explizites Lernen $^{20}$ und aktives Leben nur ein einziges Gedächtnissystem als Lager im herkömmlichen Sinne besitzt, nämlich das Langzeitgedächtnis. In dem Langzeitgedächtnis werden unsere Erfahrungen gesammelt und unser Wissen repräsentiert. Aber der Großteil des Apparates steht ständig aktiv im Informationsaustausch mit der Umwelt. Der ständig wechselnde Informations-Input wird kurzfristig in einer temporären

\footnotetext{
${ }^{20}$ Das implizite Gedächtnis hat eventuell einen anderen Verarbeitungsvorgang. Dabei werden z.B. direkte adaptive Veränderungen der involvierten synaptischen Verbindungen durch jede Verarbeitung im neurocortikalen System angenommen (vgl. Rösler, 1997).
} 
Repräsentation mit allen episodischen Charakteristika bereit („on line“) gehalten, solange sie für uns möglich und nützlich ist. Ein ständiges Auffrischen der temporären Repräsentation dient zur ökonomischen Nutzung und zum Selbstschutz. Das einheitliche System zeigt sich unter verschiedenen Situationen und äußeren Bedingungen in unterschiedlichen Ausprägungen und Charakterbetonungen, dennoch folgt die Informationsverarbeitung gleichen Prozessen und Gesetzmäßigkeiten. Es scheint hier nicht weiter sinnvoll, von separaten Gedächtnissystemen auszugehen. Tatsächlich findet der Gedanke von nur einem einzigen Gedächtnissystem in der menschlichen Informationsverarbeitung bereits viel Zustimmung in der Literatur (z.B. Anderson, 1983; Cowan, 1993).

Es konnte in der vorliegenden Arbeit demonstriert werden, dass mit einem einheitlichen Konzept der visuellen Informationsverarbeitung nicht nur ein empirischer Effekt des Gegenstandes erklärt werden kann, sondern auch die unterschiedlichen Phänomene, die mit dem so genannten ikonischen Gedächtnis im Zusammenhang stehen, erklärt und in Einklang gebracht werden können. Somit ist das ikonische Gedächtnis als ein in dem allgemeinen visuellen Informationsverarbeitungsprozess eingebettetes Phänomen zu betrachten. Andersherum betrachtet kann man sagen, dass es nur ein einheitliches aktives Informationsverarbeitungssystem gibt, das unsere mentale (kognitive) Auseinandersetzung in ständigem Austausch mit der Umwelt regelt.

In der vorliegenden Arbeit leistete die differenzierte ausführliche theoretische und empirische Auseinandersetzung mit der $P R$-Methode sowie dem Modalitätseffekt zusätzlich noch einen kleinen methodischen Beitrag für die künftige Forschung. 


\section{$\underline{\text { Kapitel } 5}$ Zusammenfassung}

Die vorliegende Arbeit geht von einem empirischen Effekt, nämlich dem Modalitätseffekt des Hinweisreizes in Untersuchungen des ikonischen Gedächtnisses aus. Zugleich wird die Entwicklung eines Modells zum Ziel gesetzt, das die bisherigen Befunde besser - als die herkömmlichen Modelle - integrieren kann.

Zuerst wurde im theoretischen Teil ein Überblick über den Gegenstand, die Geschichte der Forschung, die bisherigen Forschungsmethoden, die historische konzeptuelle Entwicklung sowie den aktuellen Forschungsstand gegeben. Der unbefriedigende Theorienstand wird anhand offener Fragen und Kontroversen dargestellt.

Der zweite Teil der Arbeit beschäftigt sich hauptsächlich mit dem Phänomen des Modalitätseffektes in der Partial-report-Aufgabe. Zunächst wurde der Modalitätseffekt mit Experiment 1 belegt. Der Modalitätseffekt drückte sich darin aus, dass in der Sperling-Aufgabe mit visuellen Hinweisreizen schlechtere Leistungen erbrachtet wurden als mit auditiven. $\mathrm{Zu}$ dem Effekt wurden anschließend theoriengeleitet Experiment 2, 3 und 4 durchgeführt, um nach einer plausiblen Erklärung zu suchen. Es wurde nachgewiesen, dass der Leistungsunterschied nicht durch die Maskierung des visuellen Hinweisreizes auf den Zielreiz zu erklären ist, nicht durch einen modalitätsbedingten Unterschied in den Reaktionszeiten auf die beiden Arten von Hinweisreizen, und auch nicht durch einen Verarbeitungszeitverlust aufgrund einer von dem peripheren visuellen Hinweisreiz verursachten Aufmerksamkeitsverschiebung. Es konnte dann belegt werden, dass der Leistungsunterschied durch eine intramodale Interferenz zwischen dem Hinweisreiz und der visuellen Vorlage verursacht wird.

Im dritten Teil der Arbeit wurde in Anbetracht des unbefriedigenden Theorienstandes bezüglich des ikonischen Gedächtnisphänomens, und auch, um eine differenzierte Erklärung für den Modalitätseffekt zu finden, ein neuropsychologisches Modell zur visuellen Informationsverarbeitung und zum ikonischen Gedächtnis aufgestellt. Dabei wurden jüngere Theorien zur visuellen Wahrnehmung und visuellen Aufmerksamkeit aus psychologischer und neuropsychologischer Sicht herangezogen und neue neurophysiologische Erkenntnisse berücksichtigt. Das vorgestellte Modell geht von der inzwischen weit verbreiteten Grundannahme aus, dass die visuellen Informationen zunächst auf zwei getrennten Wegen verarbeitet werden: die objektbezogenen Attribute durch die ventrale Bahn (im inferioren temporalen Cortex), und die räumlichen Informationen über den dorsalen Weg (im posterioren parietalen Cortex). Es wurde in dem vorgestellten Modell angenommen, dass die beiden Arten von Informationen in einem temporären Buffer (vermutlich im Sulcus temporalis superior) zusammenkommen. Dort werden sie zusammengefügt und identifiziert, und zwar unter der 
Steuerung von aktiven Instanzen im präfrontalen Cortex. Die Instanzen im präfrontalen Cortex spielen zugleich eine wichtige Rolle bei der Aufmerksamkeitskontrolle während des gesamten Informationsverarbeitungsprozesses. Mit Hilfe des thalamischen Systems, vor allem des Pulvinars, wird der Befehl aus der präfrontalen Instanz durch Selektion in verschiedenen Phasen der Verarbeitung umgesetzt.

Nach der Modellbeschreibung wurden einige Annahmen des Modells anhand des Beispiels des Modalitätseffektes mit Verhaltensdaten überprüft. Zu diesem Zweck wurden neue Experimente im Zusammenhang mit dem Modalitätseffekt durchgeführt und die bereits vorhandenen Daten neu analysiert. Die empirischen Daten unterstützten die Modellannahmen, dass die Wiedererkennung von Objekten in der ventralen Bahn parallel verlaufen kann, aber dennoch von einer perzeptuelle Kapazität eingeschränkt wird, während die Integration und Identifikation von getrennt verarbeiteten Informationen im temporären Buffer einer kognitiven Kapazitätslimitation unterliegen, da die Integration und Identifikation dort nur seriell durchgeführt werden können. Es konnte in diesem Zusammenhang demonstriert werden, dass der Modalitätseffekt in der Sperling-Aufgabe zum einen auf eine perzeptuelle Interferenz aufgrund der perzeptuellen Kapazitätsbeschränkung in dem ventralen Kodierungsprozess zurückzuführen ist (beim Ganzbericht), zum anderen auf eine Verarbeitungskonkurrenz aufgrund der kognitiven Kapazitätslimitation bei der Integration und Identifikation (beim Teilbericht). Darüber hinaus konnte gezeigt werden, dass die zwei getrennten Informationsverarbeitungswege unterschiedliche Charakteristika haben, und dass die ventrale Bahn einer perzeptuellen Kapazitätseinschränkung unterliegt, während der dorsale Weg relativ kapazitätsunabhängig, aber für zeitliche Aspekte empfindlich ist.

Im vierten Teil der Arbeit wurde ausgehend von dem vorgestellten Modell das Phänomen des ikonischen Gedächtnisses neu betrachtet, und zwar in Zusammenhang mit anderen visuellen Phänomenen und Gedächtnisformen. Mit dem Modell konnten auch die Phänomene und Effekte, die in der Partial-report-Untersuchung gefunden worden sind, gut erklärt bzw. miteinander in Einklang gebracht werden. Auf globaler Ebene betrachtet, wurde schließlich für ein einheitliches Verarbeitungssystem mit denselben Verarbeitungsprozessen plädiert und das Phänomen des ikonischen Gedächtnisses in die gesamte visuelle Informationsverarbeitung eingebunden. Der theoretische Zusammenhang zwischen den herkömmlichen Konzepten bezüglich verschiedener Gedächtnisformen wurde herausgearbeitet, so dass eine theoretische Vernetzung und Einbettung der vorliegenden Arbeit in die einschlägige Forschung erzielt wurde. 


\section{Literaturverzeichnis}

Allport, D. A. (1970). Temporal summation and phenomenal simultaneity: Experiments with the radius display. Quarterly Journal of Experimental Psychology, 22, 686-701.

Anderson, J. R. (1983). The architecture of cognition. Cambridge, MA: Harvard University Press.

Adelson, E. H. \& Jonides, J. (1980). The psychophysics of iconic storage. Journal of Experimental Psychology: Human Perception and Performance, 6, 486-493.

Appelman, I. B. (1980). Partial report and the other sampling procedures overestimate the duration of iconic memory. American Journal of Psychology, 93, 79-97.

Atkinson, R. C. \& Shiffrin, R. M. (1968). Human memory: A proposed system and its control processes. In K. W. Spence \& J. T. Spence (Eds.), The psychology of learning and motivation: Advances in research and theory (Vol. 2, pp. 89-195). New York: Academic Press.

Averbach, E. \& Coriell, H. S. (1961). Short-term memory in vision. Bell System Technical Journal, 40, 309-328.

Baddeley, A. D. (1986). Working memory. Oxford: Oxford University Press.

Baddeley, A. D. (1990). Human memory. Theory and practice. Hove: Lawrence Erlbaum Associates.

Baizer, J. S., Ungerleider, L. G. \& Desimone, R. (1991). Organization of visual inputs to the inferior temporal and posterior parietal cortex in macaques. The Journal of Neuroscience, $11,168-190$.

Biederman, I. (1987). Recognition-by-components: A theory of human image understanding. Psychological Review, 94, 115-147.

Black, I. L. \& Barbee, J. G. (1985). Effect of a partial report visual cue on information available in tachistoscopic presentations of alphanumeric characters varying in number and type. Perceptual and Motor Skills, 61, 815-820.

Bortz, J. (1993). Statistik für Sozialwissenschaftler (4. Aufl.). Berlin: Springer.

Boussaoud, D., Ungerleider, L. G., Desimone, R. (1990). Pathways for motion analysis: Cortical connections of medial superior temporal and fundus of the superior temporal visual areas in the macaque. Journal of Comparative Neurology, 296, 462-495.

Brebner, J. M. T. \& Welford, A. T. (1980). Introduction: An Historical Background Sketch. In A. T. Welford (Ed.), Reaction times (pp. 9-23). London: Academic Press. 
Breitmeyer, B. G. (1984). Visual masking. An integrative approach. Oxfords psychology series No. 4. New York: Oxford University Press.

Briand, K. A. \& Klein, R. M. (1987). Is Posner's „beam“ the same as the Treisman's „glue“?: On the relation between visual orienting and feature integration theory. Journal of Experimental Psychology: Human Perception and Performance, 13, 228-241.

Briggs, G. G. \& Kinsbourne, M. (1972). Visual persistence as measured by reaction time. Quarterly Journal of Experimental Psychology, 24, 318-325.

Cavanagh, J. P. (1972). Relation between the immediate memory span and the memory search rate. Psychological Review, 79, 525-530.

Coltheart, M. (1975). Iconic memory: A reply to Professor Holding. Memory \& Cognition, $3(1), 42-48$.

Coltheart, M. (1980). Iconic memory and visible persistence. Perception \& Psychophysics, 27, 183-228.

Coltheart, M. (1984). Sensory memory: A tutorial review. In H. Bouma \& H. G. Bouwhuis (Eds.), Attention and performance X (pp. 259-285), London: Erlbaum.

Coltheart, M., Lea, C. D. \& Thompson, K. (1974). In defence of iconic memory. Quarterly Journal of experimental Psychology, 26, 633-641.

Corbetta, M., G., Shulman, G. L., Miezin, F. M. \& Peterson, S. E. (1995). Superior parietal cortex activation during spatial attention shifts and visual feature conjunction. Science, 270, 802-805.

Cowan, N. (1984). On short and long auditory stores. Psychological Bulletins, 96, 341-370.

Cowan, N. (1988). Evolving concepts of memory storage, selective attention, and their mutual constraints within the human information processing system. Psychological Bulletin, 104, 163-191.

Cowan, N. (1993) Activation, attention, and short-term memory. Memory \& Cognition, 21 (2), 162-167.

Damasio, A. R. (1990). Synchronous activation in multiple cortical regions: A mechanism for recall. Seminar in the neuroscience, 2, 287-296.

Darwin, C. J., Turvey, M. T. \& Crowder, R. G. (1972). An auditory analogue of the Sperling partial report procedure: Evidence for brief auditory storage. Cognitive Psychology, 1, 255267. 
Di Lollo, V. (1978). On the spatio-temporal interactions of brief visual displays. In R. H. Day \& G. V. Stanley (Eds.), Studies in perception (pp. 39-55). Perth: University of Western Australia Press.

Di Lollo, V. \& Dixon, P. (1988). Two forms of persistence in visual information processing. Journal of Experimental Psychology: Human Perception and Performance, 14, 671-681.

Di Lollo, V. \& Dixon, P. (1992). Inverse duration effects in partial report. Journal of Experimental Psychology: Human Perception and Performance, 18, 1089-1100.

Dick, A. O. (1969). Relation between the sensory register and short-term storage in tachistoscopic recognition. Journal of Experimental Psychology, 82, 279-284.

Dick, A. O. (1971). On the problem of selection in short-term visual (iconic) memory. Canadian Journal of Psychology, 25, 250-263.

Dick, A. O. (1974). Iconic memory and its relation to perceptual processing and other memory mechanisms. Perception \& Psychophysics, 16, 575-596.

Dixon, P. (1985). The category effect in visual detection and partial report. Perception \& Psychophysics, 38, 286-295.

Dixon, P. \& Di Lollo, V. (1991). Effects of display luminance, stimulus, meaningfulness, and probe duration on visible and schematic persistence. Canadian Journal of Psychology, 45, 54-74.

Dixon, P. \& Di Lollo, V. (1994). Beyond visible persistence: An alternative account of temporal integration and segregation in visual processing. Cognitive Psychology, 26, 33-63.

Dixon, P., Gordon, R. D., Leung, A. \& Di Lollo, V. (1997). Attentional components of partial report. Journal of Experimental Psychology: Human Perception and Performance, 23 (4), 1253-1271.

Dixon, N. F. \& Hammond, J. (1972). The attenuation of visual persistence. British Journal of Psychology, 63, 243-254.

Donders, F. C. (1868). Die Schnelligkeit psychischer Prozesse. In Archiv für Anatomie und Physiologie und wissenschaftliche Medicin, 657-681.

Duncan, J. (1983). Perceptual selection based on alphanumeric class: Evidence from partial reports. Perception \& Psychophysics, 33, 533-547.

Duncan, J. \& Humphreys, G. W. (1989). Visual search and visual similarity. Psychological Review, 96, 433-458. 
Duncan, J. \& Humphreys, G. W. (1992). Beyond the search surface: Visual search and attentional engagement. Journal of Experimental Psychology: Human Perception and Performance, 18, 578-588.

Duncan, J., Humphreys, G., \& Ward, R. (1997). Competitive brain activity in visual attention. Current Opinion in Neurobiology, 7, 255-261.

Efron, R. (1970a). The relationship between the duration of a stimulus and the duration of a perception. Neuropsychologia, 8, 37-55.

Efron, R. (1970b). The minimal duration of a perception. Neuropsychologia, 8, 57-63.

Efron, R. (1970c). Effects of stimulus duration on perceptual onset and offset latencies. Perception \& Psychophysics, 8, 321-334.

Eriksen, C. W. \& Collins, J. F. (1967). Some temporal characteristics of visual pattern perception. Journal of Experimental Psychology, 74, 476-484.

Eriksen, C. W. \& Collins, J. F. (1968). Sensory traces versus the psychological moment in the temporal organisation of form. Journal of Experimental Psychology, 77, 376-380.

Eriksen, C. W. \& Hoffman, J. E. (1972). Temporal and spatial characteristics of selective encoding from visual displays. Perception \& Psychophysics, 12, 201-204.

Eriksen, C. W. \& Hoffman, J. E. (1973). The extent of processing of noise elements during selective encoding from visual display. Perception \& Psychophysics, 14, 155-160.

Eriksen, C. W. \& Rohrbaugh, J. (1970). Some factors determining efficiency of selection attention. American Journal of Psychology, 83, 330-342.

Eriksen, C. W. \& Steffy, R. A. (1964). Short-term memory and retroactive interference in visual perception. Journal of Experimental Psychology, 68, 423-434.

Eriksen, C. W. \& St. James J. D. (1986). Visual attention within and around the field of focal attention: A zoom lens models. Perception \& Psychophysics, 40, 225-240.

Erikson, B. A. \& Erikson, C. W. (1974). Effects of noise letters upon the identification of a target letter in a nonsearch task. Perception \& Psychophysics, 1, 143-149.

Erikson, C. W. \& Yeh, Y. (1985). Allocation of attention in the visual field. Journal of Experimental Psychology: Human Perception and Performance, 11, 583-597.

Erikson, C. W. \& Schultz, D. W. (1977). Retinal locus and acuity in visual information processing. Bulletin Psychnomic Society, 9, 81-84.

Gegenfurtner, K. R. \& Sperling, G. (1993). Information transfer in iconic memory experiments. Journal of Experimental Psychology: Human Perception and Performance, 19, 845-866. 
Goldman-Rakic, P. S. (1992). Working memory and the mind. Scientific American, 267, 110117.

Goldman-Rakic, P. S., Ó Scalaidhe, S. P. \& Chafee, M. (2000). Domain specificity in cognitive systems. In Michael. S. Gazzaniga (Ed.), The new cognitive neurosciences (2nd ed.) (pp. 733-74). Cambridge, MA: MIT Press.

Goodale, M. A. (1993). Visual pathways supporting perception and action in the primate cerebral cortex. Current Opinion in Neurobiology, 3, 578-585.

Goodale, M. A. (2000). Perception and Action in the Human Visual System. In Michael. S. Gazzaniga (Ed.), The new cognitive neurosciences (2nd ed.) (pp. 365-377). Cambridge, MA: MIT Press.

Goodale, M. A. \& Milner, A. D. (1992). Separate visual pathways for perception and action. Trends in Neuroscience, 15, 20-25.

Goodale, M. A., Milner, A. D., Jakobson, L. S. \& Gray, J. D. P. (1991). A neurological dissociation between perceiving objects and grasping them. Nature, 349, 154-156.

Gray, C. M. \& Singer, W. (1989). Stimulus specific neuronal oscillations in the cat visual cortex: A cortical functional unit. Proceedings of the National Academy of Science of the United States of America, 86, 1698-1702.

Haber, R. N. (1983). The impending demise of a icon: A critique of the concept of iconic storage in visual information processing. Behavioral and Brain Sciences, 6, 1-54.

Haber, R. \& Standing, L. (1970). Direct estimates of the apparent duration of a flash followed by visual noise. Canadian Journal of Psychology, 24, 216-229.

Hagenaar, R. \& Van der Heijden, A. H. C. (1997). Location errors in partial-report bar-probe experiments: In search of the origin of cue-alignment problems. Memory \& Cognition, 25, 641-652.

Hebb, D. O. (1949). The organization of behaviour. New York: Wiley.

Henderson, J. M. (1991). Stimulus discrimination following covert attentional orienting to an exogenous cue. Journal of Experimental Psychology: Human Perception and Performance, 17, 91-106.

Holding, D. H. (1970). Guessing behaviour and the Sperling store. Quarterly Journal of Experimental Psychology, 22, 248-256.

Holding, D. H. (1971). The amount seen in brief exposures. Quarterly Journal of Experimental Psychology, 23, 72-81.

Holding, D. H. (1975). Sensory storage reconsidered. Memory \& Cognition, 3, 31-41. 
Huckauf, A., Heller, D. \& Nazir, T. A. (1999). Lateral masking: Limitations of the feature interaction account. Perception \& Psychophysics, 61, 177-189.

Hummel, J. E. (1997). Structure and binding in object perception. In J. W. Donahoe \& V. P. Dorsel (Eds.), Neural network models of cognition: Biobehavioral foundations. Advances in psychology (pp. 203-219). Amsterdam: Elsevier Science Publishers.

Irwin, D. E. \& Brown, J. S. (1987). Tests of a model of informational persistence. Canadian Journal of Psychology, 41(3), 317-338.

Irwin, D. E. \& Yeomans, J. M. (1986). Sensory registration and informational persistence. Journal of Experimental Psychology, 12, 343-360.

Jones, E. G. (1985). The Thalamus. New York: Plenum Press.

Jonides, J. (1981). Voluntary versus automatical control over the mind's eye. In J. Long \& Baddeley (Eds.), Attention and performance IX (pp. 187-203). Hillsdale, NJ: Lawrence Erlbaum Associate Inc.

Kahneman, D. \& Treisman, A. (1984). Changing views of attention and automaticity. In R. Parasuraman and D. A. Davies (Eds.), Varieties of attention. New York: Academic Press.

Kahneman, D., Treisman, A. \& Gibbs, B. (1992). The reviewing of object-specific integration of information. Cognitive Psychology, 24, 175-219.

Kandel, E. R., Schwartz, J. H. \& Jessell, T. M. (1995). Neurowissenschaften. Eine Einführung. Heidelberg: Spektrum.

Kandel, E. R., Schwartz, J. h. \& Jessell, T. M. (2000). Principles of neural science (4th ed.). New York: McGraw-Hill

Kolb, B. \& Whishaw, I. Q. (1996). Neuropsychologie, 2. Aufl. (Übersetzung herausgegeben von Monika Pritzel, übersetzt von Marianne Mauch, Monika Niehaus-Osterloh \& Markus Numberger). Heidelberg: Spektrum.

Kosslyn, S. M. (1994). Image and brain. The resolution of the imagery debate. Cambridge, MA: MIT Press.

Kosslyn, S. M. \& Thompson, W. L. (2000). Shared mechanisms in visual imagery and visual perception: Insights from cognitive neuroscience. In Michael. S. Gazzaniga (Ed.), The new cognitive neurosciences (2nd ed.) (pp. 975-982). Cambridge, MA: MIT Press.

LaBerge, D. (2000). Network of Attention. In Michael. S. Gazzaniga (Ed.), The new cognitive neurosciences (2nd ed.) (pp. 711-724). Cambridge, MA: MIT Press.

LaBerge, D. (1995). Attentional processing. The brain's art of mindfulness. Cambridge: Harvard University Press. 
Lachman, R., Lachman, J. L. \& Butterfield, E. C. (1979). Cognitive psychology and information processing: An introduction. Hillsdale: Lawrence Erlbaum.

Lass, U., Yang, Y., Fang, Y., Yan, S., Sun, P., Chen, G., Becker, D. \& Lüer, G. (2001). Letter recognition in iconic memory experiments with German and Chinese subjects - similarities in attention allocation and differences in encoding. Manuskript in Vorbreitung.

Lavie, N. (1994). Perceptual load as a major determinant of the locus of selection in visual attention. Perception \& Psychophysics, 56 (2), 183-197.

Lavie, N. (1995). Perceptual load as a necessary condition for selective attention. Journal of Experimental Psychology: Human Perception and Performance, 21 (3), 451-468.

Löffler, H. (1982). Die visuelle Maskierung. Psychologische Rundschau, 33, 37-50.

Loftus, G. R. \& Ruthruff, E. (1994). A theory of visual information acquisition and visual memory with special application to intensity-duration tradeoffs. Journal of Experimental Psychology: Human Perception and Performance, 20, 33-50.

Long, G. M. (1980). Iconic memory: A review and critique of the study of short-term visual storage. Psychological Bulletin, 88, 785-820.

Long, G. M. \& Beaton, R. J. (1982). The case for peripheral persistence: Effects of target and background luminance on a partial-report task. Journal of Experimental Psychology: Human Perception and Performance, 8, 383-391.

Long, G. M. \& McCarthy, P. R. (1982). Rod persistence on a partial-report task with scotopic and photopic backgrounds. American Journal of Psychology, 95, 309-322.

Massaro, D. W. \& Loftus, G. R. (1996). Sensory and perceptual storage. In E. L. Bjork \& R. A. Bjork (Eds.), Memory (pp. 67-99). San Diego: Academic Press.

Mayor, E. A. (1985). Facilitory and inhibitory components of orienting in visual space. In M. I. Posner \& O. S. Marin (Eds.), Attention and performance XI (pp. 189-207). Hillsdale, NJ: Erlbaum.

Mayor, E. A. \& Hockey, R. (1985). Inhibitory components of externally controlled covert orienting in visual space. Journal of Experimental Psychology: Human Perception and Performance, 11, 777-787.

McClelland, J. L., McNaughton, B. L. \& O'Reilly, R. C. (1995). Why there are complementary learning systems in the hippocampus and neocortex: Insights from the successes and failures of connectionist models of learning and memory. Psychological Review, 102, 419-457.

McClelland, J. L. \& Rumelhart, D. E. (1981). An interactive model of context effects in letter perception: An account of basic findings. Psychological Review, 88, 375-407. 
Merikle, P. M. (1980). Selections from visual persistence by perceptual groups and category membership. Journal of Experimental Psychology: General, 109, 279-295.

Mewhort, D. J. K. \& Beal, A. L. (1977). Mechanisms of word identification. Journal of Experimental Psychology: Human Perception and Performance, 3, 629-640.

Mewhort, D. J. K. \& Campbell, A. J. (1980). The rate of word integration and the overprinting paradigm. Memory \& Cognition, 8, 15-25.

Mewhort, D. J. K., Campbell, A. J., Marchetti, F. M. \& Campbell, J. I. D. (1981). Identification, localization, and ,iconic memory“: An evaluation of the bar-probe task. Memory and Cognition, 9, 50-67.

Mewhort, D. J. K., Marchetti, F. M., Gurnsey, R. \& Campbell, A. J. (1984). Information persistence: A dual-buffer model for initial visual processing. In H. Bouma \& H. G. Bouwhuis (Eds.), Attention and performance X (pp. 287-298), London: Erlbaum.

Milner, A. D. \& Goodale, M. A. (1993). Visual pathways to perception and action. Progress in Brain Research, 95, 317-337.

Milner, A. D. \& Goodale, M. A. (1995). The visual brain in action. Oxford: Oxford University Press.

Moray, N., Bates, A. \& Barnett, T. (1965) Experiments on the four-eared man. Journal of the Acoustical Society of America, 38, 296-201.

Mozer, M. C. \& Sitton, M. (1998). Computational modeling of spatial attention. In H. Pashler (Ed.), Attention (pp. 341-193). Hove: Psychology Press.

Müller, H, J. \& Rabbitt, P. M. A. (1989). Reflexive orienting of visual attention: Time course of activation and resistance to interruption. Journal of Experimental Psychology: Human Perception and Performance, 15, 315-330.

Navon, D. \& Gopher, D. (1979). On the economy of the human processing systems. Psychological Review, 86, 254-255.

Neisser, U. (1967). Cognitive psychology. New York: Appleton-Centry-Crofts.

Norman, D. A. \& Shallice T. (1986). Attention to action: Willed and automatic control of behavior. In R. J. Davidson, G. E. Schwarts \& D. Shapiro (Eds.), Consciousness and selfregulation. Advances in research and theory (Vol. 4, pp. 1-18). New York: Plenum Press.

Olshausen, B. A., Anderson, C. H. \& Van Essen, D. C. (1993). A neurobiological model of visual attention and invariant pattern recognition based on dynamic routing of information. Journal of Neuroscience, 13, 4700-4719. 
Pagel, J. L. (1875). Geschichte der Göttinger medicinischen Schule im 18 Jahrhundert. (Dissertation, Universität Berlin).

Pashler, H. \& Johnston, J. C. (1998) Attentional limitation in dual-task performance. In H. Pashler (Ed.), Attention. Hove: Psychology Press.

Posner, M. I. (1980). Orienting of attention. Quarterly Journal of Experimental Psychology, 32, $3-25$.

Posner, M. I. (1993). Attention before and during the decade of the brain. In D. E. Meyer \& S. M. Kornblum (Eds.), Attention and performance XIV: Synergies in experimental psychology, artificial intelligence and cognitive neuroscience. Cambridge, MA: MIT Press.

Posner, M. I. \& Cohen. Y. (1984). Components of visual orienting. In H. Bouma \& D. G. Bouwhuis (Eds.), Attention \& performance X: Control of language processes (pp. 531-556). Hillsdale, NJ: Erlbaum.

Posner, M. I. \& Dehaene, S. (1994). Attentional network. Trends Neuroscience, 17, 75-79.

Posner, M. I. \& Digirolamo, G. J. (2000). Attentional in cognitive neuroscience: An overview. In Michael. S. Gazzaniga (Ed.), The new cognitive neurosciences (2nd ed.) (pp. 623-631). Cambridge, MA: MIT Press.

Posner, M. I. \& Gilbert, C. D. (1999). Attention and primary visual cortex., Proceedings of National Academy of Science: U. S. A. 96 (6), 2585-2587.

Posner, M. I. \& Peterson, S. E. (1990). The attentional system of the human brain. Annual Review of Neuroscience, 13, 25-42.

Posner, M. I., Snyder, C. R. R. \& Davidson, B. J. (1980). Attention and the detection of signals. Journal of Experimental Psychology: General, 109, 160-14.

Remington, R. W. \& Pierce, L. (1984). Moving Attention: Evidence for time-invariant shifts of visual selection attention. Perception \& Psychophysics, 35, 393-399.

Rösler, F. (1997). Neuropsychologie des Gedächtnisses. In G. Lüer \& U. Lass (Hrsg.), Erinnern und Behalten. Weg zur Erforschung des menschlichen Gedächtnisses (S. 79-116). Göttingen: Vandenhoeck \& Ruprecht.

Sakitt, B. (1976). Iconic memory. Psychological Review, 83 (4), 257-276.

Sakitt, B. \& Long, G. M. (1978). Relative rod and cone contributions to iconic storage. Perception \& Psychophysics, 23, 527-536.

Sakitt, B. \& Long, G. M. (1979). Spare the rod and spoil the icon. Journal of Experimental Psychology: Human Perception and Performance, 5, 19-20. 
Schneider, G. E. (1969). Two visual systems: brain mechanisms for localization and discrimination are dissociated by tectal and cortical lesions. Science, 163, 895-902.

Schulz, Th. (1981/82). Das ikonische Gedächtnis oder: vom schlecht zugänglichen visuellen Speicher und dem langandauernden Ikon. Archiv für Psychologie, 134, 1-31.

Schulz, Th. \& Lamann-Lison, M. (1985). Antwortinterferenz im Teilbericht. Vortrag auf der 27. TeaP, Wuppertal.

Singer, W. (1994). The organization of sensory motor representations in the neocortex: A hypothesis based on temporal coding. In C. Umiltà \& M. Moscovitch (Eds.), Attention and performance XV: Conscious and nonconscious information processing (pp. 101-130). Cambridge, MA: MIT Press.

Spencer, T. J. (1969). Some effects of different masking stimuli on iconic storage. Journal of Experimental Psychology, 81, 132-140.

Sperling, G. (1960). The information available in brief visual presentations. Psychological Monographs: General and Applied, 74, 1-29.

Sperling, G. (1964). What visual masking can tell us about temporal factors in perception. Proceedings of the seventeenth International Congress of Psychology (Washington, D. C.). Amsterdam: North-Holland.

Sperling, G. (1967). Successive approximations to a model for short term memory. Acta Psychologica, 27, 285-292.

Sperling, G. (1996). Mechanisms of visual short-term memory and attention. Paper presented at International Workshop on Short-term Storage and Processing in Human Cognition: Dynamic Characteristics and Neural Mechanisms, Leipzig.

Squire, L. R. \& Knowlton, B. J. (2000). The medial temporal lobe, the hippocampus, and the memory system of the brain. In Michael. S. Gazzaniga (Ed.), The new cognitive neurosciences (2nd ed.) (pp. 765-779). Cambridge, MA: MIT Press.

Tovee, M. J. \& Rolls E. T. (1992). Oscillatory activity is not evident in the primate temporal visual cortex with static activity. Neuroreport, 3, 369-372.

Tovee, M. J. \& Rolls E. T. (1995). Information encoding in short firing rate epochs by single neurons in the primate temporal visual cortex. Visual Cognition, 2, 35-58.

Townsend, V. M. (1973). Loss of spatial and identity information following a tachistoscopic exposure. Journal of Experimental Psychology, 98, 113-118.

Treisman, A. (1986). Properties, parts, and objects. In K. R. Boff, L. Kaufman \& J. P. Thomas (Eds.), Handbook of perception and human performance: Vol. II. Cognitive processes and performance (pp. 35/1-35/70). New York: Wiley. 
Treisman, A. (1988). Features and objects: The fourteenth Bartlett memorial lecture. Quarterly Journal of Experimental Psychology, 40A, 201-237.

Treisman, A. (1992). Perceiving and re-perceiving objects. American Psychologist, 47, 862875.

Treisman, A. (1993). The perception of features and objects. In A. D. Baddeley \& L. Weiskrantz (Eds.), Attention: Awareness, selection, and control. Oxford: Oxford University Press.

Treisman, A. (1996). The binding problem. Current Opinion in Neurobiology, 6, 171-178.

Treisman, A. (1998). Feature binding, attention and object perception. Philosophical Transactions of the Royal Society. London, Biological Science, 353 (1373), 1295-1306.

Treisman, A. \& DeSchepper, B. (1996). Object tokens, attention, and visual memory. In T. Inui and J. McClelland (Eds.), Attention and performance XVI: Information integration in perception and communication (pp. 15-46) Cambridge, MA: MIT Press.

Treisman, A. \& Gelade, G. (1980). Feature-integration theory of attention. Cognitive Psychology, 12, 97-136.

Treisman, A. \& Schmidt, H. (1982). Illusory conjunctions in the perception of objects. Cognitive Psychology, 14, 107-141.

Tsal, Y. (1983). Movement of attention across the visual field. Journal of Experimental Psychology: Human Perception and Performance, 9, 523-530.

Turvey, M. T. \& Kravetz, S. (1970). Retrieval from iconic and memory with shape as the selection criterion. Perception \& Psychophysics, 8, 171-172.

Ungerleider, L. G. \& Mishkin, M. (1982). Two cortical systems. In D. J. Ingle, M. A. Goodale \& R. J. W. Mansfield (Eds.), Analysis of visual behaviour (pp. 549-586). Cambridge MA: MIT Press.

Van der Heijden, A. H. C. (1993). The role of position in object selection in vision. Psychological Research, 56, 44-58.

Van Essen, D. C. (1985). Functional organization of primate visual cortex. In A. Peters \& E. G. Jones (Eds.), Cerebral cortex (Vol. 3, pp. 259-329). New York: Plenum.

Von der Malsburg, C. (1996). The binding problem of neural networks. In R. R. Llinas \& P. S. Churchland (Eds.), The mind-brain continuum: Sensory process (pp. 131-146). Cambridge, MA: MIT Press.

Von Wright, J. M. (1968). Selection in immediate visual memory. Quarterly Journal of Experimental Psychology, 20, 62-68. 
Von Wright, J. M. (1972). On the problem of selection in iconic memory. Scandinavian Journal of Psychology, 13, 159-171.

Welford, A. T. (1980). Choice reaction time: Basic concepts. In A. T. Welford (Ed.), Reaction times (pp. 67-78). London: Academic Press.

Wickens, C. D. (1992). Engineering psychology and human performance (2nd ed.). New York: Harper Collins.

Wolford, G. (1975). Perturbation model for letter identification. Psychological Review, 82, 184-199.

Wilson, F. A. W., O’Scalaidje, S. P. \& Goldman-Rakic, P. S. (1993). Dissociation of object and spatial processing domains in primate prefrontal cortex. Science, 260, 1955-1958.

Wright, R. D. \& Ward, L. M. (1998). The control of visual attention. In R. D. Wright (Ed.), Visual attention (pp. 132-186). New York: Oxford University Press.

Yantis, S. (1998). Control of visual attention. In H. Pashler (Ed.), Attention (pp. 223-256). Hove: Psychology Press.

Yeomans, J. M. \& Irwin, D. E. (1985). Stimulus duration and partial report performance. Perception \& Psychophysics, 37, 163-169.

Zeki, S. (1980). The representation of colours in the cerebral cortex. Nature, 284, 412-418.

Zeki, S., Watson, J. D. G., Leuck, C. J., Friston, K. L., Kennard, C. \& Frackowiak, R. S. (1991). A direct demonstration of functional specialization in human visual cortex. Journal of Neuroscience, 11, 641-649. 


\section{Lebenslauf}

Am 24. Dezember 1969 wurde ich in Shanghai, Volksrepublik China, als Tochter der Beamtin YAN Zongjun und des Beamten YAN Guangde geboren. Von 1976 bis 1981 besuchte ich die Grundschule, von 1981 bis 1984 die Mittelschule und von 1984 bis 1987 die Oberschule in der Stadt Shuicheng, Provinz Guizhou.

Im Juli 1987 wurde ich aufgrund sehr guter Leistungen in der nationalen Hochschuleingangsprüfung von der Peking Universität (Beijing Daxue) aufgenommen. Von 1987-1991 studierte ich an der Peking Universität Philosophie und ab 1988 - mit besonderer Genehmigung der Universität - als zweiten Studiengang parallel dazu das Fach Psychologie. Im Juli 1991 schloss ich beide Studiengänge erfolgreich ab. Als Jahrgangsbeste im Fach Philosophie erhielt ich den akademischen Titel „Bachelor of Philosophy“, im Fach Psychologie den Titel „Bachelor of Science“.

Ab dem Wintersemester 1993/94 studierte ich Psychologie an der Rheinischen FriedrichWilhelms-Universität Bonn. Im Dezember 1996 schloss ich dort das Studium als DiplomPsychologin mit der Gesamtnote „sehr gut“ ab.

Im April 1999 erhielt ich ein Stipendium des Bundeslandes Baden-Württemberg nach dem Landesgraduiertenförderungsgesetz an der Ruprecht-Karls-Universität Heidelberg zum Zweck der Promotion. Das Stipendium wurde aus beruflichen Gründen nicht angenommen.

Von Juni 1999 bis März 2001 arbeitete ich als Forschungsassistentin des DFG-Projektes "Einfluss von Sprache auf wahrnehmungsnahe Gedächtnisprozesse" am Georg-Elias-MüllerInstitut für Psychologie der Universität Göttingen. Von April 2001 an bis heute bin ich als wissenschaftliche Mitarbeiterin in der Abteilung für Kognition und Arbeitspsychologie dieses Instituts in Lehre und Forschung tätig.

Göttingen, den 10. Dezember 2001

YAN Song 